A collective publication coordinated by Michel Paillard Denis Lacroix Véronique Lamblin

\title{
Marine
}

Renewable

Energies

Prospective Foresight Study for 2030 

Marine

Renewable

Energies

Prospective Foresight Study for 2030 


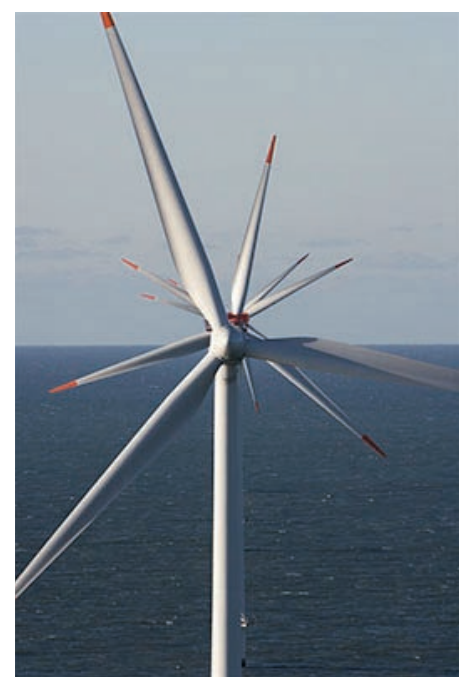

String of wind turbines in Denmark (๑ Dong Energy, DK)

\author{
Éditions Quæ \\ RD 10 \\ 78026 Versailles Cedex, France
}

(c) Éditions Quæ, 2009

ISBN 978-2-7592-0184-6

Copying is not permitted by the French intellectual property law, without the permission of owners of rights. Any breach of this principle, harmful to scientific publishing, will be severely punished. No part of this book may be reproduced without the permission of the publisher Éditions Quæ or the Centre français d'exploitation du droit de copie (CFC), 20 rue des Grands-Augustins, Paris 6 e. 
A collective publication coordinated by

Michel Paillard

Denis Lacroix

Véronique Lamblin

\section{Marine Renewable Energies}

Prospective Foresight Study for 2030 



\section{Preface}

ore than ever before, the conjunction of France's energy commitments to Europe within the domestic framework of the Grenelle environmental summit meetings, and the context created by the new oil crisis, should lead us to actively consider renewable energies.

Well aware of these considerations, in March 2007, I decided to launch a prospective foresight study on marine renewable energy sources (RES) for 2030. The ocean is a huge reservoir with wind, currents, waves, tides, biomass, thermal power, etc. France enjoys significant potential for the development of renewable energy sources having extensive seafronts in metropolitan France and overseas as well as the necessary knowledge and expertise.

Twenty French partners representing the main actors in the sector took part in this work. I would like to express my warm thanks to them for their participation. This study describes a range of possibilities for the future (depending on the world context, energy demand trends, the role played by stakeholders, etc.), the consequences of developing various known technologies, and the research and development they will require.

The work is also part of a European foresight perspective, in that it highlights the advantages of the numerous types of synergy and co-operation that can be developed between EU countries in the next twenty years.

Ifremer has thus, true to its calling, contributed to the collective think-tank, aiming to enlighten public decision-making in the field of energy and more especially, marine renewables.

It is now up to each of us to take these reflections on board and put them into action. Ifremer will draw concrete results from them in the framework of its strategic plan.

Jean-Yves Perrot Chairman and Chief Executive Officer of Ifremer 



\section{Acknowledgements}

ichel Paillard, Denis Lacroix and Véronique Lamblin thank all the Steering Committee members who accepted, from the outset, to take part in this year-long collective project. Their support and advice have greatly contributed to creating this document.

The study coordinators especially thank the Working Group members who undertook the analytical work, from defining the variables to the final summary. They all deserve to be mentioned here: Cyrille Abonnel (EDF), Marc Boeuf (DCNS), Jérôme Clauzure, Marie-Cécile Degryse, Sophie-Dorothée Duron, Cyril Pouvesle (Meeddat), Antoine-Tristan Mocilnikar (DIDD then UPM), Jacques Ruer (Saipem), Nils Siebert (Ademe), Nicolas Tcherniguin (Technip), Stéphane Thomas (Veolia) and, from Ifremer, Jean-Paul Cadoret, Bertrand Chapron, Jean-Luc Devenon, Luc Drevès, Régis Kalaydjian, Jean Marvaldi and Patrick Vincent.

They also thank Olivier Barbaroux and Gérard Véron for their contributions to the artwork, as well as all the authors of the variables fact sheets who were kind enough to illustrate them.

Warm thanks also go to Janet Heard-Carnot and Valerie Howe for translating and editing the English version of the book. Special thanks are due to the team from the Communications Department at Ifremer headquarters for their support in the final phase leading to publication, particularly Pascale Pessey Martineau and Mathieu Jahnich. And finally, we are grateful to Nelly Courtay for her efficient assistance, patience and tenacity in producing this book.
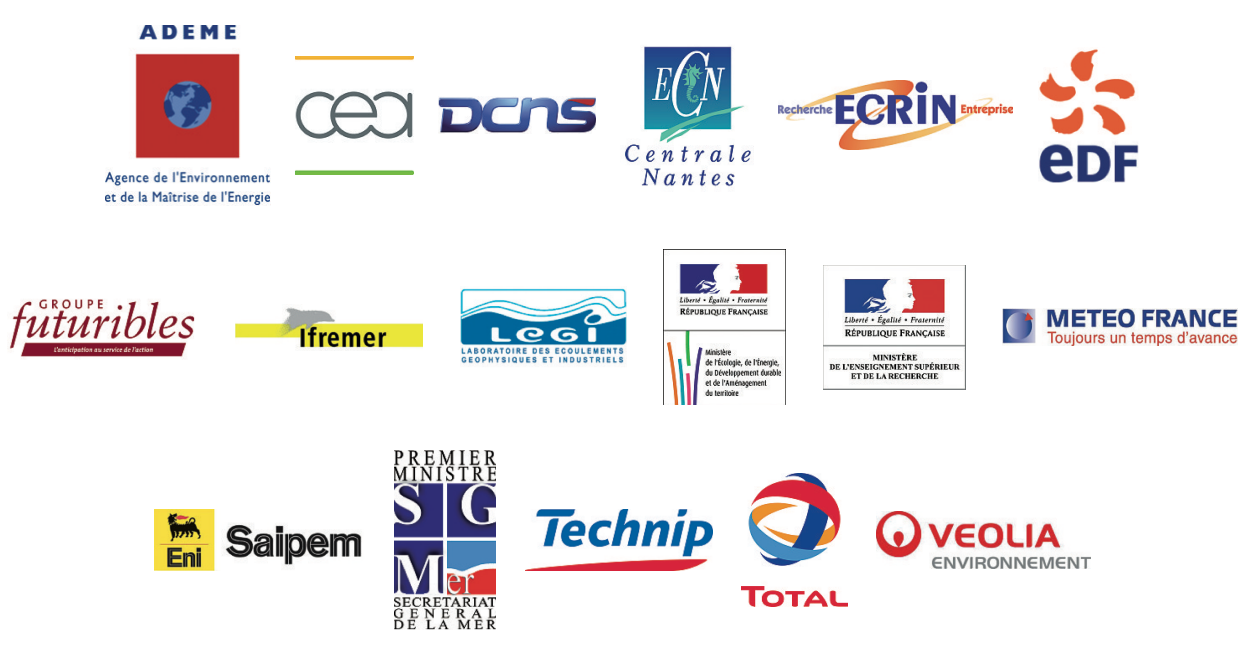



\section{Foreword}

n March 2007, the Chairman and Chief Executive Officer of Ifremer launched a foresight study by a think-tank on marine renewable energies for 2030, with some 20 French partners representing the main stakeholders in the sector: ministries, industrial leaders, research institutes and specialized agencies. The think-tank's multidisciplinary nature is largely justified by a subject, which involves not only the diversification of energy sources, Europe's commitment to fighting the greenhouse gas effect and the environmental impacts of installations and facilities at sea, but also the development of coastal zones where a wide range of uses interact and compete. The study aimed to contribute to an executive summary covering various aspects, such as identifying the stakes, the conditions for emergence and major technologies in the medium term in order to reassess Ifremer's position, beyond offering expert opinions. It also aimed to identify the partnerships and strategic programmes which fall within Ifremer's realm of competence. The issue of marine renewable energies is part of the renewable energy issue overall. The latter is vital, particularly as the Western world comes under pressure from energy needs and rising oil costs, as well as global warming. Given the efforts required to develop renewable energies, the relative scope for developing marine renewable sources must be defined in terms of their estimated cost, technological and planning constraints, both on land and at sea, and their potential environmental impacts. The study collected and summarized a large number of studies data. It has reduced the uncertainty and provides an objective capability to assess numerous opportunities for partnerships. It mobilized some fifteen experts over a one-year period. The study received the support of the Futuribles consultant's group in implementing the 'scenario' method'. After 30 factors called 'variables' were studied, four contrasting 'scenarios' were selected. Their main driving forces or 'drivers' are: the market in a crisis context; world energy policy and sustainability; national interests and energy security; and local developments with risk-taking.

Developing every technology studied here could be of interest. Their advantages vary greatly, depending on:

- the energy and socio-economic context, which will lead either to developing only the most mature technologies, such as wind, as an emergency response, or to seeking synergies between technologies, such as thermal marine energy and biomass;

- the possibility of manufacturing hydrogen to store intermittent energy and move production systems away from the coast (giving access to additional resources): of interest for floating wind and wave turbines, for example;

- the geographical scope: marine thermal energy has great potential in the tropical islands of France's overseas departments (counties) and regional authorities;

1 A glossary for the scenario method is provided in Appendix 4. 


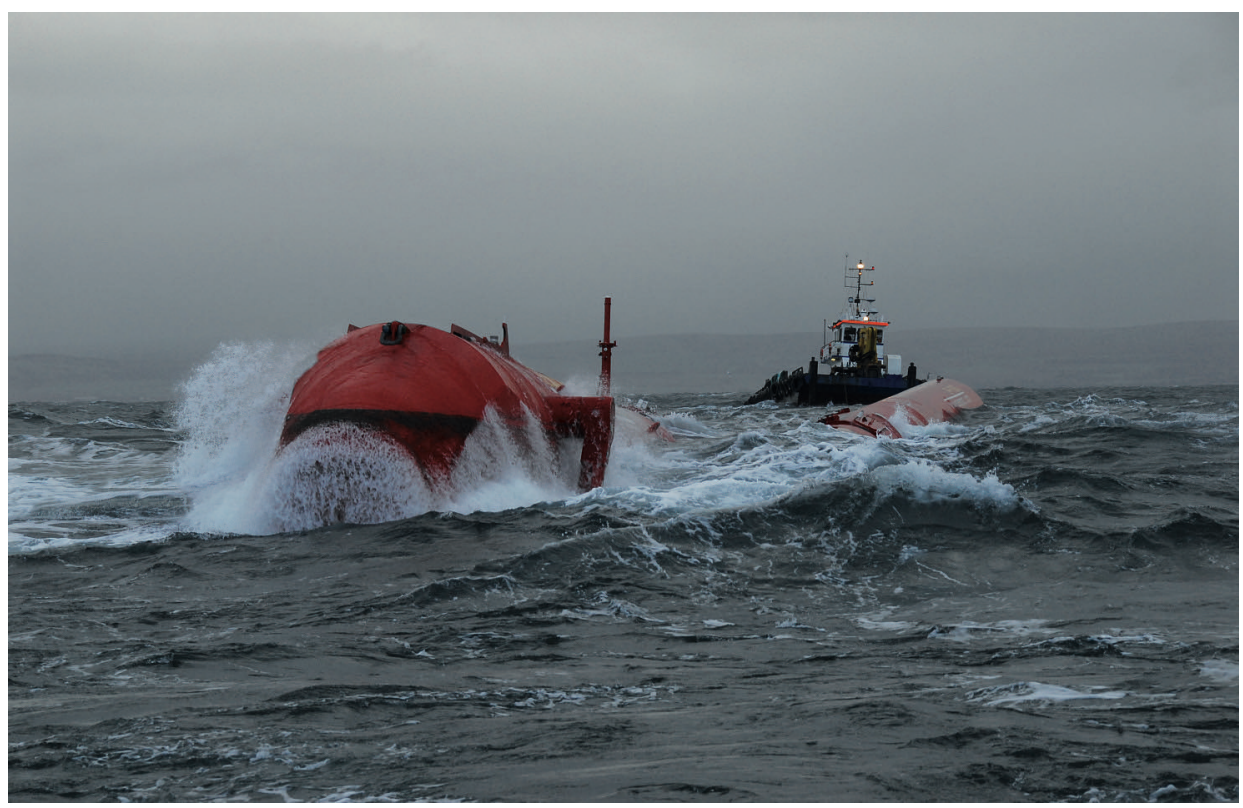

Photo 1 : the Pelamis system to recover wave energy being tested under rough conditions at the European Marine Energy Centre in Scotland (C) Pelamis Wave Power Ltd, UK).

- the specificity of energy needs: marine biomass is the only one of seven resources which can be used to produce directly a 'renewable' liquid fuel oil-substitute for transport.

Their features also differ in terms of how they fit into coastal areas, depending on the size of developments and the physical-chemical properties of the marine environment they utilize.

Since France ranks second in Europe for potential wave and wind energy at sea, along with an excellent tidal energy resource and large tropical marine areas, it can play an important role in both research and development, particularly if the risks linked to the choice of technologies are shared between all players, including the State. Indeed, the latter has several forms of leverage in pooling skills and expertise and co-financing the risk-taking. Finally, the earlier the consultation is performed, the more people will find the project socially acceptable.

Under these conditions, marine renewable sources can help to meet the objectives set by the EU for renewable energy in 2020 while developing technologies that can be exported. One 'normative' scenario including concrete and balanced hypotheses for developments shows a possible net contribution from marine energies of 1.5 million tonnes of oil equivalent (Mtoe) per year (17.2 TWh/year) by the year 2020, making $7.7 \%$ of the 20 Mtoe increase in renewable energy production, which is the target envisaged in the framework of the French environmental summit meeting. Within this scenario, the $7.7 \%$ would be divided between $5.2 \%$ for wind farms at sea and $2.5 \%$ for other marine energy sources. 
This scenario clearly indicates the efforts needed to support the industries which would have to be set up in order to reach this objective. This entails creating the conditions to promote building and strengthening French skills in the field, better support for technologies being developed in France and setting up the first demonstration installations at sea. In fact, although these supply chains have undergone sustained development efforts in a few other European countries and elsewhere in the world, no technology, except for wave turbines, has yet been validated by industrial qualification. This means that France still has time to take its place in this just-emerging future market. By the year 2020, based on the results of the first demonstrations validated at sea in France and Europe, farms could develop on an industrial scale and put the target of $7.7 \%$ of the 20 Mtoe increase in renewable energy generation within reach. 



\section{Contents}

Preface

Acknowledgements

Foreword

\section{Part 1 - Summary of studies}

Scope of the study .................................. 17

Methodology ...................................... 21

Review of marine energies: resources and technologies ............ 23

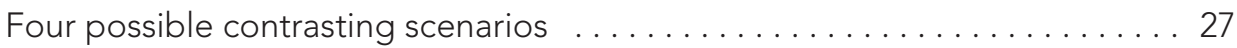

Conditions for emergence considered in these possible scenarios . . . . . . 29

Consequences of the possible scenarios on the development

of technologies................................... 35

Environmental integration: what are the impacts and risks? .......... 41

Incorporating marine renewable energies in the French energy supply..... 43

Proposal for a normative scenario in the context of the French

environmental summit meeting $\ldots \ldots \ldots \ldots \ldots \ldots \ldots \ldots \ldots \ldots \ldots$

Conclusion ......................................... 55

\section{Part 2 - Constructing the scenarios}

Context ............................................. 59

Study structure and methodology $\ldots \ldots \ldots \ldots \ldots \ldots \ldots \ldots \ldots \ldots 6$

Constructing micro-scenarios for each component ............... 67

Constructing the macro-scenarios . . . . . . . . . . . . . . . . . . . 79

Description of the macro-scenarios . . . . . . . . . . . . . . . . . 83

Scenario 1: Crisis and energy emergency.................. 83

Scenario 2: Altruistic co-operation through necessity .............. 89

Scenario 3: Few changes, every man for himself . . . . . . . . . . . . . . 96

Scenario 4: Independent local development .....................101

II Part 3 - Technical file: Components and variables fact sheets

V1: Global geo-economics ................................... 109

V2 : World climate governance ............................ 117

V3 : Energy demand, including Europe by region................123

V4 : Freshwater demand by region . . . . . . . . . . . . . . . . 131 
V5 : Security and price of fossil fuels.

V6 : Political strategy \& energy independence: targets . . . . . . . . . . . . 151

V7 : Specificities of islands (including OR and OCT) ................ 161

V8 : Enforcement \& control, relevant tools in France ................. 165

V9: Regulatory instruments for biofuels....................... 169

V10 : Energy research budget and allocation by energy source ..........171

V11: Structuring and managing the electricity grid ............... 176

V12 : Energy storage and transport technologies .................. 181

V13: Changes in centralized electricity generation .................. 190

V14 : Global population distribution including European coasts........... 197

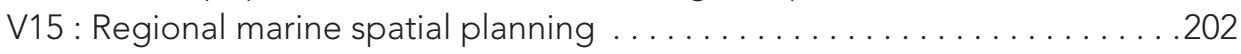

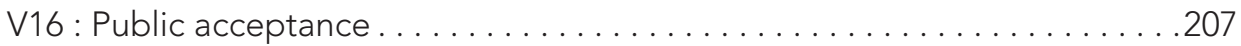

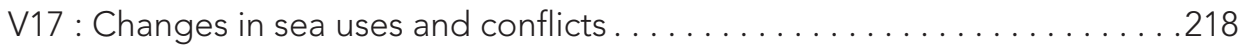

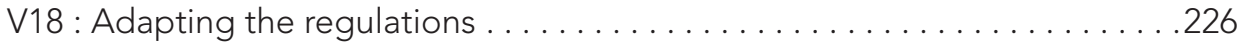

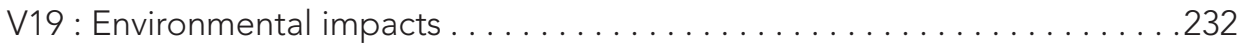

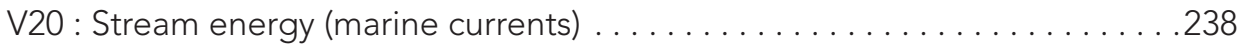

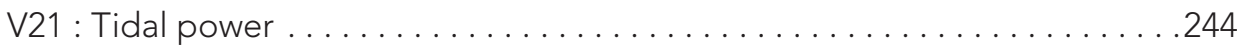

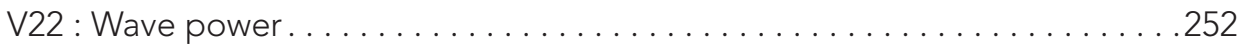

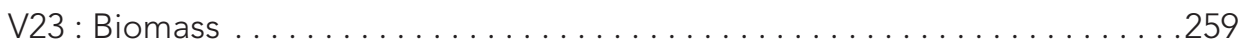

V24 : Offshore wind power. . . . . . . . . . . . . . . . . . . . . . 265

V25 : Ocean thermal energy conversion (OTEC) . . . . . . . . . . . . .273

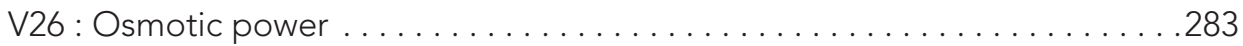

V27 : Hybrid technological solutions . . . . . . . . . . . . . . . . . 288

V28 : Potential of new sources................................290

V29 : Knowledge about the marine environment and impacts . . . . . . . . 292

V30 : Roles of public-and private-sector stakeholders ...............296

\section{Appendixes}

1. List of Steering Committee members . . . . . . . . . . . . . . . . . . 307

2. List of Working Group members ... . . . . . . . . . . . . . . . . . . 309

3. Glossary of acronyms ........................... 310

4. Glossary for the scenario method ...................... 312

5. List of 30 variables grouped by component and corresponding author(s) 313

6. Cost assessment of possible and normative scenarios . . . . . . . . . 314 
PART 1

Summary

of studies 


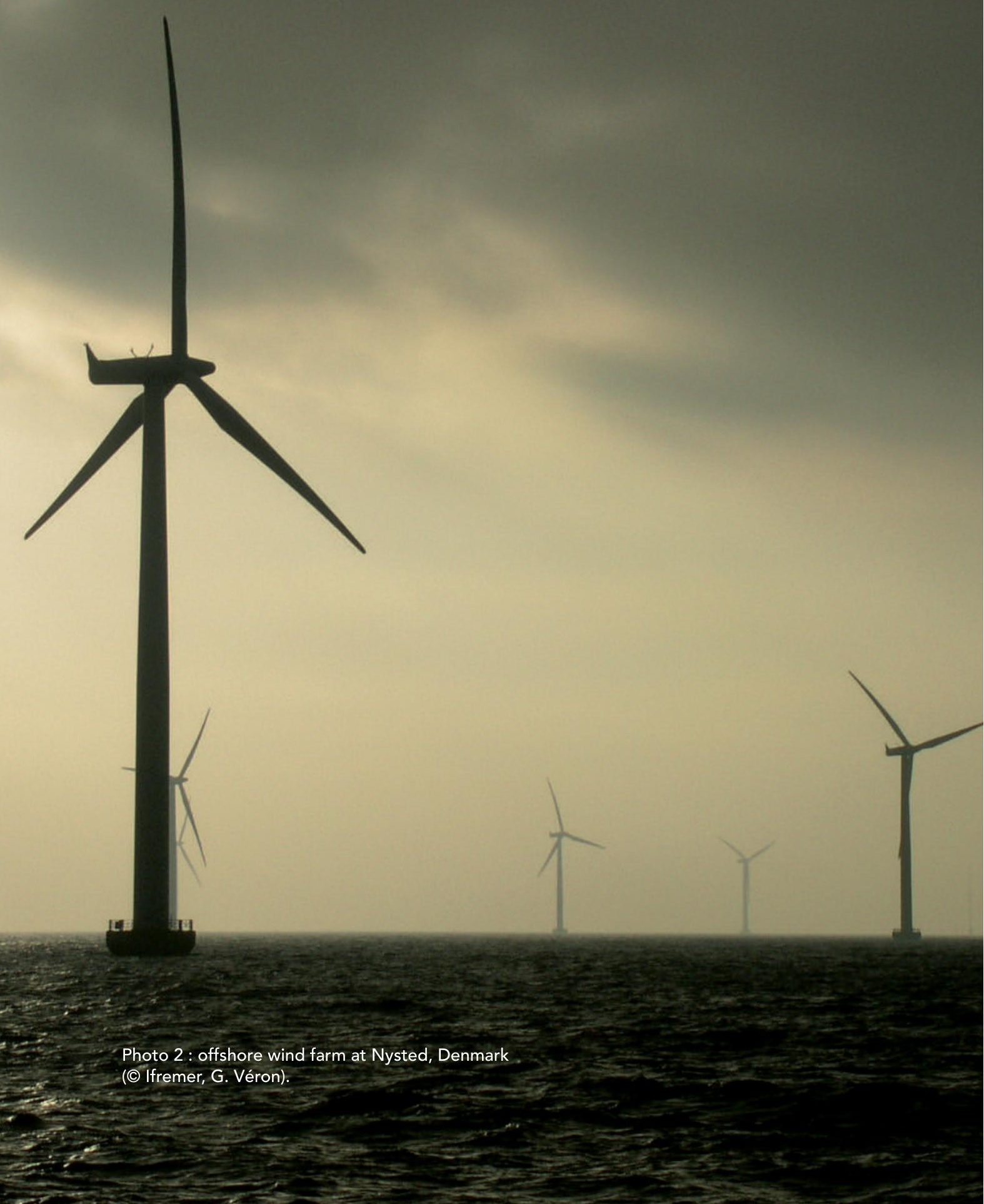




\section{Scope of the study}

arine renewable energy sources (RES) are listed as one component in Europe's energy mix set out in EU targets for the year 2020 (20\% of power consumed will have to be generated from renewable sources). A number of international conferences on the future of the environment have also referred to this issue. In March 2007, seeing the lack of clear direction on this important subject in France, the Chief Executive Officer of Ifremer proposed that the main stakeholders in marine renewable energy research and development (R\&D) and the ministries concerned, take part in a collective prospective study.

Four major justifications can be seen for exploring the subject of marine energies:

- the need to reduce greenhouse gas emissions;

- the short- and medium-term risks on oil supplies;

- the need to investigate all avenues for renewable energy production;

- the need to consider the impacts (i.e. environmental and acceptability) of these new plants on coastal areas and their uses.

France pioneered this field in the 1960s with the first tidal generator plant in the world (La Rance). Even more important are the existing developments and growing demand for marine renewables, including the distant overseas territories. A few examples include the air-conditioning for a hotel on Bora Bora, an identical project for a hospital in Tahiti, and issues of energy security and cost in the large French tropical islands.

Thus, the initial scope of the study was set out in the form of three main questions:

- What technologies can serve to produce energy from the ocean?

- What are the social-economic prerequisites to ensure that they are developed and are competitive?

- What are the respective impacts of these technologies on energy sources and the environment?

The main lines of the study were as follows:

- time horizon: 2030;

- scope of study: France - in a global, and more especially European, context;

- technologies: all marine-related technologies, except for fossil fuels;

- method: scenarios method (with support from Futuribles consultants);

- timeframe: 10 months. 
Potential RES fall into five categories:

- wind at sea to produce electricity using offshore wind-turbines (neither shipping nor routeing was covered in this study);

- water movements, generating energy from currents, waves or tides;

- water temperature, whether for recovering energy using temperature gradients between the surface and deep sea, or by directly pumping cold water from the deep for cooling purposes;

- marine biomass used to produce energy, especially marine plants like micro-algae;

- osmotic or salinity gradient power, produced by mixing two types of water with different saline concentrations (freshwater/seawater).

Fuels (apart from uranium found in seawater), which could be extracted from the sea, such as methane hydrates, fall outside the range of this study, since strictly speaking they are considered to be non-renewable resources and because using them creates greenhouse gas emissions. The study examined the interest of combining seawater desalination with power generation.

Lastly, the 'potential resources and needs' type of approach was used, calling on inputs from social sciences.

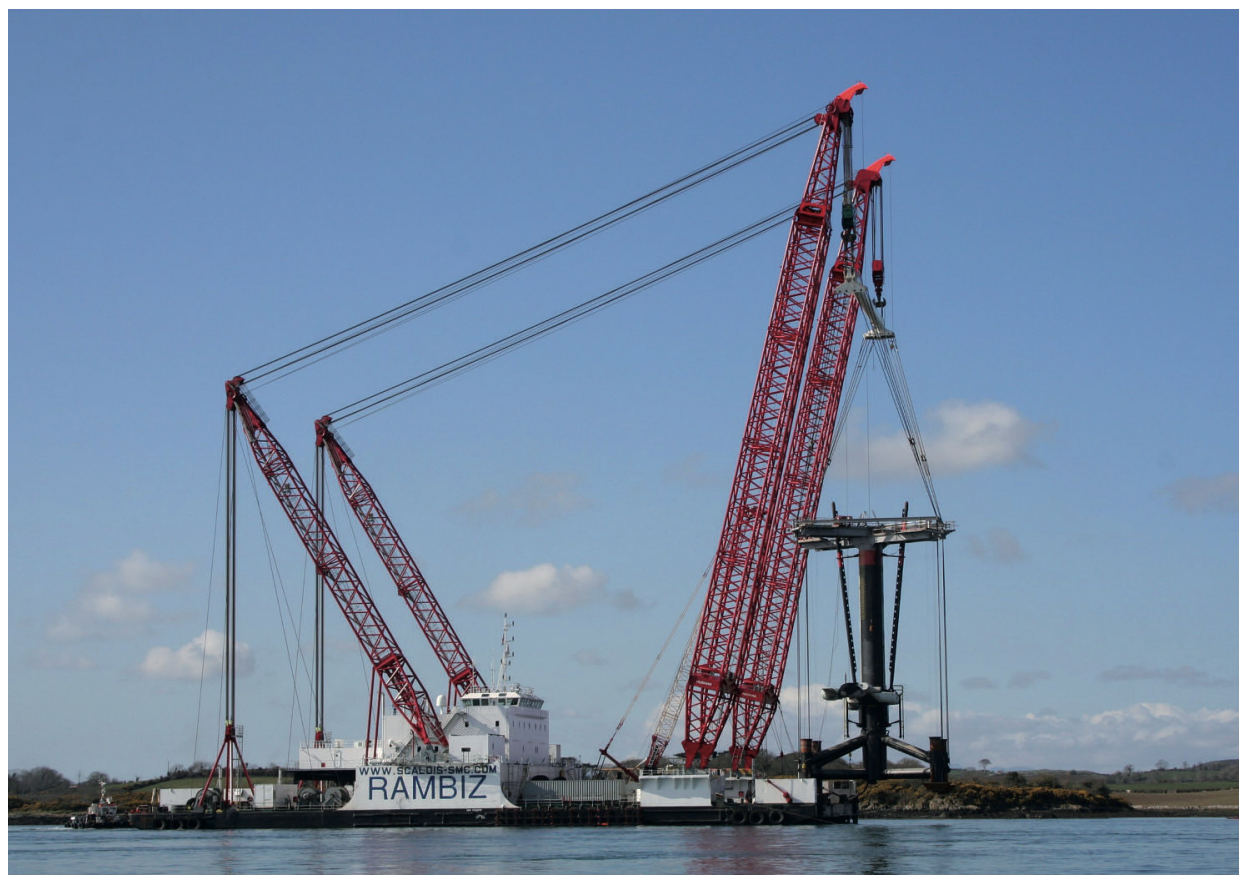

I Photo 3 : Rambiz crane-barge installing the Seagen stream turbine on the Strangford Narrows site, Northern Ireland (๑ Marine Current Turbines, UK). 
In order to analyse the factors or conditions for development of marine renewable energies in future, it is necessary to have an idea of their potential uses.

\begin{tabular}{|l|c|c|c|}
\hline \multirow{2}{*}{\multicolumn{1}{c|}{ Marine }} & \multicolumn{3}{c|}{ Uses } \\
\cline { 2 - 4 } \multicolumn{1}{c|}{ energy source } & Electricity & Heat or cooling & Fuels \\
\hline Wind & $X$ & & \\
\hline Movements & $X$ & $X$ & \\
\hline Temperature & $X$ & $X$ & \\
\hline Biomass & $X$ & & \\
\hline Osmotic pressure & $X$ & & \\
\hline
\end{tabular}

| Table 1 : marine renewable energy sources and potential uses.

Note ${ }^{1}$ : Electricity can produce cold or heat, which can be utilized for industrial purposes or for manufactured products like water (in desalination).

Note2: The following constraint should be noted: the outputs (electricity/cold/heat) for most energy sources cannot be transported, except for those from biomass and manufactured products like biofuels, water, etc. 



\section{Methodology}

- he complex, but powerful, 'scenario method' was used by the Working Group, with ongoing support from the Futuribles consultants. A Steering

Committee brought together representatives from all the organizations involved in the study, with the purpose of monitoring the work and refining the objectives as it progressed.

The Futuribles group supervised the use of the scenario method in the following series of steps:

1. defining the subject and time horizon (see above);

2. identifying the key variables and their relationships (components);

3. exploring possible trends and developments of key variables (set of hypotheses);

4. constructing exploratory micro-scenarios within the components and then macro-scenarios;

5. identifying the stakes and challenges within the scenarios and exploring outcomes and means for the development of technological research.

\section{The selection and analysis of key variables}

This phase is when the system's 'building bricks' are created. It can be broken down into two steps:

- Identification of the variables. Thirty factors were identified in the marine RES system. They were divided into five 'components', including that of technologies (seven separate technologies plus hybrid systems). The detailed list of key variables within each component group is given in Appendix 5.

- The documented analysis for each key variable followed a standard pattern: defining the variable, the relevant indicators, backcasting (over the past 30 years), forecasting (to 2030) and selecting a set of two to four hypotheses for how this variable could evolve.

\section{The development of the micro-scenarios}

This phase consists of combining sets of hypotheses for the variables within each component or theme (e.g. the global context, European and French energy regulation, areas of operation, etc.). By proceeding in this way, three or four partial scenarios, called micro-scenarios, are found for each component, using all or some of the hypotheses for each variable. 


\section{The development of the macro-scenarios}

In this phase the micro-scenarios are combined to highlight the contrasting general scenarios, which could enable the driver of technological development to be determined for each scenario. In this way, a marine renewable energy mix could be associated with each possible scenario or future situation, using the advantages and constraints of the various technologies (see the presentation in table 15, p. 81).

\section{The identification of the scenarios' stakes and leverage}

In this phase, the major underlying driving forces (e.g. market, global climate governance, energy security and local development) are analysed. This enables technologies to be chosen with regard to their advantages, constraints and development potential. Each scenario has consequences which can be estimated in terms of potential installed power or specific constraints (e.g. space at sea). Lastly, the leverage making it possible to move from one scenario to another, such as an oil-price crisis or climate trends, is identified for each sub-system.

\section{Outcomes based on conclusions from the previous phases}

This final phase examines how to improve the R\&D capability for a given technology, which would lead in turn to selecting strategic partnerships and funding to be set up or strengthened (the latter point is outside the scope of this study). 


\section{Review \\ of marine energies: resources and technologies}

t should be pointed out that for each marine energy source there are orders of magnitude differences between the size of the natural resource and what is technically exploitable, allowing for technological, industrial, administrative and environmental constraints. Of course, these technologies can only be developed in close co-operation with other users of the sea and shores. What is 'socially and economically' exploitable, due to the necessary sharing of space, will be lower than the technically exploitable potential.

\section{Offshore wind power}

Electricity is produced by turbines, which harness energy from the wind blowing over stretches of sea and the electricity is carried to shore by undersea cables. A study by the International Energy Agency (IEA) in 2000 set the technically exploitable potential in Europe at about 313 TWh/year for sites less than $20 \mathrm{~km}$ from the coast and at depths of less than $20 \mathrm{~m}$. In the future, floating wind turbines moored to the seabed could be used, since they present fewer constraints in terms of depth limitations. They would provide access to much greater wind resources because they could be set far from the coast.

\section{Ocean energy thermal conversion}

The theory behind ocean energy thermal conversion (OTEC) is to use a temperature difference of at least $20^{\circ} \mathrm{C}$ between deep water (upper limit of $6^{\circ} \mathrm{C}$ ) and the surface (lower limit of $26^{\circ} \mathrm{C}$ ) to generate electricity, as well as freshwater, cooling for air-conditioning and derivatives for aquaculture, depending on the type of process used (i.e. open or closed cycle). The global resource theoretically could generate about $80,000 \mathrm{TWh} /$ year in inter-tropical areas based on a temperature gradient of at least $20^{\circ} \mathrm{C}$. This presumed resource is only partially and locally exploitable, due to the lack of areas where electricity is consumed, particularly in the Pacific inter-tropical zone. Storing the energy by using hydrogen can be envisaged in the long term. Another thermal conversion use in temperate zones is to utilize warm water near the surface as a heat source for heating and cooling installations with heat pumps. 


\section{Stream energy (tidal turbines)}

Since it is a predictable and intermittent source, the kinetic energy from tidal currents could provide the 'semi-base load'. The technically exploitable potential worldwide has been estimated at $450 \mathrm{TWh} /$ year, while that of Europe is thought to be between 15 and $35 \mathrm{TWh} / y e a r$, for about $10 \mathrm{GW}$. The French technically exploitable potential, according to EDF Energy, is said to be between 5 and $14 \mathrm{TWh} /$ year, that is, 2.5-3.5 GW2. Potential sites with specific conditions (e.g. straits, capes, narrows, etc., where increased speeds are observed) have been clearly identified (in France: Raz Blanchard, Fromveur, Raz de Sein, Héaux de Bréhat, Raz de Barfleur, etc., and in the French overseas regions: with effects from headlands, passes, etc.). The major ocean currents (Gulf Stream, Kuroshio, etc.) could also be a significant source of marine energy.

\section{Tidal power}

According to the World Energy Council, the global potential for 'conventional single-basin sites'3 is estimated to be 380 TWh/year for $160 \mathrm{GW}$. The Rance site's 240 MW capacity was inaugurated in 1966. Renewed interest can now be seen outside France, in South Korea, with the construction of the Sihwa power plant (260 MW) and studies are underway on the Garolim project (500 MW), while in the United Kingdom studies have been re-launched for the river Severn plant (8.6 GW), calling on innovative concepts of tidal lagoons and multiple-basin plants.

\section{Wave power (ocean wave energy)}

Approximately $10 \%$ of annual global demand for electricity 4 could be met by ocean wave energy production, according to the World Energy Council, that is, a technically exploitable potential of $1400 \mathrm{TWh} /$ year. In metropolitan France, the technically exploitable potential is estimated at $40 \mathrm{TWh} /$ year, about $10 \%$ of the theoretical resource (i.e. $400 \mathrm{TWh} / \mathrm{year}$ ), which could generate some 10-15 GW, mainly along the Atlantic seafront. In France's overseas departments and local authorities (DOM-COM), strong potential is seen in Réunion Island, Polynesia and New Caledonia, as well as locally in Martinique and Guadeloupe.

\section{I Marine biomass}

It is estimated that between 200,000 and 1 million species of algae exist worldwide. This exceptionally adaptable biodiversity leads us to believe that they are proportionally rich in new molecules and lipids. Compared with terrestrial oilseed plants,

2. Depending on the annual operation times considered.

3. Estuaries with a tidal range greater than $5 \mathrm{~m}$.

4. The annual world demand for electricity is $14,000 \mathrm{TWh} /$ year. 
micro-algae have numerous characteristics favouring fatty acid production, which could be used to advantage in producing fuels. The main advantages are a biomass yield that is 10 times higher than terrestrial crops and the absence of conflicts over demand for freshwater and farmland. Production could range from 20,000 to 60,000 litres of oil per hectare per year, compared with 6000 litres of palm oil, and oilpalm has one of the best yields for terrestrial crops. The surface areas which could be used are yet to be identified and work is necessary to reduce costs.

\section{Osmotic power (salinity gradient)}

When a river flows into the sea, it releases a large amount of energy due to the difference in salt concentrations. Two ways of recovering this energy are being tested: the first (in Norway) is based on osmosis and the second (in the Netherlands) on reverse electrodialysis. In Norway, it is estimated that $10 \%$ of annual energy requirements could be met by this technology. 



\section{Four possible contrasting scenarios}

hat conditions are required for the emergence and competitiveness of marine renewables? This question was the prime objective in drawing up the scenarios. The Working Group drew up four deliberately contrasting scenarios. Table 13 (p. 79) describes their features and projections for the potential implementation of the various technologies. The four scenarios were given the following titles:

Scenario 1 - Crisis and energy emergency;

Scenario 2 - Altruistic co-operation through necessity;

Scenario 3 - Few changes, every man for himself;

Scenario 4 - Independent local development.

In each scenario, the most appropriate and promising technologies for development are presented.

\section{Scenario 1 - Crisis and energy emergency}

Here the market is the driver in a context of energy crisis and economic competition. The main challenge is to control the most competitive and best-adapted technologies through strong strategic partnerships. Since political support is weak, investments are made by clusters of private-sector operators, promoting development based on 'demonstration trials' that are increasingly scaled-up. Recurrent conflicts over access to territory lead to setting up dedicated areas or even multi-use farms. Research focuses on technological improvements, which are the key to competitiveness and a better understanding of impacts. This context favours proven technologies, such as wind, tidal and thermal conversion power. Given its strategic interest, extensive production of biomass is rapidly developed. Hybrid systems are explored in order to optimize investments. Systems applied to waves and current streams receive little or no study, since they are not profitable in the short term.

\section{Scenario 2 - Altruistic co-operation through necessity}

The driver is the political will for sustainability on an international scale in the context of regular extensions of the Kyoto agreements. The major outcome is funding for research and development of the least-mature technologies to facilitate private-sector investment and technological diversification. These efforts lead to increased risk-taking in new technologies and more especially, their hybridization, which also leads to mastering energy storage as well as opening the way to large-scale offshore systems. Research focuses on new concepts while aiming to minimize impacts on the environment. These world-scale dynamics give 
rise to several forms of technologies: deep water stream turbines, man-made tidal lagoons, wave turbine systems offshore (depth $>50 \mathrm{~m}$ ), floating wind turbines, OTEC used in association with aquaculture, large-scale use of biomass (i.e. intensive production on land, genetically modified organisms (GMOs) and multiproducts), osmotic power (perfecting cost-saving membranes with a few micropower plants). This technological profusion fosters hybrid applications, especially in the French DOM-COM ${ }^{5}$.

\section{Scenario 3 - Few changes, every man for himself}

The driver here is national interest and energy security in a context where global co-operation is limited. The major challenge is controlling energy sources nationwide as tensions and protectionism mount. After affecting the Southern hemisphere, a deteriorating climate will reveal requirements for freshwater in the North. Thus public support will move towards energy security, but at a low cost. This will result in grids not being strengthened to take in decentralized generation and the end of electricity feed-in tariffs after 2020. Dedicated energy farms will appear. Independent technological developments will be seen, entailing specialized research for each technology that will assimilate its environmental impact. This situation brings only slight developments in almost all technologies, as public- and private-sector investors opt for security rather than taking risks. Independent development of technologies will hinder both the search for synergies in funding and knowledge-sharing in impact studies.

\section{Scenario 4 - Independent local development}

The driver here is local development with risk-taking in a context of rising tension and protectionism, as well as the need for energy security. Freshwater requirements in the Northern hemisphere, together with those in the South, will justify both technologies and decentralized initiatives. Intensively produced biofuels (with photoreactors) will become cost-effective (end of tax exemption around 2015). Public support (via the regions) will aim to stimulate both the control and competitiveness of technologies. These dynamics lead to reinforcement of the electricity grids to integrate the means for decentralized generation and differentiated development of technologies, depending on the regions and their specific assets. Research supports the perfecting of technologies (local opportunities) and helps to launch local demonstration installations. This evolution and the attendant risk-taking require major involvement by political decision-makers in order to facilitate the social acceptability of these experiments. The outcome for the technologies is the appearance of niche markets whose effect of scale is only felt on a global level. Wind, thermal and biomass reach industrial-scale development, while other technologies are developed locally on a small scale. Research remains patchy and highly focused on local constraints. Coastal universities supported by regional councils play a prime role.

5. It should be noted that New Caledonia has special status and that French Polynesia is called an 'overseas country', one of the Overseas Countries and Territories (OCT). 


\section{Conditions \\ for emergence considered in these possible scenarios}

he foresight exercise does not aim to describe what tomorrow will be, but rather to describe a range of future possibilities by choosing the most contrasting examples. This means that the scenarios are an 'exaggerated version' of what could happen. In the micro-scenario building stage, the Working Group noted the indicators (called forms of 'leverage'), which would enable the various sub-systems to evolve from one configuration to another. Therefore, in the macro-scenario stage of the exercise, the factors which favour or, on the contrary, hinder the development of marine renewable energies can be identified.

\section{Elements from the global, European and French context}

A global agreement on climate (Kyoto II type), with commitments to reduce greenhouse gases in order to halve global emissions by 2050, would most likely accelerate the development of renewable energies including ocean power. The most favourable of cases would be to rapidly reach such an agreement by around 2010. This would leave time to muster political and financial support, and for the technical and industrial development of marine technologies through research. Increased tension in the energy field (e.g. price, risks of shortage or breakdown in supply) or the acute concern regarding climate hazards are also factors that could contribute to increased co-operation between different regions of the world to develop new energy sources.

In terms of both European and French energy policies, the conditions necessary to foster the development of marine energies rely both on support for the energy sectors and the co-operation of stakeholders, whether they are institutions or utility operators.

The more the political support for renewables is diversified between mature and less mature technologies, then the greater the likelihood of the development of a wide variety 6 of ocean or hybrid technologies. Without this diversified support, there is a risk of immediately trying to standardize technological solutions for renewables within a rationale based on effects of scale. Under this hypothesis, it would be difficult to design solutions, which are adapted to the diversity of local specificities and resources.

6. Variety means both the coexistence of different technologies utilizing the same resource, such as floating wind turbines complementing conventional offshore turbines, and technologies using different resources. 
European co-operation could provide powerful leverage in the development of these technologies, both in terms of planning tools for marine areas and identifying the resources available on the European scale, as well as in sharing knowledge about the impacts obtained from initial experiments on ocean power technologies.

In fact, this co-operation would make it possible for operators to build a strategy for industrial development on a European scale, through partnerships as needed, while ensuring continued progress on the technology itself or the way it is established. Such co-operation would supply the means of improving dialogue with coastal populations regarding the setting up of a marine RES project:

- on one hand, putting exploitation of a local resource into perspective with respect to European resources and feedback from experience elsewhere, whether positive or negative, together with making local populations part of the process from the outset. This would significantly facilitate social acceptability;

- on the other hand, involving scientists in consultations with the population. Theses mean might also be a factor for success, in that these experts are these experts are not 'judge and jury' for the industrial project and can thus give a more objective outsider's view.

Carrying out impact studies and environmental monitoring are expensive and currently form a significant part of the risk-taking for project developers. This, amongst other things, explains why so few innovative projects are emerging.

\section{Interesting initiatives}

There are some interesting experiences in other countries of monitoring impacts and/or co-funding.

Denmark has pioneered the field of monitoring the impacts related to marine energy installations. Indeed the Horns Rev ${ }^{7}$ and Nysted 8 farms integrated an environmental monitoring programme, the outcomes of which were delivered in November 2006 at a conference in Helsingor'. An impact assessment was also made on these farms, and a non-technical summary of it can be consulted on their websites.

The monitoring programme began in 1999, with a budget of 11 million euros for environmental studies financed by Danish consumers through their public service contributions. Various themes were explored, for example, geophysical aspects, benthic communities, fish, marine mammals, birds and socio-economic effects. The monitoring programme was coordinated by a private and public sector

7. http://www.hornsrev.dk/Engelsk/default_ie.htm

8. http://www.nystedhavmoellepark.dk/frames.asp

9. A publication reviewing the results of the studies conducted is available online from the Danish energy authority's website (http://www.ens.dk/graphics/Publikationer/ Havvindmoeller/havvindmoellebog_nov_2006_skrm.pdf). 


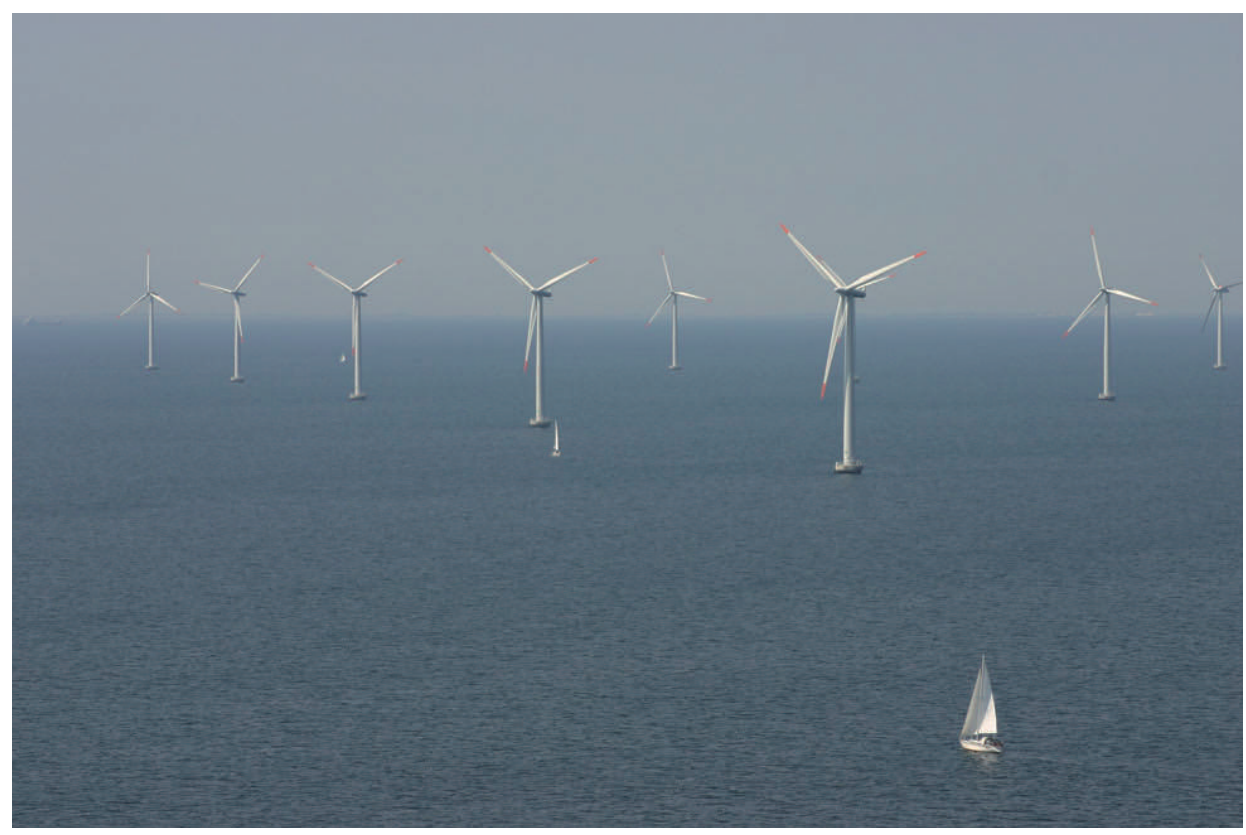

I Photo 4 : Horns Rev offshore wind farm in Denmark (160 MW) is currently the largest farm in operation (@ Dong Energy, DK).

partnership, the Danish Environmental Group, and its results assessed by the International Advisory Panel of Experts on Marine Ecology (IAPEME). Discussions with representatives of associations were held on a regular basis.

The United Kingdom has set up COWRIE (Collaborative Offshore Wind Research into the Environment), a unique organization in Europe, devoted to research and improving knowledge about the environmental impacts of offshore wind power. It was created by the Crown Estate in 2001, with the announcement of the first round of wind farm development ${ }^{10}$. Funds deposited by the 18 project developers were used to set up COWRIE and are employed to carry out a series of environmental studies (on both negative and positive impacts). A steering committee made up of marine environmental experts and specialists from relevant bodies (e.g. government departments, the British Wind Energy Association (BWEA), the Royal Society for the Protection of Birds (RSPB), developers of Round 1 projects, etc.) determines the types of research which should be carried out. The body is separate from government R\&D programmes, and the participation of developers has been a critical factor in its success. The same system of one-off payment of an option fee by the successful project developer applicants was applied in Round 2 in 2003.

10. COWRIE's website is regularly updated, with comprehensive information and all the reports on studies financed by the company (http://www.offshorewindfarms.co.uk/). 
One of COWRIE's main aims is to ensure that its results are widely disseminated. The studies conducted have improved knowledge about potential environmental impacts and above all, have led to the publication of best-practice guidance documents aimed at industry, to ensure that any impacts are minimized. The five research themes given priority are: birdlife and benthos, electromagnetic fields, seabird survey methodology, remote monitoring techniques and underwater noise and vibration. Along with COWRIE's action, the United Kingdom Government's Department for Environment Food and Rural Affairs (DEFRA) and Department for Industry (DTI) also finance research projects on offshore wind and the environment. For instance, three projects are being run by Centre for Environment, Fisheries and Aquaculture Science (CEFAS) ${ }^{11}$. They focus on assessing wave system modifications, developing guidelines for sediment transport monitoring and researching the socio-economic impacts of offshore developments on the fisheries industry.

Other countries, like Germany, are developing technological research platforms, especially for wind power. These actions could facilitate the emergence of marine renewable energies, in a positive joint approach ensuring that knowledge about their impacts at sea is shared. To this end the Agency for the Environment and Energy Management (Ademe), working in collaboration with the French Research Institute for the Sea (Ifremer), carried out a study in 2006-07 on developing national strategies for managing the impacts of marine renewable energies in Europe. A preliminary impact assessment manual for offshore wind farms is also being drawn up. The document is intended to form the basis for a future impact study guide for offshore wind farms, which could be extended to various other sources of ocean power. Like the guide published for onshore wind farms, it is designed for project developers.

\section{The need for pooling of skills and co-operation}

Co-operation between industry and research players, as well as players from other marine activities, is needed to optimize energy generation, and, if it is to be focused in dedicated areas, to avoid conflicts among the different users.

The production per square metre occupied and farm maintenance costs can effectively be improved by seeking complementarity in the area or nearby, either between several types of energy technologies or between an energy technology and another activity, such as aquaculture. Finding synergies amongst activities can also make technologies more competitive through joint studies and pooled costs (e.g. maintenance, cables to carry power shore, etc.).

However, because of their backgrounds, industrial players tend to remain specialized within the technology where they have expertise. Pooling skills and co-operation is not a natural step for them to take. The public authorities and marine researchers can contribute by bringing them together and foster mutual understanding between several stakeholders in a project.

11. http://www.cefas.co.uk/ 


\section{Essential technological developments}

Lastly, a number of technological developments would make it easier to develop marine renewable energies. The most important of these, given the breakdown in supply that it can create, is how to store the energy generated, since this enables full use to be made of the potential of variable energies like wind or wave power. Storing more permanent or predictable electricity generated from other resources when demand is low would also significantly change the exploitable potential of many energy resources (i.e. all renewable sources except biomass, which can be stored, as well as nuclear power).

One possible pathway is to store hydrogen produced by electrolysis of water. The hydrogen could then be converted into electricity using a fuel cell or into mechanical energy using a motor. Development of this energy carrier is blocked more by logistics (e.g. storage, transport, energy source used to produce it ${ }^{12}$ ) than consumption (although handling problems remain for this volatile gas, which is highly inflammable and difficult to liquefy). The second major interest in using marine energies to produce hydrogen is that the facilities could be placed far from the coast. This would increase the exploitable resource and limit the risk of conflicts over use. Hydrogen produced at sea could be transported from remote operation sites in special vessels. Other solutions, such as large-scale electrochemical storage, are being investigated.

Otherwise, storing electricity for short periods (ranging from a few seconds to a few hours, using various techniques from supercondensers to hydro-pneumatics) would improve the quality of power and management of intermittent energies in the grid.

Another type of leverage that can be used to promote the development and competitiveness of these technologies is hybridization (as illustrated in Scenario 2). This involves both creating combinations of technologies that use marine thermal energy and wave energy, for instance, and looking for technologies that can be combined with solar power or an activity like mariculture. The need for co-operation, however, remains a prerequisite for perfecting hybrid technologies that require both industrial and research expertise.

Finally, improved reliability of the technologies to reduce maintenance operations seems to be a vital challenge for short- and medium-term competitiveness, even more so in that, together with the cost of intervention, sea conditions can temporarily prevent servicing. This is the case for the systems and their moorings alike, because the devices must be designed and built to resist extreme conditions at sea.

12. In industry today, hydrogen is mostly produced for chemical applications essentially using natural fossil gas, which produces greenhouse gas emissions. 



\section{Consequences \\ of the possible scenarios \\ on the development of technologies}

Two types of analysis were performed on the outcomes of the four possible technology development scenarios:

- a qualitative analysis of the development, depending on the conditions selected for the scenario;

- a quantitative approach where, for each scenario, figures were given for an order of magnitude for the installed capacity of each technology and its output (electric terawatt hours for electricity, thermal terawatt hours and electric terawatt hours saved for air-conditioning, and volume of freshwater).

\section{Qualitative analysis}

\section{Method}

Three parameters were taken into account in assessing the development potential of the various technologies.

The resource itself: winds and waves are variable and intermittent, presenting a difficulty for electricity generation. However, progress in forecasting models based on satellite data in particular will facilitate management of inputs into the grid.

The possibility of using the technology in synergy with another use: thermal energy could bring nutrients for aquaculture from deep waters; man-made tidal lagoons could also support fish-farming or aquaculture activities. In some configurations, wave power generators can act as breakwaters to protect the coast, and wind turbines can be set up near aquaculture (shellfish) farms. When established in marine protected areas, they could contribute to Natura 2000 zone management measures under contract. However, it must be specified that marine protected areas include different types of zones with different degrees of protection.

There is a possibility of some of these technologies coexisting in dedicated farms (Scenario 1) or a hybridization of technologies (Scenario 2).

\section{Types of industries}

Offshore wind contributes the most to electricity generation, whatever the scenario. The fact that the technology is mature in Europe, together with its potential, especially in the Northern hemisphere, helps to explain its ranking. 


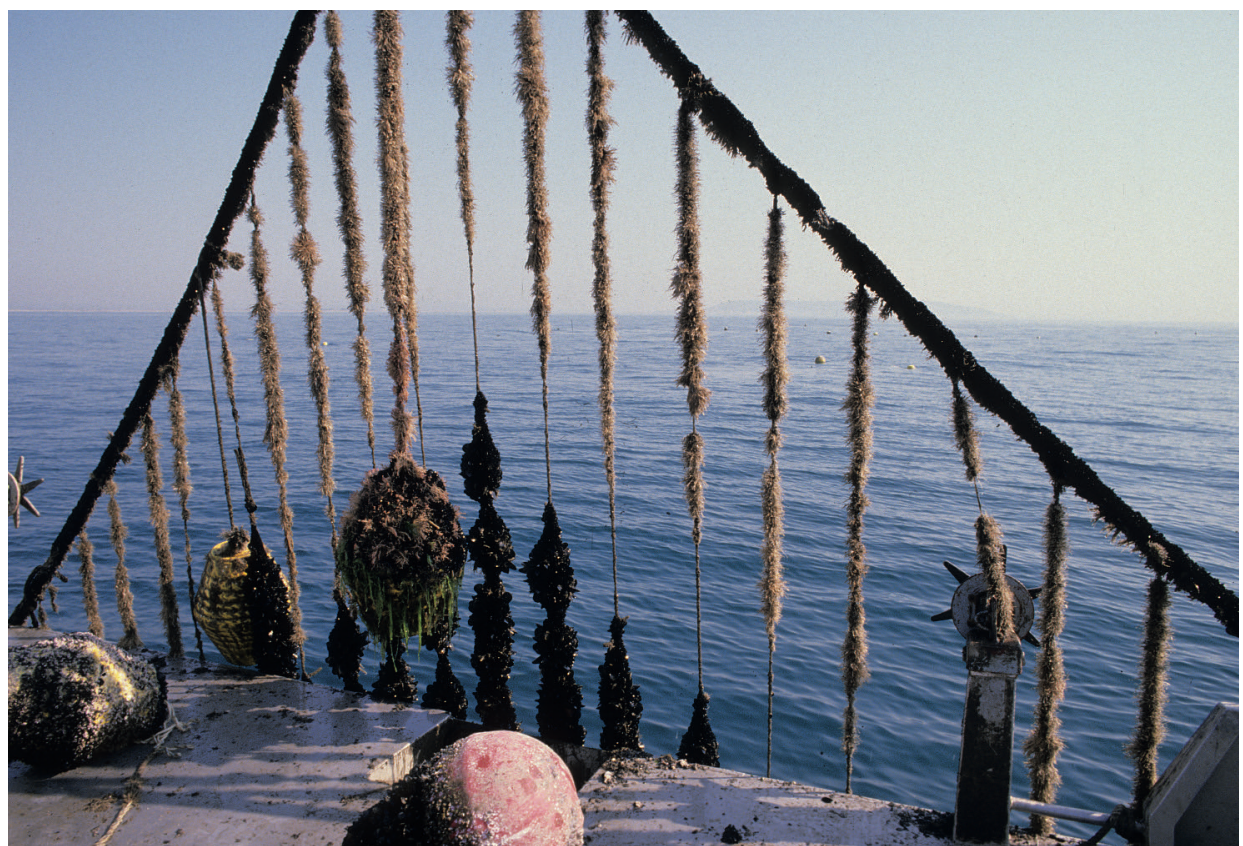

1 Photo 5 : cultivating seaweed or shellfish in the open sea to take advantage of natural or artificial productivity (@ Ifremer, O. Barbaroux).

It is obviously the technology which comes closest to commercial profitability. Its maturity also makes it possible to deliver high production figures, much more so than other technologies still in their prototype stage. Developing this technology will mean facing the challenges linked to environmental impacts and the multiple uses of nearshore marine areas. New concepts, such as floating turbines, which can be installed far from the coast, are already under study.

OTEC has the advantage of both providing cooling for air-conditioning and water and electricity generation, which is a considerable asset in terms of uses. However, only in tropical areas are all these uses viable. In temperate zones, its use is limited to heating and cooling as a thermal source for a heat pump.

Stream energy (tidal stream turbines) has less potential in Europe than other technologies. If tidal stream turbines can be perfected to operate totally under water, they could be installed in areas with maritime traffic where it would be difficult to set up other technologies or activities. In addition, the technology is relatively well known and some of the concepts could benefit from experience acquired in river turbine systems. Development should only need some incremental progress in terms of technology, although the installation (mooring) and maintenance constraints will require innovative solutions. 
Tidal energy, captured by damming an estuary is a known technology, but it has the disadvantage of affecting wetland ecosystems. To compensate for this drawback, another solution under consideration would be to build a tidal lagoon at sea. However, as with dams or barrages, this requires large-scale infrastructures, which also impact on the environment and activities there. In terms of investments, it can only be justified on the basis of a minimal power installation that would be more industrial than experimental in scope, that is, about a few hundred megawatts.

The wave power resource is well distributed in both hemispheres and it shows high potential compared with most other marine resources examined here. The main difficulty for this technology lies in its innovative nature. For it to penetrate, developers will have to prove that they can achieve the necessary technological breakthroughs. Systems which have proved their reliability and are designed to resist extreme conditions at sea will be successful. Moreover, although the risk of impact on landscapes is limited, users exploiting this energy source on the surface must take account of the risk of conflicts over use with other activities. However, the installation capacity per square kilometre is greater than that of wind power (30 MW/ $/ \mathrm{km}^{2}$ for waves and currents compared with 6-10 MW/ $\mathrm{km}^{2}$ for offshore wind).

Using marine biomass from micro-algae cultures presents clear advantages for producing biofuels, such as fast growth, high yield and good carbon dioxide sink capacity (at least 10 -fold that of the best terrestrial plant crops), as well as not causing conflict with food production. However, extensive farming of macro-algae in lagoons in Europe is limited by the available surface areas and could present a risk of blooms. The recently mentioned risks of biofuels contributing to the greenhouse effect are most likely similarly applicable to micro-algae, although no scientific data have been published yet.

Intensively culturing macro-algae in transparent vertical structures on land, along with progress made in mastering biotechnologies (i.e. GMOs), could provide high yields per hectare. These investments in biotechnologies to produce molecules for use in medicine (pharmaceuticals) or the agrifood business are justified in the medium term.

In the scenarios envisaged here, production figures for marine-based biofuels in France remain low. Trends showing an increase in relative energy prices could raise interest from industry for biotechnologies. With an extensive production approach, countries with large lagoon surface areas could become significant fuel producers.

Osmotic power (salinity gradient) is, of all the technologies considered, the least mature, owing to the difficulty of perfecting a high-performance, semi-permeable membrane. In addition, it requires the availability of both freshwater and saltwater. This limits the areas where plants could be set up, if the goal is to reduce the risk of conflicts. Finally, demand for freshwater is growing steadily, so a by-product like brackish water not only has no interest, but could be a liability. 


\section{I Qualitative assessment}

Table 2 sums up the first qualitative assessment of technologies with respect to their development in each scenario. The score indicates the level of development: 0 for none, 1 for limited, 2 for average and 3 for strong development. Adding up the scores implicitly considers that the probability of all four scenarios is the same, an initial working hypothesis which should be given more thorough study.

\begin{tabular}{|l|c|c|c|c|c|}
\hline Technology & $\begin{array}{c}\text { Scenario 1 } \\
\text { Crisis and energy } \\
\text { emergency }\end{array}$ & $\begin{array}{c}\text { Scenario 2 } \\
\text { Altruistic } \\
\text { co-operation } \\
\text { through necessity }\end{array}$ & $\begin{array}{c}\text { Scenario 3 } \\
\text { Few changes, } \\
\text { every man } \\
\text { for himself }\end{array}$ & $\begin{array}{c}\text { Scenario 4 } \\
\text { Independent local } \\
\text { development }\end{array}$ & Total \\
\hline Stream power & 1.5 & 3 & 1 & 1 & 6.5 \\
\hline Tidal power & 3 & 2 & 1 & 0 & 6 \\
\hline Wave power & 1.5 & 3 & 1 & 1.5 & 7 \\
\hline Biomass & 3 & 3 & 1 & 2 & 9 \\
\hline $\begin{array}{l}\text { Offshore } \\
\text { wind power }\end{array}$ & 3 & 3 & 1 & 2 & 9 \\
\hline $\begin{array}{l}\text { Thermal } \\
\text { conversion }\end{array}$ & 2 & 3 & 1 & 3 & 9 \\
\hline Osmotic power & 0 & 1 & 0 & 1 & 2 \\
\hline
\end{tabular}

1 Table 2 : scoring of technologies depending on the scenario.

Table 2 outlines the development potential of the technologies. This summary is mainly the case for France (including overseas DOM-COM) and undervalues some of the technologies, such as sub-sea stream turbines, which could possibly be set up with fewer risks of conflicting uses in places where other technologies cannot be established (e.g. shipping routes subject to strong currents). This approach tends to highlight three technologies, biomass, wind and thermal conversion, which can be distinguished from the second group, wave, stream, tidal and hybrids, if the scenarios are taken globally. The approach aims to minimize the risk of error in choosing one or several technologies. It should be weighted by the advantages and constraints of the various technologies, as well as by the quantitative reality of each technology's production.

\section{Quantitative analysis}

In order to compare scenarios with respect to energy production, it should first be noted that the cost assessments were made for France and its overseas DOM-COM regions. The contribution of marine renewables to energy generation is only valid in this framework. The ranking of technologies based on a costestimate comparison (by order of magnitude) for the various scenarios would be different in any other national context. Each country has its own specific natural resources to exploit for marine energy.

Energy needs on islands, particularly in the French DOM-COM, influence the technological choices found in the scenarios, more so because renewable energy 
alternatives are more cost-effective on islands far from the coast than on the mainland. France's wide range of geographical situations is an asset in that they can provide outlets for technologies, such as OTEC, the potential for which lies mainly in Southern hemisphere countries.

Whatever the technology considered, its potential is often uncertain, since the figures given in various studies, particularly for the technically exploitable potential, vary by up to a factor of ten.

The tables below show the contribution (in Mtoe/year, TWh/year) of the various industries or supply chains to energy generation for each of the scenarios for France and the DOM-COM. These values give orders of magnitude. The accuracy (to two decimal places) indicated in Table 3.1 does not imply that the degree of uncertainty is lower than the accuracy, but is due to the TWh/Mtoe conversion.

These cost estimates are given in detail in Appendix 6. The prevalence of wind power is seen in all scenarios, followed by OTEC (especially in DOM-COM regions) in three out of four scenarios. The cultivation of marine biomass is developed in all the scenarios, but not always as a fuel. Tidal energy shows more risk in terms of acceptability than for technological reasons, except for increasing the output of the La Rance plant. It is not developed in all of the scenarios. It is seen in tidal lagoon technology on new sites in two of the four scenarios. The development of stream energy, like that of wave energy, requires a strong justification (crisis/emergency or co-operation in determined efforts) to overcome the difficulties or even barriers in perfecting it technologically and its complex implementation on an industrial scale. Finally, whatever the scenario examined, favourable conditions for developing osmotic power techniques were not encountered.

\begin{tabular}{|l|c|c|c|c|}
\multirow{2}{*}{\multicolumn{1}{c|}{ Technology }} & \multicolumn{4}{c|}{ Energy production (Mtoe) } \\
\cline { 2 - 5 } & Scenario 1 & Scenario 2 & Scenario 3 & Scenario 4 \\
\hline Wind & 1.03 & 2.58 & 0.52 & 1.03 \\
\hline OTEC A/C met. France savings & 0.06 & 0.12 & 0.03 & 0.12 \\
\hline OTEC Elec. tropics & 0.03 & 0.06 & 0.02 & 0.06 \\
\hline OTEC A/C tropics savings & 0.06 & 0.31 & 0.03 & 0.31 \\
\hline Stream & 0.03 & 0.26 & 0.05 & 0.01 \\
\hline Tidal & 0.09 & 0.13 & 0.05 & 0.05 \\
\hline Wave & 0.03 & 0.52 & 0.03 & 0.04 \\
\hline Biomass & 0.05 & 2.50 & negligible & 1.25 \\
\hline Osmotic power & 0.00 & negligible & 0.00 & 0.00 \\
\hline Budget (MToe) & 1.38 & 6.48 & 0.73 & 2.87 \\
\hline Electricity & 1.21 & 3.55 & 0.67 & 1.19 \\
\hline Air-conditioning & 0.12 & 0.43 & 0.06 & 0.43 \\
\hline Fuel & 0.05 & 2.50 & negligible & 1.25 \\
\hline
\end{tabular}

- Table 3.1 : quantitative analysis of technologies according to scenarios. Estimates Mtoe/year (1 $\mathrm{TWh}=0.086 \mathrm{Mtep}$ ). 


\begin{tabular}{|l|c|c|c|c|}
\multirow{2}{*}{\multicolumn{1}{c|}{ Technology }} & \multicolumn{4}{c|}{ Energy production (TWh) } \\
\cline { 2 - 5 } & Scenario 1 & Scenario 2 & Scenario 3 & Scenario 4 \\
\hline Wind & 12.0 & 30.0 & 6.0 & 12.0 \\
\hline OTEC A/C met. France savings & 0.7 & 1.5 & 0.4 & 1.5 \\
\hline OTEC Elect. tropics & 0.4 & 0.7 & 0.2 & 0.7 \\
\hline OTEC Elect. tropics savings & 0.7 & 3.6 & 0.4 & 3.6 \\
\hline Stream & 0.3 & 3.0 & 0.6 & 0.2 \\
\hline Tidal & 1.0 & 1.5 & 0.6 & 0.6 \\
\hline Wave & 0.3 & 6.0 & 0.3 & 0.5 \\
\hline Biomass & - & - & - & - \\
\hline Osmotic power & 0.0 & 0.0 & 0.0 & 0.0 \\
\hline Budget (TWh) & 15.4 & 46.3 & 8.5 & 18.1 \\
\hline Electricity & 14.0 & 41.2 & 7.7 & 14 \\
\hline Air-Conditioning & 1.4 & 5.1 & 0.8 & 5.1 \\
\hline Fuel & - & - & - & - \\
\hline
\end{tabular}

- Table 3.2 : Quantitative analysis of technologies according to scenarios. Estimates TWh/year (without biomass and fuel). 


\section{Environmental integration: what are the impacts and risks?}

nowledge about the environmental impacts is a vital aspect of integrating marine RES facilities in coastal areas. These areas are used for many competing activities, which also exploit the sea's physical and biological resources. Good stewardship of these uses relies on analysing their impacts.

In this instance, the environmental impacts are particularly difficult to evaluate, since feed-back from experience is lacking, except for wind and tidal power. This is particularly the case for the cumulative effects, since these technologies are still in the prototype stage. In addition, environmental disturbances run the risk of being included in general variability, notably, that brought about by climate change by 2030 .

It has been proved that tidal power technology using a barrage or dam in an estuary alters the way the ecosystem functions. For the other technologies under consideration, possible risks can only be hypothesized and must then be verified. Exploiting permanent currents could modify their flow and related sedimentary movements.

If precautions are not taken, extensive farming of micro-algae could lead to uncontrolled proliferation or blooms of these micro-organisms.

On the other hand, setting up structures at sea (e.g. lagoons, wind turbines, etc.) can also create a 'reef' effect on sandy seabeds, favouring the presence of fish or even the creation of novel ecosystems. The ecological impacts of man-made lagoons for tidal power have not yet been studied. More knowledge about ecosystem trends and changes associated with the infrastructures could be gained, as seen by the improved knowledge about seabirds obtained from impact assessments and monitoring carried out on the first offshore wind farms (see the Danish experience above).

Consequently, much concern will be expressed regarding the environmental impacts of various technologies, with specific questions raised for hybrid systems. For the latter, cross-effects rather than additive ones can be expected, as seen in examples like wind/wave or thermal/biomass combinations.

Similarly, studies should be conducted at all latitudes, because biofouling in the North Sea has a very different composition and development compared with that 
in tropical areas, where coral and colonizing molluscs play a significant role in weighing down structures and moorings.

As studies are long and complex, it is legitimate to expect that funding be provided by the international community via the specialist organizations of the United Nations (e.g. United Nations Environment Programme (UNEP), United Nations Development Programme (UNDP), Food and Agriculture Organization (FAO), etc.), Europe regional commissions or international organizations like the International Union for Conservation of Nature (IUCN). 


\section{Incorporating marine renewable energies in the French energy supply}

\section{Baseline prospective energy scenarios for electricity}

To assess the degree of penetration that marine renewable energies could reach, we can compare the results of the 'possible' scenarios in this study with various foresight studies or forecasts of electrical power consumption to 2020-30.

The baseline studies ${ }^{13}$ used to compare marine RES production in 2030 with French electricity consumption in final energy were the 2004 General Directorate for Energy and Raw Materials (DGEMP) ${ }^{14}$ trend-based forecasts for energy generation/consumption by 2030, the DGEMP-Enerdata/Poles 'factor 4 ' and the Negawatt 2006 'factor 4'15.

- For the two 'factor 4' scenarios taken as references here: the DGEMP poles 'factor 4' scenario relies primarily on nuclear power to reduce greenhouse gas emissions; thus, even if energy-efficient technologies enabling low consumption are used, some heating needs and part of the power for transport and shipping require electricity, therefore, the electricity demand remains high and increases over time;

- The Negawatt scenario opts for even more drastic control of energy consumption with the aim of limiting the need to rely on nuclear power. Consequently, electricity is used less for new requirements and its consumption decreases over time.

Both scenarios achieve the European objective of $20 \%$ final energy produced from renewables by 2020.

It appears that Scenario 3 is compatible with the trend-based scenario, whereas Scenario 4 could only be built on the basis of a highly voluntary energy policy. Therefore, the latter is only compatible with a 'factor 4'-type scenario. Scenarios 1 and 4 are constructed on the basis of intermediate energy policies.

13. Recent studies made by the Strategic Analysis Centre (CAS) published in 2007 are not used as references here, for three reasons. (1) The results of the trend-based scenario in terms of electricity consumption are not very different from those of the 2004 study by the General Directorate for Energy and Raw Materials (DGEMP): the 2004 study's optimistic hypotheses on economic growth and the price of fossil fuel energy are compensated for in the 2007 study by larger population growth. (2) The outcomes of the 'determined action' scenarios for electricity consumption fall between the 2004 trend-based scenario and the two 'factor 4' scenarios selected. The 'voluntary action' scenarios from the 2007 study are not positioned in a 'factor 4' direction, but rather that of halving greenhouse gas emissions in France by 2050. (3) The European objective of $20 \%$ final renewables by 2020 is not reached in any of the 'voluntary' scenarios, which runs counter to the hypotheses used to build three of the scenarios in the marine energy report.

14. (www.industrie.gouv.fr/energie/prospect/textes/prosp-jr-2030-2050.htm)

15. www.negawatt.org/telechargement/Scenariof 
Scenarios 1, 2 and 4 will enable marine RES to produce generally over $3 \%$ of French energy consumption by 2030, provided that this is in a context of relative control of electricity demand (the two 'factor 4' references). Only Scenario 2 allows marine energies to constitute more than $5 \%$ of electricity consumption on that time horizon.

\section{Baseline prospective energy scenarios for fuels}

Today, consumption of oil products in France for transport is 50 Mtoe/year. According to the available scenarios, energy consumption for transport will vary from 40 to 60 Mtoe by 2030 . This variation is due to anticipated progress in heat-engine fuel consumption as well as changes in mobility and use of electric vehicles.

Scenarios 2 and 4 lead to a national generation which is not negligible (2 and 0.8 Mtoe, respectively) compared with current consumption at $5 \%$ and $2.5 \%$. In Scenario 1, the input of marine biofuels produced abroad in extensive farms could, however, have more influence on the same amount of fuel consumed.

It should be emphasized that the 2 Mtoe/year of marine biofuels is of the same order of magnitude as the first-generation agrofuel yields ${ }^{16}$ taken in the voluntary 'determined effort' scenarios in CAS's recent report. This gives a production rate of less than or equal to 4 Mtoe/year until 2025, which would then double (up to $10 \mathrm{Mtoe} /$ year) with second-generation biofuels between 2025 and 2030.

\begin{tabular}{|l|c|c|c|c|c|c|c|c|}
\hline \multicolumn{1}{|c|}{ Year } & 1973 & 1979 & 1985 & 1990 & 1995 & 2000 & 2005 & $2006^{*}$ \\
\hline $\begin{array}{l}\text { Consumption } \\
\text { (TWh) }\end{array}$ & 180 & 245 & 320 & 375 & 425 & 470 & 515 & 485 \\
\hline
\end{tabular}

I Table 4 : annual consumption of electricity in France in 1973-2006 (*Round figures in TWh, including consumption by energy sector) Source: Bilan électrique français 2006/RTE.

\begin{tabular}{|l|c|c|}
\multicolumn{1}{|c|}{ Horizon } & 2020 & 2030 \\
\hline Trend-based scenario DGEMP 2004 & 635 & 715 \\
\hline DGEMP 'Factor 4' 2005 & 520 & 590 \\
\hline Negawatt 2006 & 435 & 420 \\
\hline Moyenne & 530 & 575 \\
\hline
\end{tabular}

- Table 5 : forecast of annual consumption of electricity in France (in TWh/year).

\begin{tabular}{|c|c|c|c|c|}
\hline $\begin{array}{c}\text { Scenario and estimate } \\
\text { of production of renewable } \\
\text { marine energies }\end{array}$ & $\begin{array}{c}\text { Scenario } 1 \\
\text { (15.5 TWh/year) } \\
\%\end{array}$ & $\begin{array}{c}\text { Scenario } 2 \\
\text { (46 TWh/year) } \\
\%\end{array}$ & $\begin{array}{c}\text { Scenario } 3 \\
(8.5 \mathrm{TWh} / \text { year }) \\
\%\end{array}$ & $\begin{array}{c}\text { Scenario } 4 \\
\text { (19 TWh/year) } \\
\%\end{array}$ \\
\hline $\begin{array}{l}\text { Trend-based forecast } 2030 \\
\text { (715 TWh) }\end{array}$ & 2.2 & NA & 1 & NA \\
\hline Poles factor 4 (590 TWh) & 2.6 & 7.8 & NA & 3.2 \\
\hline Negawatt factor 4 (420 TWh) & 3.7 & 11 & NA & 4.5 \\
\hline
\end{tabular}

Table 6 : penetration of marine renewable energies in electricity consumption by 2030 according to the possible scenarios in the study.

16. First-generation biofuels are produced from grains and tubers (e.g. wheat, oilseed rape, sugarbeet, etc.) and second-generation fuels are made from cellulose (e.g. straw and wood). 


\section{Proposal for a normative scenario in the context of the French environmental summit meeting}

t this point in the study, it might seem difficult to progress from a range of possible scenarios (as described by the foresight analysis giving orders of magnitude for yields that could be provided by marine energies) to a concrete, operational scenario that could be the basis for specific recommendations for the use of marine energies. Therefore, the Steering Committee requested that the Working Group propose a 'normative' scenario, breaking down the contributions from various marine energies within a general objective of about $3 \%$ (not including offshore wind) of the renewable energies share in final energy consumption in France by 2020.

Following the debate sparked by the French environmental summit, the 'Grenelle meeting', this normative scenario investigated the possible contribution of marine renewables with the objective of 'reaching $20 \%$ of renewables (final energy) by 2020, under good environmental and feasibility conditions. This means that the share of renewables in the energy cluster would have to be increased by 20 Mtoe by 2020 , by following the two strategic approaches of independent empowerment and decentralization wherever possible', according to the Environment Minister, Jean Louis Borloo on 26 December 2007. Another point to bear in mind is that one of the DOM-COM Operational Committee's energy theme objectives from the Grenelle environmental summit was energy independence for French overseas regions and local authorities by controlling consumption and relying on renewable energies for $50 \%$ of requirements.

\section{Five main elements now support the need for renewables}

- The increasing gap between supply and demand for fossil fuels;

- The slow rate of development, above all in nuclear power;

- The probable extension of the Kyoto agreements with a road map indicating quantitative targets before 2012;

- The confirmation of EU ambitions in this field by 2020 and the choice of sufficiently realistic objectives to make investments possible;

- The serious probability of a wide-ranging reshaping of the energy market in the medium term. 


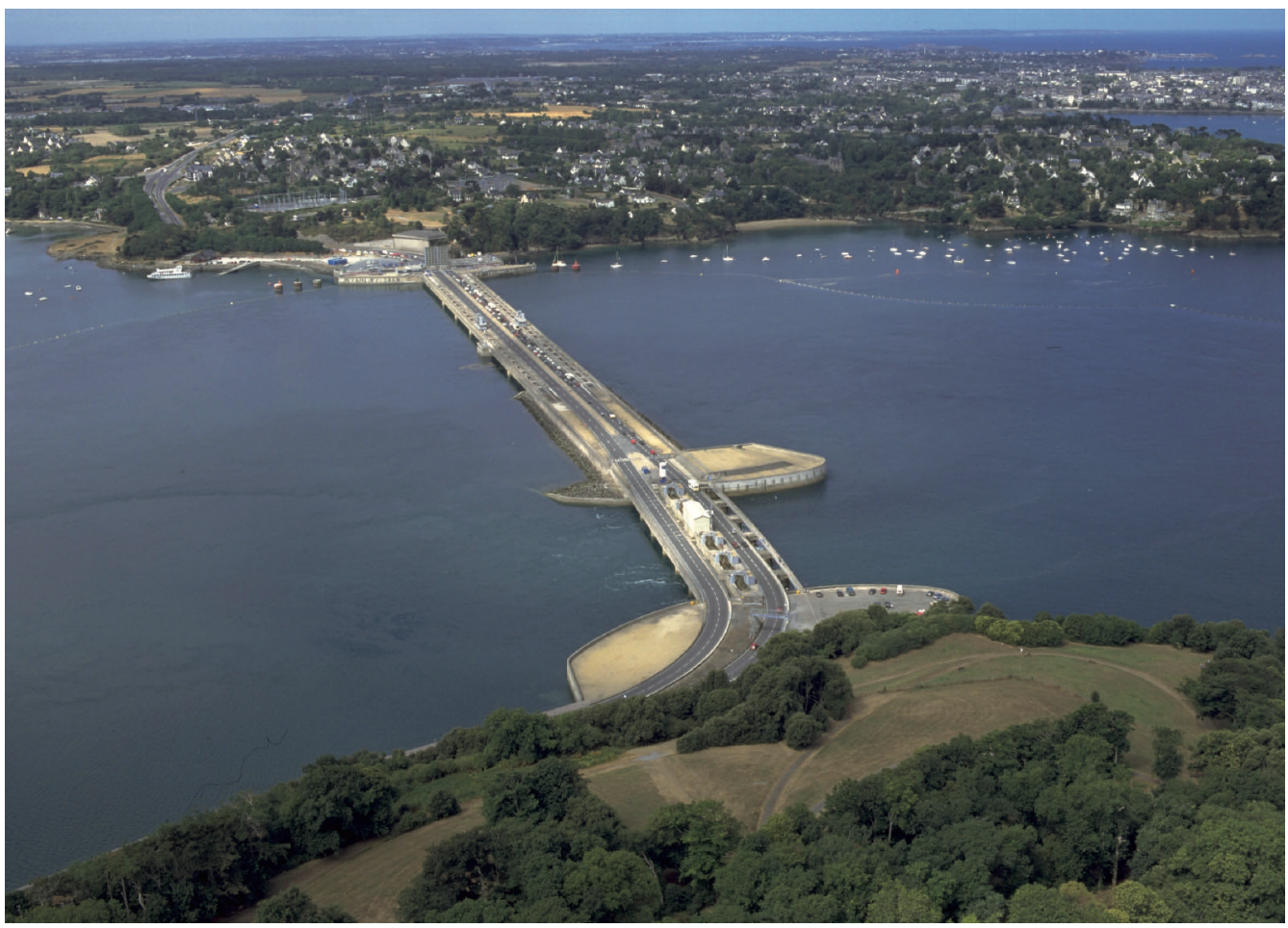

I Photo 6 : the Rance tidal power plant, France (@ EDF).

In the framework of the environmental summit meeting discussions, the consortium for renewables Syndicat des énergies renouvelables (SER) explained its view of growth potential in these sectors to reach the European target of a net increase of $20 \mathrm{Mtoe} / y e a r$ in renewable energies by 2020. Amongst the contributions from various renewable energy chains in the SER scenario, is the penetration of offshore wind with $6000 \mathrm{MW}$ installed power.

On the European level, Member States may have difficulties in fulfilling their renewable energy obligations by 2020. Although there are attractive possibilities, such as photovoltaics for solar power, EU countries will tend to move first towards the simplest and most cost-effective technologies, like wind and biomass on land.

Several things should be remembered:

- France ranks second in Europe in terms of potential, following the United Kingdom, which is highly active in the field, with wave and tidal stream power;

- with its ultramarine (DOM-COM) territory, France also enjoys very large resources for OTEC;

- in research, including applied research in industry, there is currently a critical mass for marine energies whose dynamic approach includes risk-taking capability; 
- as a 2005 study by Westwood 17 indicated, the global market for marine energies (stream and wave) represents from 10 to 30 times the European market.

This scenario makes a realistic attempt to select the technologies which are likely to develop and to assess their power and levels of generation based on forecast figures. Thus it specifically evaluates the efforts of organization, research and industrialization that must be deployed for this contribution to be realistic and relevant. Marine energy will indeed have a share, if networks of strategic partnerships and pre-industrial or even industrial experiments are implemented between now and 2020.

Thus, if a target of, say, 2-3\% was adopted for the contribution of marine RES by 2020 for France, there would be significant consequences in terms of energy policies, the way the field's R\&D system is structured in France, the creation of experimental platforms, support (all forms, whether financial or organizational) and stimulating technological developments on an industrial scale.

In the normative scenario, the following distribution, by technology, is given in decreasing order, by energy contribution (Appendix 6).

\section{Wind}

Wind technology is the most mature and developed worldwide today. France has substantial potential due to the combined criteria of regularity and force and the characteristics of its continental shelf, so several offshore wind farms are to be created on the three seafronts of metropolitan France. They will be farms with a few dozen or more high-power wind turbines (5 MW or more) set up a few kilometres from the coast as a compromise between investments and maintenance costs on the one hand and the visual impact on the other.

The most complicated aspect will be compatibility with other uses, particularly fisheries and tourism, hence the importance of starting outreach work early to raise awareness, inform and educate and, above all, to develop local employment, including jobs in energy tourism (as at the tidal power plant at La Rance). In addition, social acceptance will be all the greater if these sites set up hybrid technologies (combined with wave power, for instance) and associated uses like aquaculture. Their compatibility with the developing network of marine protected areas and their various levels of protection will also need to be taken into account.

\section{Estimate for offshore wind}

About $400 \mathrm{MW}$ installed power and approximately 1.4 TWh of energy generation, 16 farms with 50 wind turbines of $5 \mathrm{MW}$ each operating 3000 hours annually.

17. Westwood 2005. Marine Renewable Energy Report - Global Markets, Forecast and Analysis 2005-2009. Canterbury, UK: Westwood. 


\section{Thermal}

This energy source should be developed in the French DOM-COM both because it is suitable for direct use, providing long-term savings in fossil fuels, and because it will demonstrate its value to neighbouring countries in the tropics. It can be utilized in several forms (e.g. water, cooling and electricity) and improved yields could be obtained on islands with hot water from volcanic springs. The islands of the West Indies, Réunion and Tahiti will have power plants largely adapted with respect to local conditions.

\section{Estimate for thermal energy}

For electricity: $200 \mathrm{MW}$ installed power and approximately 1.4 TWh of energy generation, 10 plants of $20 \mathrm{MW}$ each, operating 7000 hours annually. For cooling: $55 \mathrm{MW}$ of electricity saved, that is, $0.4 \mathrm{TWh}$, the equivalent of 12 power plants of $20 \mathrm{MWf}$ each, operating 7000 hours annually.

\section{Stream power}

Stream power technology has considerable advantages in France, particularly because of the powerful tidal currents on the northwestern coast, predictability of yields, low visual impact at the surface and occupation of sea passages where it would be difficult to set up other marine energies or other activities. It will progress to the industrial stage, but eligible sites will remain few in number.

\section{Estimate for stream energy}

Around $400 \mathrm{MW}$ installed power and approximately 1.4 TWh of energy generation, five plants of 80 wind turbines of $1 \mathrm{MW}$ each, operating 3500 hours annually.

\section{Tidal energy}

Everyone is aware of the strength of tides and this source is positively viewed by the general public. However, the long-standing and hard-to-reverse environmental impacts mean that its development in the form of barrages in France is unlikely to occur. In order to showcase and enhance the use of French technology, an industrial-sized tidal lagoon will be built.

\section{Estimate for tidal energy}

Around $500 \mathrm{MW}$ installed power and approximately $1.30 \mathrm{TWh}$ of energy generation, for example, a $500 \mathrm{MW}$ lagoon plant operating 2500 hours annually. This scenario considers that the Rance tidal power plant, which has been operating for the past 40 years, does not contribute to the Grenelle summit target of a 20 Mtoe increase in the renewables share by 2020 . 


\section{Wave power}

The potential of wave power is high, but unfocused, and the technologies are not as mature as those for wind power. Since ways of handling hydrogen will probably not be perfected by 2020, systems far offshore will not be developed. However, seeing that wave power has greater potential than wind power $\left(30 \mathrm{MW} / \mathrm{km}^{2}\right.$ for wave, $10 \mathrm{MW} / \mathrm{km}^{2}$ for wind), several industrial sites will be set up on the Atlantic seafront and in the DOM-COM regions.

\section{Estimate for wave energy}

Around $20 \mathrm{MW}$ of installed power and about 0.8 TWh of energy. This would make, for example, 20 sites with 10 turbines of $1 \mathrm{MW}$ unit capacity, operating 4000 hours annually (50\% in DOM-COM).

\section{Biomass energy}

Although it has hardly been explored to date, marine biomass has considerable potential for energy purposes. France has numerous advantages in this field, even with a late start. The range of species which can be cultivated at all latitudes means that industrial developments will appear both in metropolitan France and in several tropical French regions, including French Guyana. Intensive systems will be chosen in the first series of developments, to better control both costs and criticism. Indeed, increasing pressure will be brought to use land for food crops, due to growing populations, food security and climate change.

\section{Estimate for biomass energy}

A site first developed as a demonstration trial then as an industrial pilot site, with some 2000 ha at 30 tonnes of oil/ha (i.e. 25 toe/ha), making approximately 0.05 Mtoe/year.

\section{Osmotic power}

The technological and environmental constraints, especially in terms of requirements for space and freshwater will not enable an industrial-scale prototype to be created.

\section{Hybrid power}

It is relatively easy to hybridize technologies in two cases: placing floating wind turbines and a wave power generator in the same perimeter and combining OTEC with biomass, due to minerals brought up from deep waters (also interest for aquaculture). Power estimates have already been accounted for separately.

\section{Summarized overview with figures for the normative scenario}

Table 7 sums up the respective inputs of technologies in the normative scenario. The large share contributed by wind energy can be noted. This is expected given the technology's maturity and the period of time to be covered. 
Thus, we see that with regard to the European objectives for France taken as a basis by the environmental summit meeting (i.e. an increase of 20 Mtoe of renewables by 2020), the contribution of marine energies, including offshore wind, in the normative scenario would be about $1.5 \mathrm{Mtoe}$, or $7.7 \%$. This is significant compared with the other renewable energy sectors. The scenario clearly indicates the efforts needed to achieve the target.

\begin{tabular}{|c|c|c|c|c|c|}
\hline $\begin{array}{c}\text { Type of renewable } \\
\text { energy }\end{array}$ & $\begin{array}{l}\text { Installed } \\
\text { power } \\
\text { (MW) }\end{array}$ & $\begin{array}{c}\text { Hours } \\
\text { of operation } \\
\text { per year }\end{array}$ & $\begin{array}{l}\text { Electrical } \\
\text { power } \\
\text { (TWh/yr) }\end{array}$ & $\begin{array}{l}\text { Energy } \\
\text { (Mtoe/yr) }\end{array}$ & $\begin{array}{c}\text { Ref Target } \\
2020 \\
20 \text { Mtoe/yr } \\
(\%)\end{array}$ \\
\hline Offshore wind & 4000 & 3000 & 12 & 1.03 & 5.2 \\
\hline OTEC - Electricity & 200 & 7000 & 1.4 & 0.12 & 0.6 \\
\hline OTEC cooling - saved & 55 & 7000 & 0.4 & 0.03 & 0.2 \\
\hline Stream & 400 & 3500 & 1.4 & 0.12 & 0.6 \\
\hline Tidal & 500 & 2500 & 1.25 & 0.11 & 0.5 \\
\hline Wave & 200 & 4000 & 0.8 & 0.07 & 0.3 \\
\hline Biomass & - & - & - & 0.05 & 0.3 \\
\hline \multicolumn{3}{|c|}{ Total } & 17.2 & 1.5 & 7.7 \\
\hline \multicolumn{3}{|c|}{ Total hours wind } & 5.2 & 0.5 & 2.5 \\
\hline
\end{tabular}

I Table 7 : technology power rating and generation according to the normative scenario. $1 \mathrm{TWh}=$ 0.086 Mtoe.

This normative scenario is put into perspective with the four possible scenarios in Appendix 6. According to the normative scenario, based on French electricity consumption for 2020 (an estimated 530 TWh - see Table 5), marine RES would contribute 17.2 TWh or 3.2\% of the total supply, which would be far from negligible.

Given the technological progress made, including breakthroughs like mastering hydrogen storage, together with improved energy yields and energy savings, particularly in cities, a faster increase in this percentage of marine energies between 2020 and 2030 can reasonably be expected. It could then reach from $4 \%$ to $5 \%$ of French electricity consumption, or even more depending on the global situation.

If the normative scenario is considered to be desirable in view of its results, there is justification for trying to see which concrete actions and decisions should be implemented for it to unfold. The situation must remain flexible to take account of results from industrial pilot sites elsewhere in the world (stream power in the United Kingdom, wave power in the United Kingdom and Portugal, biomass in Hawaii, etc.). This means that the communication of technological information is even more important. The dynamics can only be effective and lasting if all the stakeholders are organized and work in a complementary manner. There are four levels for this: the French State, maritime regions (especially overseas), enterprises and finally, the EU.

\section{The State level in France}

The State is committed to meeting its renewable energy obligations. France's credibility with respect to the EU and the other countries which have signed the 


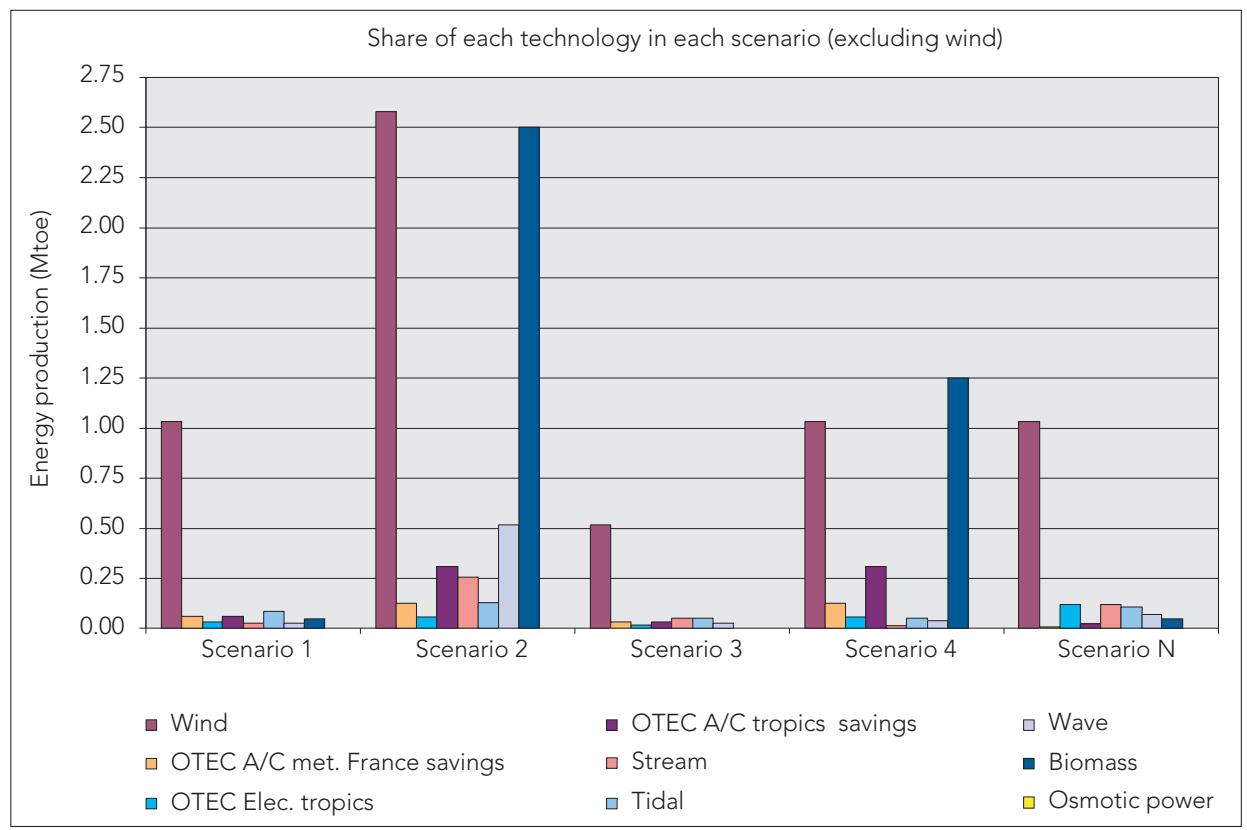

I Figure 1 : breakdown of energy production by technology and scenario (four contrasting scenarios by 2030, one normative scenario by 2020 in compliance with EU commitment) - visualization with offshore wind.

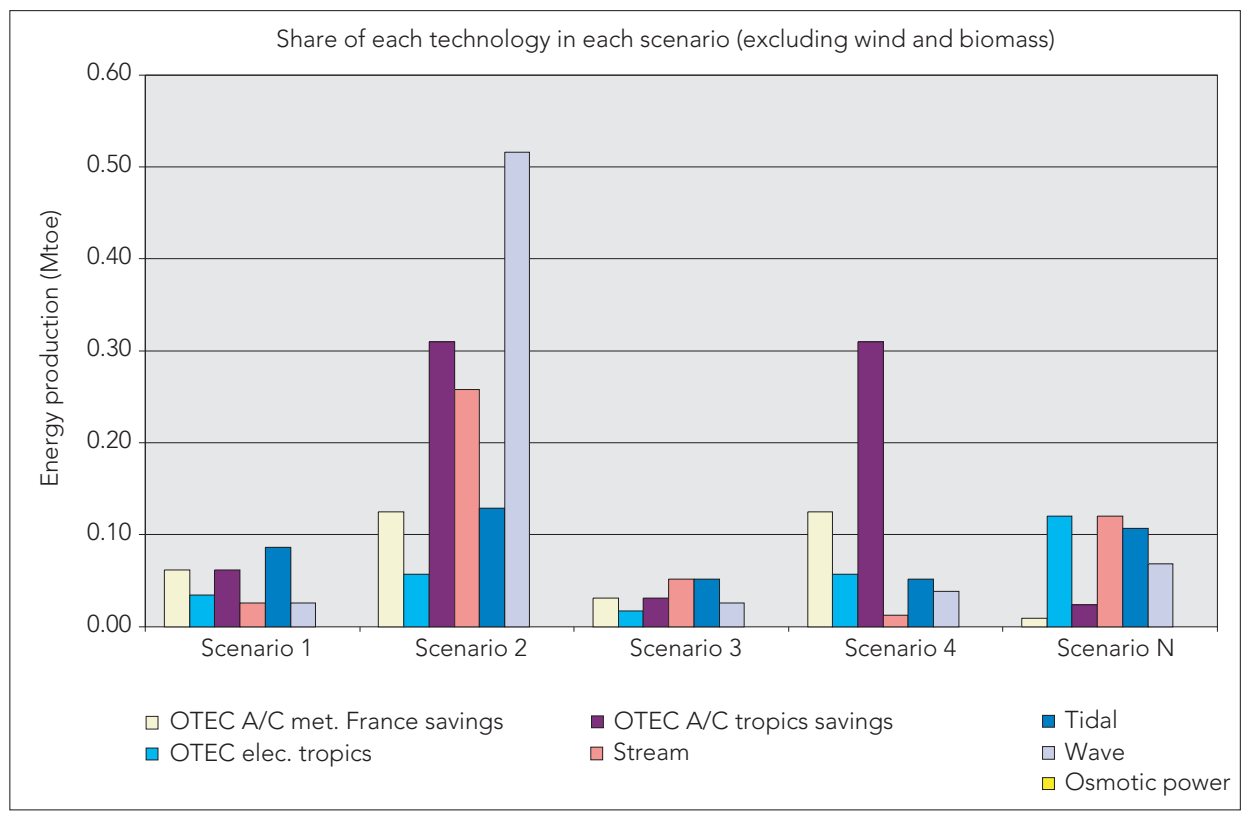

1 Figure 2 : breakdown of energy production by technology and scenario (four contrasting scenarios by 2030, one normative scenario by 2020 in compliance with EU commitment) - visualization without offshore wind or biomass. 
agreement on climate change and the Kyoto Protocol is dependent on meeting these obligations. The Working Group, which conducted this study and drew up the normative scenario, suggested that the State should provide support, information and monitoring and suggested the following avenues to explore.

\section{A support role}

Supporting public sector research by strengthening the specialized laboratories in French research institutes and universities to foster their synergy; support via the national research associations' (ANR) calls for tender, lobbying the European Commission to stimulate this sector, the future guidance agency for research and support for private sector research (extending the CIR tax credit for research), allocating research grants favouring partnerships with innovative enterprises.

Funding 'demonstration installations' to facilitate progress from experimental to industrial-scale testing.

Backing up the partnerships engaged in this sector, such as the marine clusters of Brittany and Provence-Alps-Côte d'Azur region (PACA) regions, and the various clusters devoted to 'energies' in metropolitan France like Tenerrdis, Capénergies, Derbi and Synergile in Guadeloupe, together with others being created or envisaged for the DOM-COM regions.

Support for the feed-in tariff to buy back kilowatt-hours in order to encourage risk-taking by investors.

\section{The role of information}

Technological intelligence (and stimulating scientific partnerships), mobilizing technology-watch services in embassies of the most developed countries (e.g. EU, USA, Japan, Australia) and centralizing and regularly summarizing information. With this outlook, setting up scientific partnerships should be encouraged at Ifremer

- methodology support for impact studies by drawing up a guide for environmental assessments;

- informing decision-makers in coastal areas and communications on all levels must also be developed.

\section{A monitoring role}

A monitoring and supervisory role is necessary to adapt procedures to the specificities of marine renewables and also to define the zones which are favourable for developing marine energies.

\section{For maritime regions, especially overseas}

The regions already play a major role in spatial planning and this could be greater in future since the regions provide the relevant scale for this type of development. Their early upstream involvement from the outset of projects, selection of favourable zones and exploration of how projects can provide local utilizations and benefits, appears to be a factor for development which could facilitate their public acceptance. 


\section{For companies}

There is no question of interfering with industrial players' strategies, but rather facilitating the emergence of complementary and stable partnerships. Once the critical mass is reached, these consortia must mobilize resources to be able to progress from the pilot to industrial phase.

These firms, especially the large companies in the energy sector, must be expected to assume their share of the risk in setting up projects to launch the industry in question. Smaller enterprises can also play a role in innovation by launching new concepts that can later be taken up within the industrial partnerships. Other medium-sized enterprises, such as impact-study sub-contractors, can also contribute to improving knowledge in this field and working with research institutes (e.g. with ANR funding).

\section{For the EU}

France must act to ensure specific support for marine RES within various European programmes, particularly in mobilizing research on environmental impacts, which have been insufficiently studied to date. In addition, developing co-operation between Europe and the Mediterranean should lead to specific actions for marine renewables (e.g. offshore wind, biomass, etc.).

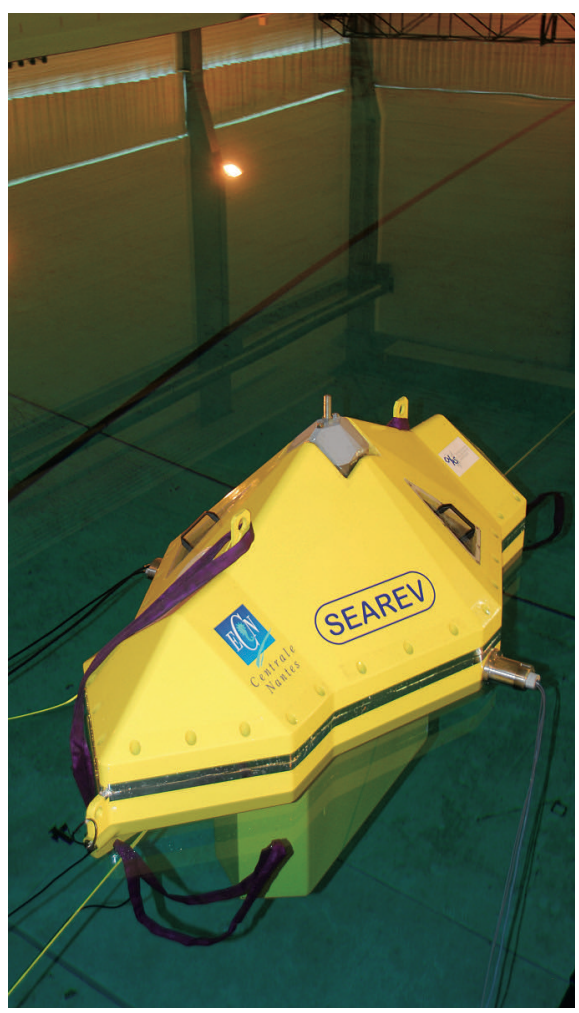

I Photo 7 : autonomous electricity system for wave energy recovery (Searev) mock-up (C École centrale de Nantes, FR). 



\section{Conclusion}

- his year-long collective effort has made it possible to reduce uncertainty and show France's great potential in this field, in terms of its natural resources, expertise and scientific and industrial resources that can be mobilized.

An analysis of the scenarios highlights the importance of the international context in defining national strategies and, on the national level, the importance of the role played by the State in developing marine renewable energies. This role could be seen as coordinating skills and resources or supporting targeted initiatives.

The drive shown by the enterprises engaged in this field must be linked with research in universities and specialized institutions and with the will to help partnerships with other companies to emerge.

It is important that all stakeholders, whether or not they are institutional bodies, adopt a shared, long-term vision that can take account of fundamental changes in the international energy context (e.g. oil prices, climate, public opinion, etc.), technological breakthroughs (e.g. hydrogen storage/transport, selecting highperformance algal strains, etc.) and impacts on the marine environment and coastal uses due to the installation of new developments.

It can clearly be concluded that it is important to reinforce R\&D studies for marine renewable energies in several fields of science and engineering. The State should maintain its role as coordinator over the long term and in determining the means of support for operators who wish to engage in these efforts, alone or collectively (i.e. enterprises, resource agencies, funding agencies, regional councils or the EU).

Moreover, the French State, in the framework of its Grenelle environmental summit meeting, is planning to set up a support fund for trial demonstrations in new energy technologies. Marine renewables should have access to it through a call for projects.

Finally, if new technological platforms were to be envisaged, marine renewable energies should stand to gain. Setting up collaborative arrangements would promote the development of trial sites and demonstration installations at sea.

Under these conditions, marine renewable energies can help meet the objectives set by the EU for renewable energy by 2020, while developing technologies with high export potential, particularly in the tropical zone. Lastly, the major trends in climate change, which can be seen today, above all in the marine realm (e.g. wind, wave, currents, algal blooms, temperature, etc.), increasingly justify the use of these forms of energy. Consequently, it is of even greater strategic importance to rapidly take these technologies on board, while we still have time to make them our competitive long-term assets. 


\section{Bibliography}

Association négaWatt, 2005. Scénario négaWatt 2006 pour un avenir énergétique sobre, efficace et renouvelable. Document de synthèse, $15 \mathrm{p}$.

Centre d'analyse stratégique, Syrota J. (président Commission 'Energie'), 2007. Perspectives énergétiques de la France à I'horizon 2020-2050. Rapport de synthèse Commission 'Energie'. Paris: Strategic Analysis Centre, $16 \mathrm{p}$.

Commission of the European Communities, 2007. Energy Policy and Maritime Policy: Ensuring a Better Fit. Brussels: Commission of the European Communities, 21 p.

European Commission, 2006. World Energy Technology Outlook. WETO H2. EUR 22038. Brussels: European Commission, $168 \mathrm{p}$.

Grenelle de l'environnement, 2008. Lutter contre les changements climatiques et maîtriser I'énergie. Rapport de synthèse du Groupe 1, 108 p.

IEA, 2006a. Review and Analysis of Ocean Energy Systems. Development and Supporting Policies. International Energy Agency's Implementing Agreement on Ocean Energy Systems, June 2006. Paris: International Energy Agency.

IEA, 2006b. Ocean Energy Systems Implementing Agreement. Five Year Strategic Plan 2007-2011, November 2006. Paris: International Energy Agency.

IEA, 2007. World Energy Outlook, China and India Insights, Summary. Paris: International Energy Agency, $18 \mathrm{p}$.

Medad, 2007. La prospective française énergétique à I'horizon 2030-2050. Direction générale de l'énergie et des matières premières. Paris: ministère de l'Écologie, de l'Énergie, du Développement durable et de l'Aménagement du territoire.

Westwood A., 2005. Marine Renewable Energy Report. Global Markets, Forecasts and Analysis 2005-2009. Canterbury: Westwood. 
PART 2

Constructing

the scenarios 


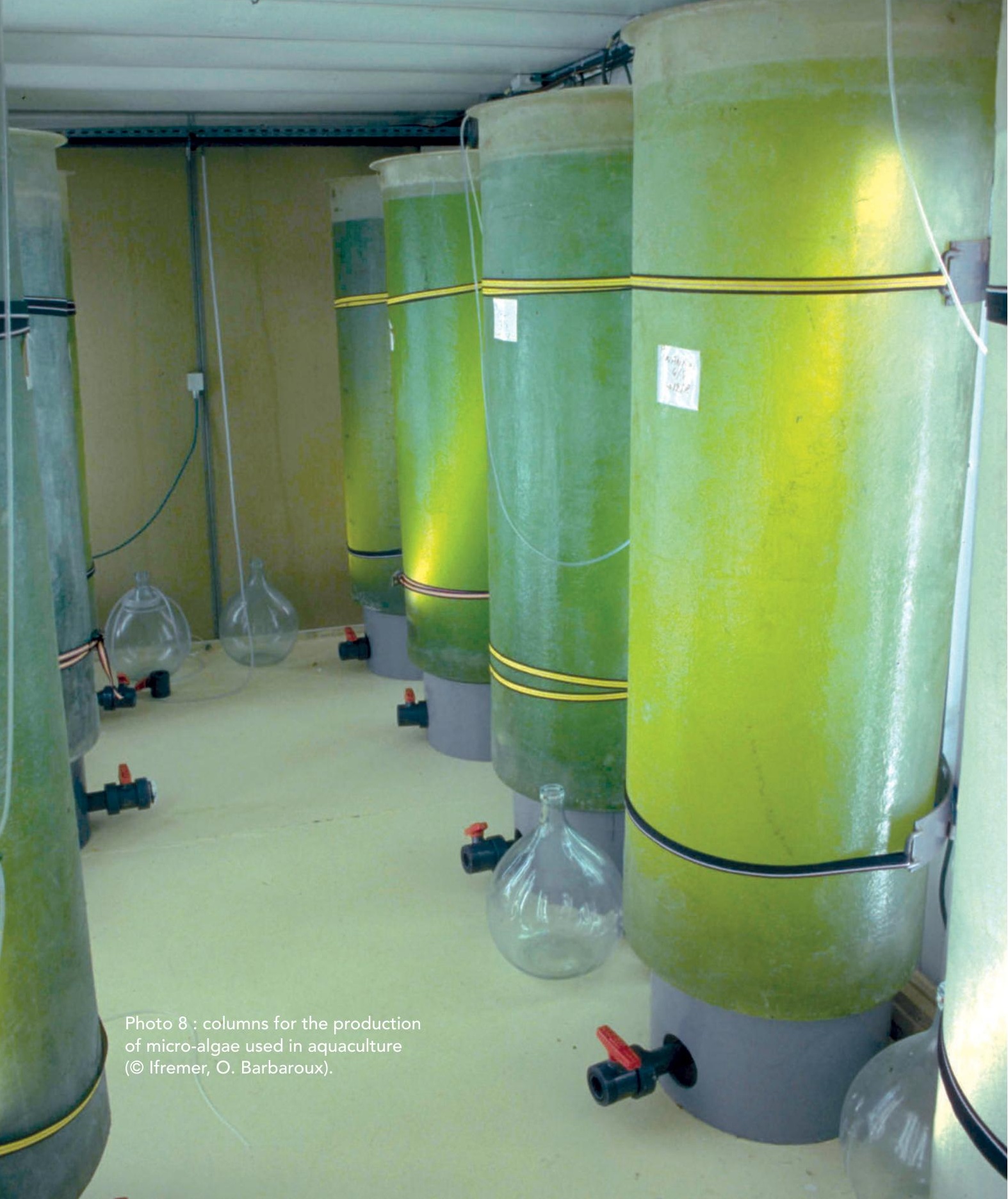




\section{Context}

aced with climate change, the commitments made by the by countries that ratified the Kyoto Protocol and their support for a drastic greenhouse gas reduction policy on national, European and international scales, require that the use of fossil fuels be curtailed. Burning fossil fuels represents $80 \%$ of anthropogenic greenhouse gas emissions today, in the context of increasing demands for energy around the world, due to population increases and industrial development in emerging countries. The increased demand for energy mainly arises from the need for fuel for transport and generation of electricity.

In addition, threats to oil supply - whether geopolitical or structural in nature makes it necessary to investigate the development of all forms of renewable energy that do not emit greenhouse gases. The possibility of oil production peaking, subsequent depletion occurring in less than 20 years and similar trends for natural gas by 2050 must be considered. If the worldwide response to an energy crisis was an even more urgent use of traditional energy sources such as coal and biomass, the risk of a climate disaster would be great. Coal, apart from a costly process of capturing and sequestering carbon dioxide, emits more greenhouse gases than oil and gas. Using biomass for energy is not a neutral choice in terms of greenhouse gas emissions unless the biomass is constantly renewed or replaced. However, current deforestation in many places is reducing the biosphere's carbon storage potential.

The increasing occupation of coastal areas by the world's population is an additional argument in favour of using marine energies. In 2001, the United Nations estimated that $44 \%$ of the world's population was living less than $150 \mathrm{~km}$ from the sea and $50 \%$ living less than $200 \mathrm{~km}$ from it ${ }^{18}$.

According to the Center for Climate Systems Research (CCSR) of the University of Columbia19, the number of people residing less than $100 \mathrm{~km}$ from the coast should increase by $35 \%$ between 1995 and 2025. By that date, 2.75 billion people will thus be exposed to the hazards of rising sea levels and more frequent hurricanes and storms. In addition, some islands have few locally available renewable resources other than the sun and sea.

All the reports on available energies for reducing greenhouse gas emissions indicate that reaching the goals recommended by scientists 20 will be a real challenge in technological, social and economic terms. This is the case even when optimistic hypotheses on the use of nuclear energy and land-based renewables

18. UN Atlas of the Oceans (http://www.oceansatlas.org/).

19. Center for Climate Systems Research. It's 2025. Where Do Most People Live? 11/2006 (http:// www.earthinstitute.columbia.edu/news/2006/story07-11-06.php).

20. To limit greenhouse gases in the atmosphere to $550 \mathrm{ppm}$ in order to cap average global temperature increases at $2^{\circ} \mathrm{C}$ and so stabilize the climate. 


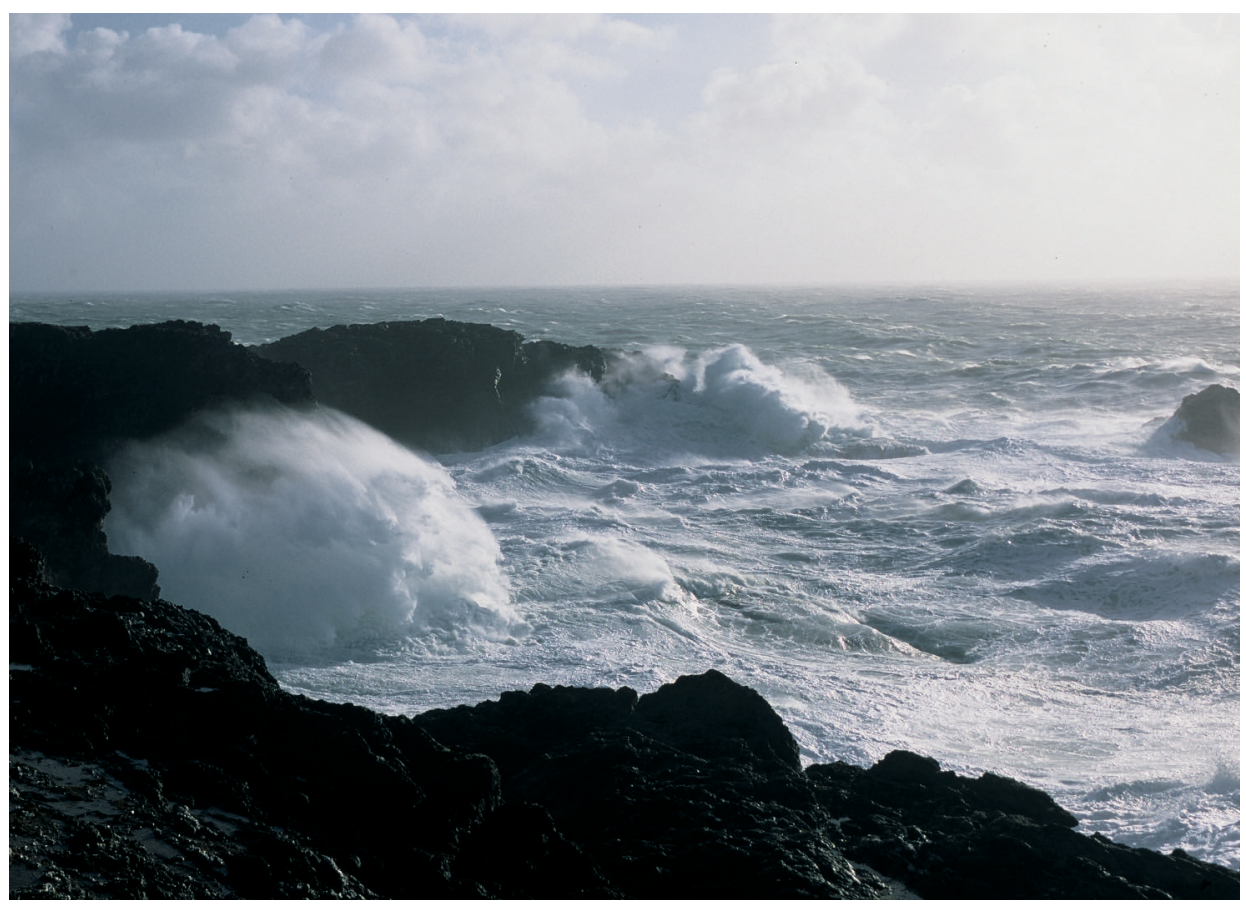

- Photo 9 : storm at Goulphar on the rugged coastline of Belle-lle-en-Mer, Morbihan (C) Ifremer, O. Barbaroux).

are considered. Yet, very often, the energy potential of the ocean is not mentioned in the list of future renewable energy sources (RES), or if so, as an afterthought. This is why this study has been undertaken: to analyse the conditions for development, uses and energy mix contribution of marine renewable energies.

The second part describes the successive steps taken to construct the scenarios:

- setting out and comparing hypotheses for each key-variable within each variable group or 'component' (the choice of hypotheses is explained in each variables fact sheet in Part 3);

- choosing three or four micro-scenarios for each component;

- selecting four macro-scenarios from the table of mini-scenarios. 


\section{Study structure and methodology}

\section{Step 1: organization}

The approach taken by the Working Group to build the scenarios and summarize what was learned was described in five steps, each validated by the Steering Committee.

1. The first step defined both subject and horizon. A list of all possible energy sources from the marine environment was drawn up, the relevant geographical zone (e.g. temperate, tropical, etc.) was defined and the timeframe of the study specified; 2030 was chosen as being sufficiently far in the future to enable any breakthroughs or changes to be assimilated.

2. The second step was to draw up the list of variables (factors) influencing the subject of the study, which is the basis of a prospective analysis system. However, since factors (e.g. energy prices) do not change without the influence of one or several actors, variables are generally a mixture of factors and actors. This list of variables must be both relevant (and include all possible highly influential factors) and hierarchical. The relationships of influence and dependence between the variables were analysed so that only the most influential factors were selected.

3. The third step consisted of a backcasting analysis by documenting the change in the variables over the number of years stipulated in the timeframe. This documentation step was shared by Working Group members, including Futuribles consultants who completed the socio-economic context sections. Backcasting led to the formulation of hypotheses on the possible evolution of these variables. A trend-based reference hypothesis was formulated for each based on this hindsight. Alternative hypotheses based on facts, the so-called threshold effects or sets of actors were drawn up.

4. The fourth step involved the construction of exploratory scenarios in the timeframe of the study by compiling the hypotheses for the different variables and components. Among the possible scenarios, only the most contrasting scenarios that best illustrated the range of possibilities (generally from three to five scenarios) were selected. The goal was to make informed choices and not to confuse decision-makers with too many variants. A scenario was defined not only by a prognosis within a given timeframe, but also by the progression that led to this view. The dynamics or the driving variables were usually different in each scenario.

5. The final step consisted in drawing lessons from this exercise by determining the risks, opportunities and stakes revealed through comparison of the scenarios. The leverage for change that takes us from one scenario to another also provides strategic information for the approach. 
Steps 2-5 required 1 to 4 full-day meetings of the Working Group. The study's chronology is shown in the following diagram (Table 8).

\begin{tabular}{|c|c|c|c|c|c|c|c|c|c|}
\hline Step $\quad$ Month & 3 & 4 & 5 & 6 & 7 & 9 & 10 & 11 & 12 \\
\hline Step 1: context & & & & & & & & & \\
\hline $\begin{array}{l}\text { Step 2: } \\
\text { factors and system }\end{array}$ & $\star$ & $\Delta \Delta$ & & & & & & & \\
\hline $\begin{array}{l}\text { Step 3: documentation } \\
\text { and hypothesis }\end{array}$ & & & $\star$ & $\star$ & & & & $\begin{array}{l}\text { scenario } \\
\text { written } \\
\downarrow\end{array}$ & \\
\hline $\begin{array}{l}\text { Step 4: } \\
\text { micro- and macro-scenario }\end{array}$ & & & & & & & $\star$ & $\star$ & \\
\hline $\begin{array}{l}\text { Step 5: } \\
\text { lessons }\end{array}$ & & & & & & & & & \\
\hline
\end{tabular}

is Working group meeting

$\triangle$ Steering committee

I Table 8 : chronology of prospective study.

\section{Step 2: description of the variables system}

The initial question asked was: what factors or variables have an influence on the development of marine renewable energies? The group drew up a preliminary list of over 50 variables, grouped into nine themes called components. Prioritizing these variables, by retaining only those with the most influence on the energy system and marine renewable energies, led to a list of 30 variables gathered into five components. They are not separate from each other. In fact, the logical links between the variables is what enabled the scenarios to be built in Step 4.

\section{Step 3: documenting the variables and the case of the technological variables}

The goal for this step was to formulate from two to five prospective hypotheses for 2030 for each of the variables. To this end, each variable was documented using the following format:

- definition;

- key indicators needed to monitor it over time;

- backcasting over the past 20 years to look at how and why the variables changed with respect to the key indicators and which actors influenced them;

- prospective hypotheses for 2030.

The seven technological variables were: stream, tidal, wave, biomass, (offshore) wind, ocean thermal energy conversion (OTEC) and salinity gradient power. They were documented using a different format (Table 8). For emerging fields, such as stream power, few retrospective elements were available. Furthermore, the resource potential, energy use, regularity of production, etc., vary greatly from one technology to another, thus, the technological variables were documented in 
terms of the current stage of development. Hypotheses for the future took account of the various possible technological advances with respect to current research outputs.

The format for documenting the seven technologies covers the following ten points:

\begin{tabular}{|l|}
\hline Definition of resource \\
\hline Known physical resources and their location in the world/EU/France \\
\hline Energy production with known technologies \\
\hline $\begin{array}{l}\text { Energy efficiency (uses, regularity/intermittence) and competitiveness } \\
\text { of the technology }\end{array}$ \\
\hline Industrial cost trends \\
\hline $\begin{array}{l}\text { Comparable land and marine energy costs for the same use (e.g. electricity, heat } \\
\text { and cooling, fuels, water) }\end{array}$ \\
\hline Life cycle \\
\hline Backcast analysis on developments (how and by whom?) \\
\hline Roadmap for the steps of potential development \\
\hline Technological hypotheses for 2030 \\
\hline
\end{tabular}

Documenting the variables highlighted the advantages and drawbacks of different technologies, as well as their potential.

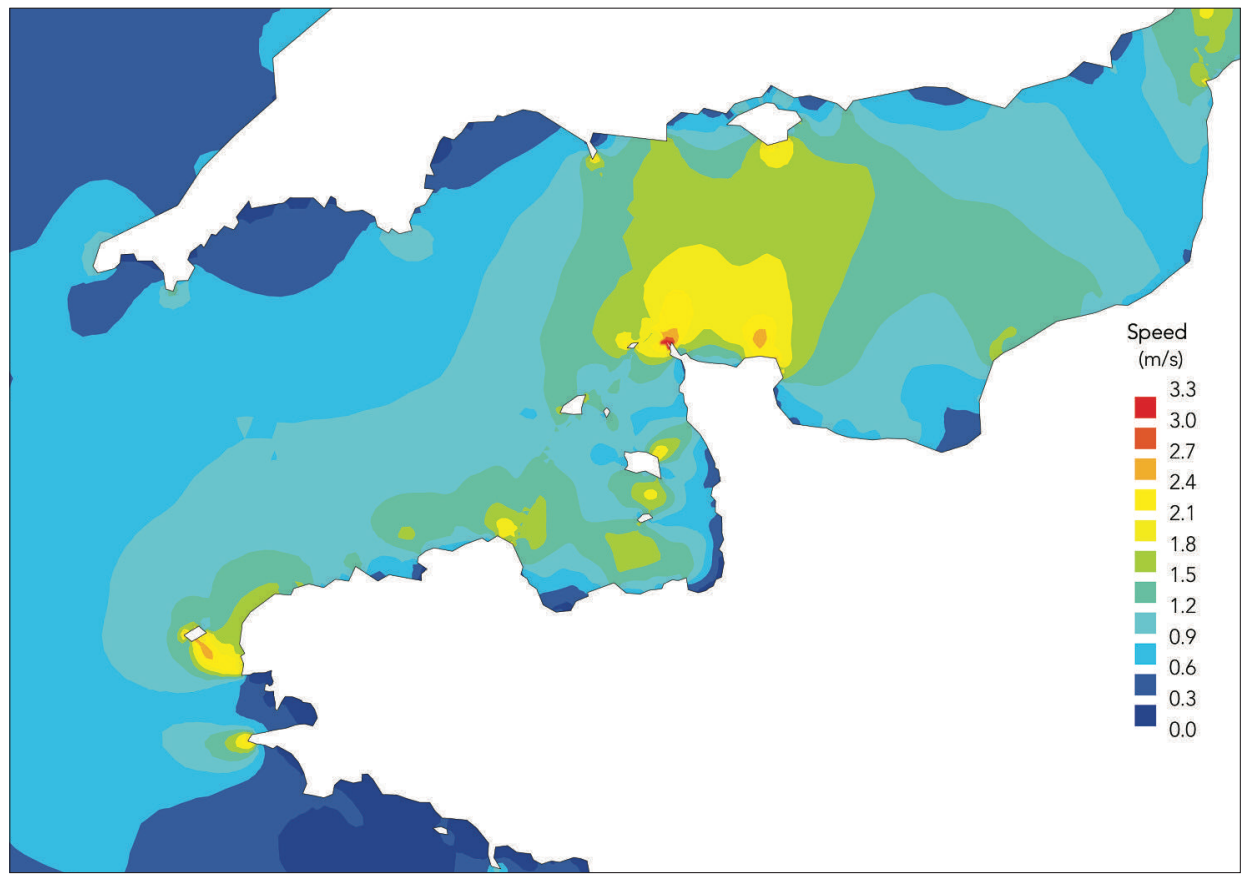

- Figure 3 : mapping of maximum tidal current velocity at mean spring tides ( $\odot$ EDF: data from the EDF/DRD Télémac model). 


\section{Step 4: constructing the scenarios}

First, micro-scenarios for each component were drawn up on the basis of the prospective hypotheses for each variable, with the exception of the technological variables. These micro-scenarios in turn became hypotheses for the macro or 'global system' and the components were then 'macro-variables'.

The so-called 'global' comprehensive systems supply the framework for various development options for a range of technologies.

In formulating the initial hypotheses about the variables, up to the global scenarios, the aim was to create a logical and coherent set of contrasting options. This coherence ensures that the range of possibilities can be mapped out for a given deadline.

The storyline described in each global scenario provides a rationale for developing marine energies and their associated technologies. For instance, in Scenario 1 'Crisis and energy emergency', it is logical to think that proven technologies will quickly be scaled-up to industrial production. 


\section{List of $\mathbf{3 0}$ variables grouped by component and corresponding author(s)}

\section{World context}

1. Global geo-economics ............................. Futuribles

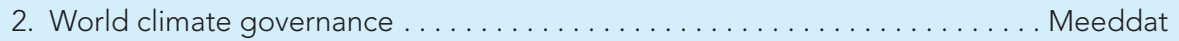

3. Energy demand, including Europe by region ................... Futuribles

4. Freshwater demand by region . . . . . . . . . . . . . . . . . . . Futuribles

5. Security and price of fossil fuels . . . . . . . . . . . . . . . . . Technip

\section{European and French context}

6. Political strategy \& energy independence: targets ................ DIDD

7. Specificities of islands (including $\mathrm{OR}$ and $\mathrm{OCT}$ ) ............ Ifremer/Collective

8. Enforcement \& control, relevant tools in France. . . . . . . . . . . . . . . . . Meeddat

9. Regulatory instruments for biofuels . . . . . . . . . . . . . . . . Meeddat

10. Energy research budget and allocation by energy source. . . . . . . . . Futuribles

11. Structuring and managing the electricity grid ................. Ademe

12. Energy storage and transport technologies .................... Saipem

13. Changes in centralized electricity generation. . . . . . . . . . . . EDF/R\&D

\section{Areas of operation}

14. Global population distribution including European coasts........ Futuribles/lfremer

15. Regional marine spatial planning. ......................... Ademe

16. Public acceptance ................................... Ifremer

17. Changes in sea uses and conflicts . . . . . . . . . . . . . . . . . . . . Meeddat

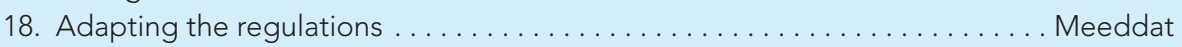

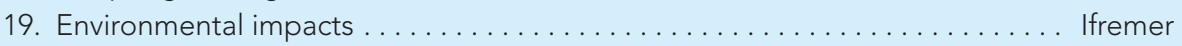

\section{Marine renewable energies}

20. Stream energy (marine currents) . . . . . . . . . . . . . . . . . . EDF/R\&D

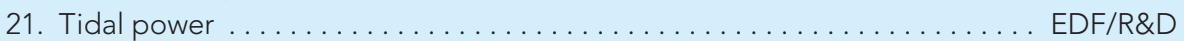

22. Wave power .................................... ECNemer

23. Biomass $\ldots \ldots \ldots \ldots \ldots \ldots \ldots \ldots \ldots \ldots \ldots \ldots \ldots \ldots \ldots \ldots \ldots \ldots \ldots \ldots$ Ifremer

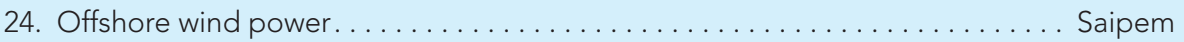

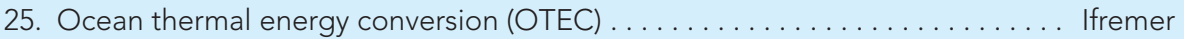

26. Osmotic power ........................................ Veolia

27. Hybrid technological solutions......................... Collective

Marine renewable energy research and development

28. Potential of new sources . . . . . . . . . . . . . . . . . . . . . . Ifremer

29. Knowledge about the marine environment and impacts.............. Ifremer

30. Roles of public- and private-sector stakeholders . . . . . . . . . . . . . DCNS/Ifremer 



\section{II Constructing micro-scenarios for each component}

- he micro-scenarios for each component are based on the hypotheses collected for each variable. The objective was to foresee the possible futures in each sub-system: the global context, European and French energy systems, areas of operation and marine energies R\&D.

Once the micro-scenarios are built, the elements of strategic leverage determining a given micro-scenario must be identified. For instance, for the 'world context elements' component, the levers which make it possible to 'shift' from one scenario to another are quality of governance and/or level of international co-operation, the risk of crisis (security and price) and finally, the potential shocks, mainly in terms of climate or energy sources.

The same outline is followed for each of the analyses below:

- table of hypotheses for each variable for the component under consideration;

- selection of sets of hypotheses to build from two to five micro-scenarios;

- the 'storyline' of each micro-scenario;

- identification of the types of leverage required to move from one microscenario to another.

\section{A: World context elements}

For the first component, all variable-based hypotheses are presented in Table 9.

\section{A1: World co-operation for energy and climate}

Confronted with climate risks, the consequences of which are increasingly being felt, and with the possibility of this worsening between 2009 and 2012, the USA and China consent to ratify a protocol (Kyoto II) on reducing greenhouse gas emissions. The two countries accept clean technologies (including nuclear power), as much to avoid long-term risks as to rapidly develop a market for them, in order to derive economic benefits. Development on the part of Southern hemisphere countries maintains the Northern countries' economic position through sales of high-tech products and expertise. The demand for energy slows (17\% with respect to current trends), due to the rapid development of technologies and processes that are more energy-efficient. Similarly, investments are made for better water management (e.g. collection, sewage treatment, low consumption farming techniques), even in developing countries, often owing to international aid. 


\begin{tabular}{|c|c|c|c|}
\hline Variable & Hypothesis 1 & Hypothesis 2 & Hypothesis3 \\
\hline \multirow[b]{2}{*}{$\begin{array}{l}\text { V1 } \\
\text { Global geo-economics }\end{array}$} & & 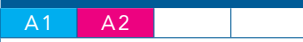 & A4 \\
\hline & $\begin{array}{l}\text { Emerging countries } \\
\text { catch up or surpass } \\
\text { developed countries } \\
\text { (Europe marginalized) }\end{array}$ & $\begin{array}{l}\text { Shared prosperity } \\
\text { (technology and OECD } \\
\text { patents exported } \\
\text { to developing countries } \\
\text { which assist each other) }\end{array}$ & $\begin{array}{l}\text { Crises } \\
\text { and protectionism } \\
\text { (every man for himself) }\end{array}$ \\
\hline \multirow[b]{2}{*}{$\begin{array}{l}\text { V2 } \\
\text { Climate/energy } \\
\text { governance }\end{array}$} & \begin{tabular}{l|l|l|l} 
A1 & & & \\
\end{tabular} & \begin{tabular}{l|l|l|l|} 
& & & $\mathrm{A} 4$ \\
\end{tabular} & \begin{tabular}{|l|l|l} 
A2 & A3 \\
\end{tabular} \\
\hline & $\begin{array}{l}\text { Kyoto II with the USA } \\
\text { and China }\end{array}$ & $\begin{array}{l}\text { Kyoto Il quota market } \\
\text { the same as Kyoto I }\end{array}$ & $\begin{array}{l}\text { Regional technological } \\
\text { partnership } \\
\text { agreements }\end{array}$ \\
\hline \multirow[b]{2}{*}{$\begin{array}{l}\text { V3 } \\
\text { Energy demand } \\
\text { including Europe }\end{array}$} & $\mathrm{A} 4$ & \begin{tabular}{l|l|l|l|} 
A1 & & & \\
\end{tabular} & \begin{tabular}{|llll}
$\mathrm{A} 2$ & $\mathrm{~A} 3$ & \\
\end{tabular} \\
\hline & $\begin{array}{l}\text { IEA trend-based } \\
\text { reference }\end{array}$ & $\begin{array}{l}-17 \% \text { reference levels } \\
25 \% \text { of primary energy } \\
\text { produced by nuclear } \\
\text { power and RES } \\
\text { (biomass) }\end{array}$ & $\begin{array}{l}\text { Radical change, }-20 \% \\
\text { reference levels } \\
\text { RES penetrate } \\
\text { more than expected }\end{array}$ \\
\hline \multirow[b]{2}{*}{$\begin{array}{l}\text { V4 } \\
\text { Regional demand } \\
\text { for freshwater/demand } \\
\text { for desalination }\end{array}$} & $\begin{array}{llll}\text { A1 } & \text { A2 } & \\
\end{array}$ & \begin{tabular}{|l|l|l|l|} 
& & & $\mathrm{A} 4$ \\
\end{tabular} & \begin{tabular}{|l|l|l|l|} 
& & $A 3$ & \\
\end{tabular} \\
\hline & $\begin{array}{l}\text { Better water } \\
\text { management } \\
\text { Desalination particularly } \\
\text { on islands }\end{array}$ & $\begin{array}{l}\text { Desalinization } \\
\text { as a supplementary } \\
\text { source in the Northern } \\
\text { hemisphere } \\
\text { and on islands }\end{array}$ & $\begin{array}{l}\text { New technological } \\
\text { breakthrough reducing } \\
\text { the cost of desalination } \\
\text { Desalination takes } \\
\text { precedence over better } \\
\text { water management } \\
\text { (desalination regularly } \\
\text { used in developing } \\
\text { countries) }\end{array}$ \\
\hline \multirow[b]{2}{*}{$\begin{array}{l}\text { V5 } \\
\text { Security and price } \\
\text { of fossil fuels }\end{array}$} & & \begin{tabular}{|l|l|l|} 
A2 & \\
\end{tabular} & \\
\hline & $\begin{array}{l}\text { US } \$ 50-60 / \text { barrel } \\
\text { and supply ensured }\end{array}$ & $\begin{array}{l}\text { US\$60-90/barrel } \\
\text { and supply ensured }\end{array}$ & $\begin{array}{l}\text { Crisis period } \\
\text { at US\$150-200/barrel, } \\
\text { stop-and-go over } \\
\text { several years }\end{array}$ \\
\hline
\end{tabular}

- Table 9 : constructing micro-scenarios for the 'World context elements' component.

Key : A1 World co-operation for energy and climate

A2 Climate shock, panic and co-operation

A3 Energy crisis and opportunities

A4 Every man for himself and general irresponsibility

Desalination is used only on islands that have no other alternative. By modifying the energy demand, conflicts over energy lessen and oil prices drop to US\$50-60/ barrel.

\section{A2: Climate shock, panic and co-operation}

Contrary to the preceding scenario, no political agreement is found on climate risk and reducing greenhouse gas emissions. A series of natural disasters (e.g. drought, flood, cyclones, etc.) between 2012 and 2020 leads to the pragmatic implementation of regional technological co-operation programmes to develop RES and energy-efficient products. In fact, climate-related disasters have demonstrated the vulnerability of power networks, especially centralized grids for electricity. Many countries opt for the more endogenous development of local, more densely inter- 
connected electricity grids to cope with these climate hazards and to promote RES. Similarly, water management has become a priority for many. Climate incidents have caused sporadic crises and world economic growth has evolved in a 'stop and go' fashion, repeatedly jolting energy consumption. Nevertheless, these crises ultimately have a positive impact. They jumpstart the development of energyefficient technologies and RES, as well as the production of clean coal with carbon capture and storage (or by establishing carbon stores through biomass), revitalizing economic growth in emerging countries. New production processes enable them to become richer. However, the move to alternative energy supplies is more chaotic and oil prices remain high (US\$60-90/barrel), but without supply crises.

\section{A3: Energy crisis and opportunities}

The oil crisis beginning in 2010-12 leads to a worldwide economic slowdown, which brings a cascade of protectionist policies. Nevertheless, this energy crisis leads to regional technological partnerships to develop both energy-efficient and renewable energy technologies (without commitments to reduce greenhouse gas emissions). Coal enjoys a new lease of life. The efforts made in developing diverse technologies result in cheaper, energy-efficient desalination techniques. For developing countries that do not have water distribution and treatment networks, investing in desalination is cheaper than trying to better manage water supplies. The energy crisis leads to a significant slowdown in oil consumption.

\section{A4: Every man for himself and general irresponsibility}

International negotiations for the climate remain at a status quo: countries which signed Kyoto I want to pursue the challenge (even if it is hard for them to meet their commitments). However, neither the USA nor the large emerging countries agree to limit their economic development by reducing greenhouse gas emissions. World energy consumption shows a rising trend, all the more so in that desalination of seawater has become common practice in southern Europe, USA and Australia to meet farming needs during recurrent droughts. This scenario leads to an oil crisis around the year 2015. The crisis impacts on developing countries more severely than it does developed countries. The oil crisis leads to greater protectionism, particularly in developed countries. While protecting themselves from competition, industrialized nations try to rebuild societies that consume less oil.

Leverage: governance and/or co-operation; risk of crises (security and price); shocks (climate or energy).

\section{B: European and French energy systems}

For the second component, the variable-based hypotheses are presented in Table 10.

\section{B1: Unmet targets and pragmatism}

Just as the goals set by the Kyoto Protocol could not be reached at the European level, the political objectives for 2020 for the reduction in greenhouse gases and the development of renewable energies are not met by 2020 . Anticipating this result, RES goals are replaced with 'clean' energy targets for 2018 to account for 
nuclear power and ocean thermal or geothermal energy production. As of 2020, the volume of carbon captured and sequestered by salt aquifers and forest biomass is subtracted from the emissions due to use of fossil fuels. This trend is justified by the policy to restart building nuclear power plants in some European countries. After aligning it to the cost of fossil-fuelled electricity, deregulated electricity production has already resulted in increased costs for the consumer. Investments to reinforce grid infrastructure are delayed so as to avoid adding to the growing cost of energy.

Feed-in tariffs for electricity generated by irregular RES are progressively phased out to avoid problems in managing the local distribution network. Feed-in tariffs were attractive when they were first offered, but no technological breakthroughs to improve electricity storage have been found. Only islands still receive subsidies to develop electricity-generating renewables in 2020, to avoid major investments in thermal power plants. The decreasing budget trend for public research in energy continues and private research investments have not taken over as hoped. Islands are the main pilot sites for research in renewable energies. In 2030, only biofuels still benefit from tax exemptions and inclusion targets since there is no alternative for curbing dependence on imported oil.

\begin{tabular}{|c|c|c|c|c|}
\hline Variable ${ }^{\text {Hypothesis }}$ & Hypothesis 1 & Hypothesis 2 & Hypothesis 3 & Hypothesis 4 \\
\hline \multirow[b]{2}{*}{$\begin{array}{l}\text { V6 } \\
\text { Political } \\
\text { strategy/energy } \\
\text { independence } \\
\text { (targets: RES, } \\
\text { carbon dioxide) }\end{array}$} & B3 & B4 & B2 & B1 \\
\hline & $\begin{array}{l}\text { Objectives } \\
\text { for 2020: } 20 \% \text { RES } \\
\text { and }-20 \% \\
\text { greenhouse gases } \\
\text { are met } \\
\text { Objectives } \\
\text { for } 2030: 25 \% \text { RES } \\
\text { and }-30 \% \text { green- } \\
\text { house gases } \\
\text { are met } \\
\text { Support strategy } \\
\text { for RES } \\
\text { generation for } \\
\text { all supply chains }\end{array}$ & $\begin{array}{l}\text { Objectives } \\
\text { for } 2020: 20 \% \text { RES } \\
\text { and }-20 \% \\
\text { greenhouse gases } \\
\text { are met } \\
\text { Objectives } \\
\text { for } 2030: \\
25 \% \text { RES and } \\
-30 \% \text { greenhouse } \\
\text { gases are met } \\
\text { Support strategy } \\
\text { depends } \\
\text { on supply chain }\end{array}$ & $\begin{array}{l}\text { Objectives } \\
\text { for 2020: } \\
25 \% \text { RES } \\
\text { and -30\% } \\
\text { greenhouse gases } \\
\text { are met } \\
\text { Objectives } \\
\text { for 2030: } \\
30 \% \text { RES } \\
\text { and -45\% green- } \\
\text { house gases } \\
\text { are met in } 2030 \\
\text { Support strategy } \\
\text { for less-competitive } \\
\text { RES }\end{array}$ & $\begin{array}{l}2020 \text { targets } \\
\text { are not met } \\
\text { and targets } \\
\text { are expressed } \\
\text { as 'clean energy' } \\
\text { with nuclear } \\
\text { and clean fossil } \\
\text { fuels } \\
\text { (carbon dioxide) }\end{array}$ \\
\hline \multirow{3}{*}{$\begin{array}{l}\text { V7 } \\
\text { Specificities } \\
\text { of islands } \\
\text { (including ORs } \\
\text { and DOM-COMs) } \\
\end{array}$} & \begin{tabular}{l|l|l|l|} 
B1 & & & \\
\end{tabular} & \begin{tabular}{|l|l|l|l|} 
& B2 & B3 & B4 \\
\end{tabular} & & \\
\hline & $\begin{array}{l}\text { Subsidies } \\
\text { and showcasing } \\
\text { marine renewable } \\
\text { energies } \\
\text { Pilot sites }\end{array}$ & $\begin{array}{l}\text { RES and energy } \\
\text { independence; } \\
\text { tourist } \\
\text { developments; } \\
\text { tax exemptions }\end{array}$ & $\begin{array}{l}\text { Islands lose } \\
\text { their attractiveness } \\
\text { (e.g. climate } \\
\text { and health risks) }\end{array}$ & \\
\hline & & \begin{tabular}{|l|l|l|} 
& & $B 4$ \\
\end{tabular} & \begin{tabular}{l|l} 
B2 \\
\end{tabular} & \begin{tabular}{l|l|l|} 
& & B3 \\
\end{tabular} \\
\hline $\begin{array}{l}\text { V8 } \\
\text { Compliance/ } \\
\text { control, regulatory } \\
\text { instruments } \\
\text { (incentives, taxes } \\
\text { carbon dioxide) } \\
\text { in France }\end{array}$ & $\begin{array}{l}\text { No incentives } \\
\text { for electricity }\end{array}$ & $\begin{array}{l}\text { No incentive } \\
\text { systems; } \\
\text { calls for tender } \\
\text { for electricity }\end{array}$ & $\begin{array}{l}\text { Attractive } \\
\text { feed-in tariffs } \\
\text { and/or green } \\
\text { certificates } \\
\text { with differentiation } \\
\text { for marine RES }\end{array}$ & $\begin{array}{l}\text { Standardized } \\
\text { green certificates }\end{array}$ \\
\hline
\end{tabular}




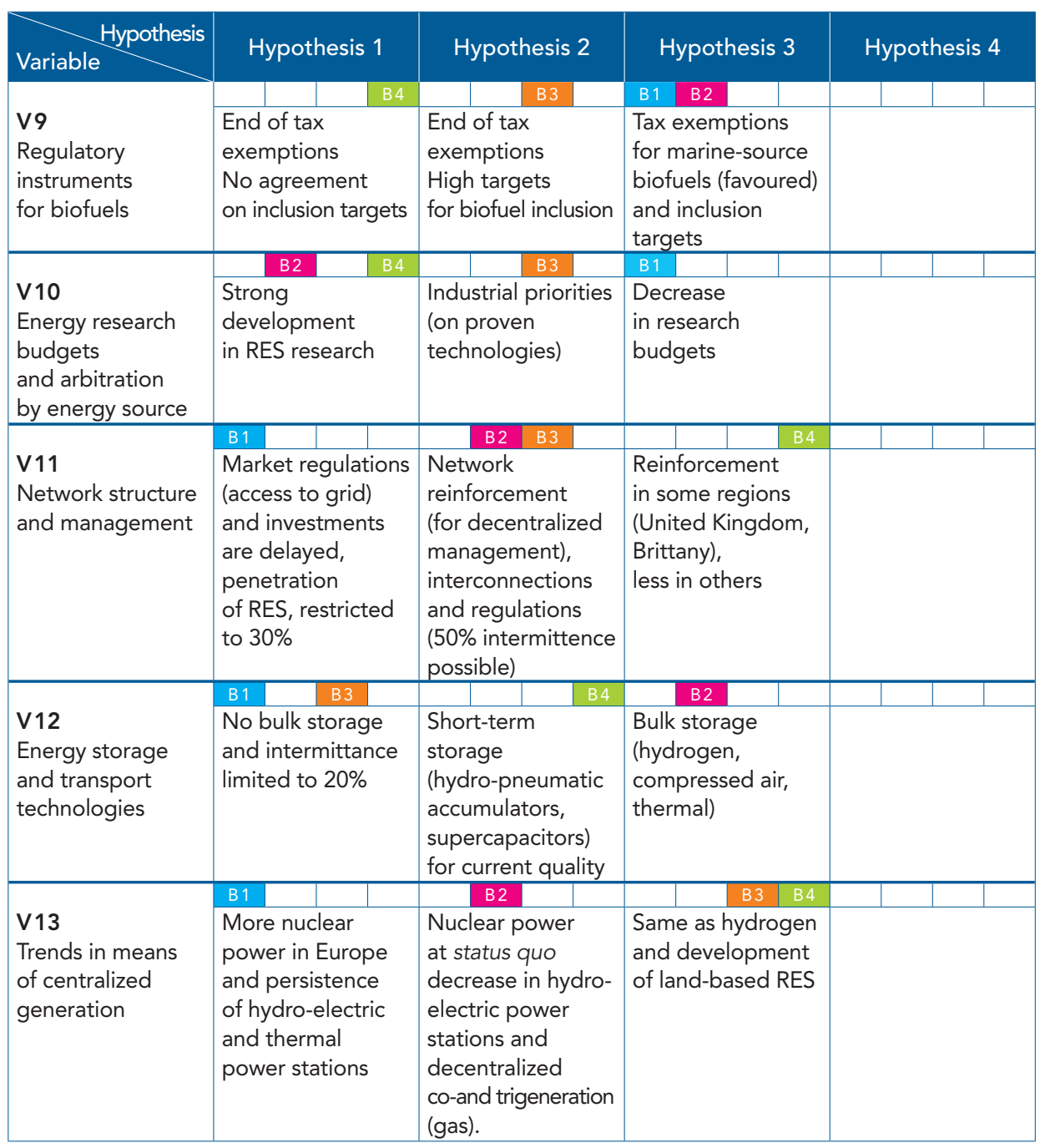

I Table 10 : constructing micro-scenarios for the 'European and French energy systems context' component.

Key : B1 Unmet targets and pragmatism

B2 Security and determined environmental efforts (diversification)

B3 Industrial priorities (proven technologies on the world market)

B4 Niche markets

\section{B2: Security and determined environmental efforts (diversification)}

Energy security and fighting global warming are priorities. Europe is promoting decentralized energy generation in response. This involves substantial investments to reinforce electricity networks and better grid infrastructure. The public authority's strategy is to give more help to the less competitive renewable energy sectors to help them mature and thus develop technologies which can be 
exported. Consequently, between 2010 and 2015, the feed-in tariff for electricity generated by wind turbines on land is reduced, since the cost price becomes cost-effective while the rate paid to buy power from marine renewables supplying electricity remains advantageous. Similarly, in addition to general biofuel inclusion targets, marine biofuels benefit from broader tax exemptions compared with land-based biofuels to promote their industrial development. Seeing the political priorities, public research budgets for renewables rise sharply, thus making it possible to improve technologies faster, as in developing bulk storage for intermittent (onshore and offshore) electricity. This development leads to producing hydrogen to supply electricity and heat during periods of peak demand as well as a contribution to petrochemistry. Some islands, as appropriate places to experiment with natural energy resources, manage to become energy independent because of tax exemptions on investments and the power generated. This island policy ultimately proves profitable due to the global popularity of ecotourism, which increasingly includes the French DOM-COM.

\section{B3: Industrial priorities (proven technologies on the world market)}

The general priorities are the same as in scenario B2, but here, European countries also rapidly strengthen their competitive edge by exporting their energy technologies on the international market. Thus national policy supports renewable energy sectors without any differentiation, so that the best will prosper. Priorities lie more in development than in upstream research on energy technologies, which means that mass storage remains undeveloped. Investments are made to reinforce and improve inter-connections in the distribution network so as to promote decentralized energy production and industrial development of renewables. Similarly, for fuels, the instrument used by public powers is biofuel inclusion targets without tax exemptions so that the most cost-efficient production sectors emerge through industry preferences. Some islands have reached energy independence through ad hoc tax exemption policies and become green tourism destinations, as well as commercial showcases to demonstrate the reliability of marine renewable energies, with a well-designed complementarity of sources. This scenario could be an emergency/energy crisis scenario that, if successful, could in time evolve into scenario B4.

\section{B4: Niche markets}

In this scenario, the stakes behind energy security and the struggle to reduce greenhouse gases results in an increase in public RES research budgets and in a support strategy that differentiates between the various supply chains. As of 2015, rising oil prices enable the development of biofuels and the suppression of tax exemptions, without particular inclusion targets. In terms of electricity, incentives for RES production are abandoned for calls for tender to favour the best providers from industry. Decentralization of energy production is promoted by investments in the distribution network, but only in certain regions, either when local consumption of fossil fuels is too high to stay within European and national targets on greenhouse gas emission (United Kingdom, Brittany), or when the risks 
of blackouts in case of an incident are high (southeastern France). These regions develop more decentralized renewables than others (up to 30\%). Investment in research has also enabled short-term storage technologies to be optimized (from supercapacitors to hydro-pneumatic accumulators, from a few seconds to several hours). They improve the quality of electrical current and facilitate the management of the grid supplied by intermittent energy sources. Islands are also the favoured sites for investment in these technologies and certain islands achieve energy independence.

Leverage: specific support for different sectors (emerging sectors); arrangements promoting decentralization; inter-connected networks and energy storage.

\section{C: Areas of operation}

For the third component, the variable-based hypotheses are presented in Table 11.

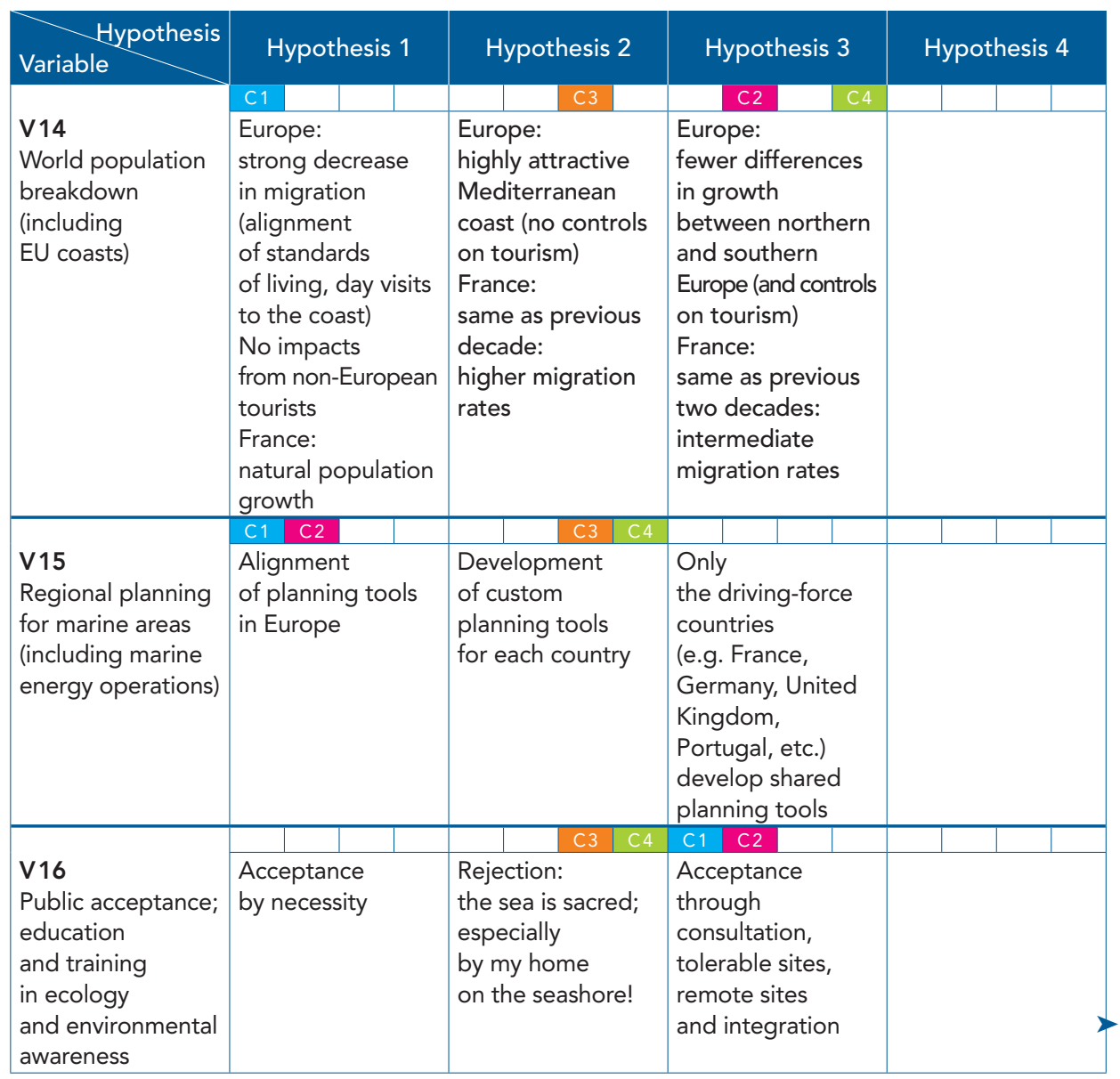




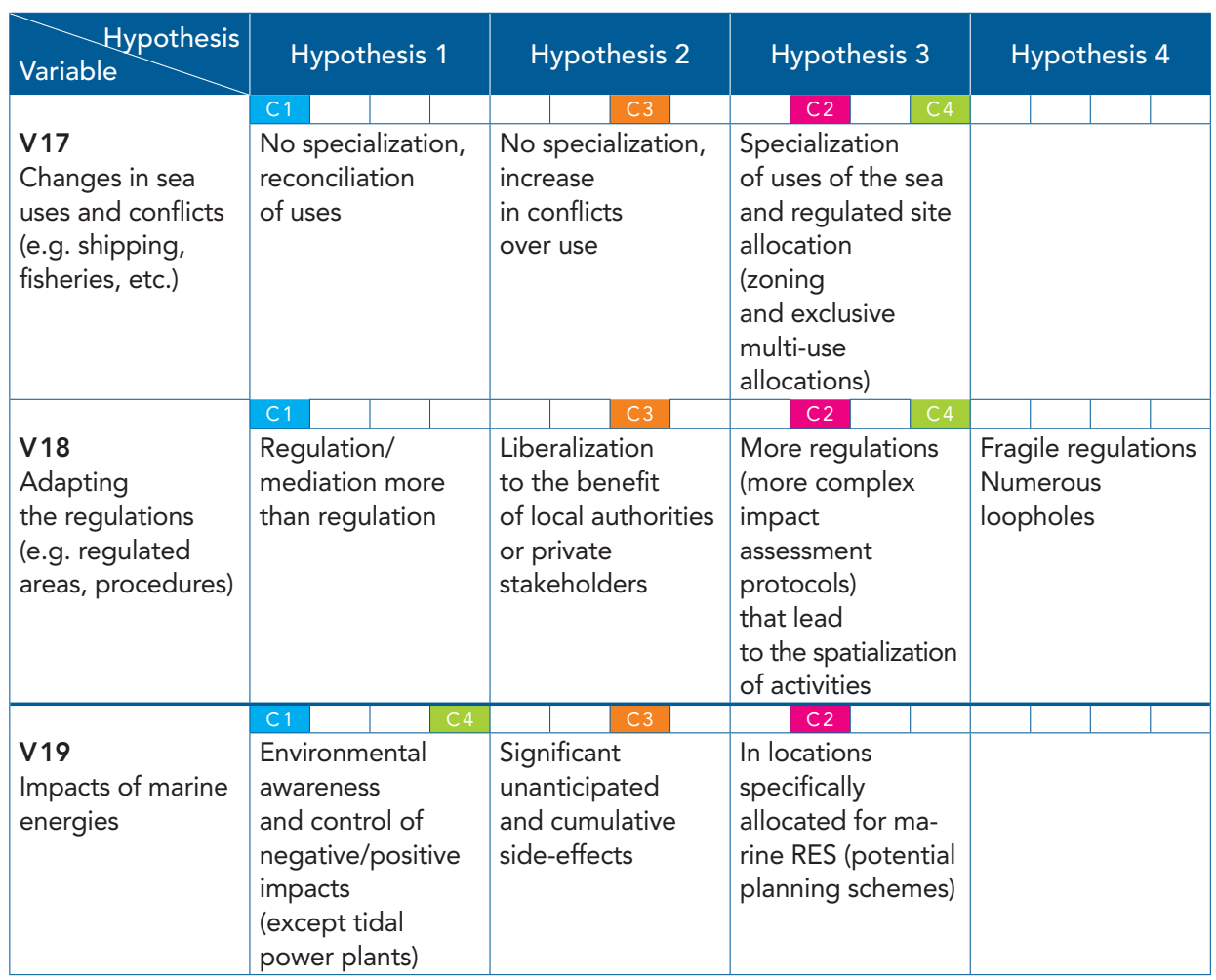

- Table 11 : Constructing micro-scenarios for the 'Areas of operation' component.

Key : C1 Integrated and collaborative operations

C2 Planned zoning

C3 Decentralized and controversial zoning

C4 Progressive acceptance or negotiated zoning (trend-based reference)

\section{C1: Integrated and collaborative operations}

Consultations set up in urban coastal communities reconcile nearshore and sea uses, such as aquaculture and tourism (e.g. visits to oyster farms), but also develop marine renewable energies on an industrial scale, providing that they blend into the local environment and do not hinder the development of other activities. This is more acceptable to the public when maps of Europe are used to demonstrate that the European coast has remarkable resources in marine energies that can help develop local economies, especially since tourism and population growth are waning. This type of development provides better environmental awareness, with two positive consequences: impacts, especially negative ones, can be anticipated and planned for and positive effects can be generated for other activities, such as fisheries.

\section{C2: Planned zoning}

The difficulties in reconciling the different uses of the sea in coastal areas and the resulting conflicts (or risks thereof) lead to more regulations and more complex 
impact assessment protocols for the development of nearshore maritime activities. All coastal activities, like water sports, aquaculture activities or marine RES operations, are increasingly set up in dedicated zones to avoid conflicts about use. The specialization of coastal areas also helps to better regulate tourist inflows. Streamlining of planning tools in Europe enables the State, working in co-operation with local authorities, to propose zones either exclusively dedicated to certain marine energies or to marine power in conjunction with other compatible uses. In places where marine energy production has been set up, they are well accepted because they protect residents from other activities that could create different types of nuisance.

\section{C3: Decentralized and controversial zoning}

The French State, having provided a tool-box of protocols and procedures to set up coastal activities, particularly through national zoning and spatial planning tools, moves to devolution of decision-making processes to the local and regional authorities level. Since each local government strives to develop its own economy, local authorities tend to promote all possible activities to attract employment and investments in the tourism sector as well as in the aquaculture and marine energies sectors. The local authorities are often overwhelmed by the successful results of their policy and must then deal with the conflicts over use between activities and their unanticipated impacts. These conflicts make the constantly growing coastal population (who have often chosen the place for its quiet, natural setting) reject these activities, particularly marine energies, which could turn this still-natural area into an artificial one.

\section{C4: Progressive acceptance or negotiated zoning (trend-based reference)}

Since the coastal population sees the marine environment as the last remaining truly natural space, they initially reject any permanent operations at sea that would denature the landscape and could disturb marine biodiversity or natural physical cycles. The first marine energy projects have difficulty in getting beyond the public inquiry stage. To overcome these difficulties, more thorough and complex impact assessments are designed to show the advantages of setting up marine RES operations. These studies result in a designation of areas allocated to marine renewables or to other activities that have similar difficulties in terms of social acceptability. Planning tools for these designated zones reflect local constraints and specificities. In this scenario, the development of marine RES requires more time, assessments and negotiation.

Leverage: conflict resolution, public debate/regulations; multi-use space allocations; knowledge about impacts (demonstration installations enabling European projects and skills to be pooled).

\section{E: Research and development in marine energies}

For the fifth component, the variable-based hypotheses are presented in Table 12. 


\begin{tabular}{|l|l|l|l|}
\hline \multicolumn{1}{|c|}{ Hypothesis } & \multicolumn{1}{|c|}{ Hypothesis 1 } & \multicolumn{1}{|c|}{ Hypothesis 2 } & \multicolumn{1}{|c|}{ Hypothesis 3 } \\
\hline $\begin{array}{l}\text { Variable } \\
\begin{array}{l}\text { Potential of new marine } \\
\text { energy resources }\end{array}\end{array}$ & $\begin{array}{l}\text { New avenues } \\
\text { of research: geother- } \\
\text { mal power combined } \\
\text { with OTEC, submarine } \\
\text { falls, biomimetics, } \\
\text { biotechnologies }\end{array}$ & $\begin{array}{l}\text { Innovation based } \\
\text { on existing technologies: } \\
\text { site domestication, } \\
\text { current concentration, } \\
\text { geomimetics, floating } \\
\text { tanks for micro-algae }\end{array}$ & $\begin{array}{l}\text { Epistemological } \\
\text { breakthroughs: } \\
\text { energy storage } \\
\text { and transport } \\
\text { Taking advantage } \\
\text { of global warming }\end{array}$ \\
\hline $\begin{array}{l}\text { V1 } \\
\text { Knowledge } \\
\text { about the environment } \\
\text { and impacts }\end{array}$ & $\begin{array}{l}\text { Shared progress made } \\
\text { on tools and methods } \\
\text { Customer pays }\end{array}$ & $\begin{array}{l}\text { Progress made in tools, } \\
\text { methods } \\
\text { and development } \\
\text { of results on national } \\
\text { or European scales } \\
\text { The State } \\
\text { or the EU pay }\end{array}$ & $\begin{array}{l}\text { Tools and methods } \\
\text { progress but } \\
\text { are not shared } \\
\text { Customer pays }\end{array}$ \\
\hline $\begin{array}{l}\text { V30 } \\
\text { Set of stakeholders in } \\
\text { marine energy }\end{array}$ & $\begin{array}{l}\text { National (European) } \\
\text { policies foster } \\
\text { public-private } \\
\text { partnerships (clusters) }\end{array}$ & $\begin{array}{l}\text { In the aftermath } \\
\text { of a crisis, industrial } \\
\text { firms launch } \\
\text { various projects }\end{array}$ & $\begin{array}{l}\text { The actors } \\
\text { in national research } \\
\text { rarely work together } \\
\text { Outside collaboration } \\
\text { based on targeted } \\
\text { needs }\end{array}$ \\
\hline
\end{tabular}

I Table 12 : constructing micro-scenarios for the 'Marine renewable energy research and development' component.

Légende : E1 Little change

E2 Crisis and opportunities

E3 Technological breakthrough and multiple partnerships

\section{E1: Little change}

Technologies progress and benefit from the experiences of forerunner countries (United Kingdom, Denmark, the Netherlands, Japan, etc.), but progress is slow because intra- and international co-operation has little support and the results are only general in scope. The private sector finances the adaptation of technologies to their needs (and constraints), protects the resulting innovations with patents and develops them under license. Investors remain more concerned with profitability and feasibility than with new technologies.

\section{E2: Crises and opportunities}

After a crisis, the industrial sector seeks to explore new avenues of research. R\&D capacities are actively mobilized by private operators to occupy operational niches, sometimes with a degree of risk-taking. If the crisis is severe and threatens to continue, institutions participate in funding to shorten the experimental and pilot phases. Investors become involved in the most efficient and profitable RES sectors, stimulating research to improve yields and economies of scale. 


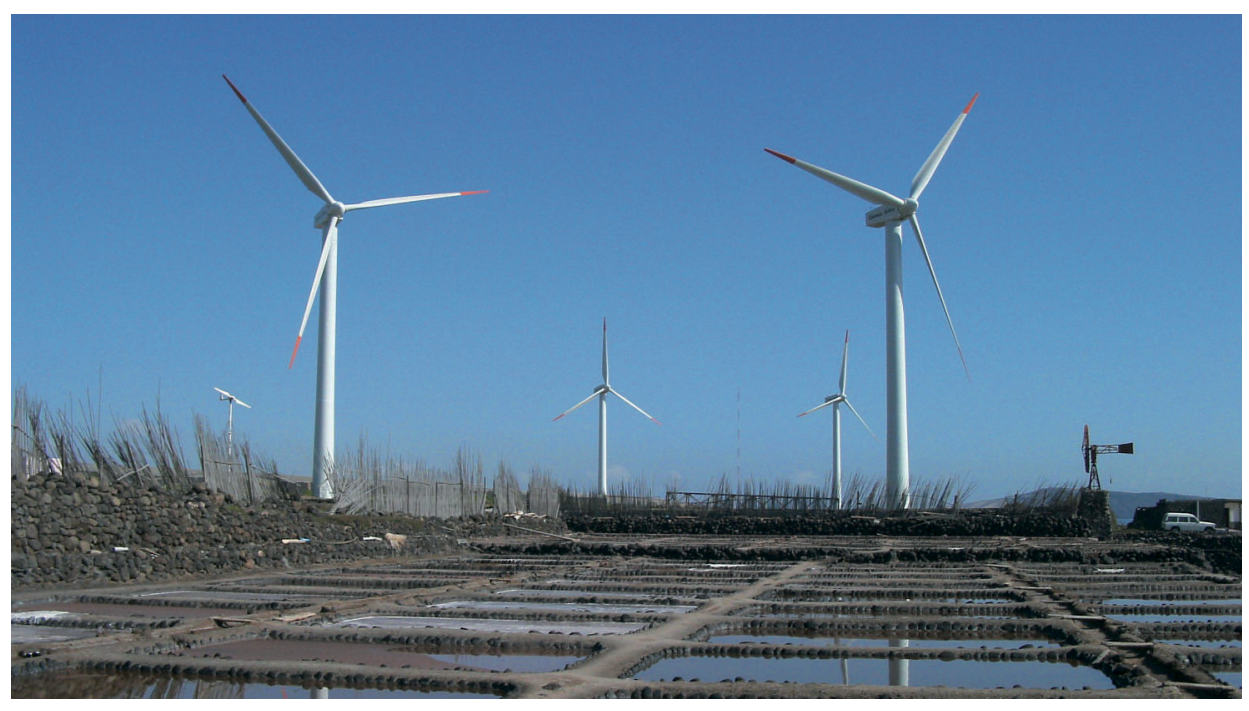

- Photo 10 : La Florida-Vargas de las Palmas (Canaries) wind form off the Spanish Coast, Canaries (C IDAE and SOSLAIRES Canarias, SL).

\section{E3: Technological breakthroughs and multiple partnerships}

Private sector R\&D reveals the potential for one or several technological advances (e.g. in energy storage and/or transmission). Given the general crisis context, or in anticipation of one, public institutions massively support development by mobilizing private firms within large partnerships (clusters) and help to assimilate technological progress into existing networks and equipment. The EU works to maintain its technological advance over the USA and Asia.

Leverage: private initiative or EU or multilateral responsibility; the payer controls the dissemination of technology and the implementation timeframes; capacity for anticipation (a crisis is sure to occur, but its extent is unknown). 



\section{Constructing the macro-scenarios}

$\mathrm{n}$ this step, the micro-scenarios produced in the previous step become the basic hypotheses, which can be combined to build global or macro-scenarios (see Table 13).

\begin{tabular}{|c|c|c|c|c|}
\hline Component & Hypothesis 1 & Hypothesis 2 & Hypothesis 3 & Hypothesis 4 \\
\hline $\begin{array}{l}\text { A } \\
\text { World context }\end{array}$ & $\begin{array}{l}\text { A1 } \\
\text { Worldwide } \\
\text { co-operation for } \\
\text { energy andclimate }\end{array}$ & $\begin{array}{l}\text { A2 } \\
\text { Climate shock, } \\
\text { panic } \\
\text { and co-operation }\end{array}$ & $\begin{array}{l}\text { A } 3 \\
\text { Energy crisis } \\
\text { and opportunities }\end{array}$ & $\begin{array}{l}\text { A4 } \\
\text { Every man } \\
\text { for himself }\end{array}$ \\
\hline $\begin{array}{l}\text { B } \\
\text { Energy systems } \\
\text { in Europe and } \\
\text { France }\end{array}$ & $\begin{array}{l}\text { B1 } \\
\text { Unmet targets } \\
\text { and pragmatic } \\
\text { approach }\end{array}$ & $\begin{array}{l}\text { B2 } \\
\text { Security } \\
\text { and determined } \\
\text { effort for ecology } \\
\text { (diversification) }\end{array}$ & $\begin{array}{l}\text { B3 } \\
\text { Industrial priorities } \\
\text { (proven } \\
\text { technologies } \\
\text { or global market) }\end{array}$ & $\begin{array}{l}\text { B4 } \\
\text { Niche markets }\end{array}$ \\
\hline $\begin{array}{l}\text { C } \\
\text { Areas } \\
\text { of operation }\end{array}$ & $\begin{array}{l}\text { C1 } \\
\text { Concerted } \\
\text { and integrated } \\
\text { operation }\end{array}$ & $\begin{array}{l}\text { C2 } \\
\text { Planned zoning }\end{array}$ & $\begin{array}{l}\text { C3 } \\
\text { Decentralized } \\
\text { and conflict } \\
\text { zoning }\end{array}$ & $\begin{array}{l}\text { C4 } \\
\text { Negotiated } \\
\text { zoning }\end{array}$ \\
\hline $\begin{array}{l}\text { E } \\
\text { Marine energy R\&D }\end{array}$ & $\begin{array}{l}\text { E1 } \\
\text { Few } \\
\text { developments }\end{array}$ & $\begin{array}{l}\text { E2 } \\
\text { Crisis } \\
\text { and opportunity }\end{array}$ & $\begin{array}{l}\text { E3 } \\
\text { Technological } \\
\text { breakthroughs } \\
\text { and multiple } \\
\text { partnerships }\end{array}$ & \\
\hline
\end{tabular}

Table 13 : constructing the macro-scenarios.

Scenario 1 : Crisis and energy emergency: A3, B3, C4, E2

Scenario 2 : Altruistic co-operation through necessity: A1, B2, C1, E 3

Scenario 3 : Few changes, every man for himself: A4, B1, C4, E1

Scenario 4 : Independent local development: A4/A3, B4, C3, E2

The initial outline of global scenarios provided the rationale behind the development of marine energies for each storyline:

Scenario 1: the most mature technologies are rapidly marketed, without risks; Scenario 2: determined political efforts to reduce greenhouse gas emissions; Scenario 3: minimal development and national security;

Scenario 4: local niches for development and worldwide efforts.

In this approach, the storyline carried by each scenario leads to the selection of a marine energy mix using the technological hypotheses drawn up during the production of the fact sheets for the 'variables'. 


\begin{tabular}{|c|c|c|c|c|}
\hline Energy Hypothesis & Hypothesis 1 & Hypothesis 2 & Hypothesis 3 & Hypothesis 4 \\
\hline $\begin{array}{l}\text { V20 } \\
\text { Currents } \\
\text { (stream power) } \\
\text { Electricity }\end{array}$ & $\begin{array}{l}\text { Technology } \\
\text { hindered } \\
\text { by maintenance } \\
\text { issues: turbines } \\
\text { kept only for use } \\
\text { at the surface (part } \\
\text { of the supporting } \\
\text { structure above } \\
\text { water) }\end{array}$ & $\begin{array}{l}\text { Underwater } \\
\text { turbines } \\
\text { (tidal currents only, } \\
\text { no conflict over } \\
\text { use on the surface) }\end{array}$ & $\begin{array}{l}\text { Operations using } \\
\text { stream turbines } \\
\text { at great depths: } \\
\text { more powerful } \\
\text { systems that use } \\
\text { ocean currents }\end{array}$ & \\
\hline $\begin{array}{l}\text { V21 } \\
\text { Tidal power } \\
\text { Electricity }\end{array}$ & $\begin{array}{l}\text { Naturally favourable } \\
\text { sites (shallowness } \\
\text { and tidal amplitude), } \\
\text { only for generating } \\
\text { electricity }\end{array}$ & $\begin{array}{l}\text { Sites developed } \\
\text { for tidal power } \\
\text { plants and other } \\
\text { uses (aquaculture) }\end{array}$ & No development & \\
\hline $\begin{array}{l}\text { V22 } \\
\text { Wave power } \\
\text { Electricity + Water }\end{array}$ & $\begin{array}{l}\text { Operation } \\
\text { in shallow waters } \\
\text { nearshore (including } \\
\text { orientation, } \\
\text { breakwater; with } \\
\text { greater regularity) }\end{array}$ & $\begin{array}{l}\text { Offshore } \\
\text { operations, } \\
50-100 \mathrm{~m} \text { deep } \\
\text { (more resources); } \\
\text { acceptable costs }\end{array}$ & $\begin{array}{l}\text { Operations only } \\
\text { at isolated sites }\end{array}$ & \\
\hline $\begin{array}{l}\text { V23 } \\
\text { Biomass energy } \\
\text { All forms }\end{array}$ & $\begin{array}{l}\text { Extensive } \\
\text { production } \\
\text { on developed } \\
\text { maritime property }\end{array}$ & $\begin{array}{l}\text { Development } \\
\text { abroad } \\
\text { (imported } \\
\text { to France) }\end{array}$ & $\begin{array}{l}\text { Application limited } \\
\text { to high-tech } \\
\text { products }\end{array}$ & $\begin{array}{l}\text { High-tech, } \\
\text { intensive } \\
\text { production, } \\
\text { land-based, } \\
\text { GMO } \\
\text { multi-applications }\end{array}$ \\
\hline $\begin{array}{l}\text { V24 } \\
\text { Offshore } \\
\text { wind power } \\
\text { Electricity }\end{array}$ & $\begin{array}{l}\text { Simple adaptation } \\
\text { of onshore wind } \\
\text { turbines for } \\
\text { offshore use } \\
\text { with lower costs } \\
\text { Limited } \\
\text { development }\end{array}$ & $\begin{array}{l}\text { Development } \\
\text { of special offshore } \\
\text { wind turbines } \\
\text { (less expensive, } \\
\text { including } \\
\text { maintenance) }\end{array}$ & $\begin{array}{l}\text { Development } \\
\text { of floating wind tur- } \\
\text { bines and access to } \\
\text { more resources }\end{array}$ & \\
\hline $\begin{array}{l}\text { V25 } \\
\text { Thermal } \\
\text { Electricity, } \\
\text { Water + Cooling }\end{array}$ & $\begin{array}{l}\text { Air-conditioning } \\
\text { and cooling } \\
\text { applications } \\
\text { (heat pumps) } \\
\text { Water and electricity } \\
\text { uses for isolated sites }\end{array}$ & $\begin{array}{l}\text { Applications } \\
\text { for cooling } \\
\text { and desalination } \\
\text { and electricity } \\
\text { and water } \\
\text { in tropical zones }\end{array}$ & $\begin{array}{l}\text { Hydrogen } \\
\text { and biological } \\
\text { utilization } \\
\text { of minerals } \\
\text { from deep water }\end{array}$ & \\
\hline $\begin{array}{l}\text { V26 } \\
\text { Osmotic power } \\
\text { Water + Electricity }\end{array}$ & $\begin{array}{l}\text { Optimization } \\
\text { of less costly } \\
\text { membranes } \\
\text { Micro-plants }\end{array}$ & No competitiveness & $\begin{array}{l}\text { Radical } \\
\text { technological } \\
\text { change (nano- and } \\
\text { biotechnology, } \\
\text { salt pump; } \\
\text { electro-osmosis) }\end{array}$ & \\
\hline $\begin{array}{l}\text { V27 } \\
\text { Hybrid } \\
\text { technologies }\end{array}$ & $\begin{array}{l}\text { Independent } \\
\text { development } \\
\text { No synergy except } \\
\text { in highly favourable } \\
\text { niches }\end{array}$ & $\begin{array}{l}\text { Opportunistic } \\
\text { development } \\
\text { (multi-use sites) }\end{array}$ & $\begin{array}{l}\text { Development } \\
\text { through } \\
\text { determined efforts }\end{array}$ & \\
\hline
\end{tabular}

I Table 14 : hypotheses for how marine energy sources will evolve. 
A maturity hypothesis for each technology (see Table 14) was thus linked to each scenario. Its context should indicate whether the number of sites with installed facilities will reflect weak, average or strong development. Table 15 briefly sums up the comparative advantages and limitations of each technology. These arguments were used to craft and develop the scenarios and their targets.

Table 16 sums up the possible technological developments for each scenario to facilitate the choice of technologies for each. The global scenarios were then developed by specifying, insofar as possible, where the different technologies will be located. Finally, the energy generation potential for each scenario was evaluated, even though exact figures could not be assigned.

\begin{tabular}{|l|l|l|}
\hline \multicolumn{1}{|c|}{ Technologies } & \multicolumn{1}{|c|}{ Advantages } & \multicolumn{1}{c|}{ Drawbacks } \\
\hline Offshore wind power & $\begin{array}{l}\text { Maturity } \\
\text { High potential if floating }\end{array}$ & $\begin{array}{l}\text { Surface use (surface/MWh) } \\
\text { Intermittent }\end{array}$ \\
\hline Stream power & $\begin{array}{l}\text { Can be used in areas } \\
\text { that cannot be utilized } \\
\text { for other technologies } \\
\text { (e.g. currents, shipping routes) } \\
\text { High yield per surface unit } \\
\text { Predictable }\end{array}$ & $\begin{array}{l}\text { Global potential } \\
\text { Limited number of specific sites }\end{array}$ \\
\hline Tidal power & $\begin{array}{l}\text { Maturity } \\
\text { Synergy with aquaculture } \\
\text { Predictable }\end{array}$ & Environmental impacts \\
\hline Wave power & $\begin{array}{l}\text { Worldwide potential } \\
\text { Can act as a breakwater }\end{array}$ & $\begin{array}{l}\text { Large surface area occupied } \\
\text { Intermittent }\end{array}$ \\
\hline $\begin{array}{l}\text { Ocean thermal energy } \\
\text { conversion }\end{array}$ & $\begin{array}{l}\text { High global potential } \\
\text { Cooling, electricity and water } \\
\text { Potential synergy with aquaculture } \\
\text { Permanent }\end{array}$ & Mostly limited to the tropics \\
\hline Biomass energy & $\begin{array}{l}\text { No impact on food production } \\
\text { Liquid fuels } \\
\text { High added-value by-products }\end{array}$ & $\begin{array}{l}\text { Costly if intensively farmed } \\
\text { on land } \\
\text { Environmental risk at sea } \\
\text { (e.g. proliferation, blooms) }\end{array}$ \\
\hline Osmotic power & $\begin{array}{l}\text { Recent technology } \\
\text { Heavy-use areas (estuaries) }\end{array}$ \\
\hline
\end{tabular}

- Table 15 : partial summary of the advantages and drawbacks of each technology 


\begin{tabular}{|c|c|c|c|}
\hline Technologies & Today & $2015-2020$ & 2020 and beyond \\
\hline Offshore wind power & Fixed (shallow waters) & $\begin{array}{l}\text { Floating } \\
\text { in nearshore areas }\end{array}$ & Far offshore \\
\hline Stream power & Prototypes & Surface and underwater & $\begin{array}{l}\text { Deep water } \\
\text { (constant currents) }\end{array}$ \\
\hline Tidal power & Barrages & $\begin{array}{l}\text { Man-made tidal lagoon } \\
\text { (small) }\end{array}$ & $\begin{array}{l}\text { Man-made tidal lagoon } \\
\text { (large) }\end{array}$ \\
\hline Wave power & Nearshore: prototypes & Offshore (close) & Offshore (ocean) \\
\hline $\begin{array}{l}\text { Ocean thermal energy } \\
\text { conversion }\end{array}$ & $\begin{array}{l}\text { Air-conditioning } \\
\text { Electricity } \\
\text { and water prototypes }\end{array}$ & $\begin{array}{l}\text { Electricity } \\
\text { and desalination } \\
\text { (tropics) }\end{array}$ & Multi-uses \\
\hline Biomass energy & Culture crops for food & $\begin{array}{l}\text { Extensive farming } \\
\text { for 'fuels' }\end{array}$ & $\begin{array}{l}\text { Intensive growing } \\
\text { for 'fuels' } \\
\text { and other molecules }\end{array}$ \\
\hline Osmotic power & Experimental & \multicolumn{2}{|c|}{$\begin{array}{l}\text { Prototype station } \\
\text { (technological obstacle: membrane) }\end{array}$} \\
\hline
\end{tabular}

| Table 16 : possible technological trends. 


\section{Description of the macro-scenarios}

- his section presents the four global scenarios which determine the marine technology mix that is likely to be developed. The same outline is followed for all four scenarios:

- keywords characterizing the scenario;

- review of hypothesis selection table;

- summary of scenario;

- scenario's 'storyline' and the consequences for marine renewables;

- estimation of how various technologies will contribute to this scenario.

- Scenario 1: Crisis and energy emergency

Combination: A3, B3, C4, E2

Driver: Market

Technologies: Investment mainly in proven technologies

\begin{tabular}{|c|c|c|c|c|}
\hline Component & Hypothesis 1 & Hypothesis 2 & Hypothesis 3 & Hypothesis 4 \\
\hline $\begin{array}{l}\text { A } \\
\text { World context }\end{array}$ & $\begin{array}{l}\text { A1 } \\
\text { Worldwide } \\
\text { co-operation } \\
\text { for energy } \\
\text { and climate }\end{array}$ & $\begin{array}{l}\text { A } 2 \\
\text { Climate shock, } \\
\text { panic } \\
\text { and co-operation }\end{array}$ & $\begin{array}{l}\text { A } 3 \\
\text { Energy crisis } \\
\text { and opportunities }\end{array}$ & $\begin{array}{l}\text { A4 } \\
\text { Every man } \\
\text { for himself }\end{array}$ \\
\hline $\begin{array}{l}\text { B } \\
\text { Energy systems } \\
\text { in Europe } \\
\text { and France }\end{array}$ & $\begin{array}{l}\text { B1 } \\
\text { Unmet targets } \\
\text { and pragmatic } \\
\text { approach }\end{array}$ & $\begin{array}{l}\text { B 2 } \\
\text { Security } \\
\text { and determined } \\
\text { effort for ecology } \\
\text { (diversification) }\end{array}$ & $\begin{array}{l}\text { B3 } \\
\text { Industrial priorities } \\
\text { (proven } \\
\text { technologies } \\
\text { or global market) }\end{array}$ & $\begin{array}{l}\text { B4 } \\
\text { Niche markets }\end{array}$ \\
\hline $\begin{array}{l}\text { C } \\
\text { Areas of operation }\end{array}$ & $\begin{array}{l}\text { C1 } \\
\text { Concerted } \\
\text { and integrated } \\
\text { operation }\end{array}$ & $\begin{array}{l}\text { C2 } \\
\text { Planned zoning }\end{array}$ & $\begin{array}{l}\text { C3 } \\
\text { Decentralized } \\
\text { and conflict zoning }\end{array}$ & $\begin{array}{l}\text { C4 } \\
\text { Negotiated } \\
\text { zoning }\end{array}$ \\
\hline $\begin{array}{l}\text { E } \\
\text { Marine energy } \\
\text { R\&D }\end{array}$ & $\begin{array}{l}\text { E1 } \\
\text { Few developments }\end{array}$ & $\begin{array}{l}\text { E2 } \\
\text { Crisis } \\
\text { and opportunity }\end{array}$ & $\begin{array}{l}\text { E3 } \\
\text { Technological } \\
\text { breakthroughs } \\
\text { and multiple } \\
\text { partnerships }\end{array}$ & \\
\hline
\end{tabular}

- Table 17 : drawing up the macro-scenario 'Crisis and energy emergency'. 


\section{Summary Scenario 1: 'Crisis and energy emergency'}

Context: energy crisis and economic competition

Energy stakes: technological partnerships and competition in this market

Political support: may the best man win!

Investment by clusters of private operators

Marketing the demonstration model

Conflicts in development, leading to dedicated farms on multi-use sites

Research: technological development and impact assessments

Impacts on technologies: proven technologies

Stream power ( $\mathrm{H} 1$ or no development): restriction to stream turbines on the surface or in shallow water

Tidal power ( $\mathrm{H} 2)$ : developed sites and other use (aquaculture)

Wave power (H1 or no development): nearshore (maximum depth of $50 \mathrm{~m}$ ) or no development

Biomass $(\mathrm{H} 1+\mathrm{H} 2)$ : extensive farming on developed land and developments abroad Wind power $(\mathrm{H} 1)$ : adapting land-based wind turbines

Thermal power $(\mathrm{H} 1+\mathrm{H} 2)$ : air-conditioning for the North, cooling, electricity and water for isolated sites in tropical areas

Osmotic power (H2): no development

Hybrid technologies (H2): development of multi-use sites

Major development of tidal, wind, biomass and cold source for thermal energy

\section{Context}

In this scenario, securing the energy supply and fighting global warming are priorities that rank just as high as economic development (see Table 17). The major regions try to increase their competitive advantages in industrial technologies in the world race. The energy crisis is amplified between 2008 and 2010, slowing growth in both developed and developing countries.

The oil crisis from 2010 onwards accelerates competition between countries to increase their market shares in energy technologies, particularly renewables. This energy crisis gives rise to regional technological partnerships (as the USA wished when they refused to ratify the Kyoto Protocol) based on energy-efficient and renewable energy-based technologies. This occurs without a global agreement on targets for reducing greenhouse gas emissions. Due to the energy crisis, reliance on renewables becomes a priority. This will even overtake the need to reduce greenhouse gas emissions, although policy-makers will continue to invoke both objectives in launching technological partnerships.

The political and economic challenge is to rapidly develop the most competitive renewable energy industries. Thus national policy supports renewable energy sectors without distinction so that the best operator will succeed. Research in both the public and private sectors gives priority to the development of the most 
mature technologies rather than upstream research on energy technologies. Similarly, in the field of fuels, public authorities use the obligation to include biofuels without tax exemptions, so that the most cost-effective industries will emerge through the industrial choices made.

Public investments are made rapidly to strengthen the electricity grid in order to promote decentralized power production and faster industrial development of renewables. Tangible demonstrations remain the best argument for the industry's international development. However, bulk storage of electricity has not had time to progress. Creating the grid and multiplying the anticipated sources of energy generation thus guarantee energy security in this context.

\section{Marine renewable energies areas of operation}

As the coexistence of activities at sea in the coastal zone leads to conflicts, increasingly complex regulations are necessary, such as the impact studies required before any installation is made on- or offshore. Streamlining of planning tools in Europe and looking for ways to mitigate conflicts over use lead the French State, working with local authorities, to propose zones either exclusively devoted to marine energies or in a combination with other compatible uses like water sports or aquaculture farms. These multi-use zones will first be set up in lesstouristic regions, such as the English Channel or North Sea. Regulated zoning appears to be the quickest way to develop production on an industrial scale.

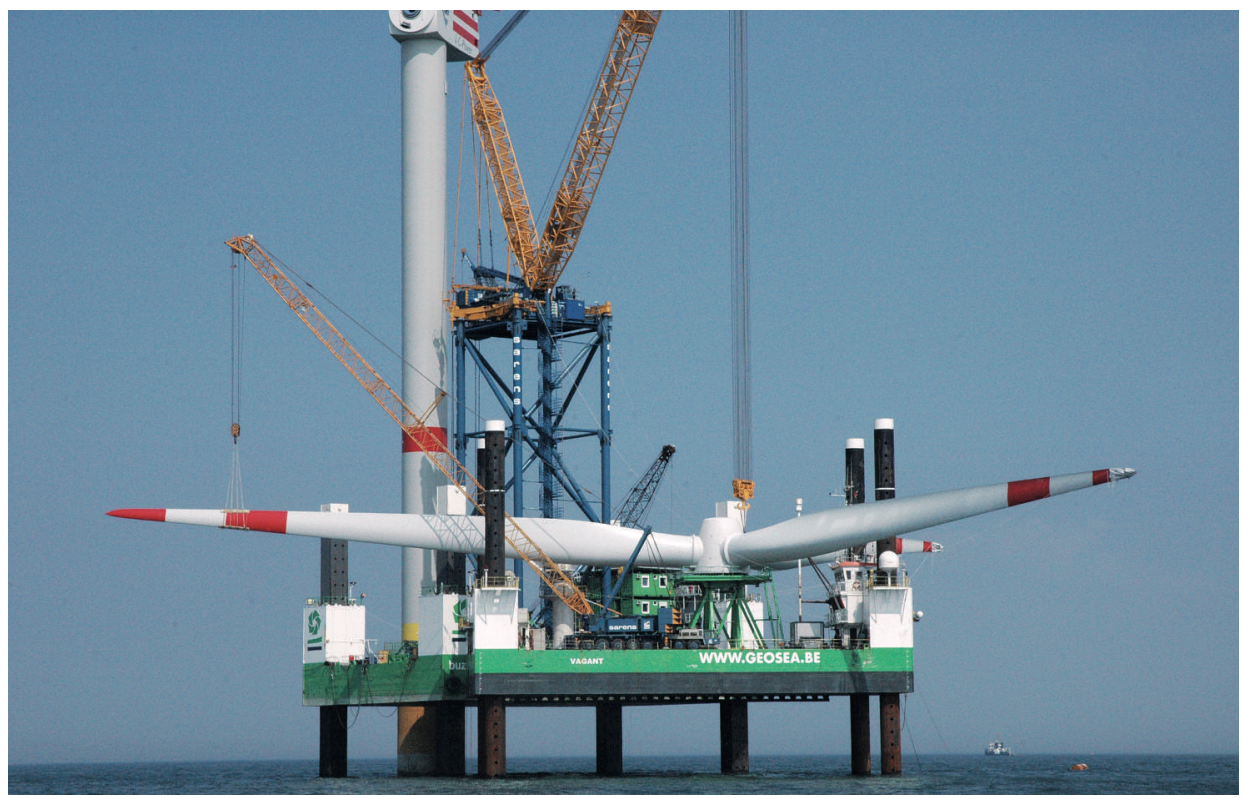

I Photo 11 : blade (126 m in diameter) being mounted on the mast in the $300 \mathrm{MW}$ Thornton bank offshore wind farm in Belgium (@ Deme, BE). 
Initially, wind farms are the dedicated marine facilities for renewable energies, due to their mainly offshore resource potential and the technology, which is relatively mature worldwide. Europe has less than $10 \%$ of the world wind power potential, but has had the majority of installed power since early 2000; its industrial experience gives it a competitive edge. Europe is developing this technology in partnerships with other world regions.

The wind turbines are still attached to the seabed and linked to the coast via cables, thus limiting them to water depths of less than $50 \mathrm{~m}$. Technological developments for turbines improves the cost factor. To make maximum use of these dedicated marine farms, wave generators are set up on the edges of wind farms at depths ranging from 40 to $50 \mathrm{~m}$. Although the supplementary electricity generated by waves is low compared with wind power generation, these installations can act as breakwaters for the coast, an aspect which fosters social acceptance of these farms.

France already has the first tidal power plant in the world, so is profiting from experience by renovating the La Rance plant: the $24 \mathrm{MW}$ turbines are replaced by $40 \mathrm{MW}$ turbines. French experience is also turned to advantage in the United Kingdom, where a tidal power plant is being built in the Severn estuary and operated jointly with an aquaculture activity.

To a lesser extent, a few stream turbine farms are developed in Brittany. The required technology is known and only needs the turbines to be adapted to strong currents. However, its development remains limited due to its lower potential, compared with wind power, and maintenance issues restrict the technological choices to surface or shallow water turbines. As in the case of wind farms, appropriate wave generators are developed for use on the boundaries of these stream power farms. Ocean thermal energy conversion (OTEC) is only used in Europe for air-conditioning of buildings by pumping sufficiently cold surface water or used with heat pumps. However, this application remains marginal in Europe, limited to new buildings. Thermal energy is used more in the French islands in the Southern hemisphere to demonstrate its freshwater and electricity-producing potential. This is partly because the bathymetry and high risk of cyclones means that these islands do not provide suitable conditions for wind energy generation and that strong, and justified, demand is growing for independent power generation. Some islands manage to become energy independent due to tax-exemption policies because of recurrent crises after 2010. They demonstrate the reliability of renewable energy generation combining OTEC with micro-algae production and, to a lesser extent, with wave power generators due to complementarities of sources and well-chosen, dedicated locations. French tropical islands become commercial showcases for marine and solar energy for the rest of the world, as well as being ecotourist destinations.

\section{The fuel stakes in an oil crisis context}

The energy crisis is first and foremost an oil crisis. Fossil fuel alternatives (whether gas or liquid coal) require carbon capture and storage to avoid increasing greenhouse gas emissions. Yet, while carbon capture and storage technologies are 
operational from 2020 onwards, their costs are high, and storage locations are often far from sites of carbon dioxide emission (thermal power plants). Production of first-generation agrofuels is limited by available arable land and food security. In addition, development is limited for second-generation biofuels (e.g. straw, wood, etc.), since these resources are used to produce 'renewable' heat with much better yields.

Micro-algae cultures to produce biofuels are developing not only in Europe but in numerous developing countries within technological partnerships, with the advantage of much higher yields than with agrofuels. Production is least costly in extensive farming of developed lagoon areas. It proves easier to devote areas to this type of crop in Southern hemisphere countries (Africa and South America) than in Europe. Europe shows great resolve and determination in producing biodiesel with micro-algae, because, contrary to other countries in the Organization for Economic Co-operation and Development (OECD), it requires more diesel than petrol. Production develops in France, French Guyana and New Caledonia.

\section{The consequences for stakeholders}

These developments are made possible between 2020 and 2030 by investments from financers and private operators convinced by the potential and effects of scale worldwide for wind and micro-algae. Clusters of private operators propose comprehensive energy farms to the authorities, which will serve as commercial showcases. Advantage is taken of the opportunity provided by wind farms (or stream power farms to a lesser extent) to develop wave energy. OTEC is developed in the tropics.

Tidal energy is deployed in a few large national projects in the world set up to replace a number of large hydraulic dam projects criticized for the problems they create in population displacement and limiting the flow of water downstream. It is less flexible than hydro-electric power in generating electricity. Sites are also limited, but the technology is reliable and has a lower social impact. Using cold water, either for air-conditioning or as a cold source for a heat pump, does not require substantial technological developments or major industrial investments.

Research mainly focuses on optimizing already mature marine technologies for industrial development and impact assessments to select areas for these activities and make them acceptable to local populations.

\section{Marine renewable energy contributions for France}

Table 18 gives the orders of magnitude for each technology's energy production. The biomass calculation basis: micro-algae can produce from 10 to $50 \mathrm{~g} / \mathrm{m}^{2} /$ day of dry matter. Taking the lowest figure, micro-algae would supply 36.5 tonne/ha/ year of dry matter, that is, 18.25 tonne of oil (50\% oil in dry matter)/ha/year.

Therefore, 2.8 million ha will be required to produce 51 Mtoe, which is the equivalent of French oil consumption for shipping and transport. France has 2.44 million 
ha of wetlands, not including peat bogs, of which approximately 1.5 million ha could potentially be used. This means that France could theoretically produce 27 Mtoe (18.25 tonnes $\times 1.5$ million ha) of oil yearly.

\begin{tabular}{|c|c|c|c|}
\hline Technology & Development & Installed power & Electricity generation \\
\hline Stream power $(\mathrm{H} 1)$ & $\begin{array}{l}\text { Average } \\
\text { to low development } \\
\text { Limited to surface } \\
\text { stream turbines }\end{array}$ & $100 \mathrm{MW}$ & $0.3 \mathrm{TWh} /$ year \\
\hline Tidal power $(\mathrm{H} 2)$ & $\begin{array}{l}\text { Strong development: } \\
\text { barrages } \\
\text { and aquaculture }\end{array}$ & $400 \mathrm{MW}$ & $\begin{array}{l}1 \mathrm{TWh} / \text { year } \\
\text { (0.5 TWh today) }\end{array}$ \\
\hline Wave power (H1) & $\begin{array}{l}\text { Average } \\
\text { to low development } \\
\text { Nearshore ( } 50 \mathrm{~m} \text { depth) } \\
\text { On the edges of wind } \\
\text { farms or stream farms } \\
\text { and isolated sites }\end{array}$ & $100 \mathrm{MW}$ & 0.3 TWh/year \\
\hline Biomass $(\mathrm{H} 1+\mathrm{H} 2)$ & $\begin{array}{l}\text { Strong extensive } \\
\text { development } \\
\text { Extensive farming } \\
\text { on developed land } \\
\text { and developments } \\
\text { abroad }\end{array}$ & $\begin{array}{l}2000 \text { ha } \\
\text { (French Guyana } \\
\text { and New Caledonia) }\end{array}$ & $\begin{array}{l}0.05 \text { Mtoe } \\
\text { (but imports } \\
\text { from abroad) }\end{array}$ \\
\hline $\begin{array}{l}\text { Wind power }(\mathrm{H} 1) \\
\text { Adapting land-based } \\
\text { wind turbines }\end{array}$ & $\begin{array}{l}\text { Strong development } \\
\text { Fixed wind turbines }\end{array}$ & $4000 \mathrm{MW}$ & $12 \mathrm{TWh}$ \\
\hline $\begin{array}{l}\text { Thermal power }(\mathrm{H} 1) \\
\text { Equivalents: } \\
3.5 \text { TWh cooling }=0.8 \\
\text { TWh electricity } \\
\text { saved } \\
\text { Water: } \\
\text { savings of } 2 \mathrm{kWh} / \mathrm{m}^{3}\end{array}$ & $\begin{array}{l}\text { Average development } \\
\text { Metropolitan France: } \\
\text { heat pumps } \\
\text { and occasionally } \\
\text { cooling } \\
\text { DOM-COM, especially } \\
\text { isolated sites: } \\
\text { cooling, electricity } \\
\text { and water }\end{array}$ & $\begin{array}{l}10 \text { Units - cooling } \\
40 \mathrm{MW}=400 \mathrm{MW} \\
10 \text { Units - electricity } \\
5 \mathrm{MW}=50 \mathrm{MW} \\
10 \text { Units - water } \\
500 \mathrm{~m}^{3} / \text { day }\end{array}$ & $\begin{array}{l}3150 \mathrm{GWh} \text { cooling/year } \\
=0.72 \mathrm{TWh} / \text { year } \\
0.4 \mathrm{TWh} / \text { year } \\
1.65 \mathrm{million} \mathrm{m}^{3} / \text { year } \\
=3.3 \mathrm{GWh} / \text { year }\end{array}$ \\
\hline Osmotic power $(\mathrm{H} 2)$ & $\begin{array}{l}\text { No significant } \\
\text { development }\end{array}$ & 0 & \\
\hline & $\begin{array}{l}\text { Total electricity, } \\
\text { fuel and water }\end{array}$ & \multicolumn{2}{|c|}{$\begin{array}{l}\text { 15.4 TWh/year, } 0.05 \text { Mtoe } \\
\text { and } 1.65 \text { million } \mathrm{m}^{3} / \text { year }\end{array}$} \\
\hline $\begin{array}{l}\text { Hybrid }(\mathrm{H} 2) \\
\text { Development } \\
\text { of sites with several } \\
\text { technologies }\end{array}$ & \multicolumn{3}{|c|}{$\begin{array}{l}\text { North: co-operation in industrial clusters: } \\
\text { - offshore wind farms linked to shore and wave generators on edges } \\
\text { (marginal) } \\
\text { - stream farms and appropriate wave generators } \\
\text { - tidal power barrage and aquaculture } \\
\text { Developing countries: } \\
\text { - OTEC, wave generator and aquaculture (algae or fish farming) }\end{array}$} \\
\hline
\end{tabular}

- Table 18 : marine renewable energy contributions for France in Scenario 1: 'Crisis and energy emergency'. 


\section{Scenario 2: Altruistic co-operation through necessity Combination: A1, B2, C1, E3 Drivers: Global policy for sustainability Technologies: Determined efforts and efficiency}

\begin{tabular}{|c|c|c|c|c|}
\hline $\begin{array}{l}\text { Hypothesis } \\
\text { Component }\end{array}$ & Hypothesis 1 & Hypothesis 2 & Hypothesis 3 & Hypothesis 4 \\
\hline $\begin{array}{l}\text { A } \\
\text { World context }\end{array}$ & $\begin{array}{l}\text { A1 } \\
\text { Worldwide } \\
\text { co-operation } \\
\text { for energy-climate }\end{array}$ & $\begin{array}{l}\text { A2 } \\
\text { Climate shock, } \\
\text { panic } \\
\text { and co-operation }\end{array}$ & $\begin{array}{l}\text { A3 } \\
\text { Energy crisis } \\
\text { and opportunities }\end{array}$ & $\begin{array}{l}\text { A4 } \\
\text { Every man } \\
\text { for himself }\end{array}$ \\
\hline $\begin{array}{l}\text { B } \\
\text { Energy systems } \\
\text { in Europe } \\
\text { and France }\end{array}$ & $\begin{array}{l}\text { B1 } \\
\text { Unmet targets } \\
\text { and pragmatic } \\
\text { approach }\end{array}$ & $\begin{array}{l}\text { B2 } \\
\text { Security } \\
\text { and determined } \\
\text { effort for ecology } \\
\text { (diversification) }\end{array}$ & $\begin{array}{l}\text { B3 } \\
\text { Industrial priorities } \\
\text { (proven technologies } \\
\text { or global market) }\end{array}$ & $\begin{array}{l}\text { B4 } \\
\text { Niche markets }\end{array}$ \\
\hline $\begin{array}{l}\text { C } \\
\text { Areas of operation }\end{array}$ & $\begin{array}{l}\text { C1 } \\
\text { Concerted } \\
\text { and integrated } \\
\text { operation }\end{array}$ & $\begin{array}{l}\text { C2 } \\
\text { Planned zoning }\end{array}$ & $\begin{array}{l}\text { C3 } \\
\text { Decentralized } \\
\text { and conflict zoning }\end{array}$ & $\begin{array}{l}\text { C4 } \\
\text { Negotiated zoning }\end{array}$ \\
\hline $\begin{array}{l}\text { E } \\
\text { Marine energy } \\
\text { R\&D }\end{array}$ & $\begin{array}{l}\text { E1 } \\
\text { Few } \\
\text { developments }\end{array}$ & $\begin{array}{l}\text { E } 2 \\
\text { Crisis } \\
\text { and opportunity }\end{array}$ & $\begin{array}{l}\text { E3 } \\
\text { Technological } \\
\text { breakthroughs } \\
\text { and multiple } \\
\text { partnerships }\end{array}$ & \\
\hline
\end{tabular}

- Table 19 : drawing up the macro-scenario 'Altruistic co-operation through necessity'

\section{Summary Scenario 2: 'Altruistic co-operation through necessity'}

Context: global collaboration and Kyoto II

Energy stakes: public and private sector investment

Public support: for research and less mature technologies

Effectiveness: intermittent energy storage, hydrogen and hybridization of technologies

Acceptance through proper consultation

Research: new concepts and hybridization; environmental impacts

Technological risk-taking

Effective and uncompromising development of most technologies

Stream power ( $\mathrm{H} 3)$ : deep water stream turbines (including ocean currents)

Tidal power $(\mathrm{H} 2)$ : developing tidal power site and other uses

Wave power $(\mathrm{H} 2+\mathrm{H} 1)$ : nearshore operation (50 m depth) and isolated sites

Biomass (H4): intensive production on land and GMOs and multi-products

Wind power $(\mathrm{H} 3)$ : floating wind turbines

Thermal power (H3): air-conditioning in the North, cooling/electricity/water for isolated sites in the tropics and biological uses for nutrients and minerals from deep water

Osmotic power (H1): micro-plant pilot project

Hybrid (H3): development through determined effort 


\section{Context}

Since the effects of climate change are increasingly felt after 2010, the USA and China finally agree to ratify a protocol (Kyoto II) on reducing greenhouse gases. China, fearing that its economic development will be curbed by available resources or the environmental outcome of its industrialization, wants to engage in clean, low-consumption development as set out in the objectives of the eleventh 5-year plan as of 2005. The change in the American presidency in 2008 also contributes to this change in awareness of the long-term environmental and economic risks. In addition, the USA has the advantages needed to develop a clean technology (including nuclear power) market. The need to start on the track of dividing emissions by four, called 'factor 4', by 2050 to mitigate global warming becomes increasingly obvious from the results of scientific studies.

In this context, the European target to limit greenhouse gas emissions becomes much more ambitious (-45\% in 2030 compared with 1990 and 30\% use of RES by the same date). To this end, renewable and energy-efficient technologies will have to be mobilized. Europe's priority is to promote both energy management and decentralized power generation. This change requires substantial investments in stronger and denser inter-connected grids.

The public authority's strategy is to give more help to the less competitive renewable energy supply chains to help them mature and thus develop technologies which can be exported. Consequently, between 2010 and 2015, the feed-in tariff for electricity generated by wind turbines on land is reduced, since the cost price becomes cost-effective, while the rate paid to buy power from marine renewables supplying electricity remains very advantageous. Similarly, marine biofuels benefit from more sweeping tax exemptions than terrestrial biofuels, supplementing the biofuel addition targets that will enable their industrial-scale development.

Given the political priorities, public and private sector research budgets for renewables increase sharply. Public institutions massively support this effort by mobilizing private firms within large partnerships or clusters and contribute to rapidly incorporating the technological advances into existing networks and plants. This not only enables renewable energy technologies to be improved more quickly, but above all develops hybrid technologies, such as marine energies combined with floating solar panels. These developments enable Europe to maintain its technological advantage in these fields over the USA and Asia. The European research community finally becomes a reality, due to experiments and benefits shared by Northern and Southern countries alike.

Finally, the technological obstacle to bulk storage of intermittent electricity (from land or sea) is removed, notably through hydrogen production. Indeed, even though electrolysis has a low energy yield for hydrogen production, it is better to produce some hydrogen, rather than lose all the intermittent electricity not used immediately. Moreover, producing hydrogen, especially for marine energies used to generate electricity, enables the use of resources further offshore, and thus raises the resource potential without losing part of the energy in electricity transmission. 


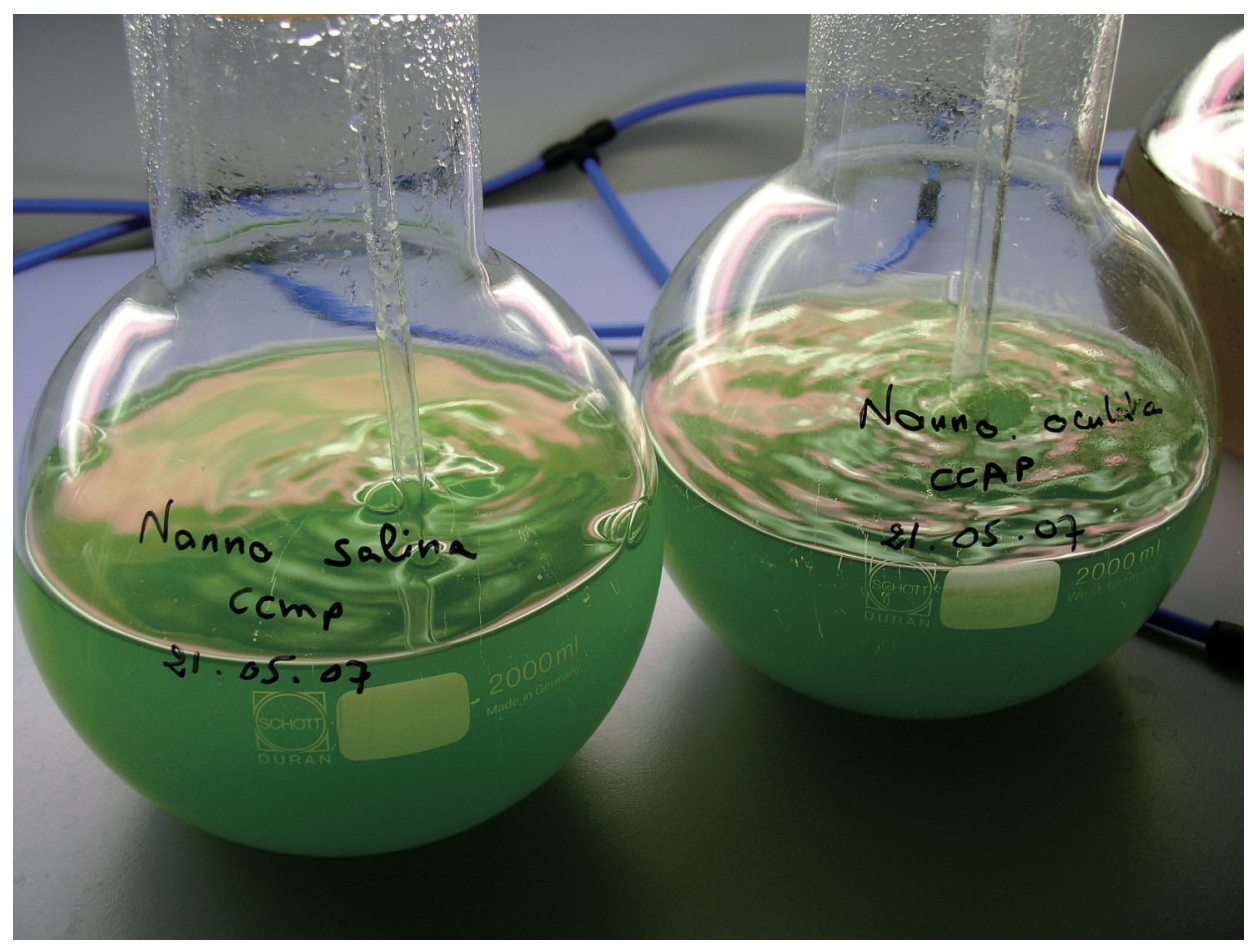

I Photo 12 : Nannochloropsis salina, an eustigmatophycean algae, grown here in a round flask is highly tolerant of salinity variations (๑ Ifremer, J.P. Cadoret).

\section{Marine renewable areas of operation}

Islands, especially tropical islands, are the first places where experiments on using marine renewables are carried out as of 2010. There are three reasons for this: their natural resources, because it is more expensive to generate energy from fossil fuel sources there, and they have specific freshwater needs.

The islands of French Polynesia manage to be energy-independent as of 2020 due to a tax-exemption plan for energy production investments. They act as pilot sites for integrating several technologies: combining OTEC and aquaculture (fish and micro-algae) and combining OTEC and wave power generators with floating barges fitted with solar panels. After 2020, these hybrid arrangements are even sometimes combined with floating wind turbines, which can be folded down during cyclones.

Since some islands have high marine energy potential but only a small population, it becomes necessary to produce hydrogen to store the power and then transport it by boat to other islands. Two $20 \mathrm{MW}$ floating OTEC plants are installed in Polynesia. Ocean thermal energy is also used for local economic development: for in situ offshore aquaculture, taking advantage of the nutrients brought to the surface by this technique and possibly to extract minerals from deep waters. This 
island policy is enhanced by green tourism tours, making the French DOM-COMs even more attractive.

In mainland Europe, developing renewable energies is a political priority to meet greenhouse gas emission reduction targets by 2010. The consultation carried out by coastal urban councils reconciles uses like aquaculture and tourism (e.g. through farm tours) as well as the development of marine renewables on an industrial scale, provided that they are well assimilated in the environment and do not hinder the development of other activities. Coastal populations become interested once they understand that this 'green energy' sector could replace traditional activities, which are dwindling due to weak demographics and the saturation level for tourist activities. Generalization of impact studies enables potentially negative impacts to be anticipated and avoided. In addition, this provides better environmental awareness, which in some cases generates positive effects for other activities (e.g. ecotourism, diving, etc.).

The first offshore wind farms are created near the coast. The interest in recovering the electrical power generated but unused justifies developing in situ hydrogen production technology. This makes it possible to create energy farms far offshore and make better use of the available natural resources. This emerging fuel supply will create demand, especially in coastal towns. Depending on the distance, hydrogen is transported by pipeline or boat.

Since hydrogen is a clean and efficient fuel, it is used in heat engines up until 2015-20 and in fuel cells thereafter. It will then become a supplementary supply

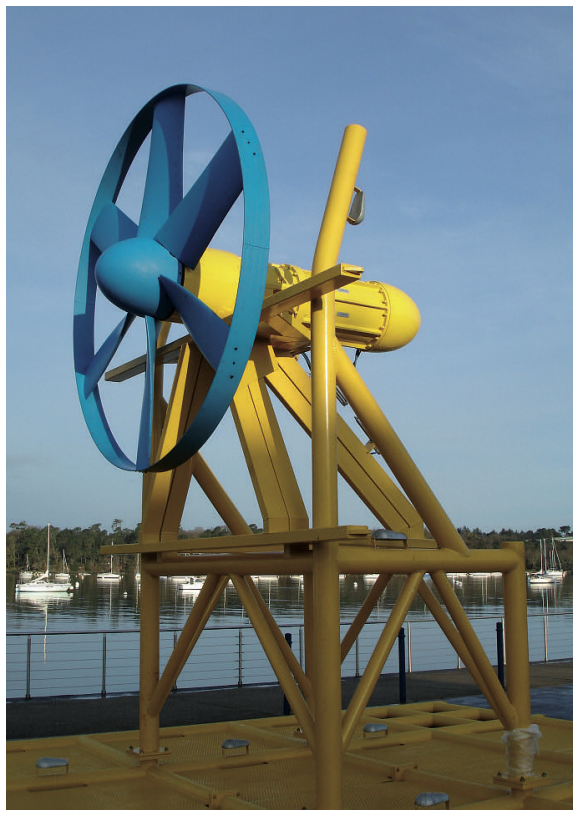

I Photo 13 : Sabella stream turbine ready to be submerged in Brittany (C J. Ruer). of electricity and heat in peak demand periods as well as contributing to the petrochemical sector (traditionally located near harbours on the coast).

The marine technologies which experience the most growth in the upper latitudes, particularly because of hydrogen production far offshore, are wind power, stream power from ocean currents and wave power generators.

Floating wind turbines are set up as of 2015, when they are no longer limited by maximum depths and can make better use of the wind resource. They are initially linked to the grid, but by 2020 they are producing hydrogen.

Stream turbines are installed in deep water $(>50 \mathrm{~m})$ to use tidal currents in areas where they are strongest (often busy shipping areas) and offshore ocean currents after 2020 once hydrogen production is possible. This considerably 
increases resources and creates effects of scale for this technology. In France, stream turbines are set up mainly off the coasts of Brittany and the Cotentin peninsula.

Wave power generators that can cover large surface areas are set up more often after 2020, when it becomes possible to install them far from the coast at depths exceeding $50 \mathrm{~m}$. This also increases the available resources and makes them less visible and intrusive, thus reducing conflicts over use.

Hybrid technologies linking wind turbines, tidal turbines or even solar panels on floating barges are developed. Ocean stream energy is also developed in combination with other technologies, such as floating wind turbines or wave power generators, to optimize the yield from areas equipped to produce power and share the necessary maintenance work.

The La Rance tidal power plant site is upgraded with more powerful turbines (40 MW), however, constructing a barrage in an estuary no longer seems to be an optimal solution, given the impact it would have on the ecosystem and the will to protect wetland areas.

The tidal lagoon technology $(60 \mathrm{MW})$ involving several ponds at sea is tested in the United Kingdom in Swansea bay as of 2015. Although it is a British initiative, Franco-British technological co-operation ensures that the project is achieved under good conditions. The success of this man-made lagoon then creates the incentive for other projects in Europe to be developed in conjunction with aquaculture. These include a $200 \mathrm{MW}$ project in France to the north of Mont-SaintMichel bay. Wind turbines and solar panels are often set up on breakwaters and jetties to optimize the energy generated on these sites. The success of tidal lagoons even initiates the idea of creating plants on sites where wave energy is concentrated or where currents are formed. Pilot experiments are carried out on them between 2020 and 2030 .

Generally speaking, hybridization of technologies improves energy site yields.

Osmotic power, also called salinity gradient power, is the least mature technology. It requires special site conditions (both fresh and saltwater), which are only available with few conflicts in Canada or Scandinavia. Thus, the first pilot sites are set up in those countries and only one micro-plant is deployed in mainland Europe.

\section{Heat and fuels}

The practice of using locally available renewables on site is developed. New buildings on the coast often use deep cold water for their air-conditioning. Similarly, the sea is often used as a cold source for heat pumps, which reduces energy consumption for heating.

From 2015, micro-algae aquaculture is developed in Europe to produce molecules used for drugs and food additives. This intensive farming is performed on land in transparent tubes of photobioreactors. Oil for diesel fuel is initially a by-product. Since the carbon capture potential of micro-algae is much higher than land-based biofuels, carbon credits enable biodiesel produced from micro-algae to be cost- 
effective, even when intensively farmed on land. As of 2025, the first sites using this technology are set up in France. By 2030, marine-based biodiesels have a significant share in France and soon in Europe as a whole as well.

\section{The consequences for stakeholders}

As of 2010, local debates are held with coastal populations about energy stakes, how to reduce greenhouse gases and the local marine renewable energy potential. Research scientists greatly contribute to the success of this consultation because of their credibility regarding the topic: they do not directly profit from the operation and are the best placed to anticipate the possible impacts these technologies could have on the marine environment.

In 2020, hydrogen production makes it possible to set up new power farms far offshore (no longer visible from shore), reducing the risk of conflict and facilitating public acceptance. Even the seafarers who were the most reticent about having these installations at sea take a more favourable view of these technologies once their boat engines have been adapted to use hydrogen (however, additional space on board must still be found for the pressurized hydrogen tanks). Furthermore, setting up plant or turbines at sea on sandy seabeds can create a reef effect, which attracts some fish and proves beneficial for fisheries.

Local hydrogen production in inshore areas is an asset for coastal fringes, since their energy resources are not subject to carbon quotas and have predictable prices. Around 2020, once the first coastal cities are using hydrogen, demand from local authorities in particular for wind and stream turbines also takes off. These developments boost the coastal areas, which had relied heavily on the residential and tourist economy and now want to diversify their traditional activities with a sector whose image is both modern and ethical.

With a global agreement on climate-related stakes, both public-private and private sector partnerships to develop marine energy farms now take the initiative. Enterprises take risks in order to develop more quickly technologies and their hybridization, knowing that the first to get their demonstration farms operational will have the competitive edge. These consortium-based projects in Europe enjoy support from the public authorities.

Research is focused on innovative technologies and more particularly, hybrid combinations of them. Indeed, the export market will grow for micro-algae biotechnologies and hybrid machines that can produce either electricity or hydrogen at sea. Development on the part of Southern hemisphere countries maintains the Northern countries' economic position through sales of high-tech products and expertise. The still growing demand for energy slows (17\%/ reference) due to rapid technological development and low-consumption processes. Investments are made for better water management (e.g. collection, sewage treatment, water-saving farming techniques) even in developing countries, often because of international aid. Desalination is used only on islands that have no other alternative. Lower tensions regarding energy, due to supply trends, enable oil prices to hold at less than 100 dollars/barrel. 


\begin{tabular}{|c|c|c|c|}
\hline Technology & Development & Installed power & Electricity generation \\
\hline Stream power $(\mathrm{H} 3)$ & $\begin{array}{l}\text { Strong development } \\
\text { Deep-water stream } \\
\text { turbines (including } \\
\text { ocean currents) }\end{array}$ & $1000 \mathrm{MW}$ & $3 \mathrm{TWh}$ \\
\hline Tidal power $(\mathrm{H} 2)$ & $\begin{array}{l}\text { Strong development } \\
\text { More power from exis- } \\
\text { ting dams or barrages } \\
\text { Tidal lagoon and aqua- } \\
\text { culture }\end{array}$ & $600 \mathrm{MW}$ & $\begin{array}{l}\text { 1.5 TWh } \\
\text { (0.5 TWh today) }\end{array}$ \\
\hline Wave power $(\mathrm{H} 2+\mathrm{H} 3)$ & $\begin{array}{l}\text { Strong development } \\
\text { Operation far offshore } \\
\text { (depths of } 50-100 \mathrm{~m} \text { ) } \\
\text { and isolated sites }\end{array}$ & 2000 & $6 \mathrm{TWh}$ \\
\hline Biomass (H4) & $\begin{array}{l}\text { Strong development } \\
\text { Intensive land-based } \\
\text { production } \\
\text { of multi-products } \\
\text { and GMOs* }\end{array}$ & 10 sites, i.e. 20,000 ha & 2.5 Mtoe* $^{*}$ \\
\hline Wind power $(\mathrm{H} 3)$ & $\begin{array}{l}\text { Strong development, } \\
\text { including floating wind } \\
\text { turbines }\end{array}$ & $10,000 \mathrm{MW}$ & $30 \mathrm{TWh}$ \\
\hline $\begin{array}{l}\text { Thermal power }(\mathrm{H} 3) \\
\text { Equivalents: } \\
\text { 3.5 TWh cooling } \\
=0.8 \text { TWh electricity } \\
\text { saved } \\
\text { Water: } \\
\text { savings of } 2 \mathrm{kWh} / \mathrm{m}^{3}\end{array}$ & $\begin{array}{l}\text { Strong development in } \\
\text { metropolitan France: } \\
\text { heat pump } \\
\text { and air-conditioning } \\
\text { DOM-COM: } \\
\text { air-conditioning, water, } \\
\text { electricity and synergy } \\
\text { with aquaculture }\end{array}$ & $\begin{array}{l}35 \text { Units - cooling } \\
40 / 80 \mathrm{MW}=2000 \mathrm{MW} \\
17 \text { Units - electricity } \\
5 / 20 \mathrm{MW}=115 \mathrm{MW} \\
20 \text { Units - water } \\
\text { of } 500 \mathrm{~m}^{3} / \text { day }\end{array}$ & $\begin{array}{l}\text { 15,840 GWh/year } \\
=3.6 \mathrm{TWh} / \text { year } \\
\text { 0.7 TWh/year } \\
\begin{array}{l}3.3 \mathrm{million} \mathrm{m}^{3} / \text { year } \\
=6.6 \mathrm{GWh} / \text { year }\end{array}\end{array}$ \\
\hline Osmotic power (H3) & $\begin{array}{l}\text { Micro-plants } \\
\text { in Norway and Canada } \\
\text { Micro-plant pilot } \\
\text { (mainland Europe) }\end{array}$ & 0 & \\
\hline TOTAL & $\begin{array}{l}\text { Total electricity, } \\
\text { fuel and water }\end{array}$ & \multicolumn{2}{|c|}{ 46.3 TWh/year, 2.5 Mtoe and 3.3 million $\mathrm{m}^{3} /$ year } \\
\hline $\begin{array}{l}\text { Hybrid }(\mathrm{H} 3) \\
\text { development } \\
\text { through determined } \\
\text { effort }\end{array}$ & \multicolumn{3}{|c|}{$\begin{array}{l}\text { North: } \\
\text { Wind, waves, floating solar and stream turbine when resource is available. } \\
\text { Tidal stream turbine (nearshore) with waves. Tidal power: lagoon, } \\
\text { aquaculture (fish farming), wind turbines on breakwaters and solar panels } \\
\text { Seawater fuel cell } \\
\text { Tropics: OTEC and aquaculture (because of OTEC), waves, floating solar } \\
\text { panels and wind (adapted to cyclones) } \\
\text { Creating new sites (e.g. focusing of wave energy) }\end{array}$} \\
\hline
\end{tabular}

- Table 20 : marine renewable energy contributions for France in Scenario 2: 'Altruistic co-operation through necessity'.

* Intensive farming and GMOs give a five-fold yield compared with extensive farming. 


\section{Scenario 3: Few changes, every man for himself Combination: A4, B1, C4, E1 Driver: National security Technologies: Minimal development}

\begin{tabular}{|l|l|l|l|l|}
\hline \multicolumn{1}{|c|}{ Hypothesis } & \multicolumn{1}{|c|}{ Hypothesis 1 } & \multicolumn{1}{|c|}{ Hypothesis 2 } & \multicolumn{1}{|c|}{ Hypothesis 3 } & \multicolumn{1}{|c|}{ Hypothesis 4 } \\
\hline $\begin{array}{llll}\text { A } \\
\text { World context }\end{array}$ & $\begin{array}{l}\text { A1 } \\
\text { Worldwide } \\
\text { co-operation } \\
\text { for energy-climate }\end{array}$ & $\begin{array}{l}\text { A2 } \\
\text { Climate shock, } \\
\text { panic } \\
\text { and co-operation }\end{array}$ & $\begin{array}{l}\text { A3 } \\
\text { Energy crisis } \\
\text { and opportunities }\end{array}$ & $\begin{array}{l}\text { A4 } \\
\text { Every man } \\
\text { for himself }\end{array}$ \\
\hline $\begin{array}{l}\text { B } \\
\text { Energy systems } \\
\text { in Europe } \\
\text { and France }\end{array}$ & $\begin{array}{l}\text { B1 } \\
\text { Unmet targets } \\
\text { and pragmatic } \\
\text { approach }\end{array}$ & $\begin{array}{l}\text { B2 } \\
\text { Security } \\
\text { and determined } \\
\text { effort for ecology } \\
\text { (diversification) }\end{array}$ & $\begin{array}{l}\text { B3 } \\
\text { Industrial priorities } \\
\text { (proven } \\
\text { technologies or } \\
\text { global market) }\end{array}$ & $\begin{array}{l}\text { B 4 } \\
\text { Niche markets }\end{array}$ \\
\hline $\begin{array}{l}\text { C } \\
\text { Areas of operation }\end{array}$ & $\begin{array}{l}\text { C1 } \\
\text { Concerted } \\
\text { and integrated } \\
\text { operation }\end{array}$ & $\begin{array}{l}\text { C2 } \\
\text { Planned zoning }\end{array}$ & $\begin{array}{l}\text { C3 } \\
\text { Decentralized } \\
\text { and conflict zoning }\end{array}$ & $\begin{array}{l}\text { C4 } \\
\text { Negotiated zoning }\end{array}$ \\
\hline $\begin{array}{l}\text { E } \\
\text { Marine energy } \\
\text { R\&D }\end{array}$ & $\begin{array}{l}\text { E1 } \\
\text { Few } \\
\text { developments }\end{array}$ & $\begin{array}{l}\text { E2 } \\
\text { Crisis } \\
\text { and opportunity }\end{array}$ & $\begin{array}{l}\text { E3 } \\
\text { Technological } \\
\text { breakthroughs } \\
\text { and multiple } \\
\text { partnerships }\end{array}$ & \\
\hline
\end{tabular}

I Table 21 : drawing up the macro-scenario 'Few changes, every man for himself'

\section{Summary Scenario 3: 'Few changes, every man for himself'}

Context: little co-operation worldwide

Energy stakes: increasing tension and protectionism, security

Freshwater requirements in the North

Public support: security, but at a low cost

- no decentralization of grids

- end of feed-in tariffs for electricity after 2020

Dedicated farms, but independent development of technologies

Research: to each his own technology and impact assessments

Minimal development, dedicated farms for each technology

Stream power $(\mathrm{H} 2)$ : undersea stream turbines

Tidal power (H3): naturally favourable sites, to be used only for electricity

Wave power $(\mathrm{H} 1)$ : operation nearshore (maximum $40 \mathrm{~m}$ depth)

Biomass $(\mathrm{H} 3)$ : production limited to high-tech products

Wind power $(\mathrm{H} 1)$ : adapting land-based wind turbines

Thermal power ( $\mathrm{H} 1)$ : air-conditioning in the North, cooling, electricity and water for isolated sites in the tropics

Osmotic power ( $\mathrm{H} 2)$ : no development

Hybrid (H1): independent development 


\section{II Context}

International negotiations for the climate remain at a status quo: the countries which signed Kyoto I want to continue efforts, but neither the USA nor the large emerging countries agree to limit their economic development by reducing greenhouse gas emissions.

World energy consumption shows a rising trend until 2015, all the more so because desalination of seawater has become common practice in southern Europe, the USA and Australia to meet farming needs during recurrent droughts. The continuing increase in oil prices from 2008 to 2015 has a less serious effect on development in Northern countries than in Southern ones. The latter must reduce their consumption and export more to pay their energy bills. This crisis leads to greater protectionism in developed countries, particularly through taxing the energy content of products.

The major renewable energy projects are developed during the period 2010-20 when tensions surrounding energy issues are increasing.

\section{Marine renewable areas of operation}

Populations do not accept structures being set up at sea, fearing that landscapes will be marred, biodiversity affected and the loss of the coast's natural attractiveness. Following public discussions, complete and complex impact assessments are launched. After a few years of studies, maritime areas are finally devoted to renewable energy production activities, mostly in conjunction with another activity, such as aquaculture. This concentrates human activities in the same area, with a preference for coastal areas with relatively low rates of employment where local elected officials consider it important to find new activities.

These dedicated zones remain near the coast to limit both maintenance costs for the various installations and the length of cable needed to bring the energy to shore.

Marine energy farm projects in these dedicated areas are granted to industrial firms through calls for tender and become operational from 2015 onwards. Either offshore wind turbines adapted from land-based technologies or wave power generators are set up, depending on the potential. Wave generators have lower generation potential for the space they occupy, but in some locations, they can also act as breakwaters to protect the coast. Marine fish-farming pens are often set up within or near these energy farms to use the energy produced on site.

The technologies are developed and installed independently, but none of the industrial firms will have perfected hybrid units by then. The rare cases of industrial companies working jointly are limited to sharing cable and maintenance operations. However, in a few farms, when agricultural activities on the coast suffer water shortages, the production of freshwater using reverse osmosis makes it possible to use this energy when demand for electricity does not use the entire production. 


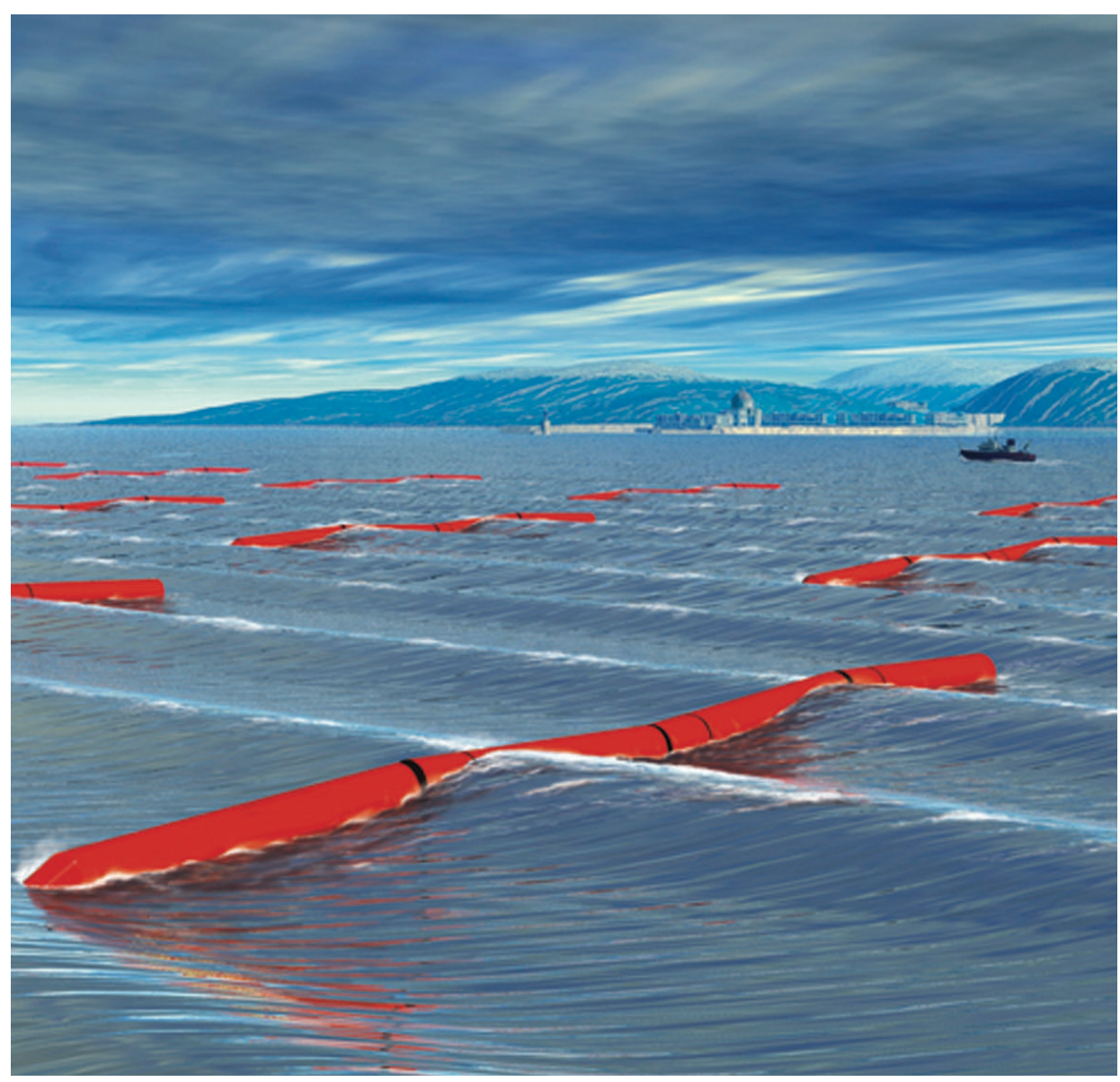

I Photo 14 : artist's illustration of a Pelamis wave generator farm (C Pelamis Wave Power Ltd, UK).

Apart from these farms, only underwater stream turbines are set up in places where tidal currents are intense (i.e. in straits or channels where shipping activity is often busy). That is why this type of machine creates much less risk of conflicting uses with other activities (e.g. leisure, aquaculture), making them easier to set up.

Marine technologies take advantage of technical advances from pioneering countries like the United Kingdom, Denmark, etc., but progress is slow due to the low level of intra-national or international co-operation. Nevertheless, co-operation becomes effective when industrial expertise is clearly complementary, for example, the French help the British to set up a tidal power plant in the Severn estuary and the British help the French to set up stream turbines and generators in dedicated farms.

In renewable biofuel production by 2012, six successful American projects for second-generation agrofuels (using cellulose, straw and wood biomass) make the 
production of biofuels from micro-algae less interesting. Biofuel projects from terrestrial biomass develop in Europe from 2015 onwards. Farming micro-algae remains limited to a few high-tech factories on land which produce specific molecules for pharmaceuticals, skin care products and agribusiness.

Finally, OTEC is used for air-conditioning in some prestigious projects for hotels or public buildings on seafronts. Air-conditioning still mainly uses electricity in coastal areas like France's DOM-COM. Thermal energy is used to generate electricity and freshwater in places where it is more cost-effective than other power solutions (i.e. essentially to supply isolated sites).

\section{The consequences for stakeholders}

Land-based (i.e. solar, wind) and marine renewable energy projects in conjunction with energy-saving incentives are not sufficient to meet the production targets for renewables that Europe has set for itself. The goals set by the Kyoto Protocol, particularly the proportion of RES and greenhouse gas reduction are not reached, either in Europe or globally.

Anticipating this result, RES goals are replaced with 'clean' energy goals for 2018 to account for nuclear power (building of nuclear plants begins again) and to subtract the volume of carbon dioxide captured and sequestered by salt aquifers as of 2020 and by forest biomass from emissions due to thermal energy production. The perspective of carbon storage enables Europe to continue producing some electricity using coal, which is cheaper than natural gas and above all, presents more diversified sources of supply.

Liberalization of electricity production will already have entailed higher costs for the consumer (bringing it into line with electricity generated using fossil fuel sources), so investments to reinforce the grid are first postponed and then abandoned to avoid adding to the rising cost of power.

In this way, feed-in tariffs for intermittent renewable-produced electricity are eliminated in 2020 to avoid local grid management difficulties. Indeed, although tariffs provided incentives for the period 2010-20, no technological breakthrough has enabled better storage and thus better matching of supply and demand for electricity.

Production of freshwater used as a storage method is only useful in a few special cases, such as nearby farms in coastal areas and to keep the area attractive for tourists in spite of recurrent water shortages (southern Europe).

On the horizon of 2030, only biofuels still benefit from tax exemptions and incorporation targets, since there is no other solution available to prevent overdependence on imported oil for transport.

French islands are the only remaining beneficiaries of subsidies for marine RES developments in order to avoid even more costly investments and subsidies to purchase fuel for thermal power plants. They remain prime pilot sites for research 
in the field. Dedicated farms appear but technologies are developed independently, entailing specialized research that takes account of environmental impacts.

The decreasing trend in budgets for public research in energy continues and private research investments have not taken over as hoped. As of 2018, research budgets are more massively redirected towards fourth-generation nuclear power, second-generation agrofuels and carbon dioxide storage.

\begin{tabular}{|c|c|c|c|}
\hline Technology & Development & Installed power & Electrical generation \\
\hline Stream power $(\mathrm{H} 2)$ & $\begin{array}{l}\text { Average development } \\
\text { but with underwater } \\
\text { stream turbines } \\
\text { near the coast }\end{array}$ & $200 \mathrm{MW}$ & $0.6 \mathrm{TWh} /$ year \\
\hline Tidal power $(\mathrm{H} 1)$ & $\begin{array}{l}\text { Naturally favourable } \\
\text { sites: barrages } \\
\text { Only for electricity } \\
\text { needs }\end{array}$ & $\begin{array}{l}\text { Same as today, } \\
\text { i.e. } 240 \mathrm{MW}\end{array}$ & 0.6 TWh/year \\
\hline Wave power $(\mathrm{H} 1)$ & $\begin{array}{l}\text { Low development, } \\
\text { nearshore and isolated } \\
\text { sites }\end{array}$ & $100 \mathrm{MW}$ & $0.3 \mathrm{TWh} /$ year \\
\hline Biomass (H3) & $\begin{array}{l}\text { Production limited } \\
\text { to non-energy products } \\
\text { (and biofuels } \\
\text { as by-products) }\end{array}$ & Other use & Negligible \\
\hline Wind power $(\mathrm{H} 1)$ & $\begin{array}{l}\text { Average development } \\
\text { Adapting land-based } \\
\text { wind turbines }\end{array}$ & $2000 \mathrm{MW}$ & $6 \mathrm{TWh}$ \\
\hline $\begin{array}{l}\text { Thermal power (H1) } \\
\text { Equivalents: } \\
\text { 3.5 TWh cooling } \\
=0.8 \text { TWh electricity } \\
\text { saved } \\
\text { Water: } \\
\text { savings of } 2 \mathrm{KWh} / \mathrm{m}^{3}\end{array}$ & $\begin{array}{l}\text { Low development } \\
\text { Metropolitan France: } \\
\text { farms and air-conditioning } \\
\text { DOM-COM, only isola- } \\
\text { ted sites: } \\
\text { air-conditioning/ } \\
\text { water/electricity }\end{array}$ & $\begin{array}{l}5 \text { Units - cooling } \\
40 \mathrm{MW}=200 \mathrm{MW} \\
5 \text { Units - cooling } \\
40 \mathrm{MW}=200 \mathrm{MW} \\
5 \mathrm{Units} \text { - electricity } \\
5 \mathrm{MW}=25 \mathrm{MW} \\
5 \text { Units - water } \\
\text { of } 500 \mathrm{~m}^{3} / \text { day }\end{array}$ & $\begin{array}{l}1600 \mathrm{GWh} / \text { year } \\
=0.4 \mathrm{TWh} / \text { year } \\
1600 \mathrm{GWh} \text { cooling/year } \\
=0.4 \mathrm{TWh} / \text { year } \\
0.2 \mathrm{TWh} / \text { year } \\
0.8 \mathrm{million} \mathrm{m}^{3} / \text { year } \\
=1.7 \mathrm{GWh} / \text { year }\end{array}$ \\
\hline Osmotic power $(\mathrm{H} 2)$ & No development & & \\
\hline & $\begin{array}{l}\text { Total electricity } \\
\text { and water }\end{array}$ & \multicolumn{2}{|c|}{ 8.5 TWh/year and 0.8 million $\mathrm{m}^{3} /$ year } \\
\hline
\end{tabular}

I Table 22 : marine renewable energy contributions for France in Scenario 3: 'Few changes, every man for himself'. 


\section{Scenario 4: Independent local development Combination: A4 (or A3), B4, C3, E2 Driver: Local development with risk-taking Technologies: Differentiated, depending on coastal regions, niche markets}

\begin{tabular}{|l|l|l|l|l|}
\hline \multicolumn{1}{|c|}{$\begin{array}{l}\text { Hypothesis } \\
\text { Composante }\end{array}$} & \multicolumn{1}{|c|}{ Hypothesis 1 } & Hypothesis 2 & Hypothesis 3 & \multicolumn{1}{|c|}{ Hypothesis 4 } \\
\hline $\begin{array}{l}\text { A } \\
\text { World context }\end{array}$ & $\begin{array}{l}\text { A1 } \\
\text { Worldwide } \\
\text { co-operation } \\
\text { for energy-climate }\end{array}$ & $\begin{array}{l}\text { A2 } \\
\text { Climate shock, } \\
\text { panic and } \\
\text { co-operation }\end{array}$ & $\begin{array}{l}\text { A3 } \\
\text { Energy crisis } \\
\text { and opportunities }\end{array}$ & $\begin{array}{l}\text { A4 } \\
\text { Every man } \\
\text { for himself }\end{array}$ \\
\hline $\begin{array}{l}\text { B } \\
\text { Energy systems } \\
\text { in Europe } \\
\text { and France }\end{array}$ & $\begin{array}{l}\text { B1 } \\
\text { Unmet targets } \\
\text { and pragmatic } \\
\text { approach }\end{array}$ & $\begin{array}{l}\text { B2 } \\
\text { Security } \\
\text { and determined } \\
\text { effort for ecology } \\
\text { (diversification) }\end{array}$ & $\begin{array}{l}\text { B3 } \\
\text { Industrial priorities } \\
\text { (proven } \\
\text { technologies or } \\
\text { global market) }\end{array}$ & $\begin{array}{l}\text { B4 } \\
\text { Niche markets }\end{array}$ \\
\hline $\begin{array}{l}\text { C } \\
\text { Areas of operation }\end{array}$ & $\begin{array}{l}\text { C1 } \\
\text { Concerted } \\
\text { and integrated } \\
\text { operation }\end{array}$ & $\begin{array}{l}\text { C2 } \\
\text { Planned zoning }\end{array}$ & $\begin{array}{l}\text { Decentralized } \\
\text { and conflict zoning }\end{array}$ & $\begin{array}{l}\text { C4 4 } \\
\text { Progressive } \\
\text { acceptance }\end{array}$ \\
\hline $\begin{array}{l}\text { E } \\
\text { Marine energy } \\
\text { R\&D }\end{array}$ & $\begin{array}{l}\text { E1 } \\
\text { Few developments }\end{array}$ & $\begin{array}{l}\text { E2 } \\
\text { Crisis } \\
\text { and opportunity }\end{array}$ & $\begin{array}{l}\text { E3 } \\
\text { Technological } \\
\text { breakthroughs } \\
\text { and multiple } \\
\text { partnerships }\end{array}$ & \\
\hline
\end{tabular}

- Table 23 : drawing up macro-scenario 'Independent local development'.

\section{Summary Scenario 4: 'Independent local development'}

Context: increasing tension and protectionism, security

Requirements for freshwater in the Northern hemisphere

Cost-effective biofuels (end of tax exemption between 2015 and 2020)

Public support: research and decentralized support for technologies (calls for tender) Grid decentralization and developing technologies: depending on location

Research: technologies (local opportunities) and grid regulation

Technological risk-taking for demonstration installations developed locally

Scenario risk: social acceptability of experiments

Niche markets (scale effect only felt at global level)

Stream power $(\mathrm{H} 1)$ : niche

Tidal power $(\mathrm{H} 3)$ : no development

Wave power $(\mathrm{H} 1+\mathrm{H} 3)$ : nearshore $(40 \mathrm{~m})$ and isolated site

Biomass $(\mathrm{H} 4)$ : intensive production on land, strain selection

Wind power ( $\mathrm{H} 2$ target regions, $\mathrm{H} 1$ elsewhere): floating and conventional wind turbines Thermal power $(\mathrm{H} 3)$ : air-conditioning (Europe) and water and electricity (tropics)

Osmotic power ( $\mathrm{H} 1)$ : micro-plant pilot project

Hybrid (H1): independent development 


\section{II Context}

The world context, countries' position with respect to the Kyoto Protocol, global energy consumption and its consequences for both developed and developing countries are the same as in the previous scenario.

This time, however, the challenges for energy security and combating the greenhouse gas effect give rise to greater public research spending for renewables and a strategy of decentralized and delegated support for the regions. The French State, having provided a tool-box of protocols and procedures to set up coastal activities, particularly using national zoning and spatial planning, then moves to devolution of the decision-making processes to local and regional authorities.

In terms of electricity, incentive systems to produce RES are replaced by calls for tender from local authorities depending on their characteristics and requirements in order to select the best industrial offers.

From 2015 to 2020, increasing oil prices enable biofuel sectors to develop, with the end of tax exemptions and no particular targets for incorporation. Indeed, by selecting the best micro-algae strains, dry matter and lipid yields can be increased. Micro-algae are farmed to produce both molecules for pharmaceuticals and agribusiness and biofuels as by-products.

\section{Marine renewable energies areas of operation}

Intensive farming of micro-algae on land is competitive if costs are mainly focused on molecules, which can be utilized as ingredients for food and pharmaceuticals. Thus, several specialized production plants are set up in southern France, elsewhere in southern Europe and in the DOM-COM regions to take advantage of favourable natural conditions. However, diesel fuel production from microalgae is very low compared with agrofuel yields, especially in the period after 2015 when second-generation biofuels are developed.

Decentralization of energy production is only promoted through grid investments in a few regions on the Channel-Atlantic and Mediterranean seaboards:

- either because local consumption from fossil fuel sources is too high to meet European and national greenhouse gas emission targets (for instance, in the United Kingdom and Brittany);

- or to make the grid secure and avoid power cuts in the case of incidents (southeastern France).

These regions develop more decentralized renewables than others (up to 30\%). Research investments have enabled short-term storage technologies to be perfected (from super-capacitors to hydropneumatics, ranging from a few seconds to a few hours). They improve the quality of electrical current and facilitate the management of the grid supplied by intermittent energy sources. Islands also receive RES investments and some become energy-independent.

Since each authority has its own economic development at stake, local actors tend to promote all possible activities to attract employment and investments to 


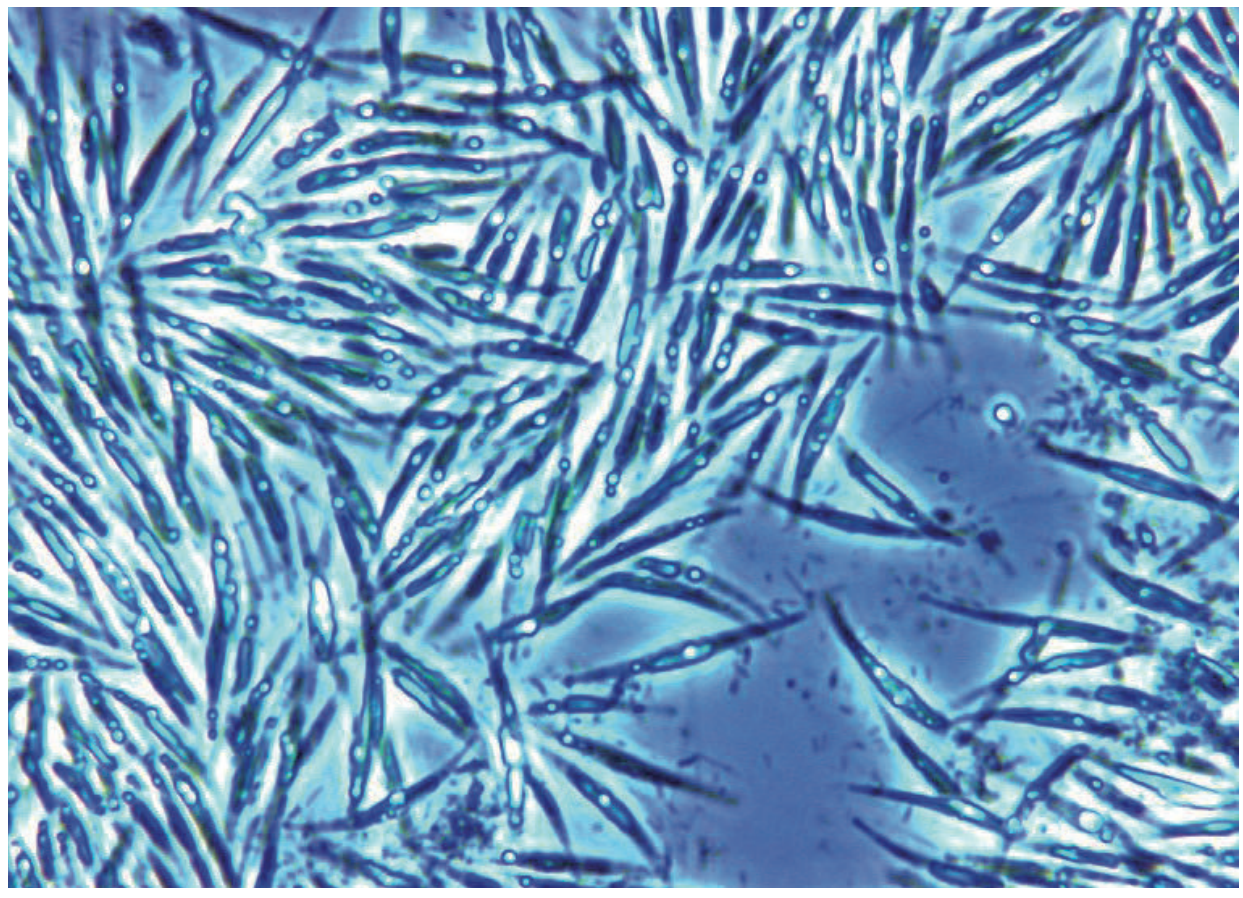

I Photo 15 : the diatom Phaeodactylum tricornutum is a model for studies on this group of algae; its entire genome has been sequenced (๑ Ifremer, J.P. Cadoret).

their area, such as tourism, aquaculture and related activities, and marine energy, particularly in Brittany and southeastern France.

Due to the high price of fossil fuel energies and attractive prices helped by local subsidies for new technologies, industrial firms explore innovative pathways. R\&D capacities are actively mobilized by private operators to occupy operational niches, sometimes with a certain degree of risk-taking. Public institutions help with financing to shorten experimental and pilot phases. Private financers become involved in the most efficient sectors and those with high development potential worldwide, which in turn stimulates research on yields and economies of scale. Offshore wind and wave power are the most developed technologies in France.

Floating wind farms and wave power generators are set up in the LanguedocRoussillon and Brittany regions. A pilot project for a micropower plant using osmotic power is built in the Camargue region to test a new, more cost-effective membrane designed by a French public-private research consortium.

Stream turbines are hardly developed at all on an industrial scale in France over the period in question, since industrial firms prefer to wait for feed-back from farms set up in the United Kingdom and Southeast Asia, where the natural potential is higher. 
Wave energy and OTEC are used to produce electricity and freshwater mostly on islands. Due to the development of OTEC, some islands in the Southern hemisphere achieve independent electricity generation.

Elsewhere, the development of marine energy systems is not advanced. Only the southern part of the French Atlantic coast shows some development of conventional offshore wind turbines (i.e. directly attached to the seabed). They are used mainly for the additional production of freshwater for agriculture to offset recurring shortages in summer. Cold water is also used more often for air-conditioning in new buildings on the seafront and as a cold source for heat pumps.

\section{The consequences for stakeholders}

Industrial firms seize local opportunities to test and perfect the most innovative technologies by targeting those with a large potential worldwide and using them as a commercial showcase. Research remains patchy and highly focused on local constraints with coastal universities supported by the regions playing a prime role. Often victims of their own successful policies, local authorities on the ChannelAtlantic and Mediterranean seafronts, are confronted with unanticipated impacts

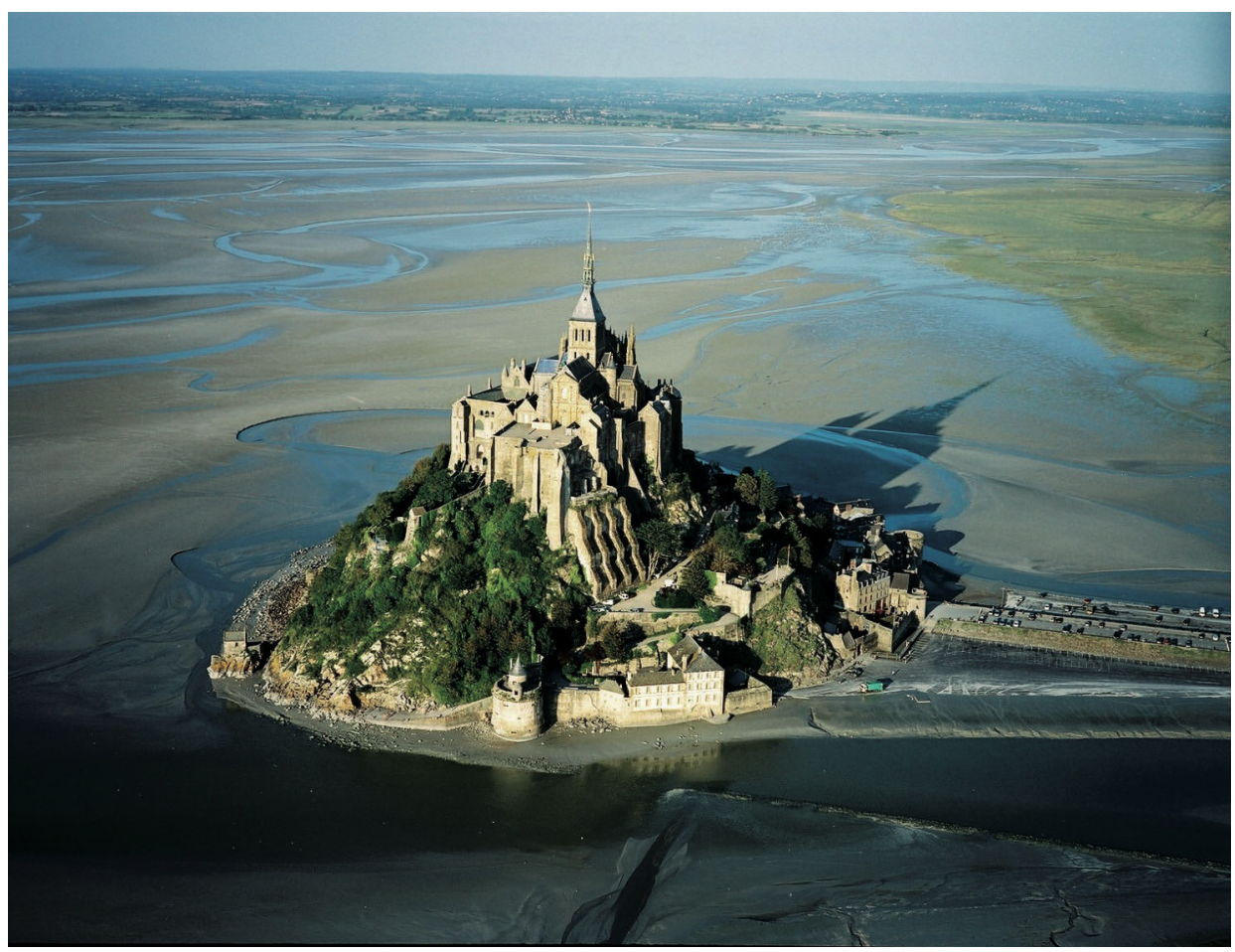

I Photo 16 : coastal planning and development must take account of several constraints including the ecological or heritage value of a site, the Mont-St-Michel Abbey in Normandy shown here (C) Office de tourisme du Mont-St-Michel, www.ot-montsaintmichel.com). 
and conflicts between activities. Effectively, wave power generators create conflict in areas where recreational water sports are practised. Fishermen fear that the vibrations from floating wind turbines will scare away the fish. In addition, the separate development of these technologies by various industrial operators without consultation creates an impression of uncontrolled and experimental development that will turn local populations into 'guinea pigs' and sacrifice their quality of life for the sake of technological progress.

The conflicts create negative feelings about these activities on the part of the large coastal populations looking for quiet, natural settings. This is notably the case for marine energy facilities, which make this last natural space more artificial. As a result, setting up technologies on a given site depends more on the quality of negotiations for social acceptance of the project than on its potential yield.

\begin{tabular}{|c|c|c|c|}
\hline Technology & Development & Installed power & Electrical generation \\
\hline Stream power $(\mathrm{H} 1)$ & $\begin{array}{l}\text { Niche, mainly } \\
\text { outside France } \\
\text { (United Kingdom } \\
\text { and Southeast Asia) }\end{array}$ & $50 \mathrm{MW}$ & 0.2 TWh \\
\hline Tidal power $(\mathrm{H} 3)$ & No development & Same as today $240 \mathrm{MW}$ & 0.6 TWh \\
\hline Wave power $(\mathrm{H} 1+\mathrm{H} 3)$ & $\begin{array}{l}\text { Low to average } \\
\text { development; } \\
\text { nearshore } \\
\text { and isolated sites }\end{array}$ & $150 \mathrm{MWh}$ & $0.45 \mathrm{TWh}$ \\
\hline Biomass (H4) & $\begin{array}{l}\text { Intensive production } \\
\text { on land } \\
\text { GMO multi-applications }\end{array}$ & Five sites 10,000 ha & 1.25 Mtoe \\
\hline $\begin{array}{l}\text { Wind power } \\
(\mathrm{H} 2, \mathrm{H} 1 \text { elsewhere })\end{array}$ & $\begin{array}{l}\text { Average development, } \\
\text { strong in target regions } \\
\text { Floating wind turbines } \\
\text { (Brittany and } \\
\text { Languedoc-Roussillon) } \\
\text { and conventional } \\
\text { wind turbines elsewhere }\end{array}$ & $4000 \mathrm{MW}$ & $12 \mathrm{TWh}$ \\
\hline $\begin{array}{l}\text { Thermal power }(\mathrm{H} 3) \\
\text { Equivalents: } \\
3.5 \mathrm{TWh} \text { cooling } \\
=0.8 \mathrm{TWh} \text { electricity } \\
\text { saved } \\
\text { Water: savings } \\
\text { of } 2 \mathrm{KWh} / \mathrm{m}^{3}\end{array}$ & $\begin{array}{l}\text { Average development } \\
\text { Metropolitan France: } \\
\text { heat pumps } \\
\text { and occasionally cooling } \\
\text { DOM-COM, especially } \\
\text { isolated sites: } \\
\text { air-conditioning, } \\
\text { water and electricity } \\
\text { Local synergy } \\
\text { for aquaculture }\end{array}$ & $\begin{array}{l}10 \text { Units - cooling } \\
80 \mathrm{MW}=800 \mathrm{MW} \\
35 \text { Units - cooling } \\
40-80 \mathrm{MW}=2000 \mathrm{MW} \\
17 \text { Units - electricity } \\
5-20 \mathrm{MW}=115 \mathrm{MW} \\
20 \text { Units - water } \\
\text { of } 500 \mathrm{~m}^{3} / \text { day }\end{array}$ & $\begin{array}{l}6300 \mathrm{GWh} / \text { year } \\
=1.4 \mathrm{TWh} / \text { year } \\
15800 \mathrm{GWh} / \text { year } \\
=3.6 \mathrm{TWh} / \text { year } \\
0.7 \mathrm{TWh} / \text { year } \\
3.3 \mathrm{million} \mathrm{m}^{3} / \text { year } \\
=6.6 \mathrm{GWh} / \text { year }\end{array}$ \\
\hline Osmotic power $(\mathrm{H} 1)$ & Micro-plant pilot project & & \\
\hline & $\begin{array}{l}\text { Total electricity, fuel } \\
\text { and water }\end{array}$ & \multicolumn{2}{|c|}{ 19.1 TWh, 1.25 Mtoe and 3.3 million $\mathrm{m}^{3} /$ year } \\
\hline
\end{tabular}

- Table 24 : marine renewable energy contributions for France in Scenario 4 'Independent local development' 

PART 3

\section{TECHNICAL FILE}

Components and variables

fact sheets 
Photo 17 : transporting the foundation

for a $5 \mathrm{MW}$ offshore wind turbine

on Thornton Bank

(C) Deme, BE).

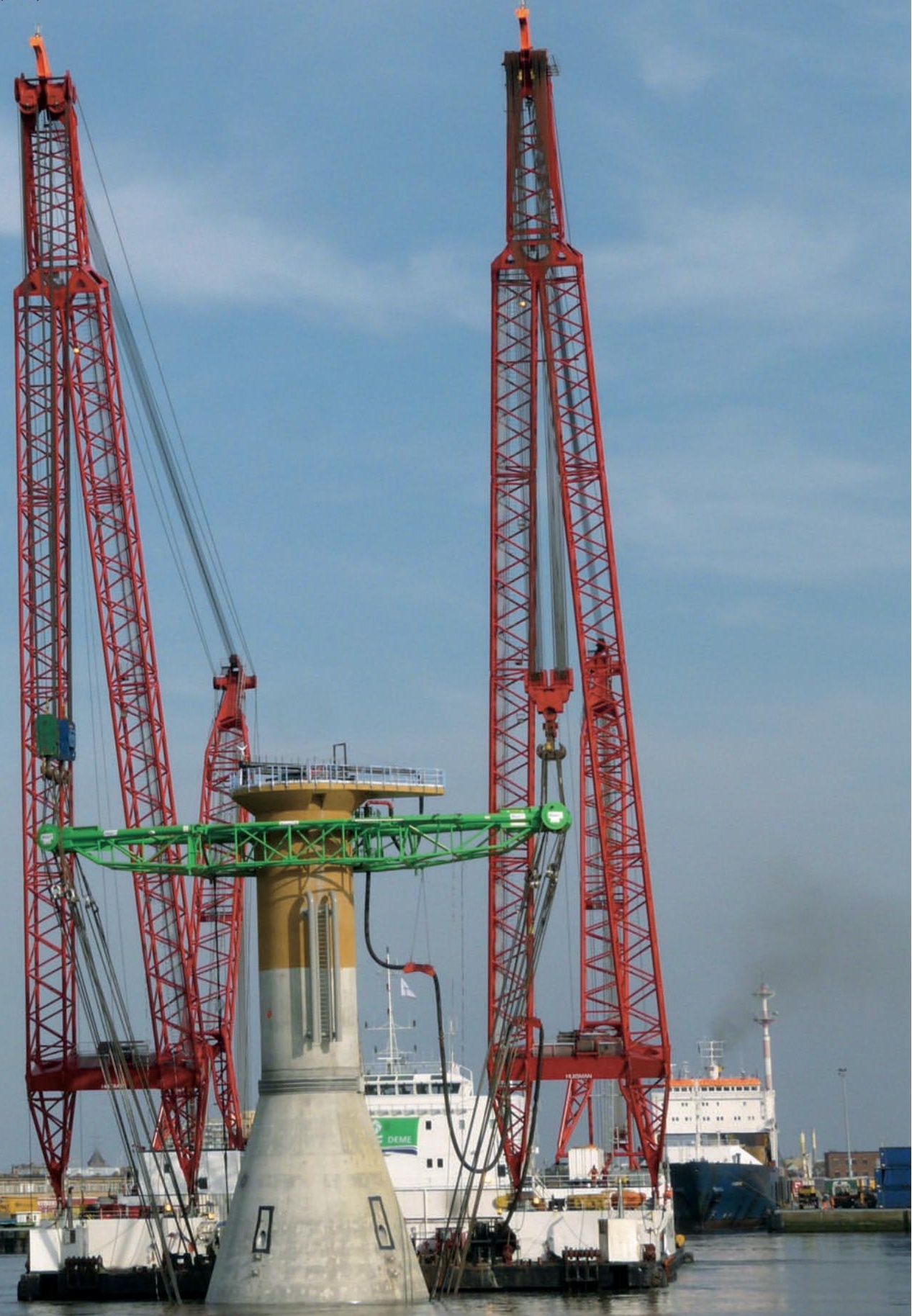




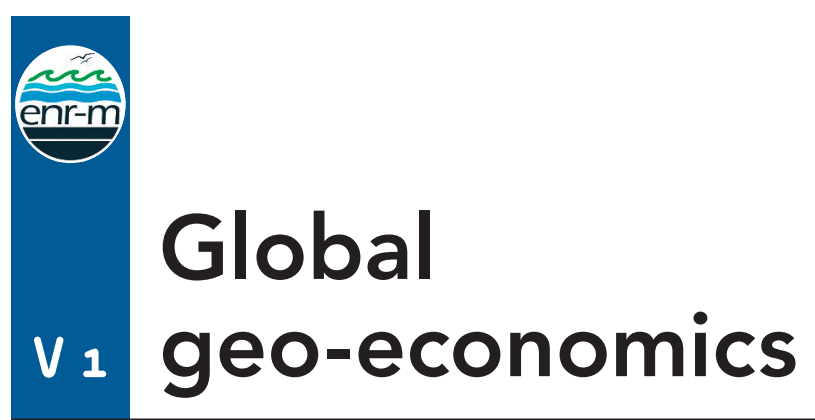

Component: 1. World context

Author: Futuribles (Véronique Lamblin)

\section{Definition}

Trade between countries has existed for centuries, but in the last 30 years it has sharply accelerated and spread to the financial and service sectors. This was made possible by massive reductions in international transport and communications costs.

The world economy has undergone a move towards globalization with the progressive creation of a global market for labour, capital funds, goods and services (Berger, 2003). This has led to a degree of specialization for countries and regions based on their respective 'comparative advantages' such as natural resources, expertise and technologies, specific human resources, etc. Far from being set, however, the global market is changing and shifting increasingly as the so-called 'emerging' countries develop.

\section{Drivers for the variables and the key indicators to describe them are}

- trade between countries/continents and the countries' share of world exports and imports;

- the number of multinational firms and market shares;

- financial exchanges (in percentage of world gross domestic product (GDP)) and amount of investment abroad;

- share in world GDP/in world GDP per inhabitant and trend.

\section{Looking back (over the past 20 years) Globalization}

Historically speaking, globalization actually began with the trade of farm produce and manufactured products, as well as resources from mining, but the percentage made up by each of these categories has changed over the past four decades. Today, manufactured products represent nearly $75 \%$ of trade and agricultural products around $10 \%$. Similarly, the pace of globalization has increased: international trade of goods is currently growing twice as quickly as production. In 50 years, the GDP 
worldwide has grown six-fold, while world trade has multiplied by a factor of 12 . Physical goods are no longer the only products affected by globalization: the trade of services has also grown rapidly. However, today, the phenomenon's main new aspect lies in financial globalization. According to the United Nations Conference on Trade and Development (UNCTAD, 2006), the world inventory of foreign direct investment (FDI) should make up 23.9\% of the GDP worldwide in 2005, compared with 6.7\% in 1980.

Globalization hides another reality, which is the regionalization of trade. The number of regional trade agreements has increased greatly over the past 30 years. The great majority of World Trade Organization (WTO) members belong to one or several regional trade agreements.

\section{Fragmentation of production processes}

The boom in world trade is explained in part by a fragmentation of the production process, or vertical division of labour. From specialization by supply chain or commodity, depending on the country, a shift has taken place to specialization by stage of productive process. Generally speaking, this means that multinational companies have maintained their activities of design, creation and marketing in Europe, Japan or the USA, while relocating their production to China and their data processing services to India (seen in examples like Dell, Nike, etc.).

This division of the added-value chain is particularly evident in the increasing proportion of parts and components in world trade (currently representing almost $16 \%$ of total exchanges). The majority of the exchanges of goods crossing borders involve transnational inter- or intra-enterprise exchanges and only $30 \%$ involve international trade as such. There are currently 77,000 multinational firms (with about 770,000 foreign subsidiaries), and their production is estimated at $25 \%$ of global production.

\section{Focusing of trade on the Triad}

Global trade tends to be focused on three centres of the world economy, also called the Triad, that is, North America, EU15 and Asia. Indeed, the majority of exports and imports worldwide go through these three poles, with the Asian pole growing significantly: from $12.4 \%$ of world exports in 1953 (1.2\% for China), this increased to $27.4 \%$ in 2005 , with China accounting for $7.5 \%$ ).

\section{Specialization of countries and world regions}

In the past 30 years, the main changes have occurred in Asia: China and the Association of Southeast Asian Nations (ASEAN) have specialized in labourintensive sectors (e.g. textiles, wood and electronics).

China and India have followed different growth strategies. China's industrialization has been based on large-scale foreign investments in the manufacturing sector. India's industrialization has been more organic in nature, mainly driven by domestic companies and capital, with little foreign investment until recently. The large private sector firms in India (e.g. Infosys, Wipro, Ranbaxys Reliance, Tata Group, etc.) are world-class, high-tech industries. However, these two models are 
moving closer: China wants to ensure that its companies can compete on a global level and in turn, India has become an attractive proposition for foreign investments, which are contributing to the boom in its manufacturing sector.

China's rapid growth has traditionally been compared with the slower economic development of India. Two researchers from the Brookings Institution have shown that the situation is more complicated (Bosworth and Collins, 2006). Indian growth is relatively strong and is tending to accelerate. In terms of growth factors, growth in China is capital-intensive while total-factor productivity plays a more important role in India.

Japan-Korea has given up its specialization in the textile sector, but holds comparative advantages in products from the second and third industrial revolutions (e.g. vehicles, mechanics and electronics).

EU30 and ALENA (USA, Mexico and Canada) are not highly specialized: EU30 has assets in the second industrial revolution sectors like mechanics, chemicals and vehicles, while, paradoxically, ALENA's strengths lie in the agri-food and mechanics chains.

The international integration of countries in Latin and Central America, Africa and Australia-New Zealand is strongly determined by their natural resources: these regions share a specialization in non-ferrous metals, steelmaking, agri-food and energy. The same is true of the Organization of the Petroleum Exporting Countries (OPEC), whose only involvement in world trade comes from its fossil fuel resources.

The increasing power of some 'emerging' countries, which traditionally exported mostly raw materials and farm produce, can now be observed. Their manufactured product exports have increased since 1960, especially medium- to high-tech products. However, care should be taken with the statistics, because they can include products made by multinational, rather than local, firms.

That said, some activities, like design and research and development (R\&D), which in principle should have remained the prerogative of developed countries, are increasingly being relocated to emerging countries. For instance, Microsoft has opened a research laboratory in Bejing (Courrier international, 2004). R\&D centres are also appearing in India for heavy industry (e.g. General Motors, General Electric, Snecma), the Internet (e.g. Google) or microprocessors (e.g. Intel and Texas Instruments). American companies in the semi-conductor and software (programming) sector have begun to relocate activities with growing added-value to Taiwan, China and India.

Currently, Chinese and Indian groups are buying up large numbers of foreign firms. In a recent report, the Boston Consulting Group considered that no less than 44 Chinese groups ranked amongst the 100 new 'global challengers' from rapidly developing economies' (Boston Consulting Group, 2006). During the first semester of 2006, Indian - multinational companies bought 76 of their European, Asian or US competitors for a total of US $\$ 5.2$ billion (Le Monde, 2006). Foreign direct investments by China, as the main indicator of this phenomenon, are increasing rapidly: in 2005, they reached US\$12.3 billion, making an increase of $123 \%$ from 2004. The official Chinese media have even said that annual outgoing 
fluxes of 'Sino-dollars' will treble between now and 2010. In 2005, FDI by emerging countries reached US\$117 billion, making 17\% of the world total, compared with $10 \%$ in 1982.

\section{What is driving the exports of other developing countries?}

India and China's requirements for raw materials (e.g. oil, ore, lumber, etc.), which fuel growth have been favourable for exports from other developing countries. These are, firstly, oil-producing countries such as the Gulf States and Russia, as well as Venezuela, Algeria, Nigeria and Angola. Countries which export metals (Chile and South Africa) are also in this situation, as are those exporting agricultural produce like cocoa and those whose farming sector is a sales force in itself, like Argentina with its transgenic soyabean or Brazil which, apart from its powerful mining sector, is one of the main cotton and ethanol exporters worldwide. These countries are benefiting from these exports, but the difficulty lies in knowing how to use this situation to prepare for the future. This specialization could evolve to the detriment of a significant manufacturing sector being created. Exploiting natural resources can raise national income, but due to its highly capitalistic nature, it creates very few jobs, particularly for unskilled workers and, therefore, has little impact in terms of reducing poverty. Other countries, which do not export, but on the contrary, must import energy or raw materials, are at a disadvantage.

\section{Outlook (for the next 20 years)}

\section{Economic projections: the world economy will shift to the South}

Economists at Goldman Sachs bank in 2003 and more recently economists at CEPII (the French Research Centre in International Economics) have produced outlook surveys for the global economy by 2050 (Poncet, 2006) (see Appendix). In general, their projections concluded that the advanced economies would see a decline in their influence on the global economy to the benefit of emerging countries, especially China, India, Russia, Brazil or South Korea. The standard of living in some of these countries could catch up to or even exceed that of developed countries by the year 2050 .

However, numerous factors carry some uncertainty for the future of emerging countries, for instance, China must correct the weaknesses in its banking system and India suffers from weak public governance. These two titans will also have to deal with the risk of a shortage of skilled personnel and meet the challenge presented by their ageing populations. The state of its infrastructures and logistics, means and facilities could also make an emerging Asia lose its competitive edge. According to $\mathrm{H}$. Kuroda, the Chairman of the Asian Development Bank (ADB): 'Inadequate transport and communication infrastructure, uncompetitive transport, logistics and industries, and high fuel costs will all push up the cost of doing business in Asia'.

Brazil is one of the countries with the greatest inequalities in the world and must contain both its inflation and public debt. Russia is far from having completed its transition and suffers from being mainly a 'rentier' economy, which is particularly dependent on oil and gas prices. 
Environmental problems can have consequences for economic development. The State agency for environmental protection indicates that pollution levels in China would rise four-fold in the next 15 years if the growth of energy consumption remains constant (Economy, 2005). Thus energy is truly the 'Achilles' heel of Chinese growth (Perelman, 2004). If today, China consumed as much oil per capita as Taiwan; its consumption would be 49 million barrels/day, or $60 \%$ of current world production!

\section{Hypotheses}

\section{Hypothesis 1 \\ Emerging countries catch up to or overtake developed countries}

Emerging countries develop rapidly, due to progress in their institutions and substantial investment in infrastructure. Growth is strongest in China, which has managed to secure its energy and mining supplies. India tries to follow, but continues to trail behind. Europe withdraws into a few high-tech and more affluent market activities, abandoning the rest of its industry, which has undergone massive relocations. It also refocuses on non-technological activities with a strong cultural identity, such as tourism, luxury goods and foods. In every case, its hold on the world market is diminished. The USA is less marginalized because of the high-tech products required by the military and biotechnologies sectors. The dollar's role also helps to maintain the USA's position in the global economy.

\section{Hypothesis 2}

\section{Shared prosperity}

(technology and OECD patents exported to developing countries, which mutually assist each other)

The development of the emerging countries benefits the entire world economy with advantages for other countries, whether developed ones, which help them with engineering, selling patents, etc., or other developing countries, which grow in turn due to their export revenues. Emerging countries are not considered as competitors but rather as the new drivers of the global economy.

\section{Hypothesis 3}

\section{World crisis and every man for himself}

As economic history has shown, downturns have already occurred in globalization, especially during the World Wars. The increase in the number of terrorist attacks, more SARS epidemics or even rising energy prices (particularly oil) could call travel and international exchanges into question. Falling back on protectionism by wealthy countries in order to defend jobs nationally, a recurrent subject on both sides of the Atlantic, could have similar consequences. 


\section{Bibliography}

Berger S., 2003. Notre première mondialisation. Paris, Le Seuil.

Boston Consulting Group, 2006. The New Global Challengers. How 100 Top Companies from Rapidly Developing Countries are Changing the World. Boston: Boston Consulting Group, 32 p. [www.bcg.com/publications/files/New_Global_Challengers_May06.pdf]

Bosworth B., Collins S.M., 2006. Accounting for Growth: Comparing China and India. Working Paper, November 2006. Tokyo: Tokyo Club Foundation for Global Studies.

Courrier International, 24 June 2004. La Chine nouveau laboratoire de Microsoft. No. 712.

Economy E.C, 2005. The River Runs Black: The Environmental Challenge to China's Future. New York: Cornell University Press.

Le Monde, 17 October 2006. Indian Federation of Chambers of Commerce and Industry, quoted in an article entitled 'Le groupe indien Tata Steel prêt à racheter le sidérurgiste Corus'.

Perelman R., 2004. L'énergie, talon d'Achille de la croissance chinoise. No. 296. Paris: Futuribles.

Poncet S., 2006. The Long Term Growth Prospects of the World Economy: Horizon 2050, Working document, October 2006. Paris: Centre d'études prospectives et d'informations internationales. (Tables in this fact sheet are taken from this document.) [http://www. cepii.fr/anglaisgraph/workpap/pdf/2006/wp06-16.pdf]

UNCTAD, 2006. World Investment Report. [http://www.unctad.org]

Wilson D., Purushothaman R., 2003. Dreaming With BRICs: The Path to 2050. New York: Goldman Sachs, 23 p. [www.gs.com/insight/research/reports/report6l] 


\section{Appendix}

\section{Economic projections}

\section{Goldman Sachs}

The economists at Goldman Sachs bank made a study in 2003, which is often given as a reference [10]. According to this study, the countries in the 'BRIC'group (Brazil, Russia, India and China) will dominate the world economy in 2050, with a GDP higher than that of the USA, Japan and European countries together (the G6).

This conclusion is not based on simply extrapolating the current GDP growth rates in the countries, but on projections made using a model, which combines the latest projections of the active population in each country with hypotheses on trends in capital accumulation and total-factor productivity. The underlying idea is that they will catch up to developed countries, in technological terms, at varying speeds depending on the countries in question and that their growth rate will steadily slow down as their development progresses.

\begin{tabular}{|c|c|c|c|c|}
\hline & Brazil & China & India & Russia \\
\hline $2000-2005$ & 2.7 & 8 & 5.3 & 5.9 \\
\hline $2005-2010$ & 4.2 & 7.2 & 6.1 & 4.8 \\
\hline $2010-2015$ & 4.1 & 5.9 & 5.9 & 3.8 \\
\hline $2015-2020$ & 3.8 & 5 & 5.7 & 3.4 \\
\hline $2020-2025$ & 3.6 & 3.5 & 5.6 & 2.2 \\
\hline $2025-2030$ & 3.4 & 2.9 & 5.2 & 1.9 \\
\hline
\end{tabular}

I Table 1.1 : annual mean GDP growth rates of large emerging countries up to 2030. Source: Goldman Sachs

However, the gap in terms of GDP per capita will remain wide, all the more so in that GDP per capita in the G6 countries will continue to grow.

\begin{tabular}{|c|c|c|c|c|c|c|c|c|c|c|}
\hline & \multicolumn{4}{|c|}{ BRIC } & \multicolumn{9}{c|}{ G 6 } \\
\hline & Brazil & China & India & Russia & France & Germany & Italy & Japan & $\begin{array}{c}\text { United } \\
\text { Kingdom }\end{array}$ & USA \\
\hline 2000 & 4438 & 854 & 468 & 2675 & 22,078 & 22,814 & 18,877 & 32,960 & 24,142 & 34,797 \\
\hline 2030 & 9823 & 9809 & 3473 & 22,427 & 35,876 & 33,898 & 30,177 & 49,944 & 41,194 & 57,263 \\
\hline
\end{tabular}

Table 1.2 : GDP per capita in large countries in the world in 2000 and 2030. Source: Goldman Sachs 
However, these projections should be taken with some sceptism, since the model describes potential growth rates, that is, what would happen if the appropriate conditions fall into place, which is far from being the case today. The authors themselves admit: 'There is a good chance that... the projections will not be realized'.

\section{I CEPII}

In 2006, the CEPII centre for prospective studies and international information drew up an estimate for the world economy's outlook by 2050. According to projections, advanced economies would see their influence in the world economy decline to the advantage of Asian countries, particularly China, India and South Korea. The rise in standard of living in some Asian countries could catch up with or even overtake that in developed countries.

These projections are based on a growth model which depends on the number of hours worked, the capital stock and the level of total-factor productivity. In this model, as in all neoclassical models, greater productivity is the main source of economic growth and income per capita, assuming that there will be wider dissemination of technology.

The USA remains the top-ranking global economic power on the horizon of the year 2050. China (and to a lesser degree, India) will take a growing share, as its economy develops. By 2050, its growth rate should be slightly higher than that of India. Its GDP remains three times higher than India's, if the currency exchange effect is not taken into account and 4.6 times higher in 2050, if the effect is included. China would be the second global economic power in 2050.

The performances of Brazil, and South America more generally, will be disappointing. Brazil will experience fairly limited growth, with respect to its emerging economy status. Over the period in question, its mean annual growth in GDP would be $1 \%$. This mediocre performance could be due to the combination of soft demographics, weak investment, low levels of education and a negative regional effect on total-factor productivity. Combined with an unfavourable exchange-rate effect, it will experience a steady decline of its world economy weight over the period.

Compared with that of the USA, the GDP per capita declines in some developed countries and strongly increases in some developing countries. In developed countries, the relatively weak growth, especially in the second half of the projection, will have a detrimental effect on standard of living trends. On the contrary, in some emerging countries, particularly in Asia (South Korea, Singapore and Hong Kong), the rise in standard of living could even go so far as to overtake that of the USA by the end of the period.

The outcomes of these crisis-free linear projections must be taken with all due reserve, since economic history shows that changes often take place through crises, notably in finance and foreign trade. In addition, the scenarios do not give any indication of the stumbling-blocks which may be encountered in coming years. Yet, in both developed and developing countries, there are many potential obstacles to growth. 


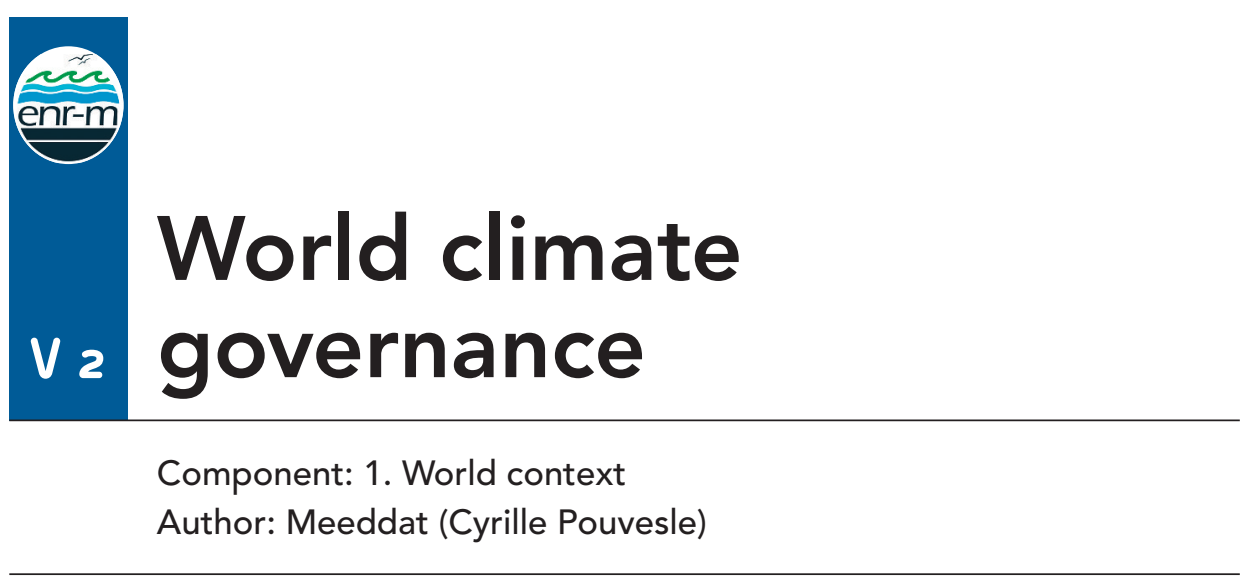

\section{1- Definition}

The variable involves setting up a world governance system which would make it possible to:

- recognize that global warming is occurring and due in part to human activities;

- define a desirable scenario;

- set objectives for reducing greenhouse gas emissions and developing relevant technologies;

- implement global tools that will enable these objectives to be fulfilled.

The governance system is based on a series of texts and laws (i.e. treaties, protocols, conventions and partnerships), which have been drawn up, signed and ratified.

\section{Looking back (over the past 20 years)}

\section{Climate stakes}

According to the fourth report by the Intergovernmental Panel on Climate Change (IPCC), the global temperature rose by $0.74^{\circ} \mathrm{C}$ between 1906 and 2005 . The global atmospheric concentration of carbon dioxide increased from a pre-industrial value of $280 \mathrm{ppm}$ to $379 \mathrm{ppm}$ in 2005 and a $430 \mathrm{CO}_{2}$ equivalent if all greenhouse gases are taken into account. The atmospheric concentration of greenhouse gases should increase by about 4 ppm/year in the next 30 years. If efforts are not made to reduce it, the concentration would then reach $550 \mathrm{ppm}$ $\mathrm{CO}_{2}$ eq in 2035 and $650 \mathrm{ppm} \mathrm{CO}$ eq in 2050 . Over the next 20 years, about $0.2^{\circ} \mathrm{C}$ warming per decade is projected.

The IPCC states that if no action is taken, by 2100 the increase could be from 1.8 to $4^{\circ} \mathrm{C}$, compared with current temperatures (mean for 1980-99). These predictions are significant on a global scale, since in comparison, it is estimated that the 
temperature difference between an inter-glacial period (like today) and a glacial era is from $5^{\circ} \mathrm{C}$ to $6^{\circ} \mathrm{C}$. The rise in sea level would be between 18 and $59 \mathrm{~cm}$. In 2100 , these levels would not be at equilibrium, since the rise in temperature and sea level will continue into the following centuries.

\section{Climate governance}

Today, international governance for the climate is based on two ground-breaking treaties: the Climate Change Convention and the United Nations Framework Convention on Climate Change (UNFCCC), which was adopted in 1992 and came into force in 1994. As of today, it has been ratified by 189 countries including the USA and Australia.

\section{The Climate Change Convention}

The Climate Change Convention is the key international treaty, providing the basis for all global co-operation on the climate. It acknowledges the existence of climate change and has set the objective of stabilizing greenhouse gas concentrations in the atmosphere at 'a level that would prevent dangerous anthropogenic interference with the climate system'. It takes several guidelines as a basis for action: their common but distinct responsibilities and the precautionary principle.

All parties to the Convention have shared commitments:

- establishing national inventories of emissions;

- implementing national policies to reduce greenhouse gas emissions and measures designed to facilitate adequate adaptation;

- promoting sustainable management and the conservation and enhancement of sinks and reservoirs (especially forests);

- co-operating to prepare for adaptation to the impacts of climate change.

In addition, developed countries have their own objectives:

- adopting national policies to bring 2000 greenhouse gas emissions into line with 1990 levels;

- assisting the developing countries that are particularly vulnerable in meeting the costs of adaptation;

- providing financial resources to developing countries to enable them to meet their commitments, particularly in terms of inventories;

- promoting, facilitating and financing, as appropriate, the transfer of, or access to, environmentally sound technologies.

The Climate Change Convention does not provide for penalties for non-compliance. In 1992, the realization that developed countries would not achieve their reduction targets in 2000 led to negotiations on a more binding instrument. This was the Kyoto Protocol.

\section{The Kyoto Protocol}

The Kyoto Protocol was negotiated in 1997 and is the daughter treaty to the Climate Change Convention. It was opened for signature on 16 March 1998 and came into force in February 2005 following ratification by Russia. A political agreement on the protocol's operational rules was reached at the Seventh 
Conference of the Parties in Marrakech in 2001. As of 1 January 2007, the protocol had been ratified by 165 countries but neither the USA nor Australia has signed it. The Kyoto Protocol is based on a relatively simple principle: developed countries and those undergoing the process of transition to a market economy (37 so-called Annex $\mathrm{B}$ countries ${ }^{21}$ ) are committed to a global target reducing their emissions of six greenhouse gases $\left(\mathrm{CO}_{2}, \mathrm{CH}_{4}, \mathrm{~N}_{2} \mathrm{O}, \mathrm{HFC}, \mathrm{PFC}, \mathrm{SF}_{6}\right)$ by $-5.2 \%$ in 2008-12 compared with their 1990 levels. Each country then undertook to meet its own reduction objective: some have set lower objectives $(-7 \%$ for the USA, $-6 \%$ for Japan) and others have raised theirs (+8\% for Australia, $+10 \%$ for Iceland). The countries set their targets in relation to projected emission growth, their capacity to pay and their political commitment to fighting climate change. EU15 agreed a collective target to reduce emissions by $-8 \%$ (called the 'European bubble'), within which each EU Member States then decided how they would spread the constraints. Germany's target is a $-21 \%$ reduction, United Kingdom's is $-12.5 \%$, Italy's $-6.5 \%$, while France aims to stabilize emissions at $0 \%$ and Spain will raise them by $+15 \%$.

To assess the actual scope of these commitments, it must be remembered that the Kyoto Protocol was negotiated in 1997. At that date, some countries' emissions already greatly exceeded the 1990 levels. The objectives for the USA, Canada and Japan involved reductions of about -15\% from the 1996 level. The EU's objective was a reduction of only $-6.2 \%$ with respect to 1996 . Russia's target was $+54 \%$ higher than its 1996 emissions! All the countries in transition were in the same situation, since their emissions had sharply decreased after 1990, following industrial restructuring created by the collapse of the former USSR. During the Kyoto negotiations in 1997, the developed countries granted these countries surplus quotas so that they would ratify the agreement.

The $-5.2 \%$ target set by the protocol actually represents a decrease of approximately $-20 \%$ compared with the level of emissions expected in 2010 if no measure to control them had been adopted. The protocol was above all designed to be a first step in getting emission reduction under way. Changing the trend is more important than the target itself.

The protocol provides for three flexible mechanisms in order to reach its objective:

- emissions trading between countries which have made commitments;

- the possibility of acquiring credits for emission-abatement projects in other developed countries (joint implementation, $\mathrm{JI}$ ) or in developing countries which have ratified the protocol (clean development mechanism, CDM); in CDMs, units are created ex nihilo, which requires greater control;

- a mechanism in the case of non-compliance (also called 'observance').

Creating a price for carbon is a key innovation of the Kyoto Protocol, since it guarantees the agreement's cost-effectiveness. This provides a benchmark for national policies. The market can separate effectiveness and equity. It is econom-

21. Three countries listed in Annex 1 of the Climate Change Convention, Belarus, Croatia and Turkey, are not in Annex B of the Kyoto Protocol. 
ically effective to reduce emissions in countries in transition or in developing countries, since the marginal cost of abatement will be low. Moreover, in the CDM system, these reductions are mostly paid for by the developed countries, which historically are accountable for these emissions.

Trading separates the primary assigned emission rights from the final breakdown of emissions made, which enables objectives of redistribution to be taken into account when the rights are shared. The protocol willingly provokes financial transfers between developed countries and those in transition, with the aim of equity. This was the condition which made countries in transition (like Russia) consent to join the wealthy countries in signing the protocol.

In the compliance mechanism, countries which are not in compliance must establish an implementation plan. In addition, over the next commitment period they must return quotas equal to 1.3 the amount which was not returned in 2008-12. This mechanism gives the international permit market credibility. However, some feel that this is an illusion, in that the international treaties intrinsically work on the basis of voluntary action. Countries are sovereign and may withdraw from the agreement at any time.

\section{Special partnerships}

The AP6 or APP (Asia-Pacific Partnership on clean development and climate change) aims to promote public-private sector co-operation for clean power technologies and fight global warming without any binding reduction targets. The Australian and US-led initiative was announced in July 2005 and officially launched in January 2006; it also includes China, India, Japan and South Korea.

\section{Differences between countries}

\section{Europe}

At the EU summit meeting in March, Europe confirmed its will to reach the strategic objective of 'limiting global warming to a maximum of $2^{\circ} \mathrm{Celsius}$ as compared with the pre-industrial level'.

\section{The USA}

The USA ratified the Climate Change Convention, but not the Kyoto Protocol. Although the US administration is reserved with respect to agreements setting specific target figures (for reduction of greenhouse gas emission or rising temperatures) and rejects systems involving binding quotas 22 , President Bush declared at the meeting of the G8 that he wanted closer negotiations with 15 countries (the main polluters) with conclusions to be produced in 2008.

The purpose of these meetings is said to be to find new principles for fighting greenhouse gases. Each country would then develop its own targets and strategies (as opposed to a treaty like that negotiated at the UN, which set similar targets for all countries). The G8 conclusions do, however, represent a move towards linking these closed-circle discussions to the worldwide discussions,

22. One of the reasons for this is that the USA is not in compliance with the emissions quota and will have to buy heat from Russia, which has a large surplus. 
which continue in the framework of the Climate Change Convention. The USA primarily relies on investing in research in their fight to reduce the greenhouse effect.

\section{China}

China ratified the protocol in 2002. Like other developing countries, China is not on the protocol's Annex B list and is thus not subject to reduction requirements for the initial commitment period (2008-12). Of the 194 countries in the UN, only 39 have commitments.

Negotiations have begun for the second commitment period. China has contradictory concerns in these negotiations. On the one hand, it will become the biggest emitter of greenhouse gases (in absolute terms, although not per capita) and will have to establish standards to protect its environment, since it fears the consequences of climate change on its territory. On the other hand, it wants the same unhindered access to economic development that the developed countries have enjoyed. Thus, developing countries demand that the developed countries set an example and first reduce their own emissions before requiring them to make reductions (principles of historical accountability and shared but distinct responsibility).

\section{Outlook}

The Kyoto Protocol will reach full-term in 2012. Some of the uncertainties about climate governance concern the period after 2012 and also 'non-protocol' initiatives, such as the APP.

\section{After Kyoto: the 'post-2012' period}

The conference of UN ministers, which was held in Nairobi in 2006, showed that the key countries for climate negotiations were not ready to progress on what should follow the Kyoto Protocol. However, recent declarations from developing countries (e.g. South Africa, Brazil) and the conclusions of the G8 tended to show a certain will to set up a 'mandate to negotiate' at the Bali conference (2007) in order to reach an international agreement by 2009 at the latest. A change in the administration in Washington may also be foreseen for that year.

\section{Partnership}

President Bush's proposal to develop a special partnership with the 15 most industrialized countries (producing more than $80 \%$ of emissions), where there will be no question of binding targets before late 2008 could weaken the 'post-2012' negotiation. The main possible hypotheses are thus structured around the following uncertainties:

- the outcome of the Kyoto Protocol (e.g. emissions market, compliance with objectives, CDM, JI);

- negotiations for the second protocol (e.g. reduction targets, ratifying countries);

- other, US-initiated, partnerships. 


\section{Hypotheses}

\section{Hypothesis 1 \\ Kyoto II with the USA and China}

'Post-2012' negotiation leads to targets based on proposals from the EU, and the USA joins the process once the new President is elected. Following the USA's engagement, China also follows. The new negotiation makes it possible for the emissions market to work as it should and thus incites States to take measures to reduce greenhouse gas emissions.

\section{Hypothesis 2}

Kyoto II quota market the same as Kyoto I

'Post-2012' negotiations lead to moderately ambitious targets, based on a compromise. The USA does not want to join the process and creates a club of countries producing a large percentage of emissions in a parallel approach. The emissions market does not really work and the objectives are not shared.

\section{Hypothesis 3}

\section{Regional technological partnership agreements}

The Kyoto Protocol fragments: the countries that do not fulfil their commitments are not punished and the emissions market does not work. The USA develops a special partnership for research. Europe tries to meet these objectives in order to stay competitive. 


\section{Energy demand, including Europe $v_{3}$ by region}

Component: 1. World context

Author: Futuribles (Véronique Lamblin)

\section{1- Definition}

Energy demand in the world's major regions, including Europe; uses which drive the energy demand; trends for energy sources by use.

\section{Key indicators}

- Consumption of primary energy and final energy broken down by region.

- Share of various energy resources used, by region.

- Energy sources by use.

\section{Looking back (over the past 20 years)}

The demand for energy first began to rise in industrialized countries to support their development. It is now increasing above all in developing countries.

While the Organization for Economic Co-operation and Development (OECD) countries account for the majority of global energy consumption, their proportion is slowly but steadily decreasing in favour of Asia and more specifically, China.

In terms of primary energy, the world consumption came mainly from oil, gas and coal, $86 \%$ in 1973. This percentage decreased to a little over $80 \%$ in 2004 . This trend is mainly due to the development of nuclear power.

\section{Increased energy efficiency}

Although global and per capita consumption is on the rise, energy consumption and economic activity are somewhat disconnected. Beyond a given critical threshold for development, an economy will need less energy per additional gross domestic product (GDP) unit.

In the OECD, energy intensity (total supply of primary energy per GDP unit) has decreased by a little over $16 \%$ since 1980 . The decline in energy intensity slowed after 1985 (with the return to real oil prices that were lower than those in the period 
preceding the oil crises), however, the fall in price did not result in strong rises in consumption. The impact of the 1973-74 and 1979 oil shocks, the tertiarization of the economy, technology innovations and the promotion of lasting energy-saving behaviours all led to this improved energy efficiency. The oil shocks led to greater diversification in energy consumption, particularly in favour of gas and nuclear power in rich countries and a $10 \%$ decrease in oil consumption, which took 15 years to return to the pre-crisis level.

\section{Outlook (for the next 20 years)}

Higher world energy demand seems inevitable by 2030 because of:

- population growth;

- industrialization of developing countries;

- inertia of consumption/production systems.

If the observed growth trends are sustained, the International Energy Agency (IEA) predicts that world growth will rise by slightly more than half between now and 2030 , with an average annual rate of $1.6 \%$. By 2015, it will have increased by over $25 \%$. Over $70 \%$ of the rise in demand during this period will most likely be due to the developing countries whose demand should grow by $2.4 \%$ annually. The growth of Chinese demand will be even greater, at 3\%. In fact, the economic development and population growth of these countries will progress faster than in OECD countries, which will displace the centre of gravity of world energy demand.

\section{Sector-based polarization}

Nearly $50 \%$ of the growth of global primary energy consumption is absorbed by electricity generation ( $+2.6 \%$ annually), and $20 \%$ by the non-electricity-based transport sector ( $+1.8 \%$ annually). The latter is almost entirely fed by oil-related fuels (+1.7\% annually) in the IEA's trend-based scenario.

The IEA proposes two scenarios: one is trend-based, called the reference scenario, and the other is an alternative scenario based on greater energy control, both for energy security and reduction of greenhouse gas emissions. In the alternative scenario, primary energy consumption is reduced by $10 \%$ compared with the reference scenario by 2030 . This scenario enables greenhouse gas emissions to be $16 \%$ lower than those in the trend-based reference script; however, these emissions will still be higher in volume, increasing from 26 Gt/year in 2004 to $32 \mathrm{Gt} /$ year by 2030. In both cases, the world population increases from 6.4 billion in 2004 to 8.1 billion by 2030 .

In the alternative policy scenario from the IEA, the policies and measures that governments are currently considering aimed at enhancing energy security and mitigating carbon dioxide emissions are assumed to be implemented. This would result in significantly slower growth in demand: $+1.2 \%$ annually instead of $+1.6 \%$ worldwide between 2004 and 2030, 0.7\% in North America rather than 1.1\%, 0.5\% in the EU instead of $0.7 \%$, and $2.3 \%$ in China instead of $2.9 \%$. In this alternative scenario, annual coal and oil consumption grows by $0.9 \%$ annually against respectively, $1.8 \%$ and $1.3 \%$ in the reference scenario (for gas, $2 \%$ to $1.5 \%$ annually). In the reference script, renewable energies make up nearly $14 \%$ of primary energies 
(renewables or RES and nuclear power 18\%) compared with $13 \%$ today $(19.5 \%$ RES and nuclear power). In the alternative scenario, RES represent $16 \%$ of primary energy generation (RES and nuclear power 23\%).

\section{Europe}

The European report ${ }^{23}$ on energy consumption trends is very close to the IEA's reference scenario, since the difference in primary energy consumption is less than 100 out of 1900 Mtoe and the increase in final consumption is only 25\%. Gas and renewables are the energy sources which increase most in response to demand over the period in question. It is mostly demand for electricity, both for the service sector and for comfort in homes 24 that drives energy demand. The demand for energy for transport rises until 2010-15, then becomes more stable.

The report for EU25 takes the hypothesis that no additional political or regulatory measures are applied beyond those already implemented in late 2004, and that trends for energy efficiency or renewable energies continue (the rate for electricity generation from renewables is derived from the model, that is, $18 \%$ in 2010 , and is not the EU target of $21 \%$ by 2010 ) without reaching any specific objectives. It is also hypothesized that car-makers will reach the $140 \mathrm{~g}$ carbon dioxide/ $\mathrm{km}$ target on average for new vehicle sales by 2009, that the EU15 countries which have made the decision to withdraw from nuclear power, will do so after 2020, and plants are replaced in part by coal-fired plants, because of the high cost of oil and gas: demand for gas increases while that for coal decreases until 2020, and then the situation reverses. The renewables share increases from 4.4\% of energy consumption to $12 \%$ by 2030 .

\begin{tabular}{|l|c|c|c|c|}
\multicolumn{1}{|c|}{$\begin{array}{c}\text { World primary energy } \\
\text { consumption (Gtoe/year) }\end{array}$} & 1980 & 2004 & 2015 & 2030 \\
\hline IEA trend-based reference & 7260 & 11205 & 14070 & 17100 \\
\hline IEA alternative scenario (-10\%) & 7260 & 11205 & 13540 & 15400 \\
\hline $\begin{array}{l}\text { ISO per capita consumption } \\
\begin{array}{l}2004-30 \\
\text { (Reference-17\%) }\end{array}\end{array}$ & 7260 & 11205 & 12800 & 14200 \\
\hline $\begin{array}{l}\text { Strong economy and renewables } \\
\text { (Reference-20\%) }\end{array}$ & 7260 & 11205 & 12500 & 13700 \\
\hline
\end{tabular}

- Table 3.1 : World primary energy consumption by region from 1971 to 2004 (Source: World Energy Outlook 2006@OECD/IEA, 2006. The first line corresponds to the WEO table "World primary energy demand in the reference scenario" (WEO 2006 p.66) but the figures are rounded off (original figures were 7,261 for 1980, 11,204 for 2004, 14,071 for 2015 and 17,095 for 2030). In the second line, the figures for 1980 and 2004 are from the same reference as line 1 and figures for 2015 and 2060 come from the "World Energy Demand in the Alternative Scenario" table in WEO 2006, on p.173, but are also rounded off (original figures were 13,537 for 2015 and 15,405 for 2030). The last two lines are Futuribles' calculations for 2015 and 2030 based on figures for 2004 published in the previously mentioned WEO 2006.

23. http://ec.europa.eu/dgs/energy_transport/figures/trends_2030_update_2005

24. Hypothesis under which the number of households rises by $25 \%$, combined with more electrical appliances and air-conditioning, leads to increased demand for electricity of $+83 \%$ for the residential sector between 2000 and 2030. 


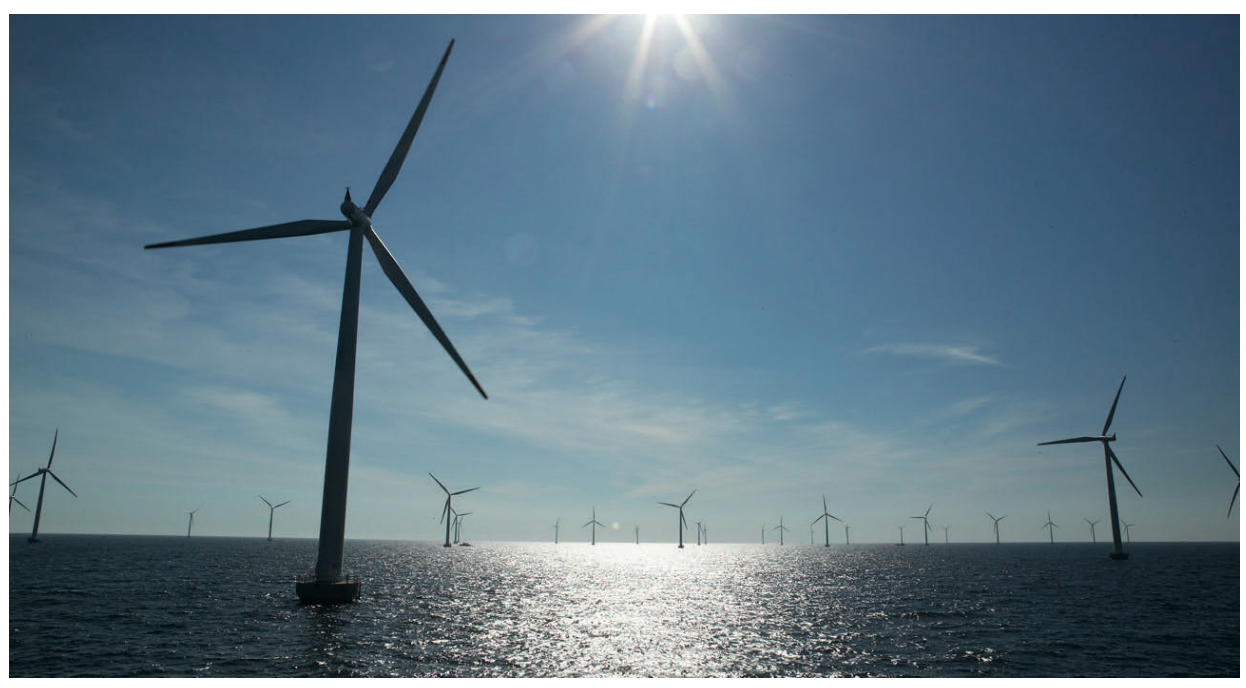

I Photo 18 : Horns Rev offshore wind farm in Denmark (160 MW). The country aims to cover $40 \%$ of its electricity requirements using offshore wind by 2030 (C Dong Energy, DK).

The European objective for 2020 is that the renewable share reaches $20 \%$, that energy efficiency be improved by $20 \%$ and that biofuels make up $10 \%$ of fuels used for transport. These objectives are not reached in the IEA's alternative scenario, in which renewables account for $16.8 \%$ of EU energy consumption by 2030 and biofuels make up 9\% of all fuels used.

The IEA alternative scenario does not enable European political objectives to be reached, so it is suggested that it be considered as a second hypothesis. 


\section{Hypotheses}

Hypothesis 1

IEA trend-based reference scenario (see Appendix)

\section{Hypothesis 2}

Reference $-17 \%$, that is $25 \%$ of primary energy with nuclear and RES (biomass), making a global demand of 14.2 Gtoe/year of primary energy by 2030

In this scenario, non-carbon dioxide energy accounts for $25 \%$ of primary energy (mainly biomass and nuclear power). This is compatible with peak oil production of 100 million barrels/day as suggested by the experts at the Association for the Study of Peak Oil (ASPO) ${ }^{25}$. This scenario also enables global greenhouse gas emissions to stabilize around 2015.

\section{Hypothesis 3}

Given the inertia of energy generation and consumption systems, it is difficult to go beyond the IEA's reference scenario of $-20 \%$

However, the hypothesis of a very small increase in energy consumption (or even a reduction per capita) would be compatible with prices of fossil fuels rising sharply (comparable with those in earlier oil crises) and a substantial effort to reduce energy consumption, particularly in rich countries but also in countries like China. The large decrease in consumption lets low-power renewables penetrate the market more rapidly for some uses. It also enables limited storage capacity to be used to compensate for intermittent supply (e.g. light emitting diode lighting supplied by photovoltaic rechargeable batteries). 


\section{Appendix}

\section{Past energy consumption and estimates for 2015 and 2030 in major world regions}

\begin{tabular}{|l|r|r|r|r|r|r|c|}
\hline \multicolumn{1}{|c|}{ North America } & 1971 & 1990 & 2004 & 2015 & 2030 & $\begin{array}{r}\text { AMGR } \\
1971-2002\end{array}$ & $\begin{array}{c}\text { AMGR } \\
2004-30\end{array}$ \\
\hline $\begin{array}{l}\text { Final energy consumption } \\
\text { (Mtoe) }\end{array}$ & 1388 & 1552 & 1906 & 2218 & 2506 & 0.9 & 1.1 \\
\hline $\begin{array}{l}\text { Fuels for transport - oil } \\
\text { (Mtoe) }\end{array}$ & 402 & 556 & 713 & 831 & 952 & 1.8 & 1.7 \\
\hline $\begin{array}{l}\text { Fuels for transport - biofuels } \\
\text { (Mtoe) }\end{array}$ & & 0 & 7 & 21 & 24 & & 0.6 \\
\hline $\begin{array}{l}\text { Fuels for transport - total } \\
\text { (Mtoe) }\end{array}$ & 420 & 575 & 738 & 871 & 996 & 1.7 & 4.9 \\
\hline Electricity (TWh) & 1956 & 3809 & 4970 & 5999 & 7255 & 2.9 & 1.2 \\
\hline
\end{tabular}

\begin{tabular}{|c|c|c|c|c|c|c|c|}
\hline Japan & 1971 & 1990 & 2004 & 2015 & 2030 & $\begin{array}{c}\text { AMGR } \\
1971-2002\end{array}$ & $\begin{array}{c}\text { AMGR } \\
2004-30\end{array}$ \\
\hline $\begin{array}{l}\text { Final energy consumption } \\
\text { (Mtoe) }\end{array}$ & & 306 & 354 & $\begin{array}{l}383 \\
373\end{array}$ & $\begin{array}{l}391 \\
365\end{array}$ & & $\begin{array}{l}0.4 \\
0.1\end{array}$ \\
\hline $\begin{array}{l}\text { Fuels for transport - oil } \\
\text { (Mtoe) }\end{array}$ & & 74 & 92 & $\begin{array}{l}96 \\
93\end{array}$ & $\begin{array}{l}95 \\
88\end{array}$ & & $\begin{array}{r}0.1 \\
-0.2 \\
\end{array}$ \\
\hline $\begin{array}{l}\text { Fuels for transport - biofuels } \\
\text { (Mtoe) }\end{array}$ & & 0 & 0 & $\begin{array}{l}0 \\
1\end{array}$ & $\begin{array}{l}1 \\
2\end{array}$ & - & \\
\hline $\begin{array}{l}\text { Fuels for transport - total } \\
\text { (Mtoe) }\end{array}$ & & 76 & 94 & $\begin{array}{l}98 \\
96\end{array}$ & $\begin{array}{l}98 \\
92\end{array}$ & & $\begin{array}{r}0.2 \\
-0.1\end{array}$ \\
\hline Electricity (TWh) & & 838 & 1071 & $\begin{array}{l}1208 \\
1161\end{array}$ & $\begin{array}{l}1280 \\
1142\end{array}$ & & $\begin{array}{l}0.7 \\
0.2\end{array}$ \\
\hline
\end{tabular}

\begin{tabular}{|l|r|r|r|r|r|r|c|}
\hline \multicolumn{1}{|c|}{ EU } & 1971 & 1990 & 2004 & 2015 & 2030 & $\begin{array}{c}\text { AMGR } \\
1971-2002\end{array}$ & $\begin{array}{c}\text { AMGR } \\
2004-30\end{array}$ \\
\hline \begin{tabular}{l|r|r|r|r|r|} 
Final energy consumption \\
(Mtoe)
\end{tabular} & 892 & 1086 & 1244 & 1380 & 1504 & 0.9 & 0.7 \\
\hline $\begin{array}{l}\text { Fuels for transport - oil } \\
\text { (Mtoe) }\end{array}$ & 149 & 273 & 351 & 374 & 394 & 2.7 & 0.5 \\
\hline $\begin{array}{l}\text { Fuels for transport - biofuels } \\
\text { (Mtoe) }\end{array}$ & - & 0 & 2 & 18 & 27 & - & 0.4 \\
\hline $\begin{array}{l}\text { Fuels for transport - total } \\
\text { (Mtoe) }\end{array}$ & 155 & 279 & 361 & 401 & 434 & 2.6 & 10.5 \\
\hline Electricity (TWh) & 1296 & 2444 & 3154 & 3673 & 4303 & 2.7 & 0.7 \\
& & & & 3484 & 3681 & & 11.7 \\
\hline
\end{tabular}




\begin{tabular}{|l|c|c|c|c|c|c|c|}
\hline \multicolumn{1}{|c|}{ Russia } & 1971 & 1990 & 2004 & 2015 & 2030 & $\begin{array}{c}\text { AMGR } \\
1971-2002\end{array}$ & $\begin{array}{c}\text { AMGR } \\
2004-30\end{array}$ \\
\hline $\begin{array}{l}\text { Final energy consumption } \\
\text { (Mtoe) }\end{array}$ & - & - & 425 & 494 & 561 & - & 1.1 \\
\hline $\begin{array}{l}\text { Fuels for transport - oil } \\
\text { (Mtoe) }\end{array}$ & - & - & 54 & 68 & 78 & - & 0.7 \\
\hline $\begin{array}{l}\text { Fuels for transport - biofuels } \\
\text { (Mtoe) }\end{array}$ & - & - & 0 & 0 & 0 & - & 1.4 \\
\hline $\begin{array}{l}\text { Fuels for transport - total } \\
\text { (Mtoe) }\end{array}$ & & - & 95 & 119 & 139 & - & 11.5 \\
\hline Electricity (TWh) & & - & 926 & 1104 & 1324 & - & 1.6 \\
\hline
\end{tabular}

\begin{tabular}{|c|c|c|c|c|c|c|c|}
\hline China & 1971 & 1990 & 2004 & 2015 & 2030 & $\begin{array}{c}\text { AMGR } \\
1971-2002\end{array}$ & $\begin{array}{l}\text { AMGR } \\
2004-30\end{array}$ \\
\hline $\begin{array}{l}\text { Final energy consumption } \\
\text { (Mtoe) }\end{array}$ & 352 & 689 & 1050 & $\begin{array}{l}1596 \\
1513\end{array}$ & $\begin{array}{l}2181 \\
1901\end{array}$ & 2.8 & $\begin{array}{l}2.9 \\
2.3\end{array}$ \\
\hline $\begin{array}{l}\text { Fuels for transport - oil } \\
\text { (Mtoe) }\end{array}$ & 8 & 30 & 104 & $\begin{array}{l}186 \\
175\end{array}$ & $\begin{array}{l}396 \\
344 \\
\end{array}$ & 7.7 & $\begin{array}{l}5.3 \\
4.7\end{array}$ \\
\hline $\begin{array}{l}\text { Fuels for transport - biofuels } \\
\text { (Mtoe) }\end{array}$ & 0 & 0 & 0 & 2 & 8 & - & - \\
\hline $\begin{array}{l}\text { Fuels for transport - total } \\
\text { (Mtoe) }\end{array}$ & 14 & 41 & 104 & $\begin{array}{l}186 \\
185\end{array}$ & $\begin{array}{l}396 \\
367\end{array}$ & 6 & $\begin{array}{l}5.2 \\
4.7\end{array}$ \\
\hline Electricity (TWh) & 144 & 650 & 2237 & $\begin{array}{l}4942 \\
4696\end{array}$ & $\begin{array}{l}7624 \\
6786\end{array}$ & 8.2 & $\begin{array}{l}4.8 \\
4.4\end{array}$ \\
\hline
\end{tabular}

\begin{tabular}{|c|c|c|c|c|c|c|c|}
\hline India & 1971 & 1990 & 2004 & 2015 & 2030 & $\begin{array}{c}\text { AMGR } \\
1971-2002\end{array}$ & $\begin{array}{l}\text { AMGR } \\
2004-30\end{array}$ \\
\hline $\begin{array}{l}\text { Final energy consumption } \\
\text { (Mtoe) }\end{array}$ & 169 & 294 & 403 & $\begin{array}{l}535 \\
508\end{array}$ & $\begin{array}{l}738 \\
652\end{array}$ & 2.7 & $\begin{array}{l}2.3 \\
1.9\end{array}$ \\
\hline $\begin{array}{l}\text { Fuels for transport - oil } \\
\text { (Mtoe) }\end{array}$ & 7 & 26 & 36 & $\begin{array}{l}49 \\
47\end{array}$ & $\begin{array}{l}77 \\
67\end{array}$ & 5.3 & $\begin{array}{l}3 \\
2.5\end{array}$ \\
\hline $\begin{array}{l}\text { Fuels for transport - biofuels } \\
\text { (Mtoe) }\end{array}$ & - & 0 & 0 & $\begin{array}{l}0 \\
0\end{array}$ & $\begin{array}{l}2 \\
4\end{array}$ & - & - \\
\hline $\begin{array}{l}\text { Fuels for transport - total } \\
\text { (Mtoe) }\end{array}$ & 15 & 28 & 36 & $\begin{array}{l}50 \\
49\end{array}$ & $\begin{array}{l}81 \\
74\end{array}$ & 2.8 & $\begin{array}{l}3.1 \\
2.8\end{array}$ \\
\hline Electricity (TWh) & 61 & 289 & 668 & $\begin{array}{l}1226 \\
1163\end{array}$ & $\begin{array}{l}2314 \\
2041\end{array}$ & 7.6 & $\begin{array}{l}4.9 \\
4.4\end{array}$ \\
\hline
\end{tabular}




\begin{tabular}{|c|c|c|c|c|c|c|c|}
\hline Latin America & 1971 & 1990 & 2004 & 2015 & 2030 & $\begin{array}{c}\text { AMGR } \\
1971-2002\end{array}$ & $\begin{array}{l}\text { AMGR } \\
2004-30\end{array}$ \\
\hline $\begin{array}{l}\text { Final energy consumption } \\
\text { (Mtoe) }\end{array}$ & 155 & 262 & 380 & $\begin{array}{l}486 \\
465\end{array}$ & $\begin{array}{l}650 \\
575\end{array}$ & 2.8 & $\begin{array}{l}2.1 \\
1.6\end{array}$ \\
\hline $\begin{array}{l}\text { Fuels for transport - oil } \\
\text { (Mtoe) }\end{array}$ & 40 & 70 & 105 & $\begin{array}{l}125 \\
115\end{array}$ & $\begin{array}{l}166 \\
130\end{array}$ & 3 & $\begin{array}{l}1.8 \\
0.8\end{array}$ \\
\hline $\begin{array}{l}\text { Fuels for transport - biofuels } \\
\text { (Mtoe) }\end{array}$ & - & 6 & 6 & $\begin{array}{l}10 \\
11\end{array}$ & $\begin{array}{l}20 \\
25\end{array}$ & & $\begin{array}{l}4.5 \\
5.4\end{array}$ \\
\hline $\begin{array}{l}\text { Fuels for transport - total } \\
\text { (Mtoe) }\end{array}$ & 41 & 76 & 116 & $\begin{array}{l}143 \\
134\end{array}$ & $\begin{array}{l}197 \\
166\end{array}$ & 3.3 & $\begin{array}{l}2.1 \\
1.4\end{array}$ \\
\hline Electricity (TWh) & 135 & 491 & 874 & $\begin{array}{l}1304 \\
1244\end{array}$ & $\begin{array}{l}1983 \\
1716\end{array}$ & 6 & $\begin{array}{l}3.2 \\
2.6\end{array}$ \\
\hline
\end{tabular}

\begin{tabular}{|l|c|r|r|r|r|r|c|}
\hline \multicolumn{1}{|c|}{ Middle East } & 1971 & 1990 & 2004 & 2015 & 2030 & $\begin{array}{c}\text { AMGR } \\
1971-2002\end{array}$ & $\begin{array}{c}\text { AMGR } \\
2004-30\end{array}$ \\
\hline $\begin{array}{l}\text { Final energy consumption } \\
\text { (Mtoe) }\end{array}$ & 35 & 172 & 320 & 502 & 656 & 7.1 & 2.8 \\
\hline $\begin{array}{l}\text { Fuels for transport - oil } \\
\text { (Mtoe) }\end{array}$ & 12 & 59 & 100 & $\begin{array}{r}150 \\
485\end{array}$ & $\begin{array}{l}1606 \\
156\end{array}$ & 6 & 2.5 \\
\hline $\begin{array}{l}\text { Fuels for transport - biofuels } \\
\text { (Mtoe) }\end{array}$ & 0 & 0 & 0 & 0 & 0 & 0 & 1.7 \\
\hline $\begin{array}{l}\text { Fuels for transport - total } \\
\text { (Mtoe) }\end{array}$ & 12 & 59 & 100 & 151 & 167 & 6 & 14.5 \\
\hline Electricity (TWh) & 21 & 240 & 588 & 976 & 1502 & 9,9 & 2 \\
& & & & 933 & 1333 & & 3.7 \\
\hline
\end{tabular}

\begin{tabular}{|l|r|r|r|r|r|r|c|}
\hline \multicolumn{1}{|c|}{ Africa } & 1971 & 1990 & 2004 & 2015 & 2030 & $\begin{array}{c}\text { AMGR } \\
1971-2002\end{array}$ & $\begin{array}{c}\text { AMGR } \\
2004-30\end{array}$ \\
\hline $\begin{array}{l}\text { Final energy consumption } \\
\text { (Mtoe) }\end{array}$ & 167 & 401 & 582 & $\begin{array}{r}732 \\
511\end{array}$ & $\begin{array}{c}954 \\
614\end{array}$ & 2.9 & 1.8 \\
\hline $\begin{array}{l}\text { Fuels for transport - oil } \\
\text { (Mtoe) }\end{array}$ & 16 & 39 & 64 & 85 & 136 & 4.1 & 2.3 \\
\hline $\begin{array}{l}\text { Fuels for transport - biofuels } \\
\text { (Mtoe) }\end{array}$ & - & 0 & 0 & 1 & 3 & - & 2.1 \\
\hline $\begin{array}{l}\text { Fuels for transport - total } \\
\text { (Mtoe) }\end{array}$ & 20 & 39 & 65 & 89 & 142 & 3.4 & 3.1 \\
\hline Electricity (TWh) & 90 & 316 & 534 & 807 & 1351 & 5.5 & 3.6 \\
\hline
\end{tabular}

Source: International Energy Agency (OECD/IEA), World Outlook 2006, ( OECD/IEA 2006, data taken from Appendixes pp. 491-563 + World Energy Outlook 2004 for 1971 data (pp. 438-441, 466-469, 474-477, 482-485, 498-501, 502-505, 510-513, 514-517) and put into table form by Futuribles.

Key: normal print $=$ reference scenario italics = alternative scenario.

AMGR = annual mean growth rate (\%). 


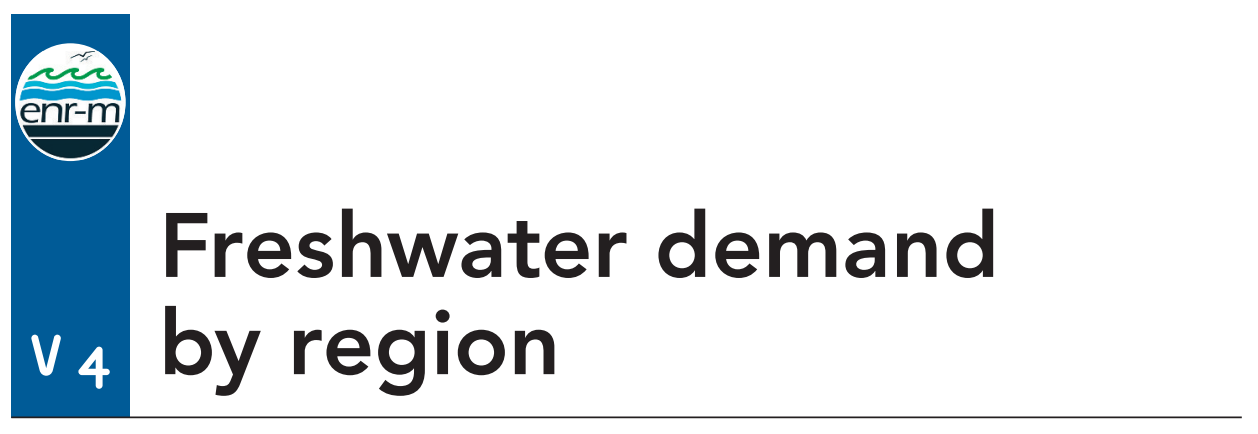

Component: 1. World context

Author: Futuribles (Véronique Lamblin)

\section{Definition}

Saltwater from the sea makes up $97.4 \%$ and freshwater only $2.6 \%$ of the Earth's hydrosphere.

Freshwater is, like air, indispensable to life and agriculture, but polluted water can be the main vector for disease. The freshwater issue stands out from other environmental concerns because of its significance, complexity and the deeprooted nature of various issues, which are simultaneously related to health, economics and geopolitics.

\section{I Key indicators}

If the variable concerns consumption alone:

- total water consumption by region;

- water consumption per inhabitant by region.

If the factor covers tension between freshwater supply and demand, which could lead to producing freshwater from brackish water or saltwater:

- water stress zones, rate of abstraction relative to (renewable) resources;

- physical water management, that is, capture, treatment and reutilization of waste water;

- water policy and price of water.

\section{Looking back (over the past 20 years)}

Global water consumption has greatly increased over the past century: out of a total renewable annual volume of 40,000 km³, consumption was $500 \mathrm{~km}^{3}$ in 1900, $1000 \mathrm{~km}^{3}$ in 1940, $3000 \mathrm{~km}^{3}$ in 1980 and is approaching $5500 \mathrm{~km}^{3}$ today. In 2005, the $5500 \mathrm{~km}^{3}$ were used as follows: $8 \%$ for domestic and urban consumption, $23 \%$ industrial consumption and $69 \%$ agriculture. Asia alone consumes $3500 \mathrm{~km}^{3}$ 
annually. The other regions of the world all consume less than $1000 \mathrm{~km}^{3}$ annually and Europe has an annual consumption of only $300 \mathrm{~km}^{3}$.

Today, 17 countries consume more water than they accumulate. Overexploitation of groundwater, which represents $90 \%$ of the world's directly usable freshwater, but which recharges very slowly $(0.1-0.3 \%$ annually), is particularly problematic. Withdrawal of water from coastal aquifers can lead to seawater intrusions and thus make them irreversibly saline. This phenomenon is already a serious issue in China and in the South Pacific and Caribbean islands (in some farming areas of Cuba, seawater penetration in aquifers can reach $30 \mathrm{~km}$ inshore) (UNEP, 2006).

Areas of water stress or scarcity depend on the geographical conditions and level of population and/or economic growth. The regions of Africa (northern and southern Africa), the Middle East and Asia, including India and China, will be particularly affected. Based on the mean demographic projections of the UN, the number of individuals who will suffer from water stress or scarcity by 2025 is estimated at 2.8 billion 26 .

\section{Outlook (for the next 20 years)}

Two factors have to be considered: population growth and increasing water consumption per inhabitant. Abstractions are rising twice as fast as population growth (PNUD, 2006).

- Over the past 50 years, water withdrawals worldwide have increased four-fold. According to the Organization for Economic Co-operation and Development (OECD), between now and 2020, water withdrawals should rise by $10 \%$ in Member States and 30\% worldwide. However, since a possible increase in consumption in developing countries is not taken into account, these figures may underestimate future demand.

- In spite of wide variations, the inhabitants of developed countries consume more water than those of developing countries. However, consumption has decreased by $11 \%$ since 1980, an encouraging fact, since it means that growth and water consumption are no longer linked.

- On the global scale, agriculture is the sector with most consumption (accounting for $70 \%$ of withdrawals) and should remain so as irrigated surface areas are growing.

Over the next 20 years, industrial demand, particularly in emerging countries, will undergo the fastest growth (doubling is forecast). However, as water is mostly used there in nuclear, thermal (cooling) and hydropower plants, and then discharged into streams, the figures given do not represent net withdrawal. All the same, this utilization affects the quality of the water (since it is warmed) or deprives users downstream (hydro-electric dams). It is estimated that irrigated

26. A region is considered to be under water stress when the annual resources, i.e. the amount of water available for all human (e.g. industry, agriculture, individual consumption, etc.) or natural (e.g. ecosystems, plant and animal wildlife) uses are less than $1700 \mathrm{~m}^{3}$ per person, and below $1000 \mathrm{~m}^{3}$ per person in a situation of water scarcity or shortage. 
food crops only return $30 \%$ of the abstracted water, while the return from industry and domestic uses is $85 \%$ to $90 \%$. Nevertheless, in many cases, for the returned water to be reused, it must be collected and treated.

In OECD countries, industrial and domestic withdrawals are lessening (higher water prices, better efficiency and relocation of some industries that use a great deal of water). However, world water demand will continue to grow, whether for agriculture, industry or households.

\section{Water stress and scarcity}

Currently, 700 million people in 43 countries live in a water-stressed situation (less than $1700 \mathrm{~m}^{3} /$ person/year), especially in Africa (25\% of the sub-Saharan Africa population is affected) and in Palestine. Yet many of these countries are experiencing rapid population growth. If the current trends continue, that means that over 3 billion people could live in water-stressed countries by 2030. This would be the case for nearly $85 \%$ of the sub-Saharan population.

The stakes for water resources call for several possible pathways of action:

- saving more water, particularly through higher-performance agricultural irrigation systems;

- mitigation of pollution sources (especially agriculture and industry) and/or retreatment and sanitation of waste water, mainly in countries which have collection networks;

- increasing the resource through desalination of seawater or brackish water.

\section{What is the outlook for seawater desalination?}

Desalination is a process that removes salt from saline or brackish water to render it drinkable or usable for irrigation. Today, there are 12,500 desalination facilities in 120 countries, making up just $0.2 \%$ of global water consumption (UNDP, 2006). Countries using seawater desalination technology are mainly located in the Middle East (e.g. United Arab Emirates, Israel, Syria), Latin America (e.g. Mexico, Chile) and Spain. The USA ranks second, following the Middle East, for the filtering of brackish waters.

The main constraint that has prevented more uptake of desalination is its energy cost. Production costs have decreased with the development of the new reverse osmosis technique: costs are three to four times higher than those for raw water treatment, but they have been halved over the past 10 years and could be halved again in the coming decade. However, energy costs remain a significant factor in production costs, and the great expense of pumping and distribution over long distances limit the interest in this solution.

For relatively prosperous cities located near the coast, desalination can provide a source of water for domestic consumption. The potential is more limited for industry and agriculture in developing countries.

In the Appendix, the stakes for water in countries bordering the Mediterranean are described. They have inspired the following hypotheses, taking account of the specific challenge for freshwater in this region. 
This variable's final objective is to assess needs for marine energies, not so much the consumption of freshwater, but rather the way in which water is managed and how freshwater is obtained, especially in water-stressed areas.

\section{Hypotheses}

\section{Hypothesis 1}

By improving the way the resource is managed (water-saving irrigation systems and crops that need less water, also collection of urban rainwater), mitigating pollutant emissions through better collection and treatment of waste water to be re-utilized, the essential water requirements, especially in the Mediterranean basin, can be met. The poorest countries (sub-Saharan Africa), however, are led to modify their food production due to lack of water. Water production by desalination mainly develops in islands where tourism is important, as an occasional supplement in some large coastal cities (and in the Gulf countries due to energy resource issues).

\section{Hypothesis 2}

Desalination as a supplementary source in the Northern hemisphere (and on islands)

Managing the resource through water-saving systems for consumption and by re-treating water is not sufficient to meet demand. In developing countries in the Southern hemisphere, agriculture must adapt. Desalination production only develops there to meet potable water needs in large coastal cities where the inhabitants can afford it. It also develops in some regions of Europe (Catalonia and Andalusia) in order to maintain food crops and for large cities during the summer.

\section{Hypothesis 3}

New technological breakthrough on desalination costs: using desalination rather than better management or retreatment (desalination is in common use in Southern countries)

Technological progress brings the cost of desalination below that of treating raw or polluted waters by 2015-20. Thus, in countries (southern and eastern Mediterranean) without efficient water retreatment networks, desalination is quickly chosen as the alternative to treating waste water in coastal regions. This hypothesis is not without consequences on the pollution of coastal ecosystems.

\section{Bibliography}

UNEP, 2006.Challenges to International Waters: Regional Assessment in a Global Perspective, GIWA (Global International Water Assessment).

UNDP, 2006. Human Development Report. 


\section{Appendix}

\section{Excerpt from the alert bulletin No. 7, 20.02.2006, from Futuribles International's pooled intelligence system 'VIGIE', Author: Sébastien Abis (CIHEAM).}

The Mediterranean area has 50\% of the world population experiencing water scarcity. Nearly 30 million people in the Mediterranean apparently do not have access to a potable water source. These rural populations, often the poorest, are the first to suffer. About $70 \%$ of the resources are found in the north of the basin, $20 \%$ in Turkey and only $10 \%$ in the south. With only $3 \%$ of global freshwater resources, but $7 \%$ of the world population, the Mediterranean is an illustration of an arid region where water is becoming a strategic form of blue gold.

The total renewable freshwater resources (groundwater and surface water) in the Mediterranean catchment basin reach $600 \mathrm{~km}^{3}$ in an average year. This figure corresponds to the mean maximum potential of natural water resources each year. Yet, $85 \%$ of this potential is found in the northern Mediterranean (including Turkey). Considering the demographic changes underway (stabilization on the northern shores, growing population on the southern shores), the imbalance in natural water resource bases per capita between the northern, eastern and southern Mediterranean will get progressively worse 27 .

The irregularity in the quantity of water resources available in the Mediterranean is compounded by their qualitative vulnerability. Freshwater in the Mediterranean basin is often naturally high in salinity, which limits the possibilities for use. Water quality is also threatened by rising pollutant emissions (e.g. domestic, industrial discharges, fertilizers and pesticides from farming activities). All these constraints could be accentuated by climate change affecting the Mediterranean basin (i.e. harsher and more frequent droughts, less precipitation in the south and east).

During the second half of the 20th century, total water demand from countries bordering the Mediterranean doubled. Growth was greatest in Turkey, Syria and France. Since 1990, however, some countries have managed to stabilize their water demand (e.g. Israel) or even reduce it (e.g. Italy, Cyprus and Malta). Rapid urban development in the Mediterranean area has sharply increased the pressures on water.

27. The mean natural renewable water resource base for an inhabitant of the southern or eastern Mediterranean in 1950 was, on average, 2.5 times lower than that of an inhabitant on the northern shores. Today, it is approximately six times lower and will probably reach eight times less by 2025. 
The ratio of withdrawals of natural renewable water resources/total renewable water resources provides an indicator for resource use. The higher the ratio, then the greater the pressure is on natural renewable water resources. Mapping this indicator over Europe shows a widely varying situation:

- countries whose ratio is close to or higher than 75\%, such as Egypt, Israel and Libya today and the Palestinian Territories and southern Spain by 2025; these countries are experiencing strong tensions regarding their natural resources and by 2025 will have to cover an increasing share of their demand by using non-conventional sources;

- countries with a high ratio (from 50\% to 70\%), but which are not expected to change between now and 2025, that is, Malta, Syria and Tunisia;

- countries with a sufficient ratio (between $25 \%$ and $50 \%$ ) to create tensions either locally or in certain contexts, currently Lebanon, Cyprus and Morocco, with Turkey and Algeria by 2025;

- countries whose ratio is under $25 \%$ and whose total demand is declining, that is, Greece, France, Italy and the eastern Adriatic countries.

These observations give rise to concern and should alert us to our duty to develop other resources for future generations, especially for those located in the south and east of the basin. Three techniques should be investigated: re-utilizing waste water, using water recovered from farmland drainage and industrially producing freshwater by desalinating seawater or brackish water. Today, they represent respectively, $1.1 \mathrm{~km}^{3}, 12.6 \mathrm{~km}^{3}$ (mostly in Egypt) and $0.4 \mathrm{~km}^{3}$ of the entire Mediterranean basin total.

Better management of the resources requires actively fighting pollution, notably by optimizing treatment of waste water (collection and purification), since one out of two inhabitants in the southern and eastern Mediterranean still has no connection to a sewage treatment plant. Better management of demand requires that rational use of water be implemented. Pricing reforms seem inevitable with a view to good stewardship of water. 


\section{. \\ Security and price $v_{5}$ of fossil fuels}

Component: 1. World context

Author: Technip (Nicolas Tcherniguin)

\section{Definition}

Fossil fuel energy is defined as the energy produced from underground deposits of fossilized remains of plants and animals, making oil, natural gas and coal. They are present in limited and non-renewable quantities and burning them emits greenhouse gases.

\section{Oil}

Proven oil reserves are estimated at 1-1.2 trillion barrels, which is roughly $150 \mathrm{Gt}$ or the equivalent of 40 years production at the current rate ( 4 Gtoe28/year) (Figure 5.1). Their distribution is scattered across the world and nearly two-thirds are found in the Middle East.

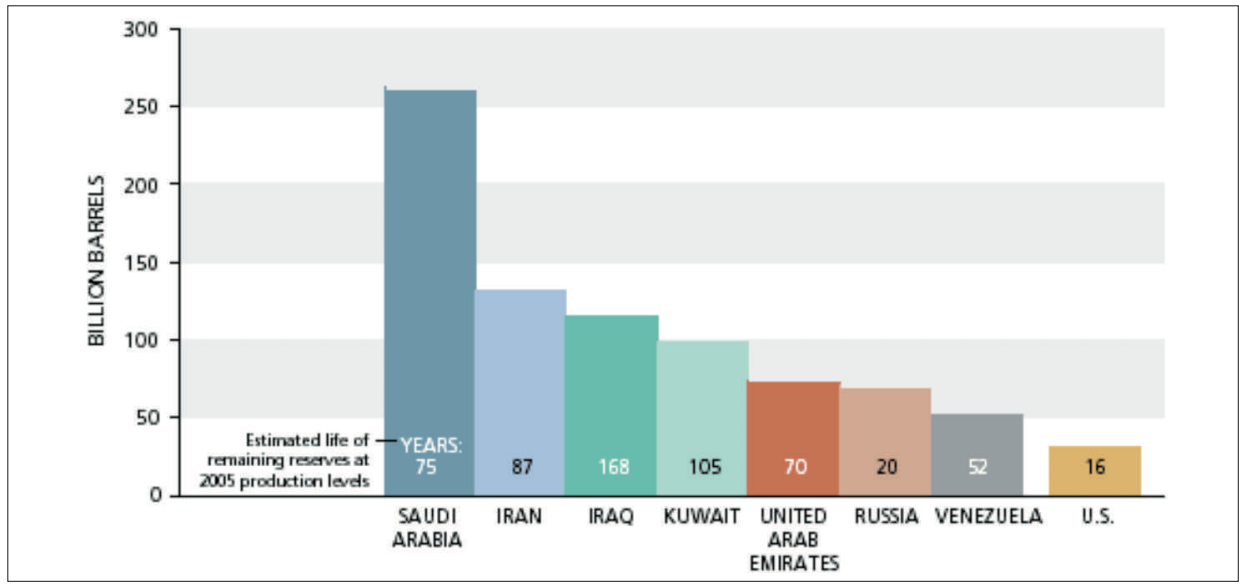

- Figure 5.1 : main countries holding proven reserves of oil (Source: National Petroleum Council Survey of Outlooks, 2007).

28. Billion tonnes oil equivalent. 


\section{Natural gas}

The proven reserves worldwide for gas are constantly increasing. Today, they are estimated to represent 180,000 billion $\mathrm{m}^{3}$, that is, 66 years of consumption at the current rate (Figure 5.2). Here again, the resources are primarily found in the Middle East (40\%) and in the Commonwealth of Independent States (CIS) countries (31\%). About $50 \%$ of world reserves are concentrated in three countries, that is Russia, Iran and Qatar. Members of the Organization of the Petroleum Exporting Countries (OPEC) purportedly hold half of global reserves.

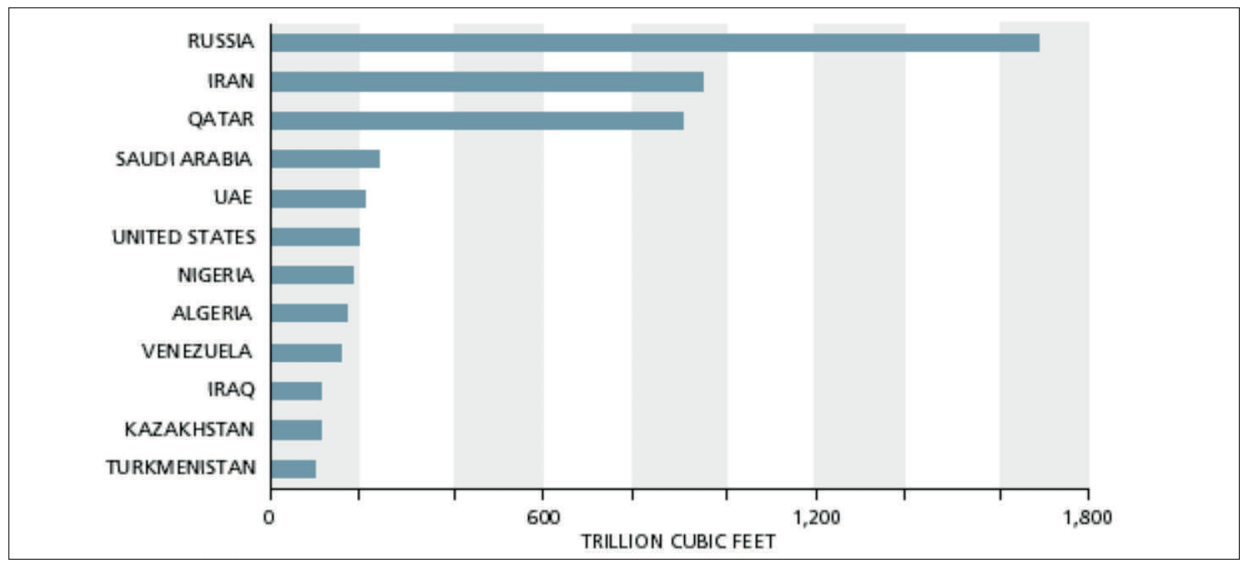

I Figure 5.2 : estimated natural gas reserves (Source: BP Statistical Review of World Energy 2006).

\section{Coal}

There are still an estimated 909 billion tonnes of proven coal reserves worldwide, enough to last at least 155 years at current rates. The USA holds $25 \%$ of reserves, the former USSR $25 \%$ and China about $12 \%$ of reserves. However, coal is a fossil fuel and a 'dirty' energy source that will increase greenhouse gas emissions and thus global warming.

Most energy scenarios anticipate tensions between oil supply and demand by 2020. By that date, according to the International Energy Agency (IEA), the demand for energy should reach 13.5 Gtoe, an increase of over $40 \%$ from the 9.2 Gtoe consumed in 2000. By 2020, annual production from all energy sources with the exception of oil (i.e. coal and lignite, nuclear, hydro-electric, geothermal, biomass and other renewable power sources) could reach 4.6 Gtoe, which is fairly close to the current level of $3.5 \mathrm{Gtoe}$. Developing these energies could effectively be hindered by several factors, that is, the time needed to build nuclear power infrastructures, environmental impacts of coal, the finite nature of current capacities and the cost of renewables. In this context, oil and gas must bridge the gap between energy production and consumption, which involves increasing oil and 
gas production by 3.2 Gtoe over the projected period (from 5.7 Gtoe in 2000 to 8.9 Gtoe in 2020).

Today's known oil and gas reserves are large enough to meet this heightened demand. In fact, in 2000, they were 140 Gtoe oil and about the same (130 Gtoe) for gas. Based on the above hypotheses, the resources should allow it to meet demand until 2025. However, if the scenario outlined above came into being, existing stocks would have to be tapped significantly. This means that during the period from 2000 to 2020, 85 Gtoe of oil would be consumed, over $60 \%$ of currently identified reserves together with 55 Gtoe of natural gas (42\% of existing reserves). These figures highlight how important the issue of renewing the hydrocarbon resources will become in the future.

It is all the more crucial in view of reminders from experts that for several years now, discoveries have no longer offset production. Thus, in the worst-case scenario, peak oil production worldwide could occur around 2015. In addition, the concentration of reserves in the Middle East (approximately two-thirds of conventional reserves still to be produced are located in this area) will inevitably increase this region's share in world oil production. By 2020, the contribution of the Middle East to oil production is expected to reach nearly $70 \%$ compared with today's $33 \%$, yet another potential risk for the security of supply for oil-consuming countries. Therefore, even if the data for gas indicate a more positive situation (the production peak anticipated for 2050 and better geographical distribution of reserves) and despite the existence of techniques that allow fossil fuels to be converted to other forms or even be substituted for one another, it is clear that everything possible must be done today to prolong the supply of oil until other forms of energy can substitute.

How can escalating needs be met and at what price? The answer depends on two relative factors: firstly, the reliability of published figures for reserves; and secondly, the development of production capacities.

Continuing increases in energy prices seem inevitable. This is due to various factors. Firstly, the period of easily extracted conventional oil is definitely over, which explains the interest in the potential of unconventional fossil fuel energies. Next, energy demand is growing faster than it can be met by new technologies creating an additional supply. This is due, for instance, to China's development or the rise in travel worldwide. It is caused by various factors. The required infrastructures are all the more costly in that the global energy system based on fossil fuels is increasingly dependent on exploiting the last existing resources.

In light of the growing needs for an increasingly rare resource, the main threat to supply security lies in the discrepancy between supply and demand and in the competition and risk of conflicts between the main consumer countries. This rivalry accounts for the race between the USA, European countries, China, Japan and India to get a foothold in countries with oil reserves and to control maritime and overland routes between oil energy suppliers and the centres of demand. The war in Iraq in March 2003, which enabled Washington to oust France, Russia and Italy, the new Baku-Tbilisi-Ceyhan oil pipeline or the recent agreement 


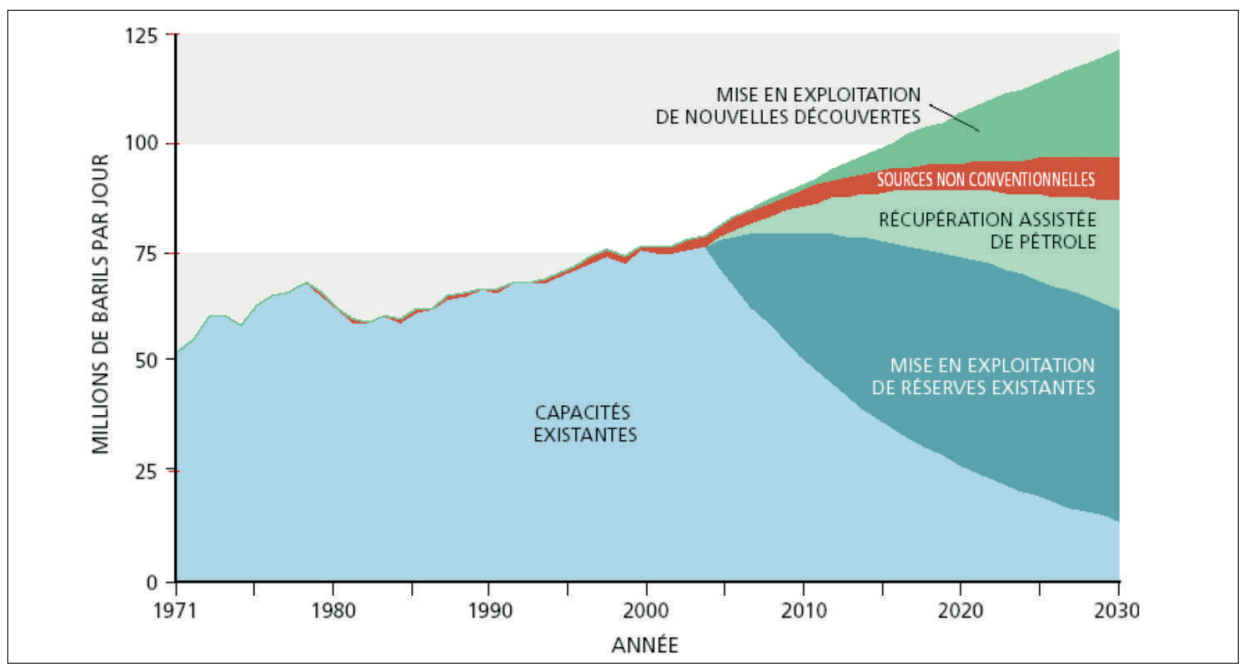

I Figure 5.3 : global oil production by type of oil (million barrels/day) (Source: IEA World Energy Outlook 2004, @ OECD/IEA, 2004; Figure 3.20, World Oil Production by Source, Chap. 3; Oil Market Outlook, p. 103).

between Germany and Russia on the North European gas pipeline to be built under the Baltic Sea, are some examples of the moves made to secure the energy needs of the countries concerned.

\section{II Key indicators}

In order to identify the main drivers of the current situation in the oil and gas sector and how it will evolve in the near future, the following elements can be noted.

- At constant prices and without new technologies, oil production will reach a peak and then decline in the next 20 years, no longer supplying demand, particularly for transport where there are no global substitutes for oil.

- Conventional oil production will come from increasingly mature fields, where the drop in yields will lead to higher unit costs and a lower energy return on energy invested to extract it.

- Less exploration will be conducted in newly targeted areas or basins. Its contribution to increasing the number of recoverable resources is not expected to surpass $20 \%$; the remainder will come from enhanced oil recovery from existing reserves.

- Use of natural gas should grow and the share of this energy source is expected to reach $26 \%$ of global energy demand by 2020 , compared with today's $22 \%$. In spite of a more favourable geographical distribution compared with oil, production centres are not located in demand centres and this could lead to a substantial increase in transport costs and energy required to produce the gas. 
Similarly, the cost and energy efficiency of conversion processes will become determining factors.

- Non-conventional fossil fuels (i.e. heavy oils, shale gas and oil shale) and coal, despite their abundance are not currently exploitable without elaborate processing to comply with environmental constraints.

- In parallel, discoveries are dwindling and the ratio of global reserves to global production is gradually but inexorably decreasing, engendering another and more immediate risk that weighs on the oil market. This is the declining production in many countries and the insufficient investments made to develop the new capacities needed to cover requirements. Can this reduction be compensated for by other exporting countries in time? Nothing is less certain.

These various indicators depict a nearing transition period dominated by the levelling out of conventional oil production. To meet the needs for development and thus higher energy demand, the oil industry is faced with a triple challenge:

- to extend conventional oil resources;

- to ensure access to new (unconventional) resources;

- to prepare a more diversified and sustainable energy balance.

\section{| Peak oil}

A peak in oil production designates the point in time (at the top of a curve) when maximum production from a well or an oil field has been reached. By extension, peak oil designates when the maximum rate for a country or the whole planet will occur. The production curve is assumed to be bell-shaped, rising to a maximum and then falling. The term is also associated with the energy crisis and its socioeconomic and geopolitical consequences that could occur after the depletion of global oil reserves. The 'peak oil' theory is derived from the work of the geologist Marion King Hubbert.

\section{Peak oil outlook}

The various organizations which have examined this question do not always agree on the outlook.

\section{The optimists}

The optimists' group is mainly made up of economists from the Massachusetts Institute of Technology, the governments of the USA and OPEC countries, and oil companies. They consider that oil production will peak around 2030 or later. They point out that previous forecasts of oil depletion have always been proved wrong. For instance, at the end of the 19th century, many experts predicted that coalbased industrial development would cease because coal reserves were then estimated sufficient for only 20 years of production. More recently, British Petroleum published a 1979 study suggesting that global (excluding the USSR) oil production would peak in 1985. Optimists then observed that the majority of exploratory drilling has been performed in countries that have been amply 
surveyed. Moreover, tapping reserves using modern technology and re-evaluating former oilfields cost less to exploit than recently discovered reserves. This is especially true in the Middle East. Exploration is, therefore, inadequate in countries that nevertheless have the greatest prospects for discoveries of new reserves.

Possible production is the result of a race between, on the one hand, depletion of identified oilfields and, on the other hand, technological progress that facilitates access to new resources. Until now, technology has always been successful with new techniques leading to relatively regular progress, lower drilling costs, improved rate of recovery and better underground imaging. Other effects are harder to predict. In the early 1980s, production of extra-heavy oils from the Orinoco Belt in Venezuela was only considered profitable if the price of a barrel of crude oil was greater than US\$40 at that time. Technical advances, mainly through the spread of horizontal drilling, have reduced this threshold to less than US\$15 (at 2004 rates).

\section{The moderates}

Various teams of specialists propose a middle-of-the-road vision. For the US Geological Survey (USGS), ultimate conventional oil reserves are estimated at 3 trillion barrels, of which roughly 1 trillion has already been consumed, a little more than 1 trillion is in proven reserves and the remaining are resources that remain to be discovered. This approximation also corresponds with the minimum estimates from geologists at the French Petroleum Institute (IFP), which are based on currently available data. They predict a peak in global oil production shortly after 2020. With slightly more optimistic theories on the amounts remaining to be discovered (based on average and not minimum volumes) and on improved recovery rates, the peak could be moved back to around 2030. If the USGS estimates were to be revised upwards, as has been done in the past, by taking unconventional resources into account, the decline could be postponed beyond 2030.

\section{The pessimists}

Pessimists, for the most part, come from the Association for the Study of Peak Oil (ASPO). They insist primarily on the political character of reserve re-evaluations that were made in 1986-87 by OPEC members and that do not correspond to actual proven reserves. They consider that peak oil will occur before 2010 at a level of the order of 90 million barrels/day, for all natural hydrocarbons combined.

In support of their theory, they observe that all the data on oilfields can now be accessed and that sampling is now sufficient for reliable prediction of undiscovered resources. The uncertainty is mainly in the future trends of volumes that can be recovered from existing resources. Conclusions diverge regarding this subject: for optimists, the average recovery rate of these volumes could, in 50 years, increase from $35 \%$ to $50 \%$ or even $60 \%$; for pessimists, only limited enhancements can be made and primarily concern heavy and extra-heavy oils. 
In 2006, daily oil production was about 85 million barrels/day. While some people consider that peak oil has been reached already, other think it will be reached in the decade of 2010 or 2020, at values varying from 100 to 120 million barrels/day. These significant differences can be explained by:

- unknowns about identified reserves and undiscovered resources described above;

- unknowns about the recovery rates that can be realized;

- unknowns about 'unconventional' oil.

Finally, the exact peak oil date depends not only on the total quantity of existing oil in the world, but also on the rate at which it is consumed. As they are progressively implemented, replacement solutions will deform the Hubbert curve.

The premise of the peak oil issue, namely that oil is a finite resource that will eventually run out, is no longer called into question today. However, many points, such as when the peak will occur, whether it can be observed and the capacity for this theory to provide reliable estimates, are still under consideration. The discussion now emphasizes the economic and social consequences of peak oil. The partisans of the peak oil theory have to be given credit for attracting public attention to the inevitable changes that will occur following the depletion of conventional oil resources.

\section{Different types of reserves}

The estimation of available reserves in an oilfield is determined when the oilfield is discovered. At discovery, geologists and engineers make educated guesses. These include the initial reserves and the oilfield sale price, investments acquired for developing the oilfield and the value of oilfield operations are all based on these initial reserves. This first estimate is not very reliable, not for scientific reasons but because of financial considerations.

Based on discovered oilfields, three types of reserves can be distinguished. It is important to define these different types so that the estimates can be interpreted correctly (Source: IFP):

- proved reserves: 'proved reserves are the quantities of oil that have actually been established and which have a better than $90 \%$ chance of being produced, given current techniques and economic context';

- probable reserves: 'probable reserves designate, for an identified oilfield, the quantities of oil that have a better than $50 \%$ chance of being commercially exploited';

- possible reserves: 'possible reserves are those that have a $10 \%$ chance of being technically and commercially exploitable'.

Given these definitions, there are several ways to 'inflate' them.

- Discovering new underground resources, conventional or not, that can eventually be extracted. Without any changes in technical or economic conditions, this leads to higher reserves.

- Incorporating additional knowledge on the volumes held by currently exploited oilfields. 
- Improving technical conditions that, in practice, translate to a better rate of recovery of oil contained in the reservoirs; this factor can play an important role.

- Adjusting technical conditions according to economic context. If the sale price of oil is US $\$ 20 /$ barrel, it is not economical for oil companies to extract oil at an extraction cost of US $\$ 25 /$ barrel, even if large quantities of oil could potentially be extracted. If the barrel is valued at US\$60, then oilfields where extraction costs are US\$25/barrel will enter into the reserve estimation.

- The value of the oil companies share being proportional to the quantities of reserves that they declare and the OPEC production quotas (two-thirds of global reserves) being proportional to the amount of reserves that they publish, it is easy to understand that reserves may vary. For instance, it is possible to shift from a high estimate to a low one, or vice versa, without modifying any technical or physical parameter, simply because what is considered to be 'reasonable' will have changed.

A 'proven' reserve is, therefore, a subjective notion by nature.

To justify the different estimates, published reports distinguish between several types of oil:

- conventional oil (95\% of what has been exploited to date);

- unconventional oil: oil shale, tar sand or oil that cannot be extracted using current technology.

However, experts consider that the amounts of unconventional oil produced will always be secondary, because even when these deposits can be exploited, extraction will always remain difficult, slow and costly. It also has the fundamental disadvantage of having a limited net energy production. Extracting and processing these unconventional oils consumes a significant proportion of their own energy (30\% in the case of tar sands from Alberta). This also increases the pollution generated per final energy unit.

\section{Rate of recovery}

Recovery rates vary from oilfield to oilfield because the characteristics of oilfields and the oils found there differ, but they also vary with the techniques used. Progress cannot increase the recoverable fraction in an oil deposit, but only increase the speed by which it can be extracted. Oil companies willingly disclose that during the last 30 years, the recovery rate has improved from, on average, $25 \%$ to $35 \%$, representing nearly a $50 \%$ increase in reserves. In so-called 'compactfractured' reservoirs, this rate is $3 \%$ and will probably not increase further. When oil is very fluid or the rock very porous and the pores are well interconnected (as in Libya and Canada), the rate can be greater than $80 \%$.

The oil industry usually leaves two-thirds of the oil in the ground. Oil companies aim to increase their recovery rates to $50 \%$, or even $60 \%$ in the years to come. It should be noted that improving the rate by $2 \%$ would add a year's consumption to the reserves. 


\section{Looking back (over the past 20 years)}

\section{Uncertainty of reserves}

Suspicions about the real volume of oil reserves are not new, but they have recently been reinforced as a result of significant downward revisions by some oil companies as well as new estimates put forward by independent geologists.

Regarding the OPEC members, the questions raised by their official estimates go back to the 1980s when the Gulf countries, one after the other, radically re-evaluated their reserves, without necessarily justifying them by new discoveries, price increases or new studies. Of course, some of these revisions were a result of new discoveries or technological advances that enhanced recovery rates. Others remained questionable, more so because almost all of these reserves are controlled by state-owned companies that refuse verification by independent external auditors. The official estimates of so-called proven reserves in OPEC countries are greater by about 400 billion barrels than those stated by private independent organizations, including the ASPO in particular. These volumes, presented by some as 'fictitious barrels', correspond to $44 \%$ of total official OPEC estimates. This does not mean that the figures given by independent organizations are any closer to reality than those announced by the exporting countries. However, the enormity of the difference in figures demonstrates the complexity of the technical and economic criteria used as well as the doubts that remain in terms of available data.

Moreover, these doubts are amplified by the fact that the estimates published by some OPEC countries have remained unchanged for long periods, as if each barrel produced was immediately replaced by a discovery or re-evaluation. For example, from 1987 to 1995, Iraq maintained its even figure of 100 billion barrels, before raising it to 115 billion. No less surprising is the example of Kuwait that, between 1991 and 2002, did not modify its proven reserves estimate of 96.5 billion barrels, in spite of a cumulative production that has surpassed 8.4 billion barrels over the same period. Based on data that were allegedly communicated by Kuwaiti oil officials, the American periodical Petroleum Intelligence Weekly stated in January 2006 that the official statistics mixed proven, probable and possible reserves. Proven reserves, apparently do not exceed 48 billion barrels.

Furthermore, the real volume of proven reserves in Russia is uncertain, because it is not clear what methods are used and how the statistics are calculated. According to some Western sources, the real volume is thought to be around $30 \%$ to $40 \%$ lower than the official estimate of 72.3 billion barrels.

Finally, even for international corporations listed on the stock market and under the control of external auditors, serious doubts remain for obvious reasons of strategic competition (Figure 5.4).

\section{New balances}

In 1992, after the Gulf War, during the Fifteenth World Energy Congress, Mr Schlesinger (US Secretary of Energy in the Carter Administration) explained that after the fall of the USSR and the end of the Soviet threat on Middle Eastern 


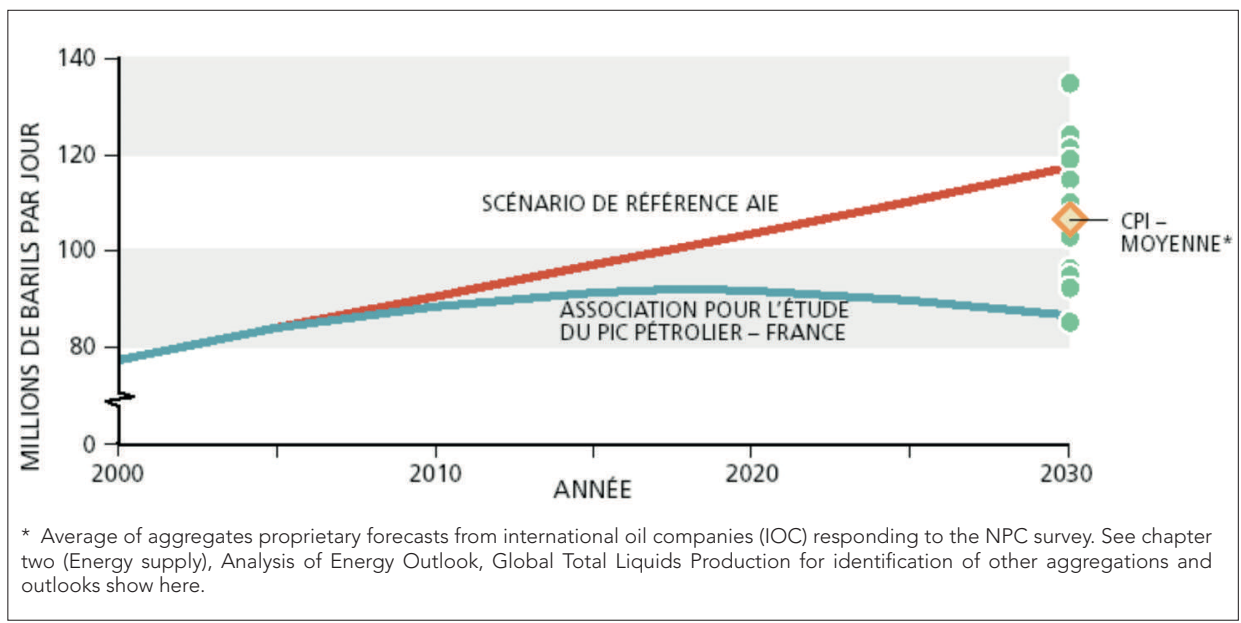

I Figure 5.4 : the discrepancy in results of global oil production forecasts (Source: IEA World Energy Outlook 2006, quoted in National Petroleum Council (The Hard Truths Report, 2007); Figure ES9, Understanding the range of global oil forecast; Chap. Executive summary, p. 31).

oilfields, the USA had fewer fears regarding supply security and the relatively low oil prices that had contributed to the decline in national production and the rise in imports were no longer a subject for concern.

However, the global landscape has profoundly changed during the last 3 years. Instead of leading to a strong increase in Iraqi production and a reduction in prices, the invasion of Iraq in 2003 resulted in sabotage, the threat of civil war and a decline in oil production from 2.5 to 1.5 million barrels/day in what was one of the main exporting countries. Combined with other factors, this led to an explosion in prices which increased, on average in OPEC countries, from US\$24/ barrel to US\$50/barrel in 2005.

In contrast to the oil crises in 1973-74 and 1979-80, this steep increase in prices was completely unexpected and the concerns regarding security were not the result of an embargo, a decrease in exports or the use of 'black gold' as a weapon by any producing country. It was caused by two sets of factors. The first is geopolitical in nature, that is, terrorist attacks and political instability in the Middle East, tensions over Iran's nuclear programme, conflicts in Nigeria, etc. The second set of factors is more worrying because they are more lasting, insofar as they affect the balance between supply and demand. Growth in consumption has unexpectedly accelerated. Following an average annual growth rate of $1.54 \%$ during the 1992-2002 period, the world demand for oil increased by $1.93 \%$ in 2003 and $3.7 \%$ in 2004, reaching a record of 82.1 million barrels/day in 2004, then 83.2 million barrels/day in 2005. In all, over a period of only 3 years, oil needs increased by 5.5 million barrels/day. The increase was the most dramatic in China especially, with a sharp increase of $7.6 \%$ in 2003 and $15.8 \%$ in 2004 . This rise in consumption has impelled countries to produce at their maximum capacity. In 
addition, transport and refining capacities have been saturated, especially in the USA which, as expected, fuelled the spiralling increase in prices.

Considered to be the main solution for replacing oil, production of natural gas also raises questions, especially since 2006, when the leading world exporter, Russia, abruptly suspended delivery to Ukraine and Georgia and, for reasons of availability, reduced exports to Hungary, Austria and Italy.

\section{II Outlook (for the next 20 years)}

\section{Food for thought}

During the past 3 years, concerns over energy supply security have heightened. They involve not only oil exports from the Middle East, a region of chronic turbulence, but also the entire system of global oil and natural gas production, refining and transport. High-ranking political officials and independent experts have been consistently raising their concerns. In its 2005 report World Energy Outlook (for the period between 2004 and 2030), the IEA expresses the generally held opinion, emphasizing that 'risks for energy security will be exacerbated in the short term' and that 'vulnerability to supply disruptions will increase with expanding international trade'.

Many specialists on the oil market confirm that the end of the 'King Oil' reign will stem not from declining reserves but, in the short term, from increasing environmental concerns. 'The Stone Age did not end for lack of stones,' observed Sheikh Yamani, former Saudi Minister of Oil.

A future without oil crises is not likely, even under the most optimistic hypotheses. Indeed, it is not enough that resources and techniques be available, investments are required for enhancing production capacities before it is too late. The most efficient way to avoid an oil shortage is a consensus on when it will occur.

\section{Oil}

Available estimates, particularly those from the IEA and the US Department of Energy (DOE), indicate that world oil consumption should increase nearly 50\% during the next 25 years, increasing from 83.2 million barrels/day in 2005 to 115.4 million barrels/day in 2030 ( 5 Gtoe annually), according to the IEA, and 131 million barrels/day according to the DOE. The IEA forecasts mean that, in terms of production, a new Saudi Arabia is needed every 8 years.

The declining resources and more costly exploitation will inevitably cause an increase in oil prices over the next two decades. Given the location of resources in a limited number of politically unstable countries, major tensions are highly likely on the oil market, which governs the whole transport sector.

\section{Natural gas}

Natural gas is the resource most likely to be developed in the megacities of poor countries since its development is more environmentally friendly, flexible and easy to deploy. Natural gas fields in Siberia, Alaska and the Middle East should 
last 20 years longer than global oil reserves. Although it is cleaner than oil, natural gas is still a fossil fuel that emits pollutants. It is also expensive to extract and transport because it must be liquefied.

Natural gas could continue its current surge, increasing from 2.5 Gtoe annually to around 4.5 Gtoe by 2020, and then reach a plateau for 50 years through controlled use before starting to decline. This decline could be even more abrupt than that for oil because although only $35 \%$ to $45 \%$ of oil is extracted economically, gas fields are already exploited at $70 \%$ of their efficient capacity, leaving less scope for costly overexploitation.

A feeling of euphoria has been engendered by the rapid growth of gas energy, but this should not avoid drastic decisions about moving from the primary energy mix to cleaner sources with greater security of supply.

\section{Coal}

There is no reason to believe that coal will disappear from the energy landscape in the near future. Its future is less tied to its reserves than to its excessive contribution to the greenhouse effect. If significant technical means for reducing carbon emissions are implemented, either through cleaner combustion methods or by carbon capture and storage after combustion, coal could continue to play a stabilizing role as a back-up reserve throughout the 21 st century. Otherwise, given the priorities for combating the greenhouse effect, its consumption will be restricted.

Research on clean coal in countries that possess coal reserves, primarily the USA and China, will without a doubt hold some surprises. It seems likely that the coal sector could considerably reduce its greenhouse gas emissions and continue to be a basic stabilizing factor for the world fossil fuel market. It may also constitute a back-up for when the depletion of other resources or strong geopolitical constraints cause oil prices to rise sharply.

\section{Consensus}

As of 2020-30, total fossil fuel production could reach 12 Gtoe, emitting 10 GtC29 (compared with today's figure of $7 \mathrm{GtC}$ ). Beyond this period, oil production will begin to decrease.

The gas and nuclear power solutions will not replace oil in the main requirement for transport in the near future. Only synthetic fuels can meet transport needs, as long as the necessary ingredients are available (e.g. coal, gas) and if a certain degree of pollution is accepted. These conditions, however, are generally unacceptable in most OECD countries.

Oil companies have almost unanimously announced that oil production will peak around 2020 (2010 for the most pessimistic, 2030 for those who place high hopes on unconventional oil sources and higher recovery rates).

29. Gigatonnes of carbon = billions of tonnes of carbon. 
The hypothesis of a strong price increase in real monetary terms is the most likely. This rise will be necessary to implement energy-saving policies in the automobile transport sector and to increase - without major subsidies - the share of renewable energies, as well as to produce synthetic fuels, restart nuclear energy programmes and develop hydrogen production from nuclear power.

\section{The energy transition, preparing future changes today}

The question of reserves and of when peak oil and gas will occur is at the heart of many debates. For the IFP, the issue of peak oil is only one facet of tomorrow's energy challenges. Beyond the debate among experts, whose evaluations diverge only between 10 and 15 years, it is navigating the transition period that constitutes the major challenge for the years to come.

Growth in global demand, progressive decline of oil and gas, difficulties in massive and rapid oil substitution for transport and petrochemicals, and environmental constraints related to climate change are all going to shape the future energy landscape.

In this context, and to avoid escalating political and economic tensions, it is essential to prepare for the energy transition now. This involves ensuring the availability of oil for as long as possible, for uses where it is irreplaceable today, while speeding up the development of alternative energies.

In conclusion, it is pertinent to cite $\mathrm{O}$. Appert (President of the IFP) who stated that, in the upcoming transition period and whenever peak oil will occur, it will be necessary to diversify, starting now, the energy mix, that is, continue to explore and exploit oil for sustainable use in transport where it cannot be rapidly and massively substituted and at the same time speed up the development of renewable energies by instituting efficient energy management policies. This is what he calls control of the energy transition.

\section{Hypotheses}

Hypothesis 1

US \$50-60/barrel and supply ensured

Hypothesis 2

US $\$ 60-90 /$ barrel and supply ensured

Hypothesis 3

Crisis period at US\$150-200, stop-and-go over several years 


\section{I Bibliography}

Babusiaux D., Bauquis P.-R., 2005. Anticiper la fin du pétrole. Le Monde Diplomatique, January 2005.

BP, 2006. Statistical Review of World Energy. London: British Petroleum.

Comité d'études pétrolière \& marines. Plan 2004-2008.

Howden D., 2007. World oil supplies are set to run out faster than expected, warn scientists. The Independent, 14 June 2007.

IEA, 2004/2006. World Energy Outlook. Paris: International Energy Agency.

IFP, 2006. Conference-debate Les pics pétrolier et gazier: conséquences et enjeux. May 2006. Paris: French Petroleum Institute.

National Petroleum Council, 2007. Analysis of the National Petroleum Council's Energy Outlook Surveys. The Hard Truths Report. Washington: Department of Energy.

Sarkis N., 2006. L'après-pétrole a déjà commencé. Le Monde Diplomatique, May 2006.

Scheer H., 2007. Plaidoyer pour les énergies renouvelables. Le Monde Diplomatique, February 2007.

World Energy Council, 2004. Survey of Energy Resources. London: World Energy Council. 


\section{Political strategy \& energy independence: targets (renewable energy sources, V b carbon dioxide, etc.)}

Component: 2. European and French context Author: DIDD (Antoine-Tristan Mocilnikar)

\section{Definition}

Measures that support the development of marine renewable energies are part of a European framework and Member States have great flexibility in determining how to apply them.

\section{Key indicators}

The level of effort, in terms of limiting greenhouse gases, that is made by public authorities in promoting all renewable energies and, more specifically, marine renewable energies.

\section{Looking back (over the past 50 years)}

\section{Slow construction of European energy systems before 2005-07}

Since the founding treaties - the Treaty of Paris (1951) that established the European Coal and Steel Community (ECSC) and the second treaty of Rome (1957) establishing the European Atomic Energy Community (EURATOM) - what was to become the EU was preoccupied with energy, although no treaty specifically referred to energy in its title.

During the 1950-70 period, the EU countries saw their oil needs grow considerably while their requirements for coal declined. However, it was only after the 1973 oil crisis, when the Organization of the Petroleum Exporting Countries (OPEC) decided to quadruple the price of crude oil, that the EU became fully aware of the need for a common energy policy.

There is no specific chapter in the Treaty of Rome dedicated to energy policies. However, an energy policy gradually evolved through the EU's major policies. It is found in the treaty articles on trans-European networks, security of energy supply, internal markets or the environment. The energy policy thus falls mainly under the 
jurisdiction of Member States: in accordance with the principle of subsidiarity, the EU does not seek to act in place of Member States in this field. In particular, the implementation of this common policy is founded on the respect of Member States' energy choices.

More specifically, the EU offered the possibility of elaborating energy strategies on a community level in certain fields. Energy must be governed by the demands of the domestic market. National gas and electricity markets are being progressively opened to all energy producers. Since 1 July 2004, all the largest energy consumers (professionals, businesses and local governments) have been free to choose their gas and electricity suppliers (directives adopted in 1996 and 1998). Since that date, households have also been able to choose their supplier from a competitive market (directives adopted in 2003). Currently, the common rules concerning consumer protection (i.e. information, transparency of contractual terms, complaint procedures, etc.) provided for by the directives have come into effect.

- In terms of the environment, one of the objectives of the EU is to ensure 'prudent and rational utilization of natural resources' (art. 174 ECT) and the EU Council can, unanimously, adopt measures to protect the environment that 'significantly [affect] a Member State's choice between different energy sources and the general structure of its energy supply' (art. 175 ECT).

- To alleviate crisis situations (e.g. shortage, embargo, price fluctuations), the EU is endowed with mechanisms destined to ensure effective solidarity between Member States, particularly through creating strategic oil stocks.

- The role of the EU in the nuclear sector was defined in the EURATOM treaty (1957); however, operational security of nuclear stations, storage of radio-active waste and nuclear non-proliferation are all mainly incumbent on Member States.

- The multi-annual 'Intelligent Energy for Europe' (2003-06) programme aims to reinforce European support for the promotion of new and renewable energies (ALTENER) and for the improvement of energy efficiency (SAVE) as well as to support initiatives that encourage energy efficiency and the use of renewable energies in developing countries (COOPENER). Moreover, the European Commission introduced a new facet to its energy policies by including the energy aspects of transport and the diversification of fuels (STEER).

- A European taxation system for energy products was adopted in 2003. An energy tax directive set up a European framework for taxation of energy products to improve the functioning of the internal market and to encourage initiatives conducive to the protection of the environment.

- The development of trans-European energy networks.

- Regarding electricity, two networks inter-connected to the main European electricity distribution grid (UCPTE network): the CENTREL electricity network that links Poland, the Czech Republic, Slovakia and Hungary and the NORDEL network that inter-connects the Scandinavian countries. Studies are currently underway for projects to extend the UCPTE network to Balkan countries, Baltic 
States, Central European Initiative (CEI) countries and the Mediterranean basin countries.

- The Energy Charter Treaty was adopted in 1991 to promote co-operation between EU and Eastern European countries. The Energy Charter Treaty and a protocol on energy efficiency and related environmental aspects became effective in 1998. These agreements provided a legal foundation for the principles laid out in the Energy Charter, including the protection of investments, freedom of energy transit and specific procedures for settling disputes.

- Funding of energy policies is essentially through loans from the European Bank of Investment (EBI) (18.9 billion euros in the past 5 years) and Structural Funds. In 2006, traditional and renewable energy sources benefited from a budget of 62.2 million euros, while nuclear energy disposed of a budget totalling 165.2 million euros. Credits allocated to common-interest projects on the transEuropean energy network amounted to 21.5 million euros.

\section{Growing momentum of climate issues}

The climate is a global issue. According to the report published in 2007 by the Intergovernmental Panel on Climate Change (IPCC) comprised of nearly 3000 experts, studies tend to show that increases in global temperature of more than $2^{\circ} \mathrm{C}$ expose the planet to significant risks. Global temperatures have already increased by $0.7^{\circ} \mathrm{C}$, a third of the increase. Admissible greenhouse gas concentrations must not increase by more than $18 \%$ of current concentrations. To stay within this limit, global greenhouse gas emissions must be halved, but if current trends continue, they will double. Reducing greenhouse gases is thus urgent and a rationale for definite decreases must be set in the next 15 years with radical reductions by 2050 .

The challenge is particularly great considering that the global need for energy the primary source of greenhouse gas emissions - is steadily increasing by $2 \%$ a year. The world population was 3 billion in 1960, it is 6 billion today and is projected to be 9 billion by 2050. Today, more than 2 billion people do not have access to energy sources. The economic explosion in Asia, particularly in China and India, makes an abrupt end to current growth unrealistic, even if industrialized countries apply drastic measures to save energy. Moreover, the limited quantity of fossil fuels, particularly coal, which can be used to produce fuel, will not solve the climate issue. Without reducing greenhouse gases, the demand for energy is expected to more than double $(+110 \%)$ by 2050 . Since economic growth favours coal, greenhouse gas emissions are increasing even faster than projected (+140\%).

To rise to this challenge, it is necessary to implement a global policy to control consumption and to make use of non-carbon-based energy more general, that is, renewable energy for the production of electricity, heat and fuel, as well as carbon capture and storage, coupled with thermal and nuclear power stations. Given the added costs, a global regulatory framework is necessary to impose renewable energies on energy system operators. The International Energy Agency (IEA) 


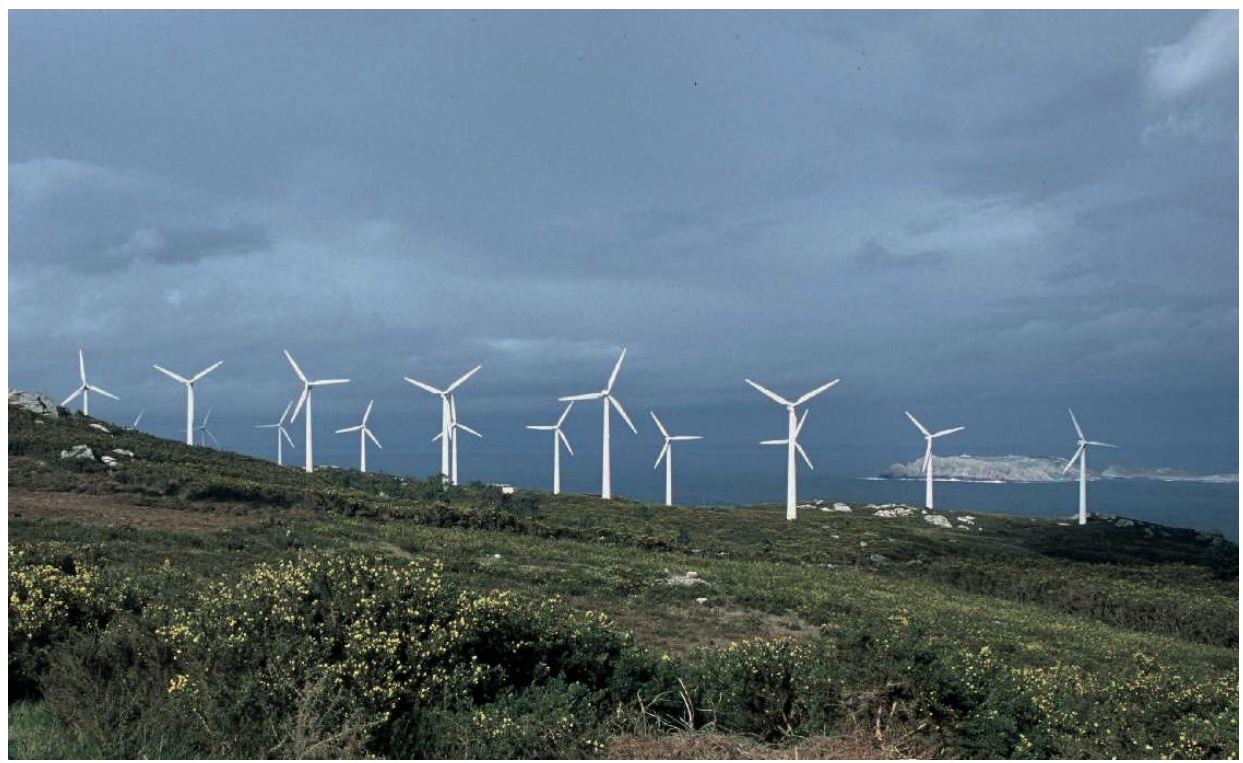

I Photo 19 : many European countries are developing onshore wind farm programmes as shown here in Spain to the south of Cape Finisterre (@ Ifremer, O. Barbaroux).

proposes a new pathway for clean development that assesses the relative position of each action. Within this framework, renewable energies represent $16 \%$ of the total effort.

The Kyoto Protocol is the most important instrument to address climate change. It embodies a commitment made by most industrialized countries to reduce their emissions of certain greenhouse gases responsible for global warming. On 4 February 1991, the Council authorized the European Commission to participate on the behalf of the EU in negotiations in the UN Framework Convention on Climate Change, adopted in New York on 9 May 1992. The Framework Convention was ratified by the European Community on 15 December 1993 and became effective on 21 March 1994.

During the fourth meeting of the Conference of the Parties that took place in Berlin in March 1995, the participating countries decided to negotiate a protocol incorporating measures to reduce emissions for the period beyond 2000 in industrialized countries. After much work, the Kyoto Protocol was adopted on 11 December 1997 at Kyoto. Overall, the parties to Annex 1 of the Framework Convention committed themselves to reducing their greenhouse gas emissions to at least $5 \%$ below 1990 levels during the 2008-12 period.

Annex $B$ to the protocol contains the quantified commitments given by the parties. The Member States of the EU must collectively reduce their emissions by 8\% between 2008 and 2012. On 31 May 2002, the EU ratified the Kyoto Protocol. This protocol entered into force on 16 February 2005 after being ratified by Russia. Several industrialized countries, including the USA and Australia, refused to ratify the protocol. After this commitment, the EU deemed it necessary to 
divide the emissions target among the 15 Member States. By the indicated time, France must stabilize its greenhouse gas emissions to the 1990 level.

The targets for emissions consented to by the developed countries are ambitious. As an additional means to meet their targets, the Kyoto Protocol provides for the possibility of resorting to 'flexible' mechanisms to complement the policies and measures implemented on the national level. There are three such mechanisms:

- international emissions trading that allows industrialized countries to buy or sell their emission allowance to other industrialized countries;

- joint implementation (JI) whereby developed countries can finance greenhouse gas emission reduction projects in other industrialized countries and thereby benefit from the emission reduction credits generated by the investment;

- clean development mechanism (CDM), closely related to the two previous measures, but where investments are made by a developed country in a developing country.

At the Community level, the EU implements emissions permits and a trading scheme. The European market of emission permits has been in effect since 1 January 2005. The trading system implemented as of 1 January 2005 as a result of Directive 2003/87 quotas, tests the 'carbon' market and anticipates the first commitment period 2008-12 of the Kyoto Protocol. The first targets are the carbon dioxide emissions from the heaviest emitting industries (i.e. paper, glass, cement, energy-related and oil refineries), representing $45 \%$ to $50 \%$ of all industrial carbon dioxide emissions. Approximately 12,000 facilities in EU25 are concerned. The principle is that for each period, the Member States set emission reduction targets for each facility through a national allocation plan, validated by the European Commission. At the beginning of each period, a given volume of quotas is assigned to each installation, based on the emissions generated by the industrial activities involved. A quota corresponds to the emission of the equivalent of 1 tonne of carbon dioxide. Two implementation periods were planned for 2005-07 and 2008-12.

As of 2005, France and the United Kingdom wished to reinforce the sustainable aspects of European energy and climate policies. This motivated a European Summit held in March 2007. During the European Council meeting at Hampton Court (October 2005, under British presidency), the Heads of State and Government expressed the desire to revitalize European energy policies, given the new challenges that Europe and the rest of the world face today, especially those concerning energy security and climate change. Since then, energy has been on the agenda at all high-level European meetings. Other than climate, the issue of supply security has received continued attention. If no measures are taken to improve European competitiveness in the energy market in 20-30 years, dependence on energy imports could reach 70\% compared with today's figure of $50 \%$. Lastly, energy needs, more and more permanent, are felt in all economic sectors. The issue of competitiveness is also a key element. These ideas will fertilize various initiatives. 
In January 2006, France submitted a memorandum to 'revitalize European energy policies with a view to sustainable development'. It proposed to implement a new European energy policy by means of some 30 measures, including:

- a prospective energy plan drawn up in each Member State of the EU detailing the medium- and long-term forecasts for managing supply and demand;

- multi-year programming of investments in generation, transport, reception and storage;

- the creation of 'energy saving certificates' that could lead to a European market for trade in these certificates;

- generalization of energy labelling on all products that consume energy or contribute to energy consumption;

- extension of the greenhouse gas emission quota trading system to air transport;

- development of inter-connections among European countries;

- increasing the use of biofuels, natural gas and liquefied petroleum gas in transport, particularly for captive fleets;

- the creation of a special representative position in the EU for energy matters, so that Europe can speak to its energy suppliers with a common voice.

The Green Paper in March 2006 entitled A European Strategy for Sustainable, Competitive and Secure Energy is largely based on the measures proposed in the French memorandum. The Green Paper contains concrete proposals divided into six specific priority areas and aims to revitalize European energy policy by:

- completing the internal electricity and gas markets in terms of growth and employment in Europe;

- improving supply security through ensuring solidarity among Member States: in particular, the Commission plans to 'create, as soon as possible, a European Energy Supply Observatory in charge of monitoring supply and demand patterns on EU energy markets, identifying likely shortfalls in infrastructure or in supply';

- strategically analysing all aspects of EU energy policy: in particular, the Commission declares that it might be appropriate to agree on an overall strategic objective to ensure a balance between sustainable energy use, competitiveness and supply security;

- combating climate change by improving energy efficiency and promoting renewable energies and carbon capture and storage;

- elaborating a European strategic plan for new energy technologies.

On 23 and 24 March 2006, the European Council laid the foundation for a more comprehensive and integrated energy policy for Europe. Moreover, to meet the objectives of the renewed Lisbon strategy and thereby, stimulate growth and employment in Europe, the EU promulgated a Competitiveness and Innovation Framework Programme (CIP) for the 2007-13 period. CIP supports actions that promote competitiveness and capacities for innovation and particularly encourages the utilization of renewable energy sources. This CIP also includes a 
sub-programme entitled 'Energy Intelligent - Europe' that supports improvements in energy efficiency, adoption of new and renewable energy sources, greater penetration of these energy sources into the energy market, diversification of energy and fuels, and reduction of energy consumption. A total of 730 million euros is allocated to the programme. The main document presented on 10 January 2007 was a communication from the Commission to the European Council and European Parliament entitled An Energy Policy for Europe. It included several reports and concrete proposals:

- a roadmap to promote renewable energy;

- a report on the progress made in the field of electricity generation from RES;

- a report on progress in the use of biofuels and other renewable fuels in the Member States of the EU;

- a communication on the prospects for domestic electricity and gas markets;

- a plan prioritizing the inter-connections for gas and electricity networks;

- a nuclear illustrative programme presented in the framework of EURATOM;

- proposals for promoting sustainable electricity generation from fossil fuels;

- a work programme in view of a future strategic plan for energy technologies;

- the action plan for energy efficiency adopted by the Commission on 19 October 2006.

The European Council could thus make definitive decisions for the entire EU. The way they will apply to each EU nation is currently being negotiated. They define three working priorities in terms of EU energy policy.

\section{Sustainability}

Since energy accounts for $80 \%$ of all greenhouse gas emissions in the $E U$, it is committed to reducing emissions to $20 \%$ below 1990 levels by 2020 . Additional objectives are a $20 \%$ increase in renewable energy sources, $10 \%$ increase in biofuels and $20 \%$ increase in energy efficiency. The reduction of greenhouse gas emissions could even reach $30 \%$ if 'other developed countries were committed to reaching comparable emission reductions and if the most advanced emerging market countries made contributions adapted to their respective responsibilities and capacities'.

\section{Security of energy supply}

Disruptions in supply of raw materials have both political and economic consequences.

\section{Competitiveness}

The internal strategy is very important: 'Providing that the right policy and legislative frameworks are in place, the internal energy market could stimulate fair and competitive energy prices and energy savings, as well as higher investment'. What is new is the development of an external strategy. The issue of competitiveness will arise if other regions in the world do not follow Europe's example. After proposing the implementation of external carbon taxes, France succeeded in convincing the Council to request the European Commission to tackle the issue of transferring carbon dioxide emission allowances to countries without 
climate policies. In the long term, this may require a global, simultaneous reform of UN institutions that deal with the climate, world economy and trade of goods and services. This would be a new Bretton Woods system - the original economic system created after the Great Depression of 1929 and the World Wars that ensued - but related to the world war against climate change.

The decisions made by the European Council constituted a move towards creating a unique market or enlarging it. This is what could be called a historic compromise or a sort of Yalta Conference on energy. It would also enable a balance to be struck between energy efficiency, nuclear power, nearly carbonneutral fossil fuel use owing to carbon capture and storage as well as renewable energies. As a result a balance could also be found between European determination and subsidiarity. Apart from a little refinement on internal aspects, this will constitute the European energy policy for decades to come. If energy issues were to be reframed within a European treaty, a summary of the Council's decisions could suffice. Thus, there is no need for a constitutional treaty to develop the subject of energy at the European level. The only challenge is to learn how to play the game with these new rules.

The general context has changed considerably for renewable energies. The former target was $22 \%$ of renewable electricity by 2010 . Now, there are two targets: $20 \%$ renewable energy and $10 \%$ biofuels by 2020 . Thus, the target has changed from just electricity to total energy, that is, heat, biofuels and electricity. This will bring about a new rationale for renewable energies. The European package will structure French practices. Each Member State will need to set national objectives from here on, taking account of the Commission's proposals.

\section{The emergence of a post-Kyoto plan of action}

In the current multilateral framework, beyond the EU, the Kyoto Protocol will reach its full-term in 2012 (also known as the 'first period'), which is the deadline for applying binding measures. So what will happen after 2012?

On the one hand, the EU has a lasting, multilateral framework that can evolve according to its implementation. On the other hand, external events, particularly influential events in the USA starting with George W Bush's initiative, may lead to modifications.

To build the framework of the future, several aspects must be taken into account. First of all, the framework must assimilate the largest emitters of greenhouse gases, that is, the USA, Canada, Mexico, Europe in its largest geographical sense, Japan, Australia, China, India, South Africa, Brazil and the main oil-producing countries. Secondly, the very different capacities and configurations of the various sectors involved must be taken into account. This leads to implicit carbon values necessary for the decarbonization of these industries and different implementation timeframes. It is thus necessary, in one way or another, to turn to decoupled regulatory tools for the next few decades. By 2050, it is hoped that all industry sectors will have converged; before then could be counter-productive. The 'real price of carbon' issue is thus left for the second half of this century. It will be necessary to implement both economic instruments (i.e. negotiable quotas and taxes) and normative 
instruments. A quota market should be flexible to allow for increased efforts. That way, it could be both geographically broad and deep-ranging in terms of liquidity. Bush's initiative most likely contains some elements that foreshadow the future. Thus, even if we are only in the beginning stages, it is useful to recall the main points.

- Establish a group of pioneer countries. Without explicitly naming them, the reference to the G8 and the Asia-Pacific Partnership on Clean Development and Climate (AP6), and the number of up to 10-15 countries, sets out a clear group: USA, Canada, Japan, France, United Kingdom, Germany, Italy, Russia, China, India, South Korea, Australia, Brazil, South Africa and Mexico.

- A new discussion forum should be created to progress more quickly in the framework of the UN Framework Convention on Climate Change (UNFCCC), but without supplanting it.

- In the short term, the goal is to reach an agreement to set global long-term reduction targets and then, for the pioneer group, individual long-term targets. Countries commit unilaterally to these targets and implement their policies independently. This means that the system is not based on the world emission quota market - nor does it prevent the market from working.

- For the medium term, the goal is to construct a framework for post-2012, when the Kyoto Protocol expires.

- A monitoring system will be set up.

- A complementary sectoral approach is also proposed, with the goal of establishing a set of rules for key sectors (i.e. electricity, transport, alternative fuels). These rules could ultimately become common rules.

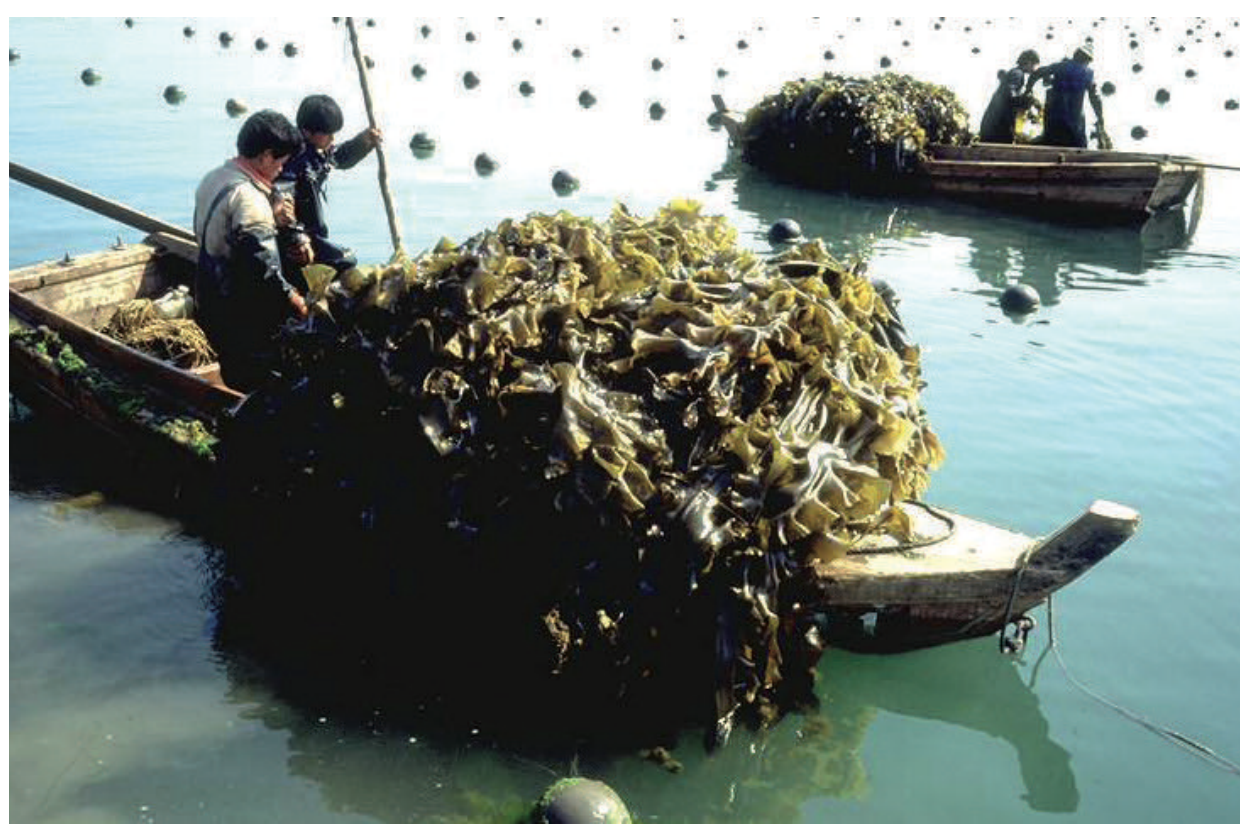

I Photo 20 : some Asian countries use macro-algae harvested on a small scale to produce algo-fuels (C) Ifremer, O. Barbaroux). 
- As always, the USA promotes technology and proposes a new approach to respond to the needs of emerging countries: eliminate cross-border barriers that hamper the transfer of clean technologies and donate technologies developed with public funds to the poorest countries.

- Concurrently, with all the UNFCCC countries, the USA proposes to immediately launch research and development in three areas: energy efficiency, promotion of clean technologies, and the development of sustainable agriculture and forestry.

Support measures and policies for renewable energies are defined and then evolve in this changing and complex context. These measures and policies help to combat the greenhouse effect and improve energy security. Energy policies will need to confront the challenges of competitiveness, which ultimately determine their long-term effectiveness.

\section{Outlook (for the next 20 years)}

From these past trends, the following hypotheses could be formulated (RES: all renewable energy sources).

\section{Hypothesis 1}

Targets met: $20 \%$ RES and $-20 \%$ greenhouse gases by 2020 and $-30 \%$ greenhouse gases, $25 \%$ RES by 2030

Support strategy for the RES industry whatever the type of supply line.

\section{Hypothesis 2}

Targets met: $20 \%$ RES and $-20 \%$ greenhouse gases by 2020 and $-30 \%$ greenhouse gases, $25 \%$ RES by 2030

Support strategy distinguishing between supply lines.

\section{Hypothesis 3}

Targets met: $25 \%$ RES; $-30 \%$ greenhouse gases by 2020 and $-45 \%$ greenhouse gases, $30 \%$ RES by 2030

Support strategy for the least competitive RES supply chains.

\section{Hypothesis 4}

2020 targets not met and targets are expressed as 'clean energy' with nuclear power and clean fossil fuels (carbon dioxide capture/ storage) 


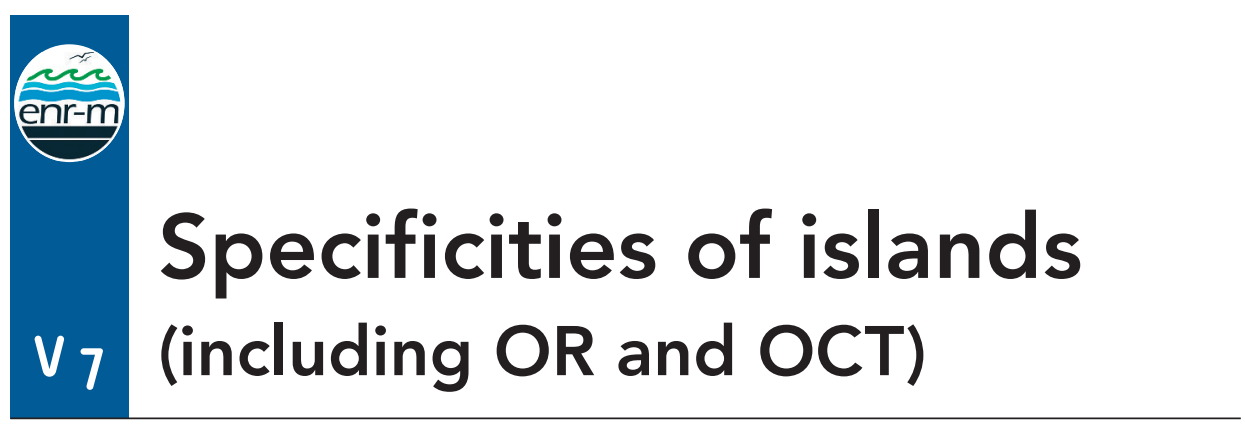

Component: 2. European and French context

Author: Ifremer and Collective

\section{Definition}

Islands pose specific problems for energy supply in general and potential marine energy operations in particular. These are due to three features.

- The physical and natural characteristics of islands determine the possibilities for project development as well as the characteristics of energy requirements. The size of an island and its remoteness or position in an archipelago, together with the distribution of areas of consumption and population density, will determine the appropriate energy supply. Physical accessibility of the coastal areas and their climate sensitivity (e.g. sheer cliffs, tropical weather events, sea level, etc.) determine whether offshore facilities can be installed and the types of RES that can be utilized.

- Social and cultural characteristics shape public acceptance of developments that are either complex or cause nuisances (especially on islands protected for tourism) as well as the appropriate human resources for maintenance of equipment.

- Economic characteristics condition the profitability of energy production: industries and services (like tourism) produce a demand for energy that cannot be covered by a single type of supply. Distance from the mainland (e.g. Outlying Regions (OR) and Overseas Countries and Territories (OCT) for the EU) can lead to specific subsidies to develop certain activities, as well as compensation for additional transport expenses.

\section{Key indicators}

There are seven kinds of relevant indicators.

- Suitability of coastal and nearby offshore areas.

- Outlying and isolated locations as opposed to proximity to active areas, possibly in an archipelago.

- Density and population distribution. 
- Protection of coastal areas specializing in tourism.

- Skill levels of the workforce.

- Economic activities and approach to development.

- Economic support policies from metropolitan France.

\section{Looking back (over the past 20 years)}

\section{In the EU}

- 1970s: the United Kingdom and Ireland join the European Economic Community (EEC). Both countries have poor areas, as do southern Italy and French Overseas Departments. Creation of Regional Development funds (EEC). EEC agreements with Africa, Caribbean, Pacific (ACP) countries, the funding of which competes with that given to EEC islands.

- 1980s: creation of social and economic cohesion policies (1985). Accession of Greece (1981), Spain and Portugal (1986) to the EEC. All these countries have remote islands and poor areas. Emergence of the concept of ORs. Reinforcement of development programmes and compensation for the costs of remoteness (programmes specific to some remote and insular European islands, such as Poseidom, Poseican and Poseima).

- 1990s: rich countries become EU members (i.e. Austria, Sweden and Finland). A declaration referring to ORs is inserted in the Maastricht Treaty (1992). The Amsterdam Treaty (1997) gives ORs legal status in the EU (art. 229).

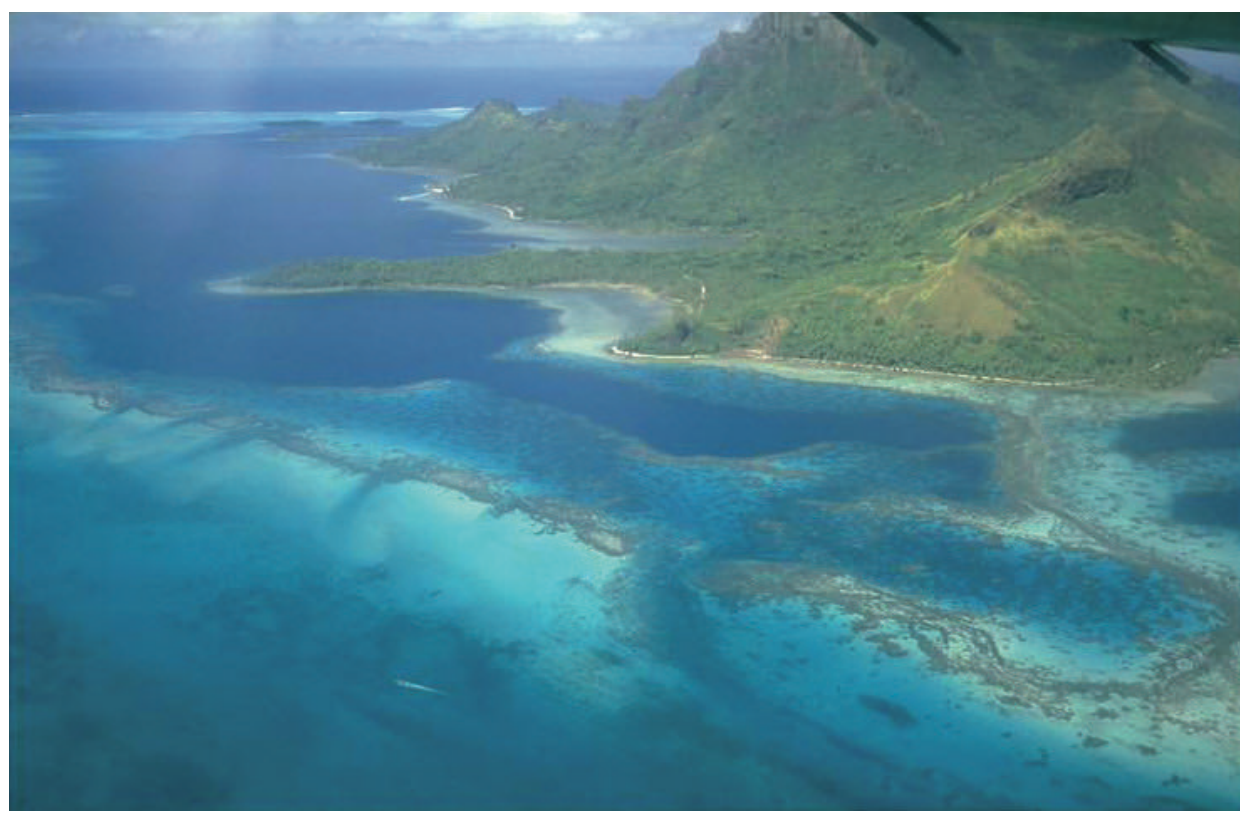

- Photo 21 : marine energy developments on islands, particularly tropical ones, create complex issues with respect to environmental protection (๑) Ifremer, O. Barbaroux). 


\section{In terms of energy}

- Utilization of renewable energies when available, for example, geothermal power in the Caribbean, particularly in the French Antilles since the 1980s. Inter-connection project with Dominica (by utilizing the archipelago's potential). A second example is the land-based wind turbines in the Antilles; climate riskrelated problems (hurricanes or cyclones) for which some manufacturers seem to be finding interesting solutions.

- Few offshore RES projects: a pilot $5 \mathrm{MW}$ ocean thermal energy conversion (OTEC) unit in French Polynesia (1982-85), which was abandoned in 1986 because it was not sufficiently competitive.

- Denmark: Samsø, a Danish island in the Baltic Sea, with an area of $112 \mathrm{~m}^{2}$ and 4300 inhabitants, has used $100 \%$ renewable energy since 2005 , including offshore wind.

- USA, a project for 130 offshore wind turbines at Cape Cod.

\section{Outlook (for the next 20 years)}

\section{Hypothesis 1}

- Continuing economic support and determined efforts to promote marine RES.

- Continuing EU subsidies to ORs.

- Favourable environment for voluntary development of RES (Kyoto Protocol and climate change), particularly marine renewables on islands. Investments in offshore wind farms and support for other supply chains depending on local physical features.

\section{Hypothesis 2}

- Continuing economic support and determined marine RES initiatives.

- Reinforcement of subsidies and tax exemptions in ORs.

- Economic and energy development strategy in ORs. Training and qualification of the workforce. Increased voluntary development of RES (including marine RES), taking advantage of island potential (e.g. coastal tourism, farming, industry, raw materials, etc.)

\section{Hypothesis 3}

- Continuing economic support, no determined development of marine RES, risks in coastal areas.

- No change in subsidies to OCRs, no other voluntary efforts.

- Persistence of difficulties that stem from the physical conditions of insular coastal areas.

- Increasingly serious climate and weather-related difficulties (global warming) with a trend for higher risks in coastal areas, particularly in the tropics. 


\section{Consequences of hypothesis 1}

- Favourable scenario for marine RES research funding. Pilot projects possible.

- Possible development of wind turbines depending on physical conditions.

\section{Consequences of hypothesis 2}

- Scenario very favourable for research. Independence for insular areas to carry out marine renewable energy pilot projects. Several operational offshore wind turbine farms. Co-financing of projects in archipelagos.

- Development of tourism coupled with coastal management efforts.

\section{Consequences of hypothesis 3}

- Little development of marine RES in insular areas.

- Increased need to invest in clean energies to limit climate risks, however, investment is made only on EU mainland. 


\section{Enforcement \& control, relevant tools in France \\ V 8 (incentives, carbon taxes)}

Component: 2. European and French context

Author: Meeddat (Cyril Pouvesle)

\section{Definition}

The schemes implemented by lawmakers to drive the development of marine renewable energies in France are described here. These incentive schemes are instruments set up to help countries reach national targets and meet European and international commitments in terms of renewable energies and marine renewable energies. The incentives should not be viewed only from the standpoint of the industrial firms developing these projects. Indeed, given the impact of RES projects on the public, lawmakers must also encourage local and regional authorities to develop RES projects in areas under their jurisdiction.

\section{Key indicators}

The main indicator is the level of support given to the development of renewable energies. This support varies with the different incentive schemes.

- The schemes include: calls for tender; guaranteed feed-in tariffs; Renewable Energy Certificates (also called green certificates).

- Local incentives: incentive instruments for local governments; offshore wind farm tax revenues.

\section{Analysis of schemes and feedback Electricity}

There are three main systems designed to promote renewable electricity generation. They can stimulate the industrial sectors involved to a greater or lesser degree. A combination of different schemes can also be envisaged.

Invitations to tender

Using competitive bidding or calls for tender, the regulatory authority defines a protected market for a given quantity of electricity generated using renewable energies, making it compulsory for utilities to source their electricity from the 
selected producers. Thus the price per kilowatt hour is reached through competitive bids. Tenders are classified by increasing cost or other criteria (e.g. environmental impacts, public acceptance, etc.), until the amount up for auction is reached.

\section{The case of offshore wind farms}

In 2004, the Ministry for Industry launched a call for tender on offshore wind farms for accumulated power generation of $500 \mathrm{MW}$. After examination of tenders, the delegated minister chose just one project located on the Alabaster coast in Normandy for a total of $105 \mathrm{MW}$ at a guaranteed tariff of the order of 100 euros/ $\mathrm{MWh}$, in contrast to 45 euros/MWh on the wholesale electricity market.

\section{Feed-in tariffs}

Feed-in tariffs have historically been the major mechanism for promoting renewables in Europe. The successes of the current German and Spanish policies, as well as the former Danish scheme, attest to the efficacy of this mechanism. Feed-in tariffs force utility companies to buy electricity produced by renewable energy suppliers located in their service area at a fixed price. This tariff is imposed by public authorities and guaranteed for a certain period (generally about 15-20 years). The tariff is usually graduated over time to take decreasing production costs into account over the life span of a renewable energy project.

Feed-in tariff: offshore wind farms (7 July 2006 decree): set at 130 euros/kWh for offshore wind turbines. After 10 years, the tariff is graduated for facilities producing more than $3200 \mathrm{kWh} /$ year.

Feed-in tariff for electricity generated with other marine renewables (1 March 2007 decree): set at 150 euros/MWh.

\section{Renewable Energy Certificates/quotas}

The generation of renewable electricity can undergo a certification scheme that attests to its renewable origin. A quota system can be implemented based on these certificates. This system aims to promote the production of renewable energies by artificially boosting demand through regulatory obligations. The quota defines the annual quantity or proportion of renewable energies that must come from eligible renewable sources. The quota obligation concerns the final sale of electricity and is imposed on operators in the electricity market. In the quota system, a penalty is applied if suppliers do not meet defined targets. Quota systems are based on Renewable Energy Certificates (RECs) that can be traded on the market. The RECs can be traded, temporarily held or used, just like any other energy commodity.

The quota mechanism applies to all sources of renewable energies declared to be eligible by lawmakers. In principle, RECs can be used to meet a quota, whatever the type of technology used to generate electricity, except when the lawmakers decide to promote different types of renewable energy contributions.

Letting competition and the market select the most cost-efficient and least risky technologies can handicap certain RES technologies. Lawmakers may wish to 
promote the diversification of energy sources and supplement support for emerging technologies with direct funding (e.g. investment subsidies, tax measures) or with other instruments, such as calls for tender or feed-in tariffs, as is the case in the United Kingdom where the government opened a call for tender for offshore wind farms.

\section{Comparing the schemes}

The fact that calls for tender are not often held prevents this mechanism from being the main instrument of support for renewable energies and the development of industrial strategies. However, if their pricing is sufficiently attractive, feed-in tariffs can theoretically generate rapid, significant and sustainable growth in renewable electricity supply chains. The main criticism is that if the feed-in tariff is too high, the system creates revenues for operators at the expense of consumers who are actually financing the mechanism.

Statistical analyses of growth dynamics in EU15 Member States suggest that feed-in tariffs show better cost-effectiveness in terms of installed generation capacity. However, the REC mechanism is still too early and empirically applied to enable the cost-effectiveness of support schemes to be determined.

\section{Local incentives}

Tax revenues (and prospects of creating employment opportunities) provided by renewable energy installations on the coasts under the jurisdiction of local authorities may trigger greater public acceptance of the installations.

\section{Example of a wind farm tax}

The French energy policy guidelines laid out in the 13 July 2005 Energy Act authorized federations of municipalities to levy business taxes on wind turbines installed on their lands, with a compensatory mechanism for towns where wind farms cause a nuisance. The amended Finance Act for 2005 complements the mechanism by extending the rules relative to economic activity zones (i.e. set tax rates, measures arising from deliberation procedures, compensation systems, county-level equalization funds) to wind farms as of 2006. As of 2007, offshore wind farms will be subject to an ad hoc local tax with a national fund to ensure the distribution of the monies raised by it (50\% to coastal municipalities where wind turbines are visible and $50 \%$ to county funds for maritime fishing and leisure activities). This tax is set at 12,000 euros/MW.

\section{Outlook (for the next 20 years)}

\section{Hypothesis 1}

No incentives for electricity. End of incentive systems. Targets are met by other types of renewable energies or are not met at all. 


\section{Hypothesis 2}

No incentive system, calls for tender for electricity

The development of marine renewable energies is spurred by calls for tender. It is, therefore, erratic. Industrial firms do not develop a long-term strategy and marine renewable energies struggle to develop.

\section{Hypothesis 3}

Advantageous feed-in tariffs and/or green certificates with differential for marine RES.

\section{Hypothesis 4}

Standardized renewable energy certificates and development. The consequences of this hypothesis are unclear due to lack of experience in this type of scheme. 


\section{enr-m \\ Regulatory instruments $v_{q}$ for biofuels}

Component: 2. European and French context

Author: Meeddat (Cyril Pouvesle)

\section{Definition}

Micro-algae can be a source for biofuel production. The schemes implemented by lawmakers to drive the development of micro-algae production in France are described here. These incentive schemes are instruments set up to help reach national targets as well as European and international commitments in terms of developing biofuels.

\section{Key indicators}

The main indicator is the level of support provided for the development of marine biofuels.

\section{Analysis of schemes}

France has implemented an incentive scheme for the production of biofuels based on two instruments.

- Tax exemptions: domestic consumption tax (TIC) partially waived; currently 33 euros/hl for ethanol (direct or ETBE), 30 euros/hl for VOEE and 25 euros/hl for vegetable oil methyl ester (VOME), animal oil methyl ester (AOME) and synthetic biodiesels (French Customs code 265b/A)30;

- VOME and AOME (-25 cents/litre in 2007);

- ethyl derivatives, including alcohol, of agricultural origin (-33 cents/litre ethanol);

- ethanol included in E85 fuel (-33 cents/litre ethanol);

- synthetic biodiesel (-25 cents/litre).

- Inclusion targets: since 2005, a biofuel ecotax (TGAP)31 has been established. This measure obliges oil companies and fuel distributors to add a certain

30. E85 also enjoys an advantageous domestic consumption tax at a rate of 33.43 euros/hl.

31. The calculation of TGAP is detailed in order no. 06013 of the French customs Bulletin Officiel des Douanes. 
percentage of biofuels to the regular fuels consumed in France. Otherwise, distributors must pay taxes proportional to the volumes of biofuels not incorporated (article 266e).

Inclusion targets are presented in Table 9.1.

\begin{tabular}{|c|c|c|c|c|c|}
\hline Year & 2006 & 2007 & 2008 & 2009 & 2010 \\
\hline Target (energy ratio) & 1.75 & 3.5 & 5.75 & 6.25 & 7.0 \\
\hline
\end{tabular}

I Table 9.1 : biofuel inclusion targets (\%) in France until 2010. Source: Article 266e III of French Customs Code.

For more general information, see also the agricultural guidance act No 2006-11 of 5 January 2006, in article 48: 'To this end, notably by approving new production capacities, the State creates the conditions which will enable the proportion of biofuels and other renewable fuels to reach $5.75 \%$ as of 31 December $2008,7 \%$ on 31 December 2010 and 10\% on 31 December 2015 in the energy content of the total amount of oil and diesel fuels offered for sale on the national market for transport purposes'.

The budget effort devoted to support for biofuels was 167 million euros in 2004, 192.9 in 2005, 266 in 2006 and 485 in 2007. By 2008, this should be five times higher than in 2005 and 10 times higher by 2010 (Source: General Directorate for Energy and Raw Materials (Meeddat)).

\section{Outlook (for the next 20 years)}

\section{Hypothesis 1}

End of tax exemptions - no approval for inclusion

End of tax exemptions for biofuels because they weigh too heavily on the budget. Marine biofuels are approved to be part of inclusion targets.

\section{Hypothesis 2}

End of tax exemptions - high targets for biofuel inclusion

End of tax exemption for biofuels. Inclusion targets rise regularly and marine biofuels enjoy moderate development.

\section{Hypothesis 3}

Tax exemptions for marine biofuels (favoured) and inclusion targets

Partial tax exemptions for marine biofuels are made as they require fewer resources than other fuels (particularly in terms of water resources). This leads to the development of biofuels from marine sources. 


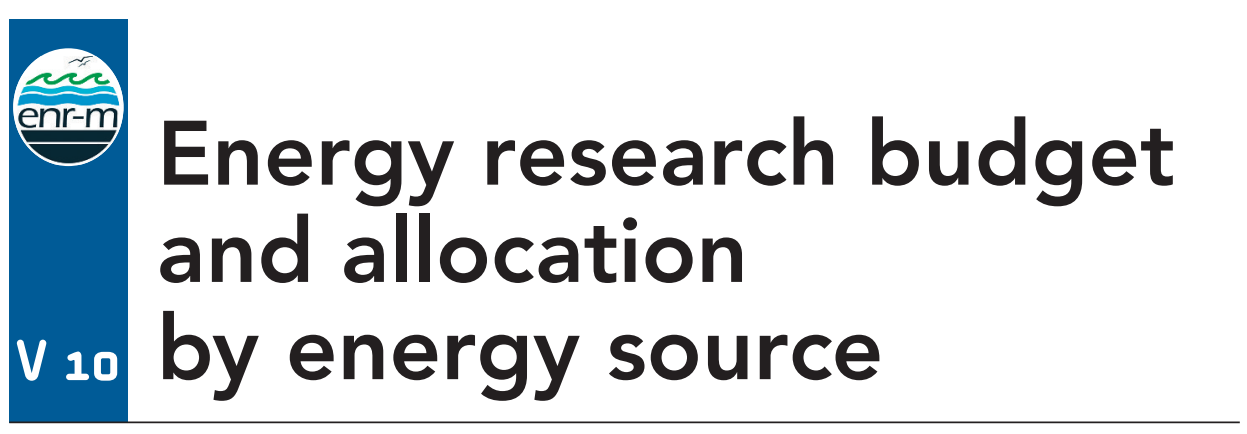

Component: 2. European and French context

Author: Futuribles (Véronique Lamblin)

\section{Definition}

This variable is defined as funding for research in the field of energy at the European and French levels, from the public or private sectors and its allocation by subject (e.g. fossil energy, renewable energies, energy management, storage, etc.).

\section{I Key indicators}

Sums actually allocated to research as a proportion of the total research budget. Expenditure by research topic.

\section{Looking back (over the past 20 years)}

\section{EU expenditure: framework programmes}

EU energy research support through framework programmes (FP) has steadily decreased in real terms over the years and even more so in terms of the proportion of the total R\&D budget: down from 66\% in FP1 (1983-86) to 12\% in FP6 (2003-06). $R \& D$ funds for nuclear energy have remained stable in real terms (estimated at 1 billion euros), but its proportion of total R\&D funds was reduced to $7 \%$ in FP6.

Renewable energies have become more important over the years. $R \& D$ expenditures in renewable energies represent around $50 \%$ of the non-nuclear R\&D budget since 1994 (World Energy Council, 2001: 100-101).

\section{Public spending in Member States}

Overall, public spending in Member States (EU15) in energy research has been three to five times the amounts spent by the EU through the FPs.

Since the 1980s, EU15 public spending in energy research has decreased more than in the other Organization for Economic Co-operation and Development (OECD) countries (only Japan has continued to increase its energy research budget 
over the same time period). Today, of all OECD countries, Japan represents $40 \%$ of public research in the field of energy, the USA 33\% and the EU15 about 20\%.

While Europe and Japan continue to invest a good part of their budget in nuclear energy (46\% and 70\%, respectively), the USA focuses its research on other topics (e.g. nuclear energy only accounts for $11 \%$ of the energy R\&D budget). It should be noted that the USA, like Japan but unlike EU Member States, has increased its research budget in energy management since the mid-1990s.

The EU15 Member States spent 17\% of their budget on renewable energies in 2001, but this is 15\% higher than that of the USA and double Japan's investment. However, comparisons between the EU15, the USA and Japan should be interpreted with care. While the overall energy research budgets (excluding nuclear energy) in EU15 and Japan are comparable, they are structurally different in coherence and efficiency. Japan, via its Ministry for Economy, Trade and Industry, and the USA, via its Department of Energy (DOE), directly or indirectly guide and coordinate their energy research programmes.

Moreover, research priorities are highly dispersed among European countries. This is due to inherent national differences in past energy choices (e.g. nuclear energy in France), available energy resources and industrial policies. For example, since 1991, Germany's fossil energy research budget has been entirely dedicated to coal (including carbon capture and storage) and its nuclear energy research budget is essentially allocated to fusion power. The United Kingdom maintained a budget for oil, gas and coal research until 2003 and since then, only carbon sequestration is funded (oil and natural gas production in the North Sea is on the decline).

In France (data until 2002 only), the nuclear energy research budget is essentially dedicated to nuclear fission power, while research on fossil energy is only concerned with natural gas and oil (although France has no significant resources, one of the major oil companies is French).

A third of European public spending on renewable energies and half of the related personnel in Europe come from Germany alone. Denmark and the Netherlands have the highest ratio of renewable energy in total national R\&D budgets (roughly $0.7 \%$ in 2001). The Nordic or Scandinavian countries (Finland, Denmark and Sweden) and the Netherlands had the highest ratios of renewable energy R\&D to gross domestic product (GDP) at the time of this assessment.

In the International Energy Agency (IEA)'s database of statistics (Note: budgets allocated to wind power do not distinguish between offshore and onshore), only the United Kingdom (with the largest budget), Denmark, Sweden, Norway, Ireland, the Netherlands, Portugal and Greece have specifically allocated budgets for marine energies over the past few years.

\section{Private spending}

Private funding of energy research is not as well documented as public spending. The available data are too limited and patchy to indicate trends. In a report on the distribution of $R \& D$ funding in renewable energies, the European 


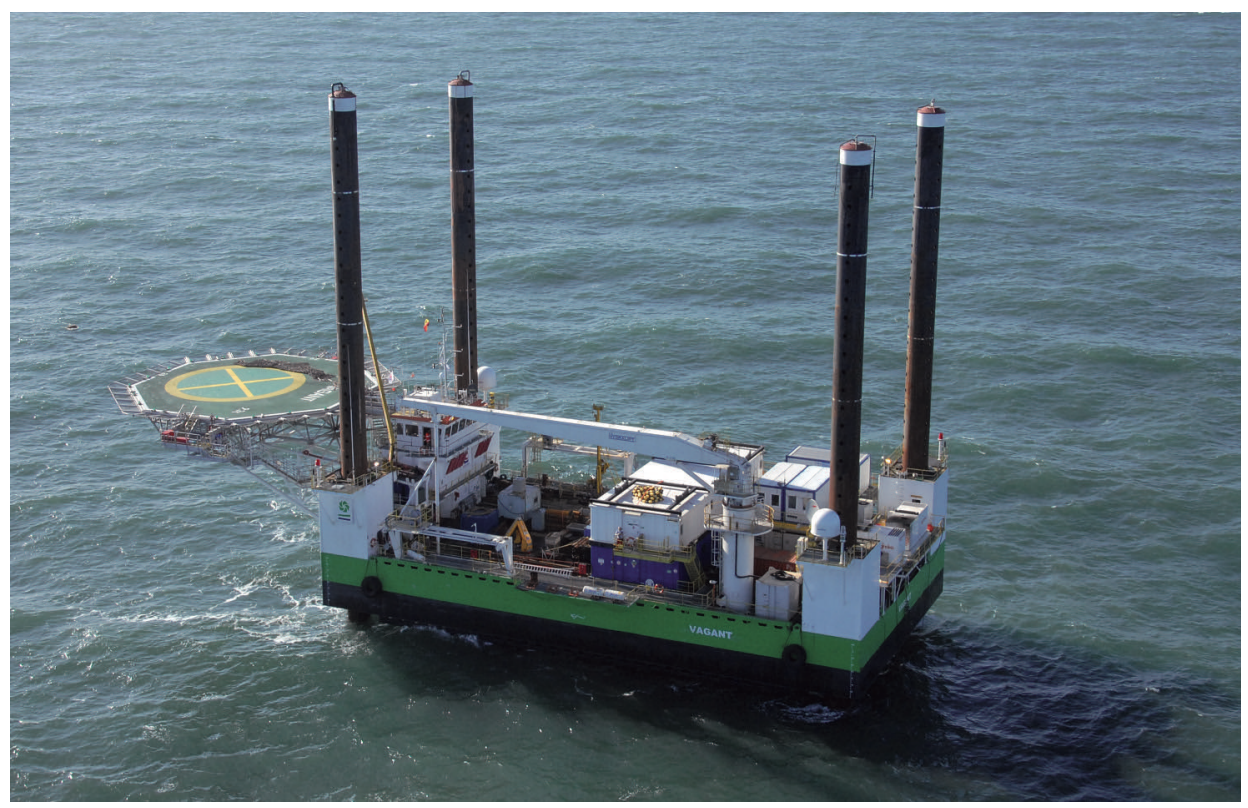

Photo 22 : ocean energy farms require thorough, and costly, preliminary studies (@ Deme, BE).

Commission 32 estimated that research funds are made up by approximately half public funding (from States) and half private funding. In 2001, public spending on renewable energy research totalled an estimated 350 million euros, private research 340 million euros and EU contributions reached 90 million euros.

The French Trade mission in Tokyo ${ }^{33}$ estimated that private R\&D efforts reached 5 billion euros, five times the amount of public R\&D spending in Japan, excluding nuclear power. The French Trade mission in Washington estimated that private R\&D efforts amounted to 1 billion euros (this amount is often directed to projects in partnership with the DOE, which generally requires that federal funds be matched or bettered by the investor).

\section{French R\&D}

In France, according to IEA statistics, energy R\&D spending is essentially dedicated to nuclear energy (between $80 \%$ and $90 \%$ from 1985 to 2001, and $77 \%$ in 2002). Nevertheless, the amount spent on research in renewable energies and on energy management increased between 1999 and $2002^{34}$.

32. Report on the breakdown of R\&D financing in renewable energies; European Commission, 2004.

33. Report on New Technologies for Energy, Working Group presided by T. Chambolle, Ministry for Economy, Finance and Industry, June 2004.

34. In 2002, budgets totalled 25 million euros for energy efficiency, 37 million euros for fossil energy, 31 million euros for renewable energies and 406 million euros for nuclear energy. 
It should be noted that public spending in research on renewable energies was lower in 2002 than in 1985. Solar energy reaps the majority of the funds.

\section{Main sources}

- Key technologies for Europe: Energy, B.H. Jørgensen, Risø National Laboratory, August 2005. DG Research.

- Report on New Technologies for Energy. Working Group presided by T. Chambolle, Ministry for Economy, Finance and Industry, June 2004.

- IEA statistics website.

\section{Summary}

Compared with past figures, public energy research budgets in Europe have increased after oil crises and in response to the development of nuclear energy. The post-oil crisis and the moratorium on nuclear power in certain European countries have led to large reductions in energy research budgets. Since the beginning of the 2000s, public research budgets for renewable energies have risen in Europe, including France - most likely in response to the greenhouse effect, but also to the more recent increase in price and insecurity of oil - even though overall energy research budgets have been decreasing. Research on marine energies benefits from this resurgence of interest in renewable energies for the time being, and is essentially being carried out in the United Kingdom and Denmark.

\section{Outlook (for the next 20 years)}

From these past trends, the following hypotheses for public research can be formulated.

\section{Hypothesis 1 \\ Strong development in RES research}

Steady increase in research budgets for RES in Europe. Spending on nuclear power is mostly dedicated to fourth-generation concepts and is collective. All countries with significant marine coastlines invest in research on marine energies.

\section{Hypothesis 2 Industrial priorities}

Continuing increases in research budgets for non-fossil energy, however, the demand for non-fossil energy production is high and, developing countries and European industrial firms in particular, compete to penetrate these energy markets. As of 2012, national research priorities are redefined to improve competitiveness of proven industrial technologies (decrease in costs) and to support national industries, including both nuclear power and renewable energies (solar and wind power and biofuels). 
Hypothesis 3

Lower research budgets.

Although the proportion of research budgets allocated for RES increases until 2020, the downward trend in total research budgets continues, both in France and Europe overall. This leads to stagnating RES research budgets between 2012 and 2020 that then decrease after 2020. 


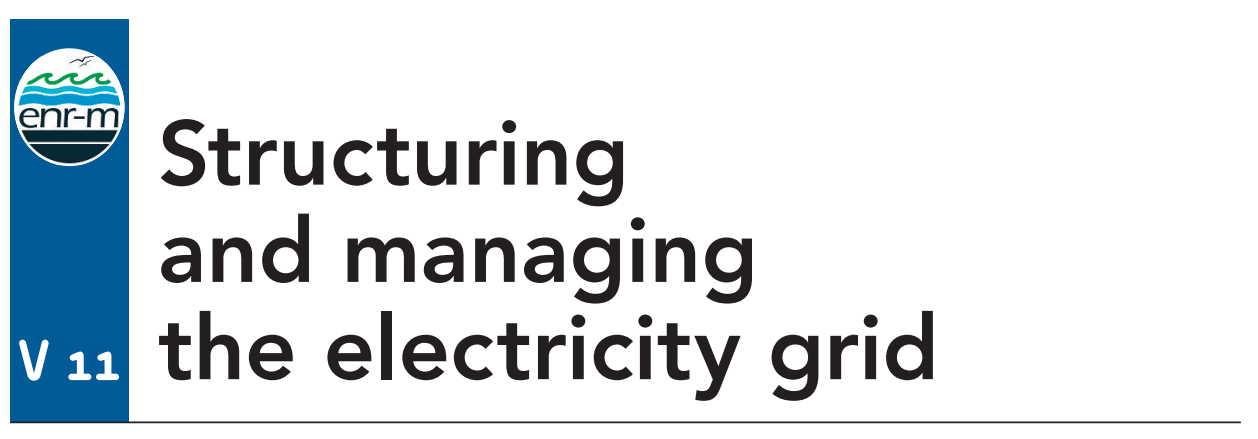

Component: 2. European and French context

Author: Ademe (Nils Siebert)

\section{Definition}

There are two aspects to this variable, that is, how an electricity network or grid is structured and how it is managed. They are related because they are interdependent.

Network structure comprises the following components: generation facilities, the transport and distribution grid, the charges supplied by the network and their spatial organization.

Network management comprises all the procedures and methods that maintain the network's balance through a reliable and efficient response to demand. Several tasks are included in network management: predicting demand, forecasting production from sources that are either difficult or impossible to control, planning and implementing generation facilities.

The structure of European networks and the methods for managing them from present day to 2030 is presented here. More specifically, the ways in which substantial quantities of RES (particularly wind power) will be integrated into the network from now until 2030 are identified. Within this framework, the focus is centred on an examination of the primary energy sources and the properties of the transmission network. The structure of demand is only addressed marginally.

\section{Key indicators}

The penetration rate of a particular type of RES into the existing network is an indicator of the carrying capacity of the network with respect to this RES. The level of penetration can be defined in terms of energy or power. In terms of energy, the penetration rate is the ratio of the quantity of energy supplied to the network by the RES relative to the total amount of energy injected in the network over a given period of time. In terms of power, the penetration rate is most often the ratio between the maximum amount of power supplied to the network relative to the power demand at a given moment. Thus in 2004, the penetration rate of 
wind power in the Danish network was $20 \%$ in terms of energy, but for several hours a year, it supplied more than $100 \%$ in terms of power.

\section{Looking back (over the past 20 years)}

Electricity networks were first developed at the end of the 19th century. In the beginning, networks were small and belonged to local companies that generated and distributed the power. Generally speaking, it was only after 1945 that nationalized networks became large, vertically integrated monopolies that undertook electricity generation, transmission and distribution.

In this monopoly-based system, grid operators defined network structure and the management methods needed to meet their public service mission as reliably and efficiently as possible. Given this context, networks adopted a structure and management methods adapted to their mission. This structure can be qualified as centralized: the network was planned and run by a single power station. Furthermore, power stations can be broadly characterized as large hubs with high inertia, supplying basic demands as well as smaller sub-stations that have low inertia and that respond to peak demand consumption. In this framework, only a small part of power generation comes from non-controllable (intermittent) sources.

After the oil crisis in the 1970s, European countries wanted to diversify their energy sources. This resulted in 'new' electricity power generation sources becoming available for networks, particularly modern wind power generation in Denmark and the USA. Nevertheless, during this period, relatively few non-controllable renewable energy sources were connected to the network and integration was not an issue.

During the 1980s and 1990s, European networks were faced with two different types of change. Firstly, the existence of vertically integrated electricity monopolies was called into question. Secondly, concerns over anthropogenic climate change as well as diminishing resources and increasing prices of 'conventional' energies (i.e. coal, oil, gas) pressed the EU Member States to implement measures to promote RES.

Thus, electricity monopolies were dismantled and the activities of generation, transmission, distribution and delivery were separated. Since transmission and distribution are both natural monopolies, only generation and delivery were opened to the market. This change resulted in a highly regulated electricity market that guarantees free competition among all the stakeholders. For their part, network transmission and distribution companies ensured network operational security.

The development of RES, particularly wind power, introduced networks to less- or non-controllable power sources. As long as the penetration of non-controllable (intermittent) sources is low, the current management methods and networks can handle these types of power sources without too much difficulty. Nevertheless, 
during the 1990s, the intense development of wind power impelled network operators to review their management methods and network structure to be able to integrate larger quantities of non-controllable power.

These two types of change prompted the stakeholders in the electricity sector to rethink future network structures and management. The issue was how to shift from a centralized network to a network where planning and management do not depend on a single power station, but on a growing number of stakeholders whose interests do not always converge.

Today, the second most developed RES sector is wind power, after hydropower. Most studies concerning the future of networks are restricted to the impact of wind power on network structure and management. The majority of studies carried out to date show that a penetration rate of $20 \%$ wind power can be achieved without any major technical difficulties and at low added costs for the consumer (in the order of 0.05 cents/kWh) (EWEA, 2005). Beyond this level of penetration, added costs are higher and changes must be made to the network system. Nevertheless, there are no technical limitations to integrating wind power sources into electricity networks. An in-house study made by the Danish transmission network company Energinet explored the consequences of installing a wind farm that could theoretically cover up to $100 \%$ of the annual demand for electricity (Chabot, 2007). This study showed that if no wind-generated electricity was exported beyond the Energinet network, there would be no need to stop wind turbines at up to $30 \%$ penetration in terms of energy. If the wind farm was sized to cover $100 \%$ of demand, only $31 \%$ of theoretical wind power generation would occur during times of lower demand.

Today, the uncertainties that hinder the massive integration of RES into networks are economic and regulatory, rather than technical, in nature.

\section{Outlook (for the next 20 years)}

In the prospective analysis, several studies can be cited, although most only consider wind power. The European Wind Integration Study (EWIS) published on the European Transmission System Operators website highlights the impacts that significant integration of wind power would have on the European grid (ETSO, 2007):

- transmission capacity may be limited in certain cases;

- increased reserves are required to cope with the irregularity of wind power;

- losses over the grid are greater since the sites where wind power is generated are far from where it is consumed;

- this distance also increases the need for more reactive power;

- wind power generation prevents other conventional power sources, whose costs are competitive, from accessing the network.

The study gave the following recommendations to deal with these impacts:

- harmonize incentive schemes for wind power, so that wind farms are developed only at the windiest sites, thereby leading to a more scattered spatial distribution of wind power capacity; 


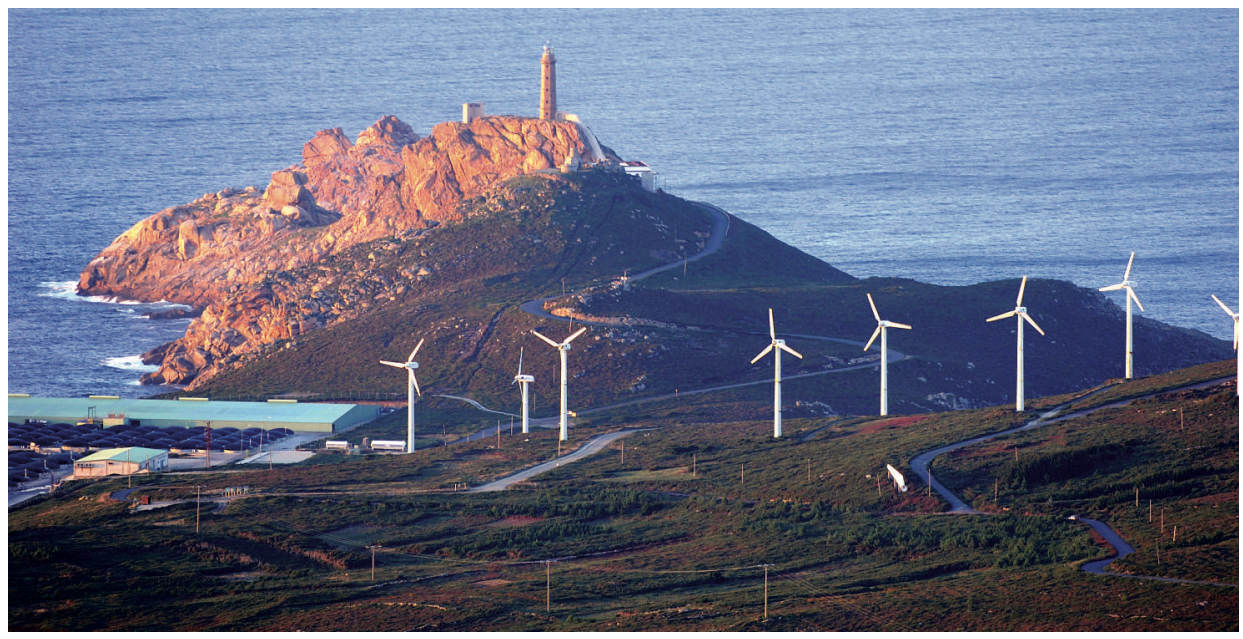

I Photo 23 : Spanish wind farm at Cabo Villano, Camariñas, Spain (@ Sociedad de Salvamento y Seguridad Marítima, ES).

- speed up procedures to approve new transmission lines;

- modify the market adjustment rules so that the high cost of wind power is applied as an overhead;

- improve the connection requirements for wind turbines to reduce instability during sudden voltage or frequency drops in the network.

The study on integrating wind power conducted by the European Wind Energy Association (EWEA, 2005) contradicts the recommendation of the EWIS study on a certain number of points. It recommends the following:

- reinforce inter-connections between grids, which would promote competition at the European level and would smooth the generation of wind power owing to greater proliferation;

- set up network management methods to better integrate less- or non-controllable generation sources; use short-term prediction tools to better manage the system;

- reinforce the load flow of European networks through concerted efforts; this back-up is not only due to wind power integration but also to increased demand and changes in the overall electricity power system;

- better recognize the contribution of wind power to the balance of supply and demand; although it is variable, wind power contributes to the capacity of electricity networks;

- improve connections to meet foreseeable needs of the network;

- continue R\&D efforts, particularly in forecasting power generation, assessing the impact of wind farms, including network dynamics, and determining ways to make networks more flexible: storage, new management systems (microgrids), etc. 
In short, changes in network structure and management depend on the regulatory measures and policies implemented for the different generation sources (e.g. RES incentives, carbon taxes, surcharges for different technologies) and decisionmaking processes when planning the future of networks (e.g. consultation of stakeholders, deadlines for extending and strengthening the grid, distribution of costs related to upgrades) and network developments based on technological advances. The latter include: large-scale storage, management methods and techniques (e.g. forecasting power generation from intermittent sources, stochastic management algorithms), network services provided by RES power producers, new paradigms for network structure, like micro-grids at the distribution network level.

\section{Hypothesis 1}

Investments and regulatory instruments are set up to change network systems. Penetration of RES is not restricted: $50 \%$ RES is foreseeable on a European level by 2030.

\section{Hypothesis 2}

Regulatory instruments and investments are delayed. Penetration of RES is limited by networks' carrying capacity. This hypothesis corresponds to a prediction of $30 \%$ RES penetration by 2030.

\section{Bibliography}

Chabot B., 2007. L'intermittence et les aléas météorologiques, un frein au développement de l'électricité renouvelable? L'exemple de l'éolien, Liaison Energie - Francophonie Global Chance - numéro spécial: Énergies renouvelables, développement et environnement - Discours, réalités et perspectives, pp. 23-25, April 2007. Quebec: Institut de I'énergie et de l'environnement de la francophonie [http://www.iepf.org/docs/lef/ LEF-GC-07.pdf]

ETSO, 2007. European Wind Integration Study (EWIS) Towards a Successful Integration of Wind Power into European Electricity Grids. Final Report, January 2007. Brussels: European Transmission System Operators. [http://www.etso-net.org/activities/ Renewables/e_default.asp]

EWEA, 2005. Large-scale Integration of Wind Energy in the European Power Supply: Analysis, Issues and Recommendations, Report, December 2005. Brussels: European Wind Energy Association. [http://www.ewea.org] 


\section{Energy storage and transport technologies \\ 12 (including hydrogen)}

Component: 2. European and French context

Author: Saipem (Jacques Ruer)

\section{Definition}

\section{Introduction}

Most marine renewable energies that can supply mechanical or electrical energy are intermittent. In the case of electricity generation, there is no reason that wind, wave, tidal or stream power will match the instant requirements of a local grid at a given point. As long as the penetration rate of intermittent-source electricity does not go beyond $15 \%$ to $20 \%$ of network capacity, the absorption of variable power loads is possible without greatly destabilizing the network. This is termed negative consumption, since the renewable energy source takes away a share from the conventional energy generation. Beyond this threshold, conventional generators are necessary to relay the intermittent sources.

An alternative would be to store the electricity generated and transmit it according to demand. It is thus useful to examine to what extent the implementation of the various forms of energy storage could influence the development of marine renewable energies.

\section{General background}

Some renewables are characterized by intrinsic storage:

- wave power: water retained in the basin stores energy as long as it does not flow through turbines;

- ocean thermal energy conversion (OTEC): where the primary energy source stores thermal energy;

- biomass energy: enabling energy to be stored until it is consumed;

- freshwater production: this can be stored between the time it is produced and used.

Storage is not a problem except in the case of intermittent electricity generation and this will be the only case examined here. 
Electricity storage can take various forms, as the following examples show.

- Small, isolated networks (islands): batteries are used as a buffer to provide several hours of consumption and to protect primary consumers (e.g. emergency services). Islands that are powered by solar energy always have battery storage, so storage does not only concern ocean-based energies. Storage adds a cost to energy, but the desired level of service requires the storage of energy. In case of need and on sites when periods of low productivity arise (without wind or sunlight), it is necessary to adopt a hybrid system with a thermal generator. The energy is thus stored in chemical form (fuel).

- Beacon equipment: batteries are used to store electricity generated by solar panels, wind turbines or wave power generators.

- Tidal power plant: water is stored in a basin to be sent through turbines at the optimal time.

- High-power offshore wind: the financial cost of offshore wind farms favours high capacity installations. Coastal networks may also have limited short-circuit power making it complicated to connect large wind farms to grids. This creates an interest in temporary electricity storage, which is, of course, the most difficult case that will require technological advances in large-capacity storage in the future.

Electrical energy cannot be stored directly and must first be transformed into another form of storable energy. This second form of energy must then be reconverted into electricity according to demand.

Generally speaking, all storage systems can be characterized by the following parameters:

- storage capacity: measured in Joules, kWh, MWh;

- energy density: measured in $\mathrm{kWh} / \mathrm{m}^{3}$ or per tonne of storage system;

- charge and discharge capacities (sometimes different): measured in W or kW;

- storage period: time during which the system charged at its maximum is able to supply its discharge capacity, in seconds, minutes or hours;

- energy yield: quotient of electricity restored, compared with the amount of electricity consumed during the charge;

- self-discharge rates: time taken by the maximally charged system to discharge by itself without being put to use;

- lifetime: number of cycles that the system can make before degrading; this number generally increases when the depth of discharge decreases;

- price of stored energy: in euros/kWh;

- price of power: in euros $/ \mathrm{kW}$.

In the case of marine energies, storage systems can also be classified as onshore or offshore.

Generally speaking, storage provides a service to the network by evening out the effects of intermittence, but storage comes at a cost. 


\section{Main electricity storage technologies}

The following forms of energy are used for storage.

- Electrostatic energy in supercapacitors. Today's industrial production provides storage capacities of $10-50 \mathrm{Wh} / \mathrm{kg}$ capacitor. The charge and discharge of the capacitors are controlled by appropriate power electronics. Storage is adapted for the evening out of intermittent generation in the order of several seconds and could be of use in wave power generators.

- Magnetic energy storage: electricity is stored in the magnetic field created by the flow of current in a superconducting coil. Super-conductive windings must be used and this storage is not adapted to marine energies in its current technological state.

- Inertial energy storage: the kinetic energy of a flywheel rotating at high speed. The rotor rotates freely on magnetic bearings. This system has already been employed (onshore) to improve current quality by ENERCON wind turbines (it compensates for intermittence of several seconds related to wind turbulence). Energy density is in the order of $1-5 \mathrm{Wh} / \mathrm{kg}$.

- Batteries: the chemical compounds produced by electrolysis during the charge stay in physical contact with the electrodes of the electrolyzer. Lead batteries are widely used. There are many different types of batteries, for example, nickel-cadmium, lithium-ion, sodium-sulphur, etc. Energy density ranges from $30 \mathrm{Wh} / \mathrm{kg}$ (lead battery) to $150 \mathrm{Wh} / \mathrm{kg}$ (lithium battery) and efficiency is in the order of $70 \%$ to $90 \%$, according to use. Among the many available types of batteries, those that deliver high specific power (nickel-metal hydride, lithiumion, etc.) generally have low specific energy and vice versa. This characteristic is a serious limitation for electricity storage in a grid. Furthermore, none of the technologies available today can store large quantities of energy without extremely high costs. There is also another procedure that uses fuel cells called half fuel cells or half-batteries, where the fuel is provided by a metal (zinc or aluminium). The metal can be replenished when the electrode has been consumed. These fuel cells may prove more advantageous than other traditional rechargeable batteries, as shown in Table 12.1. However, it should be noted that fuel cells depend on metallurgical industries to provide zinc and aluminium.

\begin{tabular}{|l|c|c|c|c|}
\multicolumn{1}{|c|}{ Accumulator } & $\begin{array}{c}\text { Theoretical } \\
(\mathrm{Wh} / \mathrm{kg})\end{array}$ & $\begin{array}{c}\text { Actual } \\
(\mathrm{Wh} / \mathrm{kg})\end{array}$ & $\begin{array}{c}\text { Density volume } \\
(\mathrm{Wh} / \mathrm{l})\end{array}$ & $\begin{array}{c}\text { Power density } \\
(\mathrm{W} / \mathrm{kg})\end{array}$ \\
\hline Lead-acid & 252 & $30-45$ & $70-80$ & 200 \\
\hline Lithium-ion & 631 & $130-160$ & 260 & 800 \\
\hline $\begin{array}{l}\text { Half-battery } \\
\text { zinc-air }\end{array}$ & 1050 & $200-300$ & $130-330$ & $80-100$ \\
\hline $\begin{array}{l}\text { Half-battery } \\
\text { aluminium-air }\end{array}$ & 8140 & $350-450$ & $350-700$ & $500-600$ \\
\hline
\end{tabular}

| Table 12.1

Energy storage capacities for various types of accumulators (Source: Damery E. Note technique CEA/DTEN, No. 2002-11). 


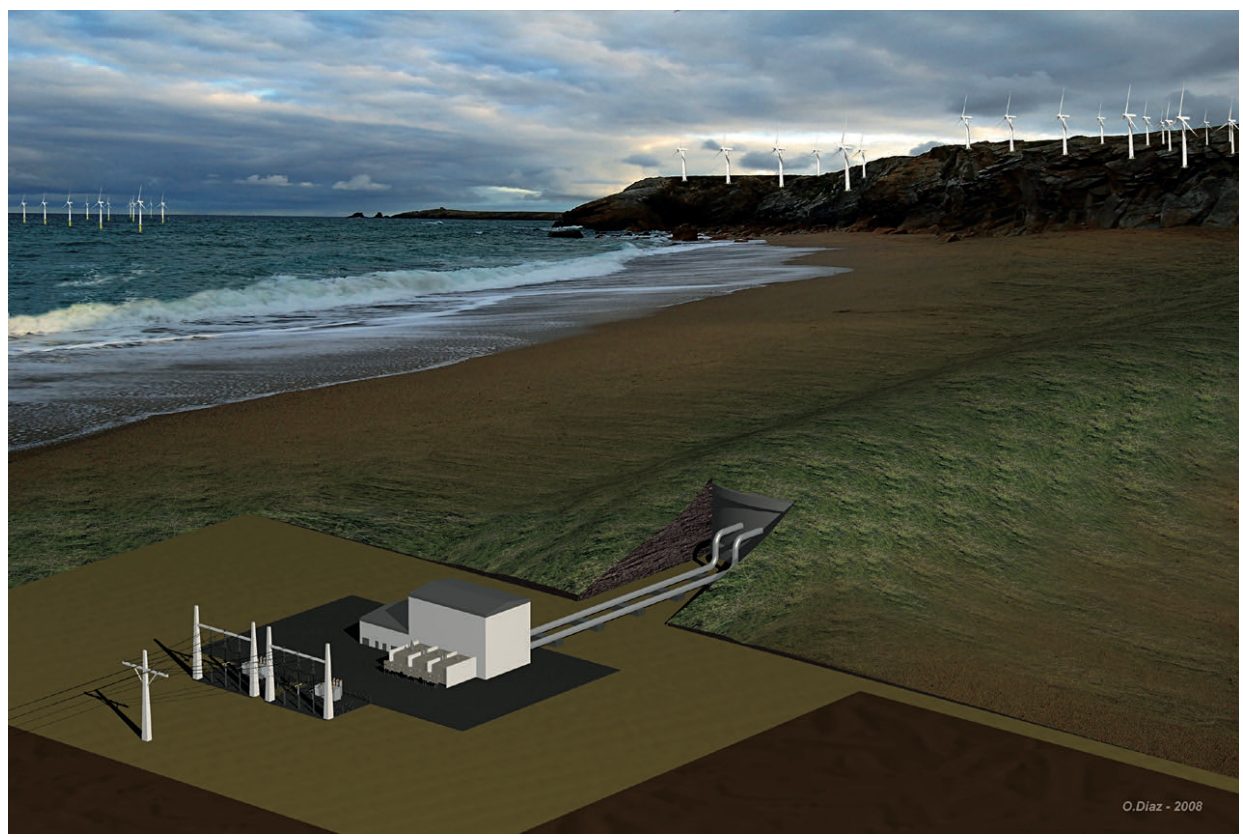

I Figure 12.1 : illustration of the concept of thermal storage in underground reservoirs (Source: Saipem).

- Flow batteries: electrolysis produces chemical compounds dissolved in a liquid. One compound is reduced and the other oxidized, giving this system the name of 'redox'. The liquids charged with energy are stored externally in tanks, hence the term 'flow battery'. For example, VRB Inc. is developing a 1.5 MW $\times 8$ hour storage project at Sorne Hill in Ireland [http://en.wikipedia.org/ wiki/Sorne_Hill_wind_farm].

- Hydrogen and oxygen production: systems requiring only low levels of power use regenerative or reversible fuel cells (RFCs). In large installations, fuel cells and electrolysis units can be used separately. In its current state of development, RFC overall efficiency is about $50 \%$.

- Thermal energy: electricity is used to pump high-temperature heat. This system is being developed by Saipem. Efficiency should be greater than $60 \%$ and it is possible to store great quantities of energy (a few dozen gigawatt hours) without the need for a special site.

- Potential energy: water is pumped into elevated reservoirs. Pumped-storage hydro-electricity is the most common form of grid energy storage and is adapted to mountainous areas. Several hundred gigawatt hours can be stored with an overall yield in the order of $75 \%$. In France, approximately $6.3 \mathrm{GW}$ of power is in gravity storage at hydro-electric plants for a total generation capacity of approximately $116 \mathrm{GW}$. 
- Closed circuit compressed gas: hydraulic accumulators. Oil is pumped into a reservoir and compresses a bladder of nitrogen. It is frequently used in wave power systems.

- Compressed air energy storage: low capacity systems can use steel tanks (tubes or spheres). About $8 \mathrm{Wh} / \mathrm{kg}$ can be stored (steel tanks at 200 bars). Large reservoirs are located underground (e.g. salt caverns, underground mines). It is easy to create reservoirs at sea with weighted, non-rigid storage bags in deep waters. The greater the depth, the more economical the system. Compression causes gas to heat up. In the current installations, heat from compression is lost and air is reheated prior to expansion using a natural gas-fired burner. The techniques being developed aim to store the heat used for compression and reuse it during expansion. The overall energy yield is improved. Auxiliary heat sources can also be employed. It is also possible to store compressed air in deep aquifers, like natural gas [http://www.windstoreproject.com/.

The main energy storage technologies are briefly presented in Tables 12.2 and 12.3 [1].

\section{1- Key indicators}

\section{Storage capacities for stationary systems}

Batteries: several watts to several hundred kilowatt hours.

Compressed air in underground caverns: several tens of megawatts to several tens of gigawatts.

Retaining dams: several hundred megawatts to several hundred gigawatts.

High-temperature heat turbines: several tens of megawatts to several tens of gigawatts.

\section{Energy yields with known technologies}

From $50 \%$ to $75 \%$ depending on the system.

\section{Industrial costs (euros/kWh capacity)}

Lead batteries: 50-200 euros/kWh.

Lithium-ion batteries: 700-1000 euros/kWh.

Compressed air in underground caverns or aquifers: 50-80 euros/kWh.

Pumped hydro-gravity storage: 70-150 euros/kWh.

High-temperature heat turbines (target): 50-200 euros/kWh.

\section{Technologies (road map)}

If bulk energy storage for high penetration of renewable energies is considered, the following scenario could be envisaged:

- 2010: acceptance that electricity networks will not be able to support more intermittent generation, that the balance cannot be reached simply through deregulation and that there is a real need for bulk energy storage;

- 2015: initial results from demonstration energy storage projects for renewable energies, change in paradigm and acceptance of high penetration of renewable energies;

- 2020?: energy sources other than electricity come into operation (hydrogen?) and integration of storage owing to this new source? 


\begin{tabular}{|c|c|c|c|c|c|c|c|c|c|c|}
\hline 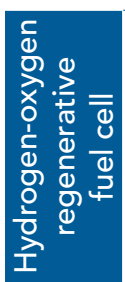 & 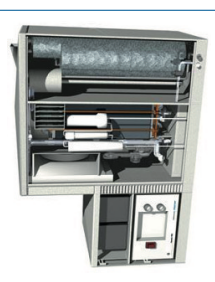 & $\frac{\Phi}{2}$ & 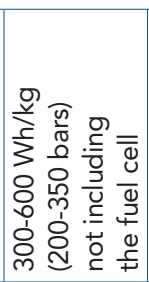 & ¿ & 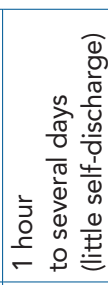 & $\approx:$ & $\begin{array}{l}n \\
0 \\
0 \\
m \\
0 \\
0\end{array}$ & 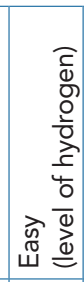 & 8 & 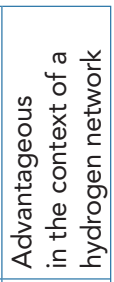 \\
\hline 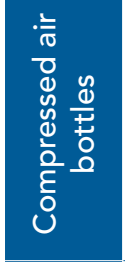 & & 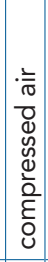 & 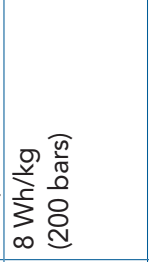 & 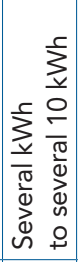 & 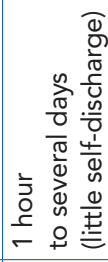 & 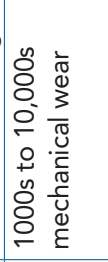 & 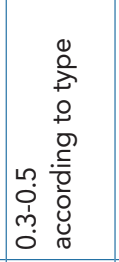 & 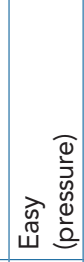 & $\sim$ & \begin{tabular}{|l}
$\frac{0}{0}$ \\
$\frac{0}{2}$ \\
3 \\
0 \\
\end{tabular} \\
\hline $\begin{array}{l}\bar{\Phi} \\
\Phi \\
\frac{\mathscr{g}}{3} \\
\frac{\lambda}{\amalg}\end{array}$ & & 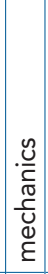 & 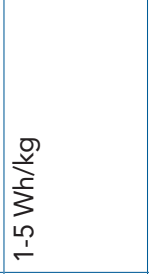 & 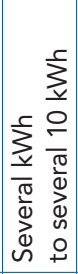 & 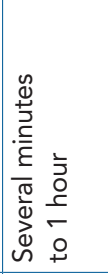 & 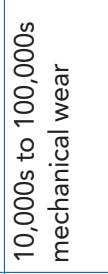 & 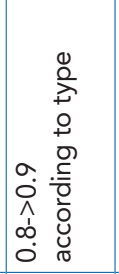 & 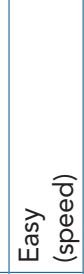 & 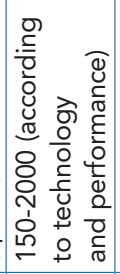 & 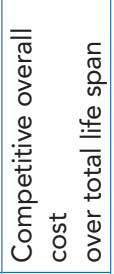 \\
\hline 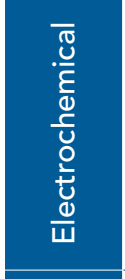 & & 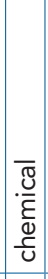 & 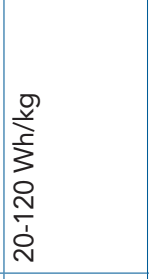 & 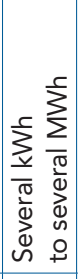 & 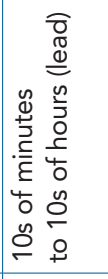 & 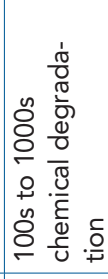 & 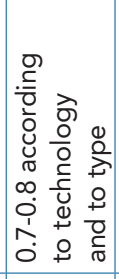 & 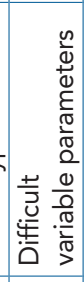 & 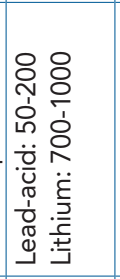 & 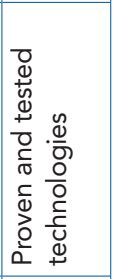 \\
\hline $\begin{array}{l}\frac{1}{0} \\
\frac{0}{0} \\
\frac{0}{0} \\
\frac{0}{0} \\
\frac{0}{0} \\
\frac{0}{0} \\
\frac{0}{5}\end{array}$ & & 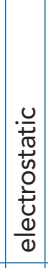 & 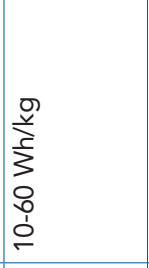 & 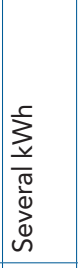 & 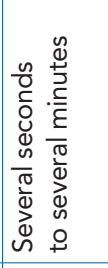 & $\begin{array}{l}8 \\
8 \\
0 \\
8 \\
0 \\
0 \\
0 \\
0 \\
8 \\
8 \\
0 \\
0\end{array}$ & 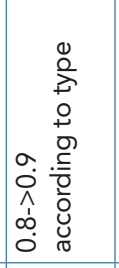 & 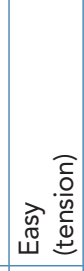 & 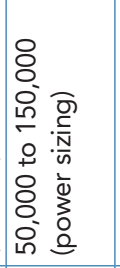 & 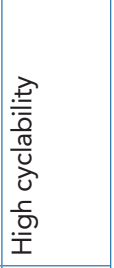 \\
\hline 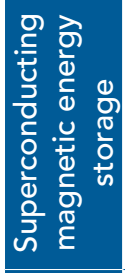 & 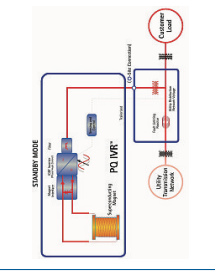 & 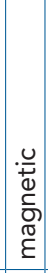 & 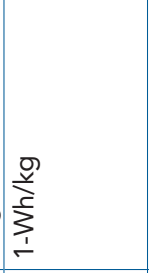 & 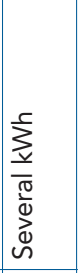 & 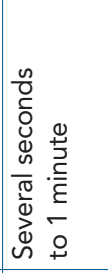 & 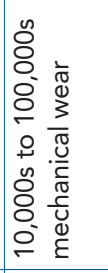 & $\begin{array}{l}0 \\
0 \\
\wedge\end{array}$ & 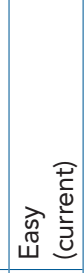 & 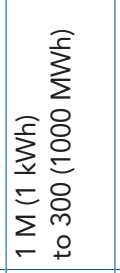 & 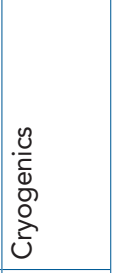 \\
\hline 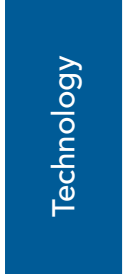 & & $\begin{array}{l} \\
\text { के } \\
0 \\
0 \\
0 \\
4 \\
40 \\
5 \\
0 \\
0 \\
4\end{array}$ & 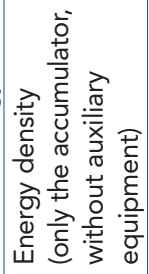 & 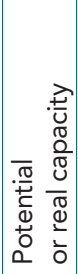 & 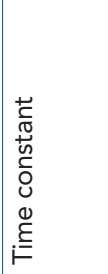 & 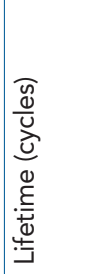 & 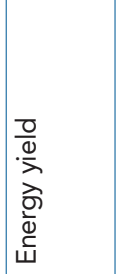 & 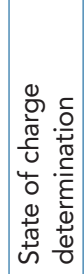 & 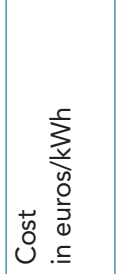 & 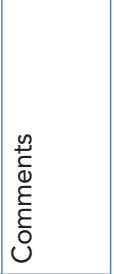 \\
\hline
\end{tabular}




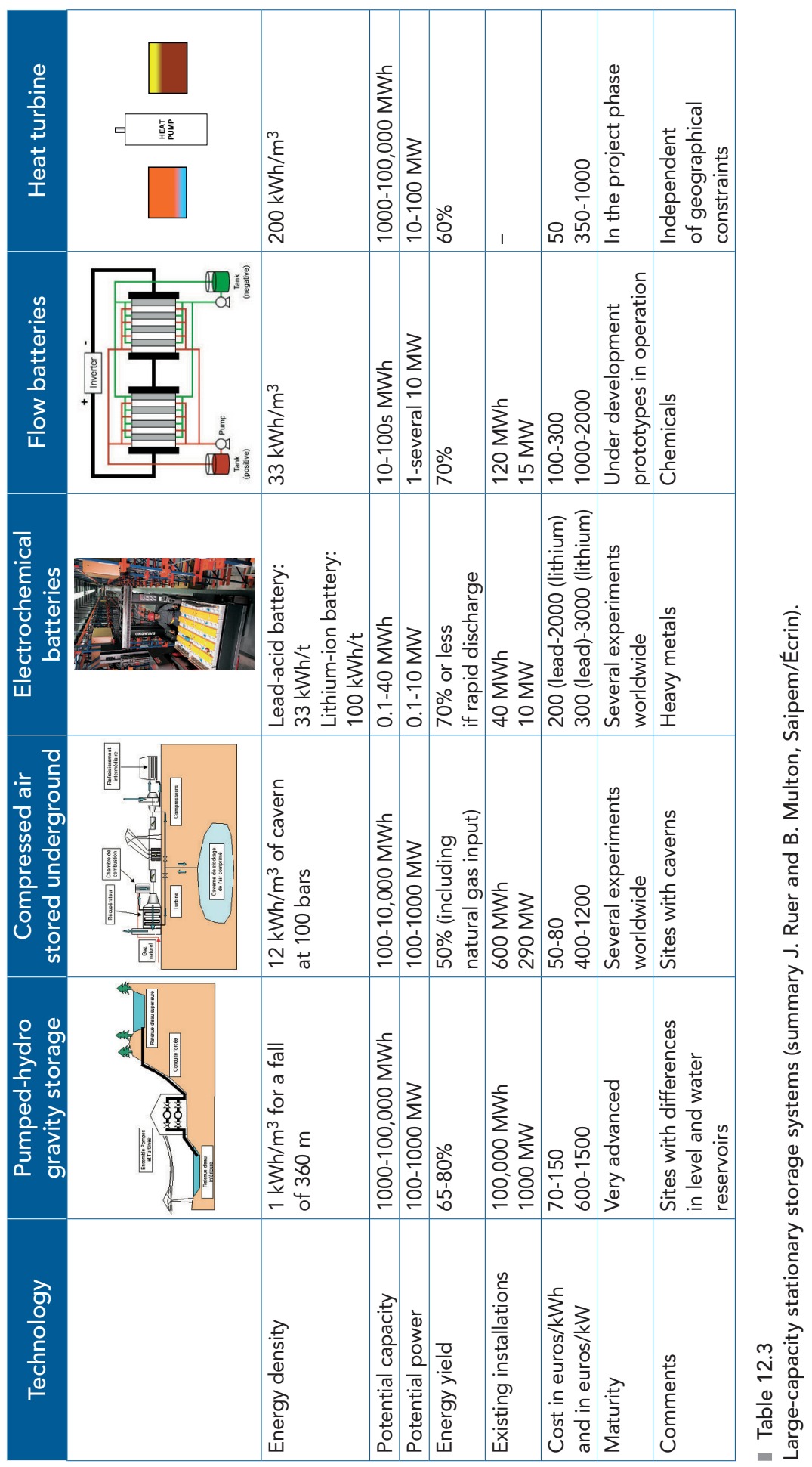




\section{Looking back (over the past 20 years)}

Electricity stored in the AC form is not possible without energy conversion, which requires the use of power electronics. Without available power electronics technology, it has long been thought that electricity cannot be stored.

For a long time, the only electricity storage technologies were lead-acid batteries, then cadmium-nickel batteries, limited in capacity by their costs, volumes, short life spans, and the environmental concerns for their production and recycling. Mass production of batteries allowed prices to reach an acceptable level for small-capacity storage and electrochemical batteries are still the preferred means of storing solar energy or energy in isolated systems.

Pumped hydro storage was practically the only bulk energy storage method until recently. It was used from the beginning of the 20th century in all countries with mountainous areas. Potential sites are now equipped and it is difficult to create other plants with closed dykes.

Storage in the form of compressed air has not developed widely because it requires geologically favourable sites (e.g. salt domes, dry caverns, leak-proof aquifers).

After the introduction of pricing schemes based on-peak and off-peak hours, ripple control, that is, identifying consumers willing to be cut off from the network if necessary, became possible making grid management more flexible.

At the outset of onshore wind farms, generation costs were too high to consider a supplementary cost related to storage to compensate for intermittence. The policy that was adopted forced network companies to accept this new form of energy in spite of its intermittence. Renewable energy operators agreed and then denied that intermittence was a problem, since the grid could cope relatively easily with $15 \%$ to $20 \%$ intermittent generation.

This paradigm still exists today although the system is nearing its limits. On certain days, the balance of the network is unstable in several northern European countries.

It is now clear that there is a real necessity to develop bulk energy storage technologies. The European Commission favours the development of energy storage technologies. Inaction on the part of the stakeholders, however, will cause a delay of several years before the necessity is generally recognized.

Energy storage technologies are already being developed.

\section{Outlook (for the next 20 years)}

Energy storage will first be introduced in marine RES generation systems to improve the quality of electrical current and to eliminate problems in the network. A good example is energy storage in wave power systems to eliminate flicker. 
Corresponding technologies are hydro-pneumatic accumulators, supercapacitors and inertial flywheels.

Energy storage possibilities will then spread to isolated wind farms to enable them to use intermittent generation sources in low-power networks. This is already the case for islands supplied with wind turbines, solar panels and buffer batteries. The gradual decrease in costs will make it possible to consider more powerful installations (e.g. the Sorne Hill project). These means of storage will not suffice to change the opinions of transmission network companies, because the stored quantities will remain an order of magnitude lower than those transmitted on the grid. Corresponding technologies are flow batteries, compressed air in submarine bags, pumped hydro-electricity or compressed air in caverns where possible.

In the more distant future, perfecting the bulk energy storage technologies currently in development will lead to a complete change. Energy stores will be such that intermittence will no longer hamper RES penetration. Corresponding technologies are hydrogen and fuel cells, compressed air in aquifers and thermal storage.

\section{Hypothesis 1}

\section{No bulk storage and intermittence limited to $20 \%$}

No development of bulk energy storage. Intermittent renewable energies limited to $20 \%$ of network capacity and local restrictions on power injection into grids.

\section{Hypothesis 2}

Short-term storage (hydro-pneumatic accumulators, supercapacitors) for current quality

Progressive development of new bulk energy storage techniques but no changes in the way networks are managed. Storage facilitates the interface between intermittent generators and the network but grid companies do not use storage to authorize high penetration of marine RES (e.g. compressed air).

\section{Hypothesis 3}

\section{Bulk storage (hydrogen, compressed air, thermal energy storage)}

Bulk storage technologies considerably mobilized, acceptance of RES penetration well beyond $20 \%$ (nearly 40-50\%?) (e.g. hydrogen).

\section{Bibliography}

Multon B., Ruer J. 2003. Stocker l'électricité: oui, c'est indispensable et c'est possible. Pourquoi, où, comment? Écrin contribution to the national debate on energy, April 2003 [http://www.ecrin.asso.fr/energies/] 


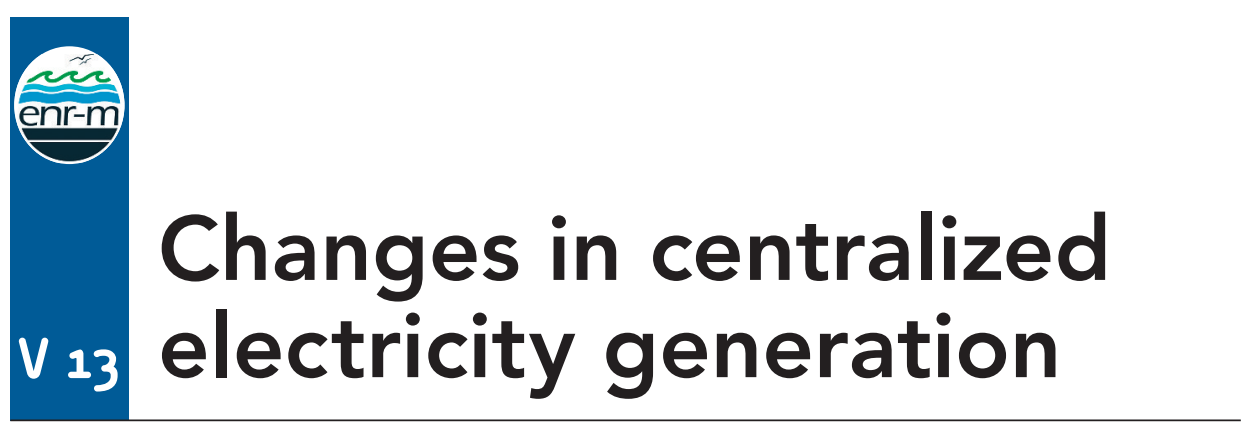

Component: 2. European and French context

Author: EDF/Research \& Development (Cyrille Abonnel)

\section{I Definition}

Several types of primary energy sources 35 are used in France: nuclear energy, which accounts for most of the electricity generated; fossil fuel energies as raw materials from rocks made by fossilization of plants and animals creating oil, coal and natural gas; and renewable energy supplied by the sun, wind, heat from the earth, waterfalls or oceans. France's production capacity was mainly developed in 'French energy policy', which was engaged immediately following the first oil crisis in 1973-74. Indeed, at the time, as stated by the Ministry of Industry36, the public authorities had decided to make France more energy independent. To this end, the government launched a programme in 1974 to build nuclear power plants (taking production from 15 TWh in 1973 to 450 TWh in 2006), while continuing to develop hydro-electricity generation. The latter grew by over $45 \%$ between 1973 (48 TWh) and the early 2000s (about 70 TWh). In 2006, France's energy balance according to the Energy Observatory (2007) was as shown in Figure 13.1.

\section{Key indicators}

\section{Technologies}

In the report on baseline prices for electrical production (DGEMP/Dideme 2003), the General Directorate for Energy and Raw Materials (DGEMP) studied several centralized facilities. The main ones were as follows.

- Nuclear power: the benchmark is the European pressurized reactor (EPR), which carries on from existing techniques with advances made in flexibility and enhanced security; unit power $1590 \mathrm{MW}$.

35. Raw energy, that is, not transformed after extraction (e.g. coal, lignite, crude oil, natural gas, primary electricity).

36. www.industrie.gouv.fr/energie/comprendre/q-r-elec-pdt.htm 


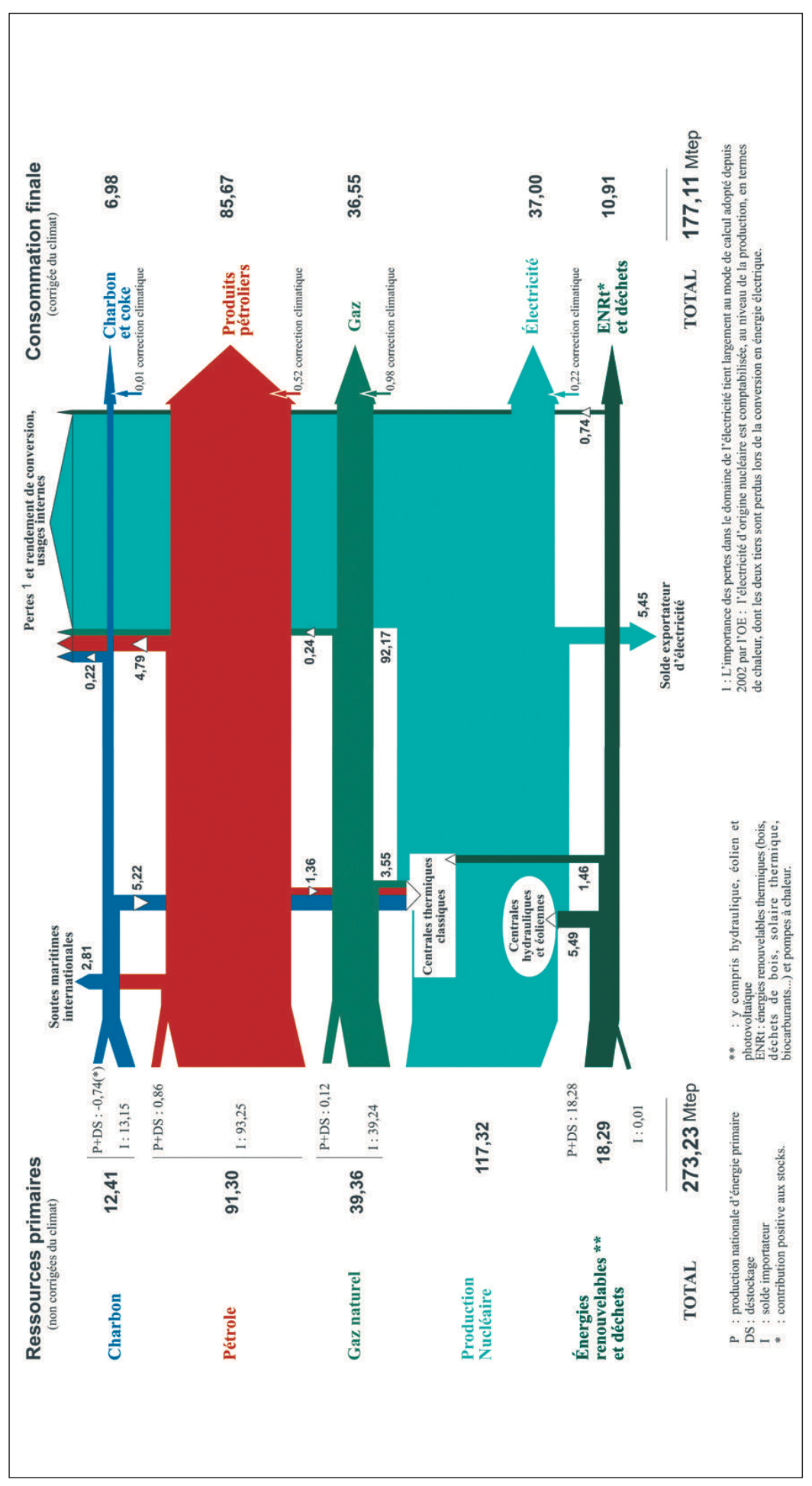

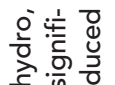
웡 둘 을 宅寉 कृ है 흥ㅎㅁ

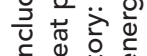
$\therefore \stackrel{0}{\simeq}$ * 宊 ำ is s ò ธ논 욱으월 을 월 ปั บ

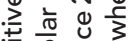

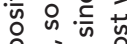
$\therefore$ 이의

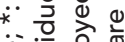
iे

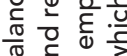
㐘 tris 은 은 운 운

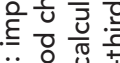

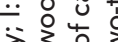
齐范范 कें ते ฮำ 033 बे 过 के 잉응 눙 बิ $\sum \ddot{1} 0$

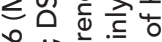
ठํํㅊㅎํ है है

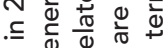

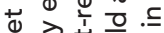
웅 중 근

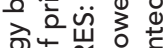

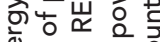
ब in

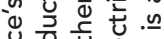

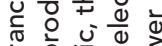
娄

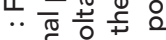
$\overline{\dot{m}}$ 으응 $m$ ब

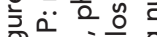
문 
- Pulverised coal with treatment of flue gases: the selected benchmark was a supercritical pulverized coal facility $(2 \times 800 \mathrm{MW})$ equipped with wet flue gas desulfurization and catalytic denitrification units.

- Circulating fluidized bed coal-fired plant: is a process which combusts the fuel suspended in the air over a relatively long time. The plant in question has a 400 MW capacity for electricity generation.

- Combined cycle using gas: this technique combines a gas-fired turbine with a steam turbine using the heat from combustion gases. It has become the main generation technique implemented for power plants abroad, and several projects have been examined in France by independent generators or newcomers to the market. In DGEMP/Dideme (2003) the benchmark installation considered for 2007 has two 400 MW lines, each with a combustion turbine, a gas turbine and an alternator, mounted on a single axis.

- Gas-fired (GFT) and oil-fired turbine: this supply chain is designed to supply peak energy. The benchmark here is a single cycle gas or oil fired turbine whose total power is $300 \mathrm{MW}$.

\section{Energy performance with known techniques (benchmark standards (DGEMP/Dideme, 2003)}

- Nuclear power: the net yield under ISO conditions is $3.61 \%$.

- Pulverized coal with treatment of flue gases: net yield of $43.1 \%$ for plants beside streams and $44.1 \%$ for those on the seafront with open circuit cooling.

- Circulating fluidized bed: net yield of $42.4 \%$ for plants beside streams and $43.4 \%$ for those on the seafront with open circuit cooling.

- Combined cycle using gas: net yield under ISO conditions $\left(15^{\circ} \mathrm{C}\right)$ of $57.1 \%$.

- Gas combustion turbine: net yield of $42.4 \%$ for plants beside streams and $43.4 \%$ for those on the seafront with open circuit cooling.

- Combustion turbine using domestic heating oil: net yield under ISO conditions $\left(15^{\circ} \mathrm{C}\right)$ of $32.7 \%$.

\section{Life cycle}

- Nuclear power: 60 years for EPR.

- Pulverized coal with treatment of flue gases: 35 years.

- Circulating fluidized bed: 35 years.

- Combined cycle using gas: about 25 years.

- Gas-fired turbine: 25 years.

- Combustion turbine using domestic heating oil: 25 years.

\section{Costs}

- Nuclear power: capital cost 1043 euros/kW; production base cost by 2015 of 28.4 euros/MWh.

- Pulverized coal with treatment of flue gases: capital cost (construction) estimated at 1100 euros/kW; production base cost in 2007 of 35.1 euros/MWh 
to which 3.1-15.6 euros/MWh of carbon dioxide costs must be added, depending on the price per tonne of carbon dioxide chosen (4 euros or 20 euros).

- Circulating fluidized bed: capital cost (construction) estimated at 1130 euros/ $\mathrm{kW}$; production base cost in 2007 of 36.5 euros/MWh to which 3.2-16 euros/ MWh of carbon dioxide costs must be added, depending on the price per tonne of carbon dioxide chosen (4 euros or 20 euros).

- Combined cycle using gas: capital cost (construction) estimated at 453 euros/ $\mathrm{kW}$; production base cost in 2007 of 35.7 euros/MWh to which 1.5-7.3 euros/ MWh of carbon dioxide costs must be added, depending on the price per tonne of carbon dioxide chosen (4 euros or 20 euros).

- Gas-fired turbine: capital cost (construction) 295 euros /kW.

- Heating oil-fired turbine: capital cost (construction) of 295 euros/kW.

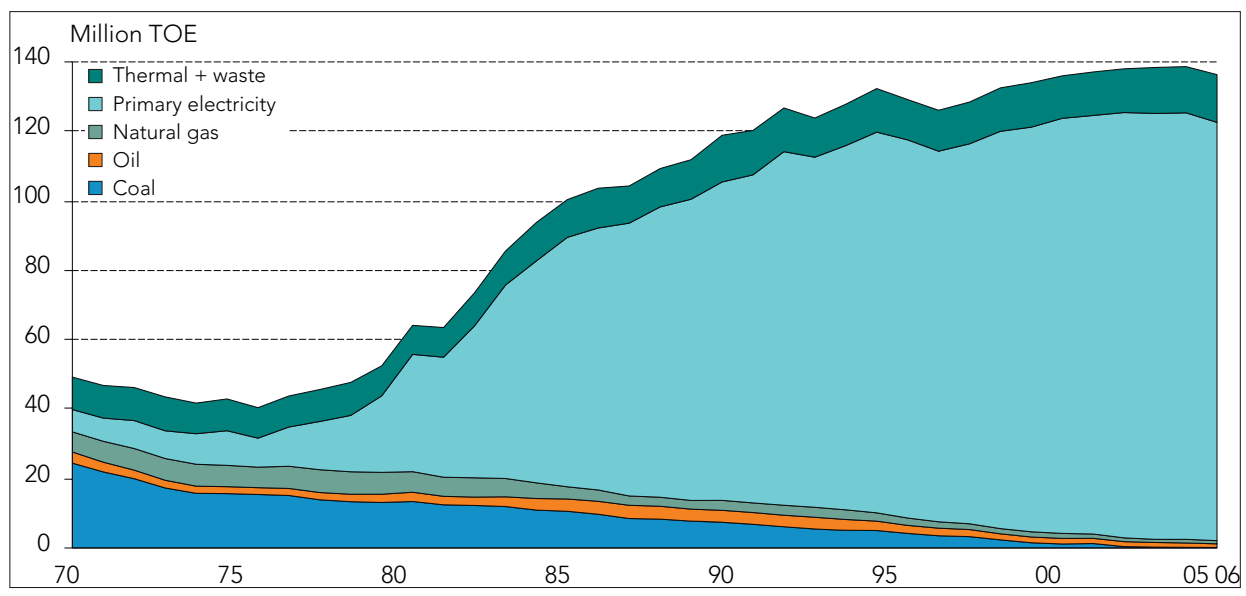

I Figure 13.2 : primary energy production by energy source (Mtoe) (Source: Energy Observatory).

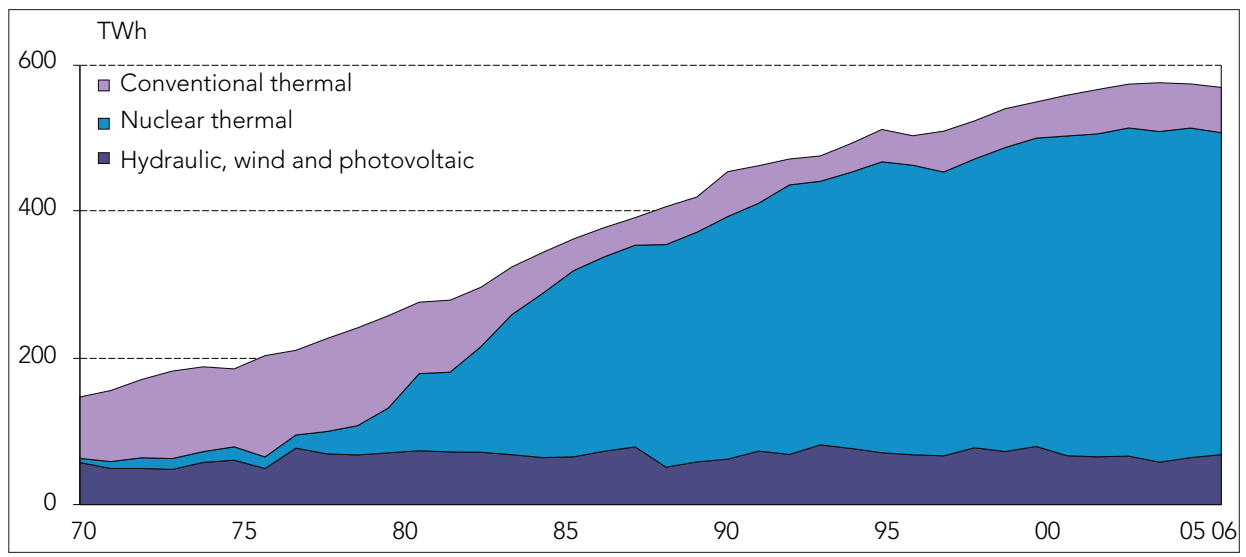

I Figure 13.3 : gross electricity production (TWh) (Source: Energy Observatory). 


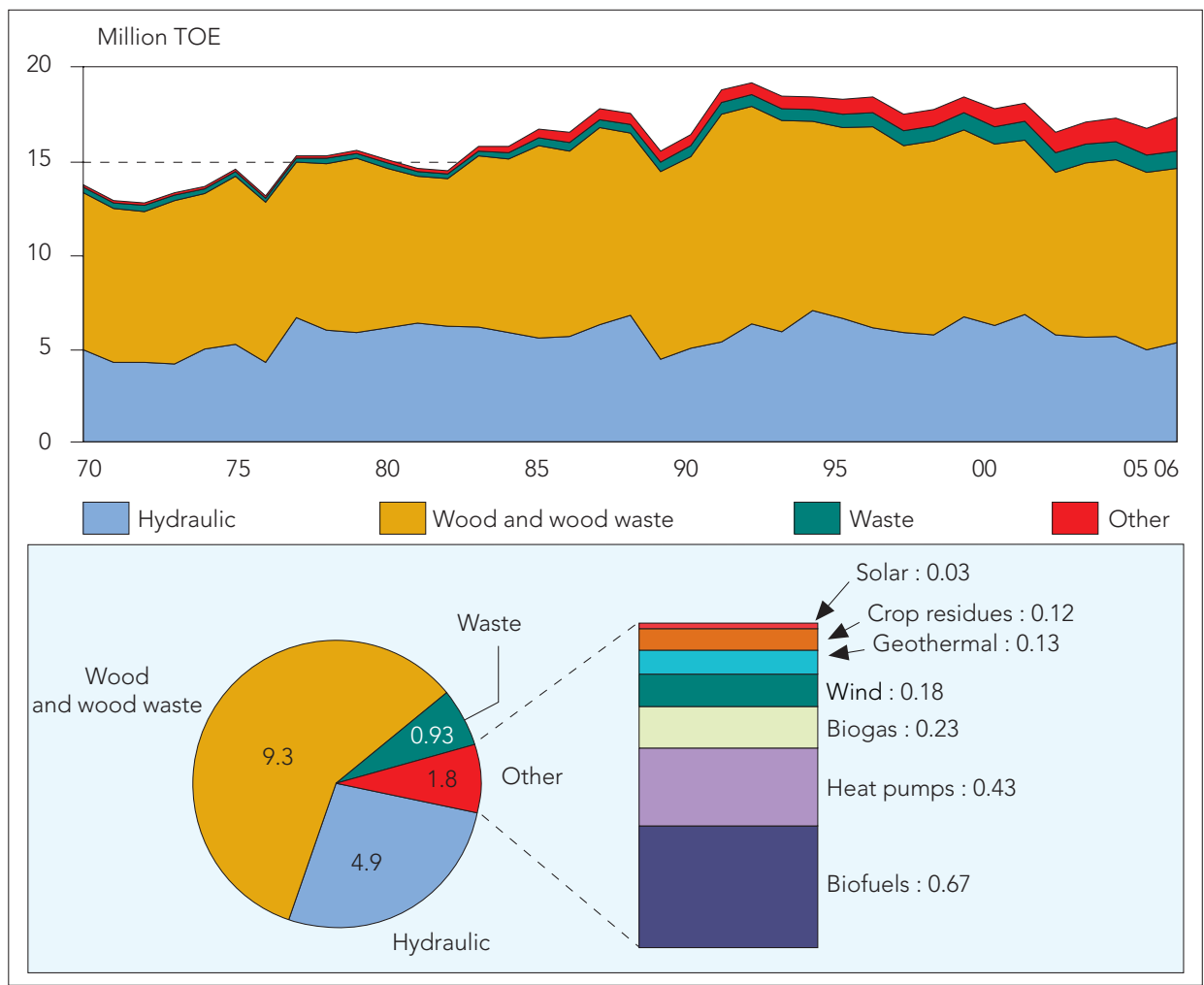

I Figure 13.4 : top: total production from renewable energy sources (Mtoe ${ }^{37}$ ) from 1970 to 2006 ; bottom: breakdown of RES in 2006. The graph on right shows 'other' RES (Source: Energy Observatory).

\section{Looking back (over the past 40 years)}

According to the Energy Observatory (2007), during the period 1960-1973, the growth of energy demand seemed closely linked to economic growth. Oil use was booming at the time, making it possible to both fuel industrial development and replace the declining use of coal. Between 1973 and the late 1980s, the rise in oil prices made it necessary to make choices about energy sources and production system, as well as curbing consumption. The implementation of the nuclear power programme led to a substantial increase in national production of primary energy, which increased from 44 Mtoe in 1973 ( $9 \%$ from nuclear energy) to 138 Mtoe in 2006 ( $85 \%$ from nuclear energy), while oil and natural gas extraction continued to decline and coal extraction was definitively stopped in April 2004. As a result of imports, conventional thermal production stayed at about 11\% (60 TWh, which was not more than $50 \%$ of production in 1973). Concurrently, efforts to consume less energy made annual savings of approximately 30 Mtoe possible, compared with the situation of 1973. Following the oil 'counter-shock' in 1986, previously slowed energy-saving efforts have been reinvigorated since 1999.

37. Equivalence for electricity: 0.86 toe/MWh for geothermal energy and 0.086 toe/MWh for other sources. 
This trend can be seen in Figures 13.2-13.4 from the Energy Observatory below. They show respectively, the primary energy production by energy source (Mtoe), gross electricity production (TWh) and total production from renewable energy sources (Mtoe).

\section{Outlook (for the next 20 years)}

The report on the multi-annual budgeting of electricity production investments published by the La Direction de la Demande et des Marchésénergétiques (Dideme) in 2006 (DGEMP/Dideme 2006) for the time horizon of 2015, identified the following trends for the French electricity generation mix:

- development of RES: at least 5 GW in 2010 and 12.5 GW in 2016 from wind power; at least an additional 6 TWh from biomass by 2016, based on maintaining at a minimum the same level of hydro-electricity generation (potential for development having been determined at 7 TWh);

- an EPR being put into operation in 2012;

- 2.6 GW from heating-oil plants being put back into service;

- commissioning of $500 \mathrm{MW}$ from combustion turbines, $0.8 \mathrm{GW}$ (semi-base load) in late 2009, 5.2 GW (2.6 GW semi-base load and 2.6 GW peak load) by the end of 2015.

Since this report was published, current events seem to bear out the recent boost for nuclear power worldwide, while the increasing use of renewables appears to be confirmed.

Based on the Dideme scenario, the following three hypotheses are suggested.

Hypothesis 1

More nuclear power in Europe and maintaining hydro-electricity and thermal power plants

Hypothesis 2

Nuclear power at status quo and also for hydro-electric power and decentralized co- and tri-generation (gas)

Hypothesis 3

Same as hypothesis 2 with development of land-based RES

\section{II Bibliography}

DGEMP/Dideme, 2003. Coûts de référence de la production électrique. Paris: General Directorate for Energy and Raw Materials.

DGEMP/Dideme, 2006. Rapport sur la programmation pluriannuelle des investissements de production électrique (PPI). Paris: General Directorate for Energy and Raw Materials.

Energy Observatory, 2007. L'énergie en France - repères, 2007, drafted for French ministries. [http://www.industrie.gouv.fr/energie/statisti/pdf/reperes.pdf] 


\section{Appendix}

\section{Energy pooling methodology for electricity (Source: Energy Observatory)}

Three cases can be determined:

- electricity produced by a nuclear power plant is accounted for using the primary equivalent at production method, with an installation conversion yield equal to $33 \%$; thus the substitution coefficient is $0.086 / 0.33=0.260606$ toe/MWh;

- electricity produced by a geothermal power plant is also accounted for using the primary equivalent at production method, with an installation conversion yield equal to $10 \%$; bringing the substitution coefficient to 0.86 toe/MWh;

- all other forms of electricity (using conventional thermal plant, pumped hydroelectricity, wind, tidal photovoltaic, etc., foreign exchanges, consumption) are accounted for using the energy content method, with a coefficient of 0.86 toe/MWh. 


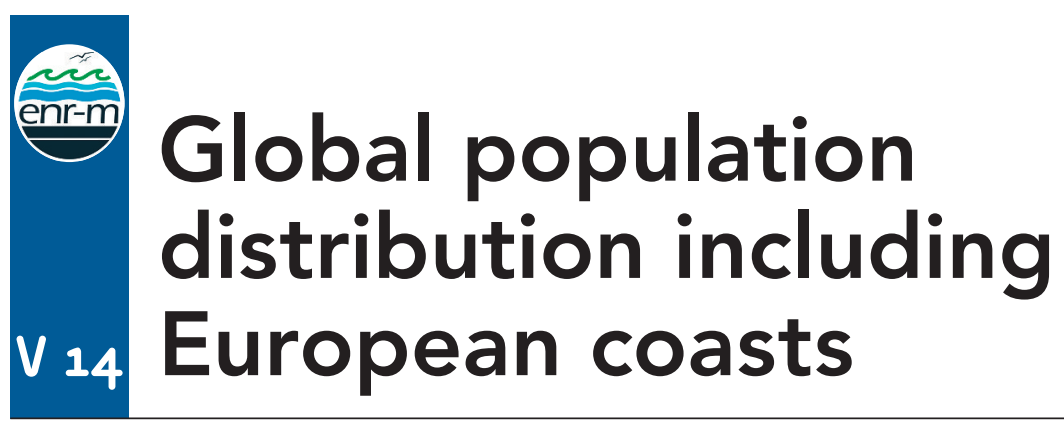

Component: 3. Areas of operation

Author: Futuribles and Ifremer (Régis Kalaydjian)

\section{Definition}

The term 'coastal population' refers to the inhabitants residing along the coastline. In France, the coast considered is the geographical area formed by coastal municipalities or parishes. In Europe, the available statistics do not provide information on these towns, but on coastal territorial units as defined by the Nomenclature of Territorial Units for Statistics division 3 (NUTS3). The broader 'coastal area' is considered here, rather than just the coastal strip.

Note: NUTS3 is the sub-division of regions (NUTS2). For France, NUTS3 are the departments (counties) and thus include the overseas departments (DOM).

\section{Key indicators}

- Number of inhabitants in each type of habitat.

- Population density.

- Population growth rate.

- Population influx to coastal areas.

- Economic activities in coastal areas, including tourism (major factor).

\section{Looking back (over the past 20 years)}

In France

- Population density on the coast is higher than in the rest of continental France.

- Migration is responsible for $64 \%$ of population growth in coastal municipalities in continental France. This factor has increased in recent years: from 1982 to 1990, natural population growth contributed more than migration to the coastal demography; from 1990 to 1999, migration played a greater role, except for the English Channel and North Sea seafronts where net migration was negative. 
- The coastal population is very urban: $76 \%$ of the population in coastal municipalities (4.4 million inhabitants out of a total of 5.8 million) live in urban areas (average of $61 \%$ for continental France). Recent growth has mainly been in suburban zones.

- Suburban growth has led to a spreading of building and contributes to urban sprawl in coastal areas.

- Saturation of available space, the real estate market and the protection of natural or specific-use areas have shaped the intense development of coastal areas more than specific planning policies.

- The demographics have evolved differently on different coasts. High population growth in the overseas DOM-COM (e.g. Reunion, Antilles); increasingly residential coastal economies and demography (e.g. French Mediterranean); the trend is toward rationing of coastal land and pushing out certain activities, particularly through inhibitory property prices.

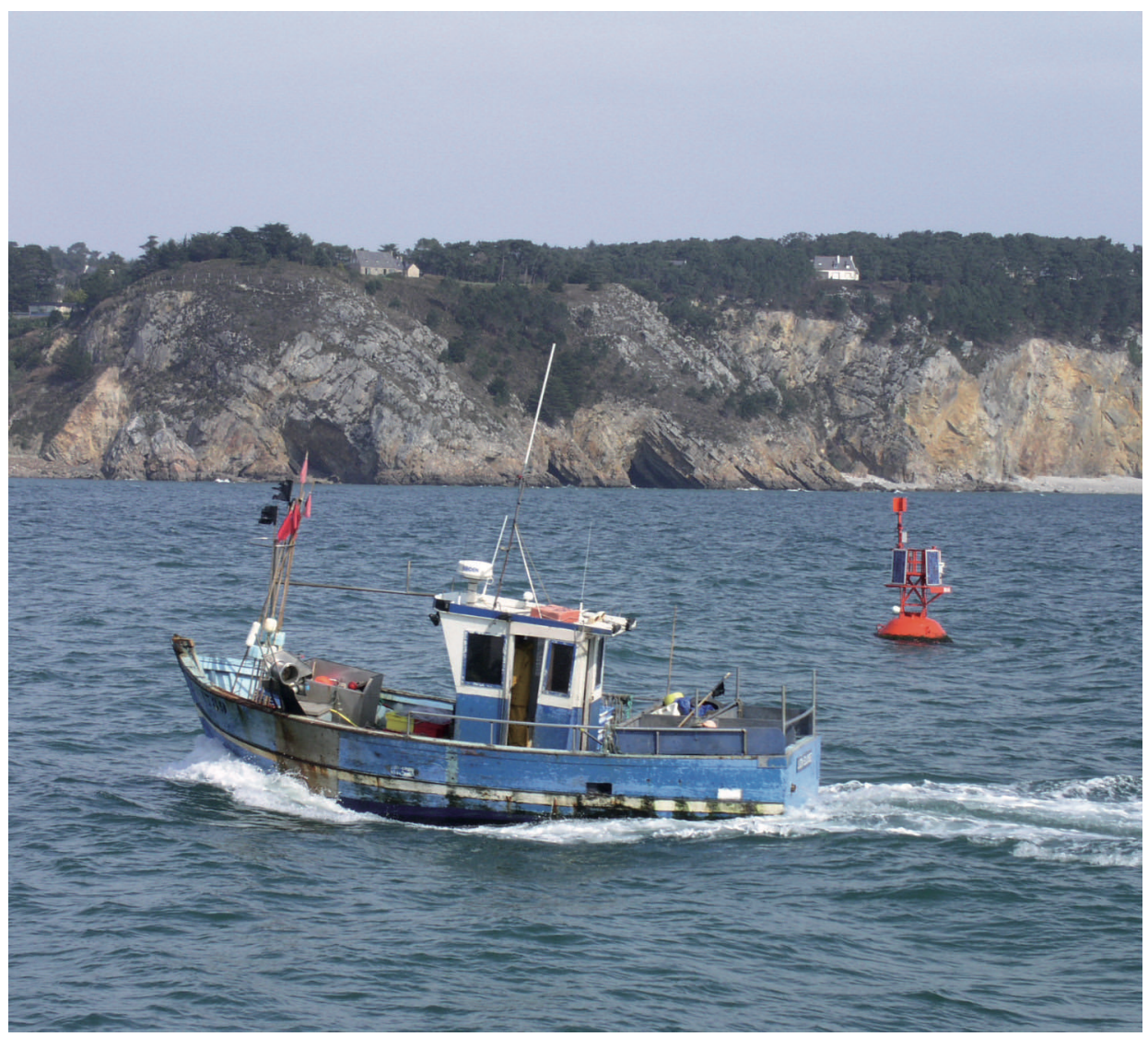

I Photo 24 : Regional planning for marine areas must take account of age-old activities like fishing (C) Ifremer, G. Véron). 


\section{In Europe}

- Population densities are higher on the coast than in the hinterland.

- The highest densities are found in southern Europe, and the lowest in northern Europe.

- For 18 European countries analysed (for which there was reliable data), the population continued to concentrate in coastal NUTS3 during the 1990-2000 decade, with high variation around this mean.

- The phenomenon of urban spread seen in France is also generally seen in Europe, albeit with a few regional variations. It occupies a large area.

- Soil sealing due to construction (mainly urban and residential areas, port-based industry infrastructures) is concentrated in a $1-\mathrm{km}$ wide coastal strip.

\section{Outlook (for the next 20 years)}

\section{Hypothesis 1}

France: coastal population grows only through natural population growth (no migration).

Europe and world:

a) natural population growth in most European countries; substantial decrease in migration;

b) trend for standards of living to even out in the $\mathrm{EU}$; current trends in population growth continue in Asia (around 10\%);

c) regulation of non-European tourist populations (maintained at year 2000 levels);

d) no coastal planning in France and Europe.

\section{Hypothesis 2}

France: coastal population grows with migration continuing at 1990-99 levels (highest rates).

Europe and world:

a) in Europe, continuation of recent migration trends;

b) trend for standards of living to even out in the EU; current trends of population growth continue in Asia (around 10\%);

c) no regulation of tourist populations; the Mediterranean coast thus attracts many tourists;

d) no coastal planning in France or Europe. 


\section{Hypothesis 3}

France: coastal population grows with migration continuing at 1982-99 levels (intermediate rates).

\section{Europe and world:}

a) migration continues at intermediate rates in Europe also;

b) standards of living even out in the EU; Asian population growth moderate (around $5 \%)$; slow growth in Europe, and differences between northern and southern Europe are maintained;

c) rises more moderate than expected in tourist spending and tourist populations (+30\%); European policies to control tourist populations;

d) France and Europe: thorough coastal planning efforts, organization of public transport, increase in tourist taxes; in France, increase in the Coastal Conservatory's budget.

\section{Consequences of hypothesis 1}

- Reinforcement of residential economy trends in Europe, particularly in the south (via tourism). Eviction of traditional and industrial activities continues, but to a lesser degree.

- Differences among French coasts: the northern coast where the population is younger grows more quickly. The western and southern coasts suffer negative population growth. Saturation in French DOM-COM.

- European coasts: urbanization and residential development continue. A slight trend for higher population growth through natural growth in northern Europe compared with southern Europe. However, by 2020, densities remain higher in the south.

- Moderate increase in coastal property prices in Europe and France.

\section{Consequences of hypothesis 2}

- Residential and urban trends are exacerbated compared with H1, particularly in southern Europe, including France; further eviction of traditional activities (e.g. almost no new sites available for aquaculture, pressure from other users on existing sites) and industrial activities; activities in existing sites are intensified.

- European tourism: $+70 \%$ by 2020 (projection by the World Tourism Organization). Coastal areas are highly attractive, especially around the Mediterranean: risk of saturation (i.e. transport, energy consumption) and lower tourist use of some areas, due to lack of control in planning and population movements.

- Very high population growth in southern Europe. Areas already saturated grow slower than other coastal areas (eviction through sharp rises in property prices). 


\section{Consequences of hypothesis 3}

- Persistent residential and urban development trends but more moderate than for $\mathrm{H} 1$ and $\mathrm{H} 2$. Changes that avert exacerbated congestion on the coast; populations spread inland, increases in property prices are moderate and favour social diversity; lower eviction rates for traditional and industrial activities.

- European coastal tourism showing moderate growth, promoted by the policy of regulation and the attractiveness of coastal areas. Rise in tourist spending and the average cost of a night's stay, favouring the middle to upper socialprofessional categories and home-owners.

- Controlled migration and protection of sensitive areas cancel or delay depreciation of coastal areas. Sustained population growth on European coasts, particularly in France, but more moderate and more spread out than in $\mathrm{H} 1$ and H2: demographic and urban expansions towards the hinterland. 


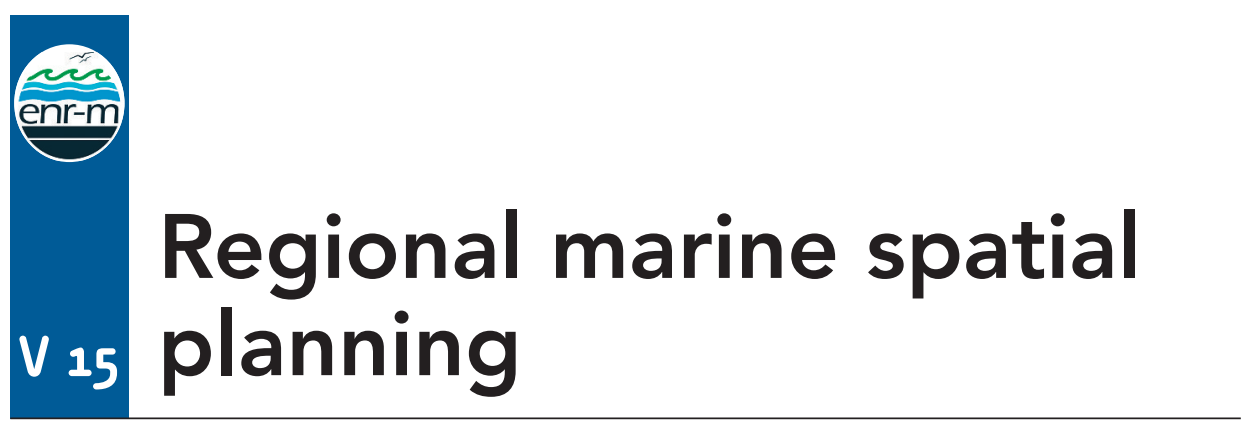

Component: 3. Areas of operation

Author: Ademe (Nils Siebert)

\section{Definition}

Marine spatial planning aims to define the uses of the marine environment and to provide for the sustainable exploitation of marine resources. The main challenge in planning is in co-ordinating the multiple and competing uses of the sea.

Marine spatial planning has an impact on marine RES operating sites when these are found close to the shore. This is where conflicts over use are the most important. Marine spatial planning results in the implementation of national regulations, which organize the activities that exploit marine resources. It also provides planning tools to help decision-makers identify the conflicts of use in each area and mediate among the different users in a given area.

Since the regulatory aspects are examined in the framework of variable 18, this fact sheet mainly deals with planning tools for marine areas.

\section{Key indicators}

Marine spatial planning can be characterized by the implementation of regulations to govern the different uses of the sea as well as the implementation of planning tools that help decision-makers find compromises between competing users in certain marine areas.

For marine renewables, planning tools can be defined as a means of strategic analysis to help identify the favourable and appropriate areas where future marine RES electricity generation operations could be developed. These tools are intended for public authorities or more generally for all stakeholders (e.g. associations, local authorities and project sponsors). They usually take many different factors into account, including environmental data (e.g. geology, morphology, ecology, fisheries, etc.), easements, network connection constraints and uses (with the potential conflicts that may arise). The final decision to establish (or not) an operating site in a specific location is then based on a compromise between the various limitations and is ultimately a political choice. 


\section{Looking back (over the past 20 years)}

\section{Denmark}

Little information is available concerning the implementation of planning tools in Denmark. Only information about offshore wind farms is presented here.

The first offshore wind farm in history was built in Denmark in 1991. Strong political support for the development of this industry led Denmark to produce the first cost-efficient wind farms. Software called WindPRO was created as a planning tool for wind farm development. Nevertheless, Denmark does not have a strategic planning tool that covers all marine RES.

\section{Germany}

The federal authority in charge of maritime affairs is the Bundesamt für Seeschiffart und Hydrographie (BSH). The responsibilities of the BSH cover various activities, such as economic issues, maritime transport security or research in marine areas (see articles 1.10a and 5 on federal responsibilities in the marine environment). It is the institution that delivers the licenses and authorizations required for setting up offshore wind farms.

The BSH also delivers authorizations for projects in the exclusive economic zone (EEZ) (Article 2 of the marine facilities regulations). The regional authorities for maritime affairs must be consulted and confirm that a project does not pose safety problems and is compatible with navigation. Approval is denied if safety cannot be guaranteed and, in the case of significant threats to the marine environment, if there are no restrictive or compensatory measures.

In 2004, the BSH was asked to organize the development of the EEZ. The BSH compiled a large database for the EEZ from various sources. It is very active in this field and organized an international conference on the subject in November 2004 at Rostock with representatives of national hydrographic services from many different countries. From these efforts the CONTIS database was developed. The database is coupled with a geographic information system (GIS) that produces maps with overlaid information on marine resources and different sea uses and constraints. The maps can be consulted on the BSH website [http://www.bsh.de/ en/Marine\%20uses/Industry/CONTIS\%20maps/index.jsp].

\section{United Kingdom}

The United Kingdom offshore wind industry is the most mature RES industry in Europe. Indeed, greater progress has been made in this technology than in other forms of marine energy. As a consequence, the regulatory framework for offshore wind projects is well defined in terms of site selection, obtaining licenses, meeting obligations during the construction phase (such as environmental impact assessments) and carrying out the dismantling phase.

The Ministry of Trade and Industry (DTI) commissioned a study called the 'Atlas of UK Renewable Energy Resources' to map the British coastline and show the 


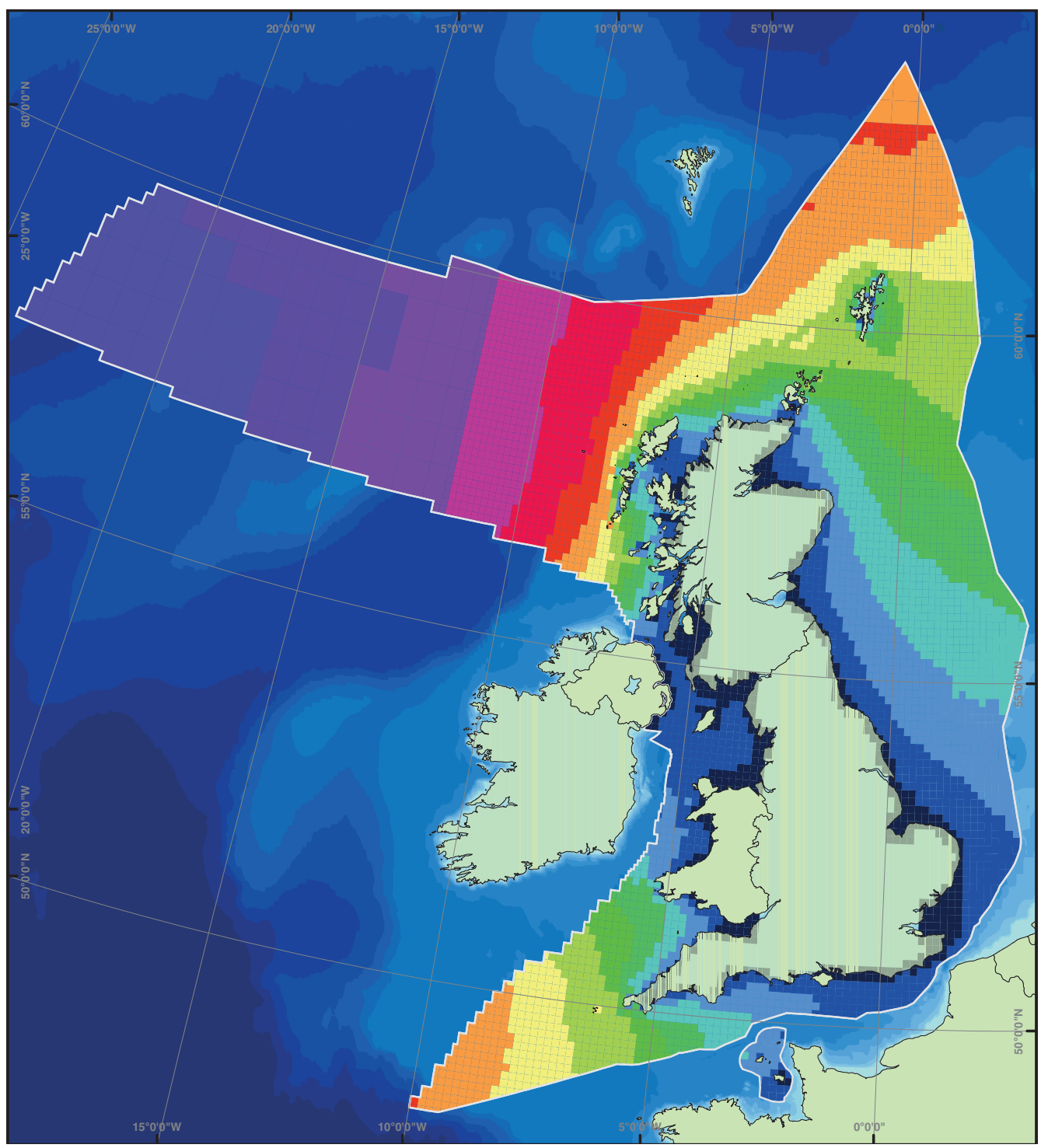

Mean Wave Power ( $\mathrm{kW} / \mathrm{m}$ of wave crest)

$>70 \quad 36-40$

- $66-70 \quad 31-35$

- $61-65 \quad 26-30$

- $56-60 \quad 21-25$

51-55 $16-20$

- $46-50 \square 11-15$

41-45 6-10

$\square$ Land 0

UK Continental Shelf

\& Channel Island

Territorial Sea Limit

\section{Annual Mean Wave Power}

Figure 15.1 : annual mean wave power off UK coast (Source: ABPmer, UK. Atlas of UK Marine Renewable Energy Resources: Technical Report, R1432, ABPmer, 2008). 
potential for setting up offshore wind farms, tidal power plants and wave power systems. Suitable sites, chosen in consideration of various drawbacks, were proposed. The results were published in 2005 and are accessible on the DTI website [www.dti.gov.uk/publication].

ABP Marine Environmental Research Ltd (ABPmer) carried out a study in collaboration with Garrad Hassan and Partners, the British Meteorological Office and the Proudman Oceanographic Laboratory. All the data used in this study are available for the geological information system (GIS).

The goal of the atlas was to map and quantify the potential of three marine energy sources on a regional scale along the British continental shelf. This tool was designed to determine the potential sites for the next calls for tender.

Other mapping studies were carried out either for the entire United Kingdom or for specific zones. Two major studies which can be mentioned are:

- Preliminary Regional Plan for the Irish Sea. This was carried out by the Marine Spatial Planning Pilot Consortium and published in November 2005. The Irish Sea is intensely used for many different types of activities, but most conflicts of use have been avoided or are dealt with on a case-by-case basis. Use of the sea has grown over the past few years and demand is expected to continue. Spatial planning must consider both current uses and future projects, especially when space is limited.

- An environmental study on the Scottish marine renewables strategy, conducted by the Scottish government. It aimed to estimate the wave and tidal power potential on the west coast. The study area was chosen with respect to preferences expressed by developers. The report gives the parameters and criteria used and a list of stakeholders consulted. These rather general factors are based on available environmental data as well as the constraints of different technologies.

\section{France}

The Agency for the Environment and Energy Management (Ademe), working in collaboration with the relevant ministries, the Secretariat-General for the Sea and the French Research Institute for the Sea (Ifremer) (all members of the project steering committee) is developing a strategic analysis tool to identify appropriate areas for future marine RES electricity generation operations. This includes offshore wind and wave and current energy on the coasts of metropolitan France. The tool is designed for the State services to help them structure future national calls for tender to select future electricity generation projects. Decisions for the installation will then involve negotiated compromises rather than political choice.

Currently there is no one instrument that can globally analyse the issue and devise zoning which is favourable for the development of projects. This type of instrument is needed to:

- support a call for a proposals approach and to assess environmental and socioeconomic impacts of the development of marine RES chain supplies on these sites (e.g. proximity to the coast, competing uses, etc.); this type of approach 
will soon be standard procedure in application of the European Directive 2001/42/CE;

- assess realistic RES development scenarios for the 2007-10 period with respect to technological progress (e.g. systems' power, accessible depths, etc.) and installed power requirements;

- guide other developments that are directly related (e.g. grid expansion or reinforcement, etc.) or indirectly related (e.g. planning for other sea uses) to RES.

\section{Outlook (for the next 20 years)}

\section{Hypothesis 1 \\ Generalization and harmonization of planning tools in Europe}

This hypothesis is developed within a framework of heightened co-operation in planning on the European level. It assumes co-operation in studies that aim to constitute a marine environment database. Harmonizing the regulations appears to be a necessary, or at least likely, a condition for this hypothesis to be carried through.

\section{Hypothesis 2}

Development of custom planning tools for each country

Each country develops its own tools in accordance with its regulations. There is no scheme for pooling of efforts, therefore, coordinating planning efforts on the European level is difficult.

\section{Hypothesis 3}

Only the driving-force countries (i.e. France, Germany, United Kingdom, Portugal, etc.) develop shared planning tools

Only the countries motivated in developing marine RES produce planning tools. More or less close co-operation is foreseen: a common planning tool is possible. Nevertheless, cross-border coordinated planning is difficult owing to the distance from the territorial waters of these countries. 


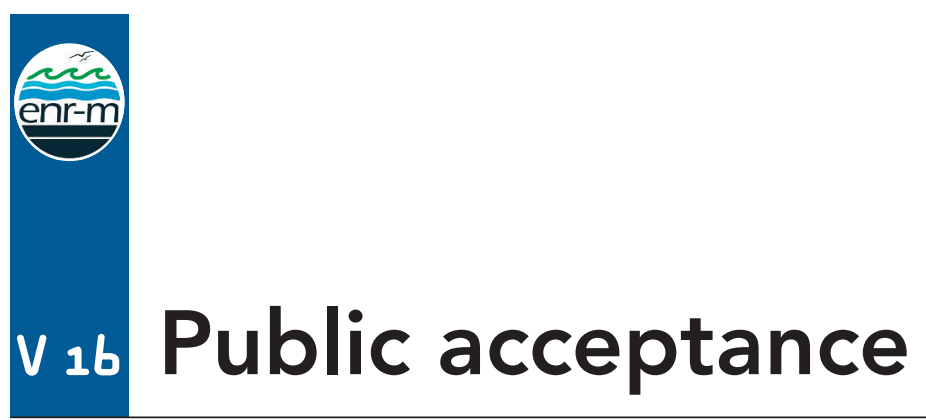

Component: 3. Areas of operation

Author: Ifremer (Denis Lacroix)

'What our fellow citizens demand is not zero risk, but zero disrespect'

(Noiville and Gouyou, 2000)

\section{Definition}

The question posed is complex and its study invokes several disciplines. To be able to arrive at a set of operational hypotheses, public acceptability, whether positive or negative, with respect to a given change is defined as the reaction of a majority of people (on a given scale) when confronted with a significant modification of their environment, their activity or the meaning of their work.

The term 'public acceptance' relates to five main groups of parameters:

- geopolitical contexts;

- economic data;

- scientific data;

- categories of stakeholders;

- perceptions.

The first three categories of data are addressed in the specific variables fact sheets. They are not, therefore, dealt with here, although their interactions with the last two categories are important. It is clear that change in oil prices or world growth will play a decisive role in the acceptance of marine RES.

With regard to the global impact of marine RES, the impact on the landscape is initially considered to be most important in the general public's mind [6, 21]. Ocean thermal energy conversion (OTEC) power plants or osmotic power plants resemble any other industrial installation, with the advantage of being non-polluting. They do not even need to be on the coast. Tidal stream power systems are invisible as are offshore wave power systems. They only affect users of offshore marine areas, that is, fishermen, merchant mariners and authorities at sea used to negotiating navigation routes and sea space for their activities, which is quite different from the millions of permanent or temporary (tourist) residents. 
Finally, systems with heavy onshore impact, such as tidal barrages or systems using coastal waves have not yet been developed or are only in the early stages. Their impacts are high and their reconversion after they are no longer in use is expensive, reducing their potential for development.

For these reasons, for the most part, the analysis for this variable was carried out using marine wind power as the benchmark marine RES.

The issues of training and education in ecology and environmental awareness are fundamental and deserve to be specifically addressed as a separate variable. Clearly, these issues will continue to gain importance in the future for all ages and in most countries, but they are not specific to marine RES. They are thus considered as an integral part of the changes in citizens' awareness of the ecological consequences of development and the advantages and urgency for developing renewables worldwide.

\section{Key indicators}

\section{Reminder of the geopolitical contexts}

While the cost of energy already concerns almost all societies worldwide, changes in public opinion, people's perception of the environment and their capacity to understand the technical stakes strongly depend on their history and relation with energy issues. Hypotheses on geopolitical trends in the major world regions suggest that relationships between these regions will become more complex and that the gap between regions will grow, giving rise to tensions, migration and conflicts. In this context of turmoil and divergence, with growing risks of an energy crisis, the weight of coastal populations' opinions will probably vary considerably as new criteria appear, such as priority given to energy security, advantages of renewable energies, necessity to reduce greenhouse gas emissions, less attractive coastlines, etc.

In this context, are conflicts over development and environmental protection vectors for redefining social links, a characteristic of nation-states? Experiences of actual conflicts in the Camargue region in the 1990s demonstrate two fundamental movements: one where the citizen thinks locally and wants to have a voice and the other where the State, guardian of the community of citizens, is responsible for giving them a voice. This compromise consists in collectively constructing the 'acceptable'.

\section{Categories of stakeholders}

\section{Related to their proximity to the sea}

Populations that reside on the coast all year round are the first to be concerned, but also the first to become accustomed to the landscape and/or directly perceive the positive and negative effects of installations.

The temporary users of the coast (especially tourists) have an easily idealized vision of the setting in which they pay to live temporarily for recreation or relaxation. 


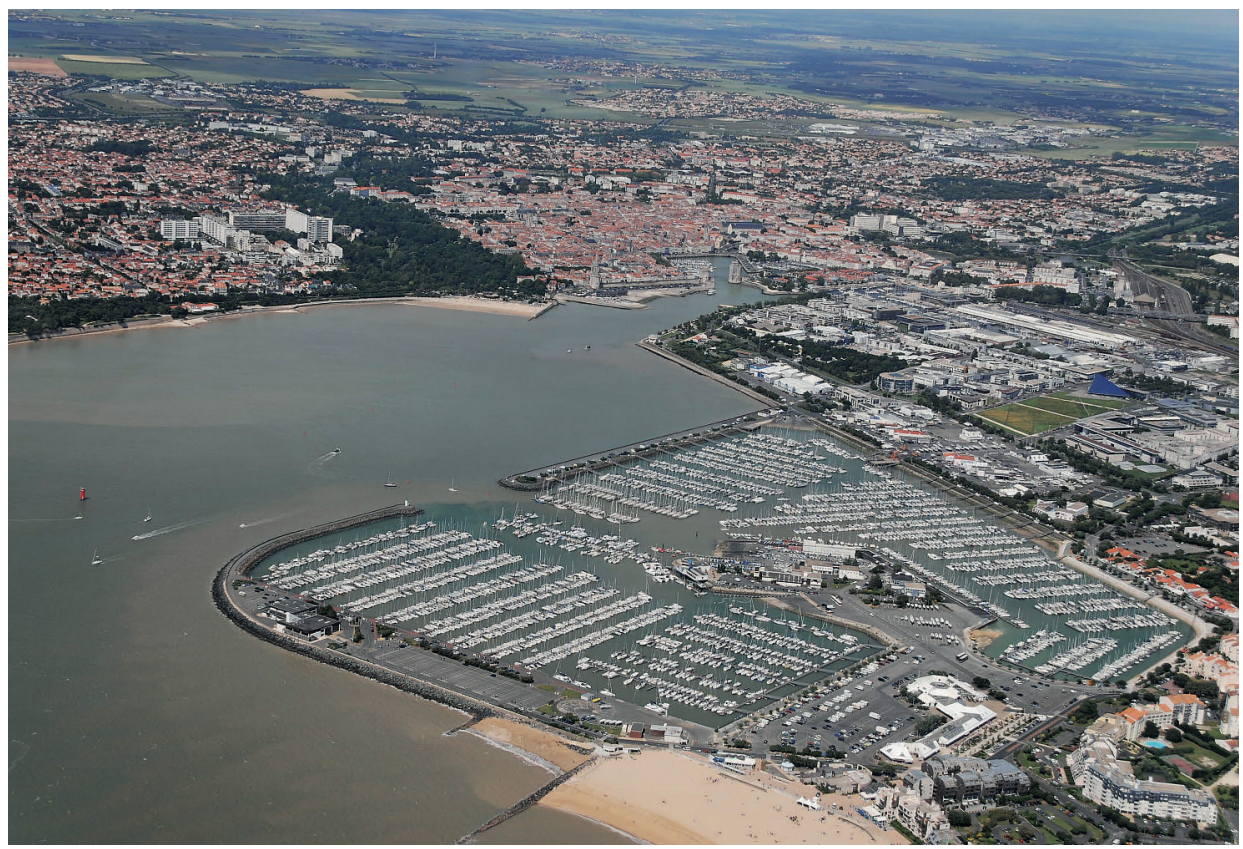

1 Photo 25 : coastal cities (La Rochelle shown here) are a focus of all the causes of conflicts about use, but are also where energy needs are highest ( $\odot$ F. Giraudon for the Office de tourisme de La Rochelle, FR).

The rest of the population will be sensitive to energy benefits and the symbol represented by the sea.

\section{Related to occupation}

The main interests of certain social groups will also play a major role in the construction of public opinion. The closer the group is to the decision-making process, the more influential they will be. These include:

- fishermen and other users of the continental shelf; they will first see traditional, even immemorial (and thus sacred) work space being invaded;

- recreational sailors and coastal tourists; their first concern will be in terms of heritage, with the refusal of any 'industrialization of the sea', especially if it is visible;

- those whose livelihood is derived from tourism and want to protect their customers;

- those who are ready to accept sacrifices for a more secure energy supply;

- people and associations who want to protect nature and ensure that there are no unwanted consequences;

- businesses and local elected officials who will see sources of revenue and employment.

When it is necessary to manage both space and resources, consultation is an essential tool for enacting social change. It brings stakeholders together and 
leads to collective construction of rules and organizations. Often, 'lost' time is time saved. The approach can be summarized in four steps: the legitimacy of participants, clearly setting out the controversy, translation of the different viewpoints, facts and ideas, and finally the construction of a final assessment framework (Beuret, 2006; Pennanguer, 2005).

\section{Perceptions (the 'image')}

Zero risk is an impossible ideal and a paralysing one since the situation is hypothetically one of scientific controversy. 'We have acquired the means to destroy the planet, but have not modified our ways of thinking; is the solution only in the procedures, whether they be democratic or not?' (Dupuy, 2002). Studies carried out on issues as diverse as the mad cow disease crisis, nuclear waste disposal and bird flu show that the core of the problem is tied more to the contexts and institutions in charge of the issue than to the problem itself. Poor initial positioning of debates is costly in terms of image, as is the energy necessary to correct this image when it is false: 'When a simple and apparently founded idea is in the public mind, it takes a long time to eradicate it'. (McLuhan).

\section{Looking back (the past 20 years)}

\section{An old problem: the science-society gap}

Through the deep-reaching transformations in lifestyles and the environment it created, the Industrial Revolution prompted the first questions on the power of technology and the consequences of its unbridled development. Philosophical and anthropological interpretations were rife in the 20th century. For instance, Heidegger said: 'the essence of technology is not technology, it is human... Science does not think'. (The Principle of Reason). Freud (Civilization and its Discontents), Husserl (The Crisis of the European Sciences) and Arendt (The Human Condition) all emphasized the division between knowledge and life and the risk of dehumanization, both collectively and individually. Today, the evolution of modern sciences is only acceptable if humankind keeps it under control. This leads to a worried public, and the more uncertainty grows, the greater the need to ensure that effects can be reversed.

\section{An interesting precedent: onshore wind farms}

Offshore wind farms are the main focus of potential criticisms directed at marine RES. It is thus useful to examine the criticisms of onshore wind farms. A comparison of several wind farms in the Netherlands, the United Kingdom and Germany reached the same conclusion as a Japanese study [15]: local acceptance is always the most difficult problem, especially because it is always underestimated by the promoters of the project. The best solution is to have local authorities take part in the funding and planning of the project. This situation can enable criticisms to be turned into advantages, with greater empowerment of the population.

The Agency for the Environment and Energy Management (Ademe) study made in 2003 (Ademe, 2003) clearly summarizes what is at stake: wind power is an 
environmentally friendly energy par excellence with high approval rates (92\%) because it is clean, cheap, natural, safe, climate-neutral and can be dismantled. However, wind turbines spoil the landscape (61\%) and are noisy (47\%) (Note: at the actual site of the wind farm, local residents reverse these percentages). In sum, the public powers can develop wind farms as long as they consult all stakeholders.

\section{Rules for managing the environment - society - science triangle}

The relationships between the general public and scientists are long-standing and complex. They have evolved into three successive 'models': educating the public from the top down (sometimes condescendingly); public debate, sometimes with excessive media coverage; and co-production of knowledge, a form of two-way collective education. The underlying political stakes involve 'reconstructing social links based on acknowledging the existence of minorities' in a large-scale collective project (Callon et al., 2001).

In fact, in complex societies, controlling events requires that more stakeholders are involved both before and after any project. The Aarhus Convention (1998) provides a general framework for access to information and impartiality in debates and participation. The establishment of procedures is left to the nations that ratified the Convention.

In France, the Barnier law (1995) established the national commission for public debate. It ensures that 'ordinary' lay citizens are involved, to complement the representative function of democracy through a rationale of increased participation (Blatrix, 2002).

\section{Outlook (for the next 20 years)}

\section{Global foresight visions}

These visions are multiple and divergent, but when analysed reveal complicated, although rather convergent, trends. Several wide-reaching studies have helped to change mindsets. In the study commissioned by the Ministry for Research in 1990-91, Gaudin (1990) saw things in the following way: mankind will progressively transform nature until it becomes a technological nature, a sort of 'planetary garden', as long as ecosystem dysfunction remains reversible. The danger comes from the complicated trends where individual freedom and personal satisfaction are demanded in a world where values are relative and negotiable (or the 'nimby' syndrome - 'not in my backyard').

In 1998, in a study on 24 European countries, Skakolczai and Füstös (1998) showed that the main social values depended less on economic levels or the degree of liberalism (or communism) than on the forces of Protestantism and Enlightenment and socialism's degree of maturity. Moreover, they show that all the required conditions for paradigm change are met due to the weakening of centralized power, which benefits individual initiative and accountability.

In his book Defense of an Enlightened Catatrophism, Dupuy (2002) comments that the continuation of the human experience is the result of constant combat 
between life and self-destruction. The field of energy is involved with irrational 'millennium' fears on the one hand, and blind faith in technological progress on the other. Decision-makers must constantly try to reconcile these two extremes, manoeuvring between being excessively lax or lenient (i.e. whatever can be done will be done) and an excess of control (the paralysing effect of the precautionary principle, a 'Big Brother' type of society or a police state). Similarly, a study conducted at the Massachusetts Institute of Technology (Jamieson, 2005) showed that mankind's necessary adaptation to climate change and structural changes imposed by technology cannot be separated from ethics, because ethics have moral consequences (what humanity must do for the good of society) and justice (equality principle).

The EU conducted a major study in 2006 on Europe's place in the world mosaic by 2025 (Institute for Security Studies, 2006). In it, the global trend is described as 'worrying', with inevitable crises concerning energy resources, the environment and, on a political level, the risk of the world dividing into competing, or even antagonistic, poles, seriously postponing the ideal of a world centred on multilateral co-operation to guarantee sustainability of human life in an acceptable environment. With regard to energy, the study notes that the demand for energy in 2030 is expected to be $50 \%$ greater than in 2006 and, even if renewable energies develop more rapidly than other energy forms, especially in Organization for Economic Co-operation and Development (OECD) countries, they will still only represent a modest proportion of the energy supply.

In 2006, the World Value Survey, a survey conducted in 80 countries every 5 years on the characterization and classification of values, published its results (World values survey, 2007) and proposed a synopsis in the form of a 'map' with 'survival' and 'self-expression' (individualism) values on the $x$-axis and 'traditional' and 'rational modernity' values on the $y$-axis. It can be speculated that the development of renewables mobilizes values of individualism (e.g. security of supply) and rational modernity (e.g. adaptation to modern ways of life), given a basically favourable perception for countries qualified as 'Protestant' (e.g. Denmark or English-speaking USA), 'Confucian' (e.g. Japan) and 'Catholic' (e.g. France)38. Considering the three scenarios on the evolution of religions for 2037 (Mayer, 2007), that is, the proliferation of religions, the emergence of a single world religion and the return to traditional religions, the first two would tend to favour decentralized renewable energies owing to the foremost desire for independence and free will in all realms of action.

\section{Categories of stakeholders}

Social development, like human development, cannot be bought or forced. It is cultivated by daily actions. 'It is humans themselves, more and more conscious of

38. However, a word of caution: the worldwide study emphasizes the importance of religions in the choice of values but does not position Islam (1118 million believers; Barrett, 2001) on the analytical map. This suggests that the issues were biased and the final analysis gave more weight to Christianity compared with other major world religions (Hinduism and Buddhism were also absent). 


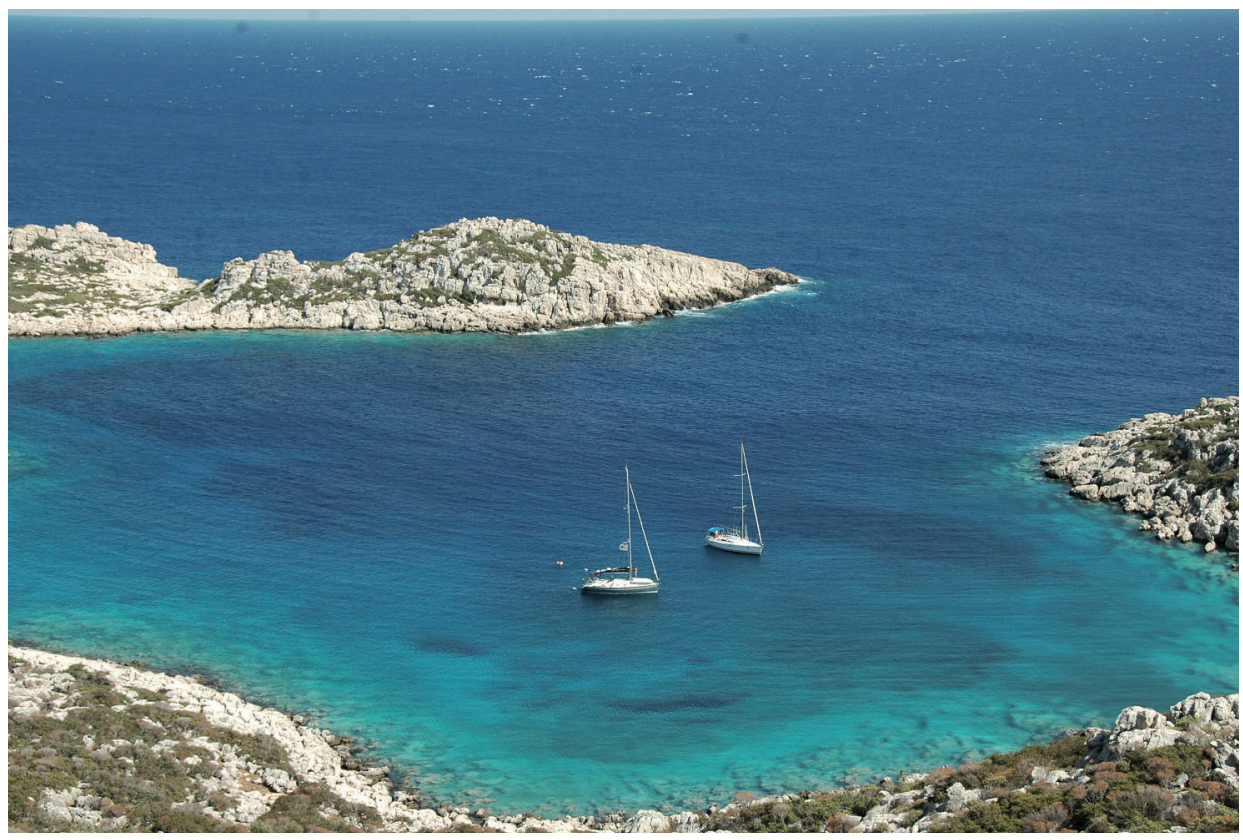

Photo 26 : on some tourist sites, marine energy farms should be set up so as to remain invisible from the surface to lessen the risk of conflicts (C) C. Binachon).

their universal co-responsibility who, by choosing to integrate ethics in all levels of decision-making, become both the gardener and the fruit of society's growth' (Dherse and Minquet, 1998).

Controversies involving all stakeholders allow the parties to explore where scientific and technological developments have overstepped their boundaries: 'Controversies draw up an inventory of the situation... making it more intelligible. They, therefore, enhance democracy' (Callon et al., 2001).

The simple and classic solution in case of opposition to RES-type developments is to assess the socio-economic burden and to provide compensation (Le Tixerant et al., 2006). However, this does not result in a long-term solution and, above all, it maintains the gap between 'laymen', even if they include professionals that know the environment well, fishermen, for example, and the 'experts' who make the decision. It is this dichotomy that generates conflicts and misunderstandings which must be overcome by a real 'Copernican revolution' ensuring that the debate is correctly set out right from the start and involves all the stakeholders from the outset until the final compromise (Callon et al., 2001).

\section{Perceptions}

One of the best tools to 'map' societal perceptions is polling, a technique already extensively used for onshore wind farm developments. 'Before' and 'after' perceptions of wind farm projects are thus available. 
The comprehensive Community-supported Agriculture poll in 2003 (CSA, 2003) demonstrates that, in the public mind, wind turbines make clean, renewable, inexhaustible energy (75\%), but they spoil the landscape and are noisy (13\%); more could be set up (63\%) and in fact wind turbines are attractive (56\%); they could be set up offshore (46\%), but not near beaches (47\%) or cultural sites (56\%). In short, more could be set up (75\%) but you would not put them on a postcard (67\%)!

In Languedoc-Roussillon, the Mediterranean Environmental Agency presented the following synopsis: offshore wind farms have a promising future but the rule of 'When there are too many, it is ugly' holds. The relevant decision-making level, beyond the regional level, is the federation of municipalities. This should be the primary framework for the policy debate because it is at this level that all stakeholders can be informed as openly as possible (Faure and Meiffren, 2003).

The TNS-Sofres poll in 2004 describes the advantages of offshore wind farms: 'a natural source of energy that diversifies the energy supply, can be visited by tourists, can be dismantled and has a positive impact on local economy'.

On the contrary, a study conducted on the acceptance of an offshore wind farm with 80 wind turbines set $5 \mathrm{~km}$ off the northeastern coast of Ireland (Geraint et al., 2007) acknowledges that polls can lead to a tougher and more radical stance between those 'For' and those 'Against' and that the complexity of arguments defies any rational construction that could lead to a consensual decision.

This study, nevertheless, counters the results of consensus conferences held in Europe since 1987, based on the Danish model. The conclusions of meetings on this issue could be summarized: renewable energies are the energies of the future and should be developed as soon as possible. This development will meet many forms of opposition founded on preconceived ideas or lack of information, and sometimes on simple conservativism. However, since these wind farms will occupy a space and it can be assumed that people will (hopefully) be better informed and educated, the solution for better public acceptance is to involve the public as fellow decision-makers in all choices from the outset of the project, especially in sensitive areas with important heritage or cultural value. For countries outside the OECD, the differing levels of poverty (and thus the level of need, as in Africa) and cultural perceptions (as in Asia, China and India) require a region-by-region approach.

In all cases, marine RES have a number of universal advantages for the general public: they are natural, decentralized, renewable and clean energy sources. These qualities are as valid in Jakarta as they are in Los Angeles. However, they cannot be uniformly implemented everywhere.

\section{Summary}

The first main hypothesis is the necessity for massive development of renewable energies for good reasons, beginning with security of supply, which is a State obligation on the part of the public powers. The capacity for providing locally 
produced renewable energy without greenhouse effects clearly justifies developing marine RES on a large scale. In this case, public acceptance is foreseeable, at worst, forced by external constraints (e.g. expensive oil, insufficient nuclear power, difficulties in reducing needs, etc.) and at best, welcomed through dialogue involving the public throughout the process.

The second hypothesis, in contrast to the first, is one of lasting massive refusal of marine RES because they are perceived as a needless 'industrialization' of the sea - a free, open and natural space. In this case, energy needs are supplied by traditional sources, such as nuclear power or other renewable resources located onshore (e.g. wind, geothermal, individual solar power, etc.), without any potential crisis for individuals or businesses.

The third hypothesis is the least extreme and the most likely: it considers that even if fossil fuels become increasingly expensive and criticized (the greenhouse effect), the adaptation period when switching to cleaner energy sources is long enough to develop both technologies and dialogue on local, national, European and global (through NGOs) levels. This is the advent of local participative democracy, largely described under various designations as 'ideal' and where technological advances are taken on board by the general public. Although this hypothesis is plausible for OECD countries, it remains very hypothetical for most countries in the world, particularly in Africa and Asia, in spite of the billions of people involved.

\section{Hypothesis 1 \\ Acceptance by necessity}

Heightened awareness of the need for marine renewables and acceptance because:

- the price of fossil fuels will be high;

- RES are clean and renewable, thus 'environmentally friendly';

- climate change, consequence of greenhouse gases (carbon dioxide), will impact on daily life;

- a whole generation will have been prepared and educated for this need;

- the EU will need to reinforce its security of supply and energy independence;

- real energy-saving or energy-efficiency programmes will have been set up and proved that they work (providing that energy is stored efficiently). 


\section{Hypothesis 2}

\section{Refusal because the sea is considered as sacred and already has many} uses; rejection of all developments here or elsewhere

Massive refusal because:

- the sea is a free and inalienable space;

- the marine area is already occupied by many uses;

- energy needs on the coast can be reduced (e.g. insulation, savings, etc.);

- energy can be produced more inconspicuously (e.g. solar panels on roofs);

- other, more centralized sources of energy will remain less expensive;

- nuclear power will have advanced in reliability, efficiency, security and waste treatment;

- efficiency requires many turbines and 'when there are too many, it is ugly!';

- there are many suitable onshore sites;

- 'nimby' - not in my backyard!, 'banana' - build absolutely nothing and near anything

\section{Hypothesis 3}

Acceptance providing that consultations are held, tolerable or remote sites are chosen and there is integration with other uses

The end of fossil fuels and growing energy needs necessitate mobilizing all possible technologies and space, including marine RES that are easily accepted on the condition that:

- dialogue is always initiated from the beginning of the project with all the stakeholders involved, that is, public authorities, associations, businesses, scientists, etc.;

- sites are chosen in areas that are the most tolerable for local residents (e.g. industrial areas) or are located offshore or underwater, thus out of sight of local residents, and situated far from the majority of coastal activities;

- other uses are assimilated on or near the marine renewable technologies sites, such as aquaculture, fisheries, tourism, outreach and education, etc.

- the municipalities involved enjoy positive economic benefits;

- the public and authorities are reassured that all risks are reasonably controlled.

\section{Bibliography}

Ademe, 2003. Sondage sur la perception et la représentation de l'énergie éolienne en France. Paris; Agency for the Environment and Energy Management, $18 \mathrm{p}$.

Beuret J.E., 2006. La conduite de la concertation: pour la gestion de l'environnement et le partage des ressources; Coll. Politique et Sociologie. Paris: L'Harmattan, 350 p.

Blatrix C., 2002: Devoir débattre: les effets de l'institutionnalisation de la participation sur les formes de l'action collective. Politix, 15 (57): 79-102. 
Breukers S., Wolsink M., 2007. Wind power implementation in changing institutional landscapes: an international comparison. Energy Policy 35: 2737-2750.

Callon M., Lascoumes P., Barthe Y., 2001. Agir dans un monde incertain: essai sur la démocratie technique; Coll. La couleur des idées. Paris: Seuil, 358 p.

CSA, 2003. Impact potentiel des éoliennes sur le tourisme en Languedoc Roussillon. Community-supported Agriculture, $63 \mathrm{p}$.

Dherse J. L., Minguet H., 1998. L'éthique ou le chaos. Paris; Presses de la Renaissance, 378 p.

Dupuy J. P., 2002. Pour un catastrophisme éclairé ; Col. La couleur des idées. Paris: Seuil, $215 \mathrm{p}$.

Faure M., Meiffren D., 2003. Eoliennes et paysages: le point de vue des populations ; enquête de l'AME en Languedoc Roussillon, 10 p.

Gaudin T. (ed.), 1990. 2100 récit du prochain siècle; étude collective du Ministère français de la Recherche. Paris: Ed. Payot, 689 p.

Geraint E., Barry J., Robinson C., 2007. Applying Q-methodology to understand public acceptance of wind farm proposals. Journal of Environmental Planning and Management 50 (4); 517-551.

Institute for Security Studies, 2006. The New Global Puzzle: What World for Europe in 2025. Edited by N. Gnesotto and G. Grevi. London: Institute for Security Studies, $250 \mathrm{p}$.

Jamieson D., 2005. Adaptation, mitigation and justice. In Perspectives on Climate Change: Science, Economics, Politics, Ethics. Oxford: Elsevier, pp. 217-248.

Le Tixerant M., Gourmelon F., Véron G., 2006. Modélisation du déroulement d'activités humaines en mer côtière. $17 \mathrm{p}$.

Maruyama Y. et al., 2007. The rise of community wind power in Japan: enhanced acceptance through social innovation. Energy Policy 35 (5): 2761-2769.

Mayer J. F., 2007. Les courants religieux à I'horizon 2037 : les religions entre mondialisation et individualisation. Futuribles 337: 55-69.

Pennanguer S., 2005. Incertitude et concertation dans la prise de décision en gestion durable de la zone côtière. UQAR thesis - Ensar, $370 \mathrm{p}$.

TNS-Sofres, 2004. Le projet de parc éolien de la côte des isles (Cotentin). Website Internet TNS-Sofres/études.

Szakolkczai A., Füstös L., 1998. Value system in axial moments: a comparative analysis of 24 European countries. European Sociological Review 14 (3): 211-229.

World Values Survey, 2007. Website; Ingelhart-Welzel Cultural Map of the World.

Wüstenhagen R. et al., 2007. Social acceptance of renewable energy innovation: an introduction to the concept. Energy Policy 35: 2683-2691. 


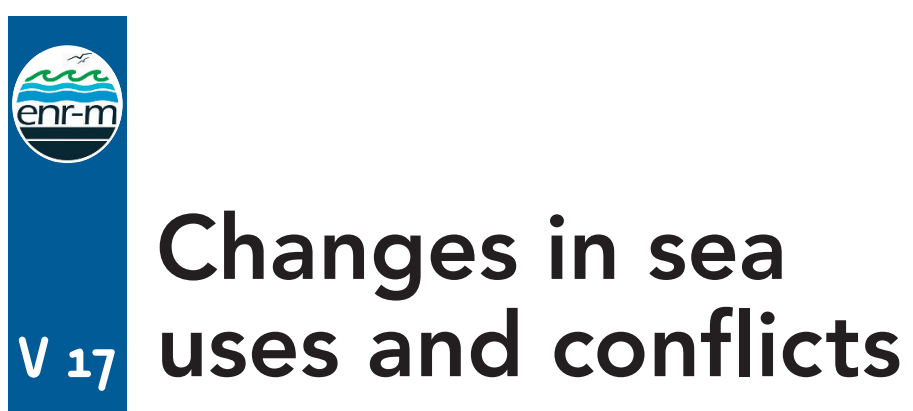

Component: 3. Areas of operation

Author: Meeddat (Jérôme Clauzure)

\section{Definition}

This variable concerns the different uses of the sea and their conflicts, as well as prospects for progress.

The three-dimensional marine environment is generally characterized as being 'non-specialized'. This variable can be analysed with respect to several 'zones', including:

- harbours, seawalls, piers, jetties and slipways (artificial constructions and infrastructures);

- the natural coastal area not including the previously described infrastructures;

- the water surface;

- the water column;

- the adjacent air column;

- the seabed (seafloor and underlying layers).

This variable also raises a range of issues:

- access to the coast, infrastructure and services;

- rights, property, sharing, management, exploitation and protection of resources, species and natural areas;

- limiting or developing certain human activities.

Traditional uses of the sea can generally be distinguished from 'new uses'.

The traditional uses include shipping, fishing, commercial and recreational boating, naval navigation, shellfish farming and many other activities, which have been practised for centuries or at least decades including yachting, angling, laying cables, aggregate mining (e.g. sand, calcareous materials, etc.). Some of these activities have developed greatly in the past few years, such as leisure activities (in nearshore areas for the most part), or extraction of marine aggregates (formerly confined to nearshore areas but which could develop in more offshore areas). 
The new uses that have appeared more recently are related to the increased exploitation of marine resources, whether they are living or renewable, such as oil extraction, production or energy transmission (especially with offshore wind and tidal power, but most likely in the long term with wave or stream power, geothermal or ocean thermal energy), freshwater production (by desalination of seawater or capturing sub-sea springs), mining of metals, mariculture or offshore shellfish farming, exploitation of bio-resources, artificial reefs and fish aggregating devices.

These activities can also be classified with respect to the space they occupy:

- 'mobile' activities not linked to a particular space, or that only occupy space temporarily (boating and fishing);

- 'fixed' activities generally linked to the exploitation of marine resources (in particular, the exploitation of energy and mineral resources, as well as shellfish farming).

\section{Several examples of conflicts over use can be given}

These may be conflicts between activities, for example, professional and recreational, or between an activity and environmental protection (nature, landscape and natural heritage).

- Extraction of maerl and environmental protection; extraction of aggregates and fisheries.

- Dumping of dredge spoil and environmental protection.

- Commercial fisheries and boating (recreational fishing, in particular).

- Commercial fisheries and sub-sea cables (lost and new cables).

- Marine parks and other marine protected areas (Natura 2000, vulnerable species) and activities at sea.

- Fisheries and shellfish farming.

- Yachting and shellfish farms and/or bathing.

\section{Key indicators}

It is difficult to define indicators for this variable, which can be both subjective and qualitative (e.g. social and human relations, cultures and characters, etc.). Nevertheless, several indicators could be chosen from among the following quantitative factors (if available):

- maritime transport: number of vessels, number of tonnes transported, number of containers transported;

- commercial fisheries: number of fishing vessels, number of fishermen, tonnage, etc.;

- shellfish farming: number of farms, number of employees, production, etc.;

- water sports and recreational yachting: number of pleasure boats registered or sold, number of sailing days per vessel per year, number of mooring rings in harbours and other mooring capacities other than berths or rings, number of members in watersport federations. 


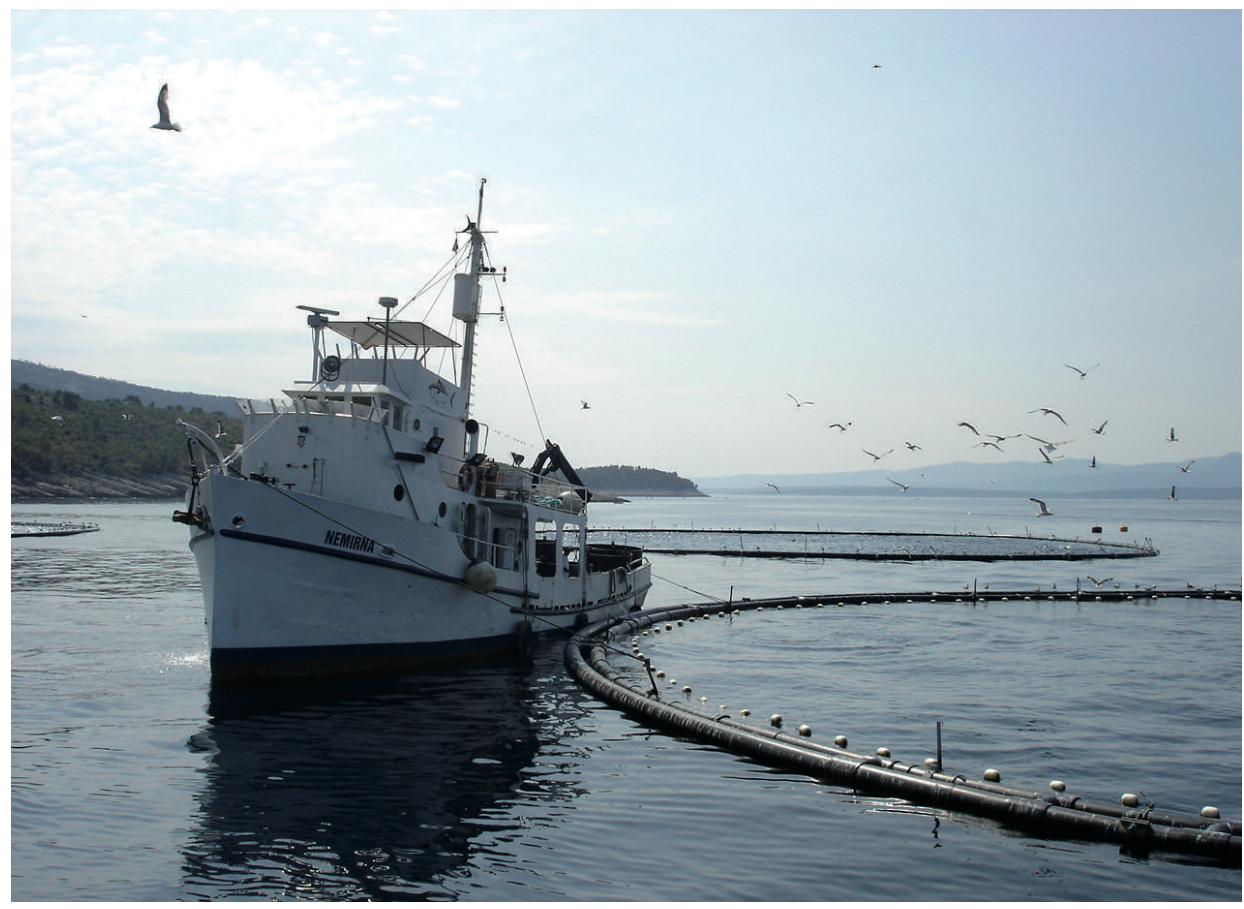

I Photo 27 : fish farm in Croatia; aquaculture, like fisheries, can encounter conflicts of use, but also synergies with offshore wind in the open sea (@ Ifremer, D. Lacroix).

\section{Looking back (over the past 20 years)}

The pressures directed at and on coastal areas, a finite and fragile space, are proliferating.

- Migratory inflows and rising population on the coast all year round as well as during the tourist season. (The development of leisure activities together with more free time since the 1970s has intensified population changes on the coast between the high and low seasons.)

- Shipping: increase in merchandise, relative stability for passenger transport.

- Overexploitation and dwindling living resources in seas and oceans causing a decline in fisheries and the implementation of quotas.

- Significant development of electronic communication and trans-continental telephone links and networks, which require the laying and use of increasingly numerous or large underwater cables.

\section{Some observations on frequent conflicts and their recent trends}

Fisheries. Fishermen are often in conflict with other users (e.g. non-commercial fishing). Through consultative efforts and some concessions, partial or total reconversions of fishing harbours can be successful, but this is not always the case.

Shellfish farming. Water quality and catchment inputs are crucial for this sector, but some activities create chronic or acute pollution. 
Water sports, recreational boating. These activities are growing rapidly and create problems of access, parking of machines, vehicles or lorry trailers, as well as of fairways and navigation in general.

National defence. Total or partial 'demilitarization' in certain areas opens possibilities for reconversion, new environmental protection and developing traditional or new activities. However, even when reconverted, certain military zones are not completely 'free': it is sometimes necessary to keep a minimum distance from the remaining military zone and to avoid fairways or reserved channels.

Landscape. The development of associations that strive to protect the environment when wind farms are set up on land suggests that a strong movement for the protection of coastal landscapes could arise.

Tourism. Its strong development is coupled with sometimes contradictory expectations: the need for infrastructure and additional services and a desire for a preserved environment.

\section{Some comments on how to manage some of these conflicts}

- Master-plans like the Sea reclamation scheme master-plan (SMVM) for sea reclamation and use help to define - following an initial study for site analysis and diagnosis - a project and its guidelines (often with zoning). They take into account the different uses and fixed activities like shellfish farming, and are generally able to resolve conflicts of use. Unfortunately, this regulatory tool is seldom used, but may be revitalized by a recent adaptation.

- Both the State and EU promote the integrated management of coastal areas, which provide incentives and encourage the consideration of all users.

\section{What does the EU Green Paper have to say?}

'An all-embracing maritime policy of the EU should aim at growth and more and better jobs, thus helping to develop a strong, growing, competitive and sustainable maritime economy in harmony with the marine environment. It should assist in avoiding and minimizing conflict and, where conflicts do arise, should set out clear and agreed paths for their resolution. It should provide increased certainty for industry and stakeholders and define a more efficient approach to marine conservation.' 


\section{Outlook (for the next 20 years)}

\section{Hypothesis 1 \\ No 'specialization' of sea space and global resolution for conflicts regarding use; threshold (resolution) and baseline (no specialization hypothesis)}

This hypothesis is based on the current situation and optimistic projections, but it can be threatened by greater pressures on sea space, particularly coastal spaces, and the development of various sea uses, necessitating strict space allocation or at least restrictions on other uses in a particular area. This is both the threshold hypothesis for this variable, when the increase in conflicts is controlled and stabilized, and the baseline hypothesis, where the number of conflicts remains under control.

\section{Hypothesis 2}

No 'specialization' of sea space and many conflicts regarding use; the most protected and best defended uses and users win conflicts

Free access to all remains the general rule for marine areas. In reality, however, some would like or could claim more space than others; a pessimistic scenario, but which could occasionally be realized: for example, absolute environmental protection with drastic limitations on other activities, privileged uses for a given activity sector at the expense of others. In particular, this situation could arise from a lack of political will or difficulties in enforcing complex regulations in mediating conflicts and in carrying out efficient assessments. This is the baseline hypothesis for this variable, given the rise in conflicts linked to pressure on marine areas, particularly on the coast.

\section{Hypothesis 3 \\ 'Specialization' of sea space and regulated allocation of sea uses}

This projection is not congruent with the French legal tradition. However, as coastal areas are confronted with stronger pressures, procedures for zoning and allocation, whether exclusive or prioritized, are viable alternatives to consultations and conflict resolutions that break down or fail. More specialization occurs for sedentary activities, as is already the case for shellfish farms. This is the breaking point hypothesis for this variable. 


\section{Appendix}

\section{Taken from the EU Green Paper Towards a Future Maritime Policy for the Union: A European Vision for the Oceans and Seas}

\section{Maritime governance}

\section{Policy-making within the EU}

Any form of ocean governance has to take into account the principles set out in the Treaty in relation to policy areas and the distribution of competences between the EU institutions, the Member States, the regions and the local authorities. On this basis and in accordance with the principle of subsidiarity, consideration must be given to sectoral and regional specificities.

An all-embracing maritime policy of the EU should aim at growth and more and better jobs, thus helping to develop a strong, growing, competitive and sustainable maritime economy in harmony with the marine environment. It should assist in avoiding and minimizing conflicts of use issues related to sea space and, where conflicts do arise, should set out clear and agreed paths for their resolution. It should provide increased certainty for industry and stakeholders and define a more efficient approach to marine conservation. The European social dialogue in maritime sectors has an increasingly important role to play in this context.

The Commission encourages the social partners to work together to achieve positive outcomes such as improved working conditions and career prospects.

All this requires a coordination and integration among sectoral policies. This is supported by the commitments undertaken in the context of the 2002 World Summit on Sustainable Development and the provisions of UNCLOS.

Furthermore, the progress of science and technology now makes it possible to better understand interactions and relationships relating to the oceans and their use. Developing technology, including the monitoring and surveillance of the seas, makes for integration of data services to an extent unheard of in the past. Economies of scale resulting from the development of technology are best realized through integrated policies.

In relation to law enforcement on the sea, there are efficiencies to be realized through coordinated use of the scarce, but expensive, assets of Member States.

Some general principles could be agreed for maritime policy-making, including spatial planning:

- in view of the complexity of the relationships, procedures should ensure the integration of the best technical and scientific advice available; 
- given the difficulty of policing activities on the seas, and that stakeholders should be fully supportive of the restraints to which they are subjected and in order to understand the side-effects on interested parties of actions envisaged, all relevant stakeholders should be consulted;

- policy-making relating to the seas and oceans should be subject to strong coordination, in order to ensure coherence across sectors, policy objectives, geography and our external policies; institutional competences and means for co-operation, collaboration, coordination, and integration should be identified;

- the consideration of sea-related issues, where relevant, should be promoted in EU policies, paying particular attention to the coherence of policy objectives;

- policy-making should include the setting of targets against which to assess performance, and a continuous improvement of policies and their implementation based on these assessments.

In the EU, the principles set out above can be implemented partly through existing institutions, including the Economic and Social Committee and the Committee of the Regions. Sectoral advisory bodies set up by the Council (e.g. Regional Advisory Councils in the Fisheries Sector 107) or the Commission (Sectoral Industry and Civil Society advisory committees, scientific advisory committees for different sectors 108) will, however, have to be supplemented by appropriate cross-sectoral bodies.

The Commission has already taken steps towards strengthening its internal coordination on ocean and sea affairs and expects this to be reflected in its policy proposals in the future.

An example of a structure to further integration of policies can be found at the level of the UN, where the 'UN-Oceans' office has been created to better coordinate oceans-related policies in 12 different UN organizations.

\section{Shipping}

\section{France, fourth ranking world trade power}

France is the fifth biggest exporter and sixth biggest importer worldwide in terms of goods value. Its foreign trade balance is about 650 billion euros, representing 480 million tonnes of goods, including all forms of transport, that is, $12 \%$ of exports made by EU Member States. Nearly half of this tonnage is shipped by sea.

\section{An advantageous geographical situation}

France has a very long coastline $(5500 \mathrm{~km}$ in metropolitan France and $1500 \mathrm{~km}$ overseas), which has some 564 ports of all types (merchant, fishing and yachting harbours).

Maritime activity plays a vital role in French trade, tourism and industry. Some 340 million tonnes of cargo are handled by French seaports each year; half of 
which is liquid bulk (especially oil), one quarter is dry bulk (cereals, coal, ores) and one quarter general cargo, which is increasingly containerized.

On average, a merchant vessel enters a French port every 6 minutes. Every year, 34 million passengers enter or leave the country through a French harbour, over 20 million of whom go through Calais alone, making it one of the top passenger ports worldwide.

French ship-owners have some 200 French-flagged vessels and over 100 flying other flags.

As the world's top ranking manufacturer of sailing yachts and inflatable boats, France exports $40 \%$ of its boatyard production. 


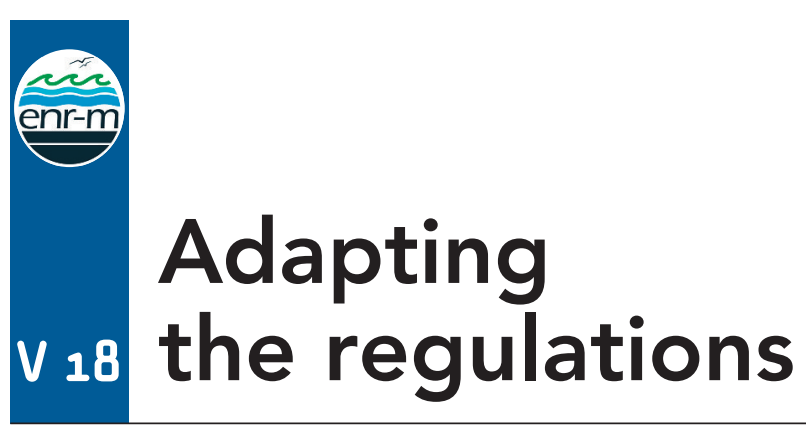

Component: 3. Areas of operation

Author: Meeddat (Jérôme Clauzure)

\section{Definition}

This indicator concerns the regulatory tools for coastal areas, both in substance (i.e. authorizations, prohibitions, definition, scope and organization) and in form (i.e. procedure, implementation, etc.). The regulatory aspects related to managing conflicts of use (but which can themselves sometimes give rise to conflicts) are not addressed here to any extent, but are dealt with in variables fact sheet 17.

\section{Key indicators}

The concept of a relevant indicator is difficult to establish in terms of regulations. However, recourse can be had to some of the following statistics (where available):

- a number of urban planning procedures: Territorial cohesion scheme masterplan (SCOT), Local urban planning scheme (PLU), PPRI, Sea reclamation scheme master-plan (SMVM);

- surface area and shoreline of land acquired by the Coastal Conservatory (Conservatoire du littoral) or managed by it;

- extent of protected areas including outstanding areas, Special Protection Area (SPA) and Special Area of Conservation (SAC) (Natura 2000), marine nature parks, national parks and regional nature parks along the seafront, registered sites, etc.

\section{Looking back (over the past 20 years)}

The marine environment and the coast have received special attention from French and European lawmakers and public authorities. Several regulations dealing with various approaches to this area, environmental themes and maritime activities include:

- water (e.g. legislation on water); 
- biodiversity ('habitat' and 'birds' directives, SAC and SPA Natura 2000 zones);

- the environment (national parks, marine nature parks and regional nature parks);

- integrated coastal zone management (ICZM);

- urban planning and development (e.g. SCOT, PLU, PLD, SMVM, etc.);

- natural and man-made public maritime property (harbour code and how the natural public property of the maritime domain can be occupied);

- the coastal area (coastal law and the Coastal Conservatory for the coastal area and lake shores);

- fisheries and more generally, exploitation of biological resources from the sea;

- mining and oil resources, extraction of various marine aggregates;

- national defence (sensitive military zones, military ports and bases);

- transport, ship safety and hazardous substances.

Action taken by lawmakers and the public authorities is guided by the following general principles.

- The sea is a public place as are the resources it holds. There are zones which fall under the jurisdiction of the coastal State, where it has certain sovereign rights, but this jurisdiction also brings obligations (especially in terms of marine environmental protection).

- The maritime public domain is managed by the State.

- Some constructions require building permits and are thus subject to a local town planning scheme.

- Managing the sea (the space and publicly owned resources) should be performed above all with the objective of public interest and the common good. Collective uses (sharing the space) should also be preferred to private uses (exclusive allocation) and temporary uses to permanent ones. Generally, use of the space should be optimized to limit private utilization or constraints on other users.

- The management of the area and resources should be ensured or supervised by the State, which guarantees public interest.

- The marine area is both inalienable and imprescriptible.

- Uses made should not unjustifiably deteriorate the environment or make it more artificial: reinstatement or rehabilitation should be the rule and the responsibility of the beneficiary of the right of use.

- Public resources are a shared capital which should not be employed unless there is no private, land-based alternative (space or resources). Renewable resources should be used sustainably; non-renewable marine resources should be saved.

- For all activities at sea, a precautionary approach should be taken; their impacts systematically assessed and monitoring set up in case of doubt.

- The consequences that an activity at sea has for the community (unless it is an activity in the public interest) be at the expense of the beneficiary and not the 


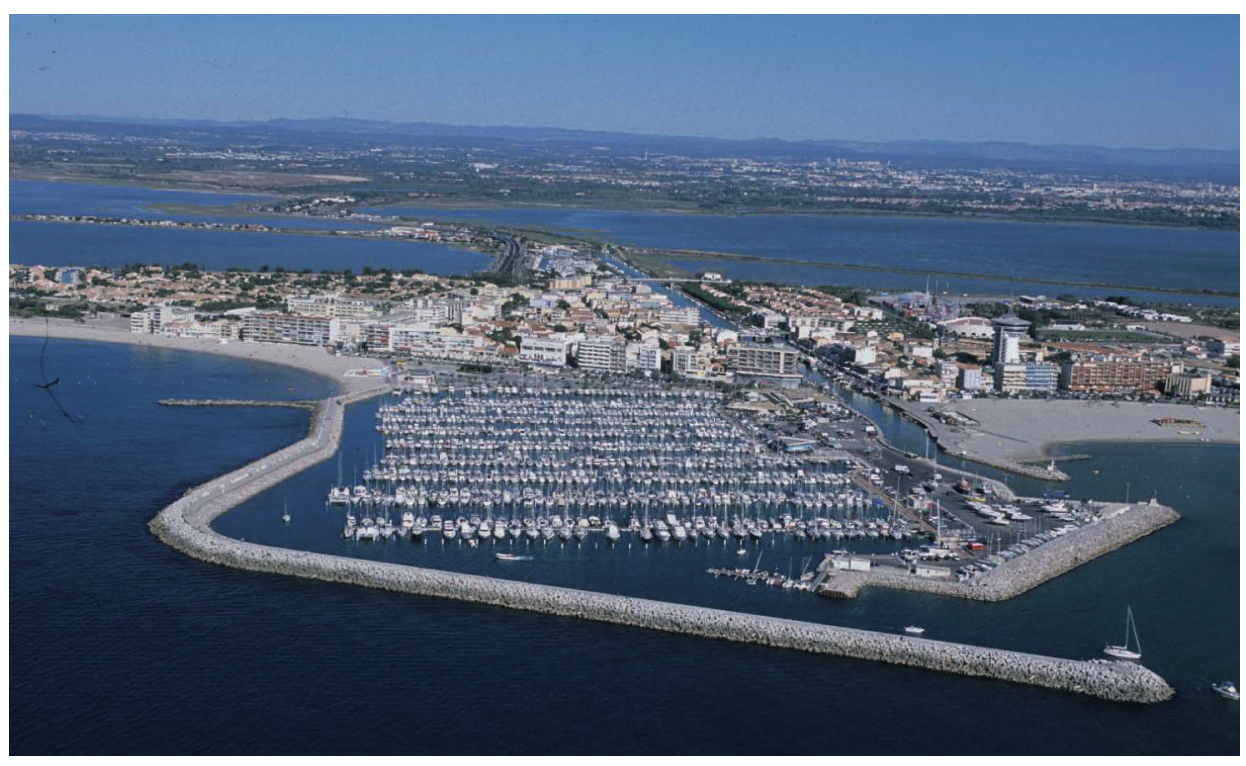

1 Photo 28 : a view of Palavas-les-Flots and coastal lagoons (the town of Montpellier in the background); coastal zone planning must take account of several levels of planning (๑ Ifremer, O. Barbaroux).

community (e.g. aftermath of accidents and pollution, additional costs incurred for policing or surveillance, etc.).

The general trend for the French administration over the past 30 years has been devolution of powers and decentralization of responsibilities; the State does less direct administration and more regulation. Playing an increasingly smaller role as arbitrator or sole decision-maker, the State ensures the coordination and involvement of local stakeholders to whom responsibilities have been transferred. It provides technical and regulatory tools (some recent examples being the decentralized drawing up of SMVM master-plans, turning over the public maritime domain to the Coastal Conservatory, which in turn generally has the land managed by local authorities). The State also establishes national strategies in keeping with European guidelines and directives (e.g. ICZM). The State and lawmakers have not just redistributed the competence to act, but the new governance they promote should enable all legitimate stakeholders to exercise fully their competence without taking the place of the others.

\section{Outlook (for the next 20 years)}

\section{Hypothesis 1 (the 'threshold hypothesis')}

The State and perhaps the EU, complete existing regulations (rules and procedures for their implementation) with the growing role of regulator ensured by the State, as the guarantor of public interest and consultation. The State would only 
act as arbitrator in cases where regulation and reconciliation have been ineffective. Outside these exceptional cases, the action and impetus of the State and European authorities would enable each legitimate stakeholder to exercise fully their competence without taking the place of the others. Finally, the lawmakers, European or national, will simplify the laws and regulatory instruments concerning the coast and the sea and make them more coherent (e.g. with fewer 'layers' of laws, zoning, types of protection, etc.).

Note: this hypothesis is closest to the current trend; in the framework of the sustainable development policy on French, European and international levels desired by citizens and their representatives, the authorities will remain committed to coastal and marine issues and deal with them in accordance with the principles of the ICZM. These principles, which have recently come to the fore are being further specified and refined and new methods and tools to implement them are being developed.

This hypothesis corresponds, if not to today's reality, at least to the intentions displayed by public authorities and certainly to the expectations of fellow citizens. Since this hypothesis consists in keeping the 'volume' or the 'weight' of regulations at its current level or at least to restrain their natural and usual tendency to be expanded, we shall call this the 'threshold hypothesis'.

\section{Key points of hypothesis 1}

- the EU and the State set the course and supply the ICZM 'tool box';

- the State is guarantor of the public interest, regulator and conciliator, and arbitrator as a last resort;

- local authorities, stakeholders and other players are involved in sustainable development;

- the subsidiarity principle is implemented and complied with;

- instruments and laws are streamlined (and simplified).

\section{Hypothesis 2 (the 'breaking point hypothesis')}

'Liberalization', 'privatization' or 'decentralization' of the marine area: State invention decreases or tends towards minimal regulation in order to avoid only the most serious consequences. Public (local authorities like regions) or private entities acquire certain rights and responsibilities or prerogatives in 'managing the sea'.

Note: this highly uncertain hypothesis assumes that public authorities will be disengaged and disinterested, which is contrary to the current trend. However, occasionally and in some specific fields, this type of hypothesis could hold true to a limited extent. This hypothesis runs counter to French culture and tradition, which is why it is called the 'breaking point hypothesis'.

\section{Key points of hypothesis 2 :}

- not necessarily less regulation, but 'flexible' regulation;

- regulation which gives more latitude and leeway to private players who are less supervised and perhaps less controlled; 
- increasing influence and power of a given category of individuals or corporations (in one case, the boating industry, in another, associations for environmental protection, or yachtsmen and fishermen, residents and holiday makers and tourists, etc.).

\section{Hypothesis 3 (the 'baseline hypothesis')}

Continuously increasing regulation means significant limitation or restrictive supervision of uses, with much specialization of areas (zoning), either as an objective and strong will to protect the environment and promote sustainable development, or in response to prevailing pressure.

Note: this hypothesis reflects imagination failing, energy running out and a lack of efforts - in spite of the fact that they only recently began - aiming at new governance and ICZM. However, occasionally, in specific fields, this hypothesis could hold true to a limited extent: for instance, in a local case in response to a powerful lobby or an association putting strong pressure on public decisionmakers, or in response to strong political will to promote a given activity at all cost.

\section{Hypothesis 4}

The regulations set out by the lawmakers are too 'fragile' in terms of setting up marine RES, because they try to reconcile existing uses as a priority (i.e. fisheries and military operations), while developing protection of natural spaces and species. Given the difficulties raised by the first permits to build offshore wind farms or zoning attempts, which are strongly opposed, developers become discouraged.

Hypothesis 1

Regulatory approach and conciliation more than regulations

(The State would only act as arbitrator in cases where regulation and reconciliation have been ineffective)

Hypothesis 2

Liberalization to the benefit of local authorities or private stakeholders

Hypothesis 3

More regulations which lead to the specialization of areas

Hypothesis 4

Weak regulations 


\section{Appendix}

\section{Legislative and statutory texts}

\section{European and national laws and regulations}

1. Recommendation on 30 May 2002 of the European Parliament and Council concerning the implementation of a strategy for integrated coastal zone management (ICZM) (JOCE L 148 on 5 June 2002), which was tangibly implemented by France in 2003 and rendered concrete by CIADT on 14 September 2004.

2. Directive proposal related to the strategy for marine environmental protection on 14 October 2005.

3. The Commission's Green Paper Towards a Maritime Policy of the Union: a European Vision of Oceans and Seas (adopted on 7 June 2006).

4. The 'habitat' and 'birds' Directives (92/43/EEC and 79/409/EEC).

5. Action plan 'Halting the Loss of Biodiversity by 2010 - and Beyond' on 22 May 2006.

6. INSPIRE Directive (2007/2/EC on use and dissemination of spatial data).

7. Act $86-2$ of 3 January 1986 on coastal planning, protection and promotion (Journal Officiel, 4 January 1986).

8. Act 2005-157 of 23 February 2005 on developing rural territories.

\section{International laws, authorities and agreements}

1. Helsinki Commission for the protection of the Baltic Sea.

2. Oslo and Paris Conventions for the Northeast Atlantic.

3. Barcelona Convention for the protection of the Mediterranean Sea.

\section{Hazardous substances and maritime shipping}

Consolidated law from Division 411 on the carriage of hazardous and noxious substances as packaged goods by sea.

Division 411 as modified by the Order of 22 December 2006. 


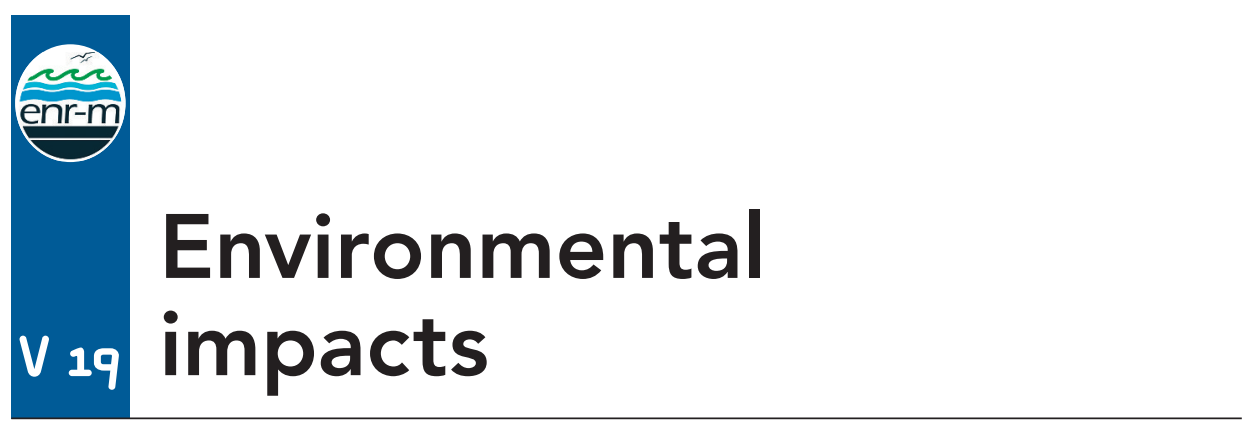

Component: 3. Areas of operation

Author: Ifremer (Luc Dreves)

\section{Definition}

Any development in the coastal sea (e.g. creating or maintaining harbours, developing mariculture, laying underwater cables, etc.) often raises opposition primarily based on conflicts of use. Some of these conflicts cannot be admitted publicly or in the media (e.g. abusive corporatism, territorial claims, refusal of change, visual disturbance, etc.), so the so-called 'green' impact will be emphasized. Thus, some people who discover a calling to protect the environment once a project that concerns them is launched will promote ecological arguments to a degree proportional to the importance of the true reason for their discontentment.

In order to define this variable, several things should be mentioned.

- Since conflicts of use are dealt with elsewhere, this fact sheet will only list the physical, biological and other impacts of a RES project.

- With respect to presently known projects, this fact sheet will consider that cables are used as the means of transmitting the power generated. With marine RES projects located much further offshore in deeper water, and which are larger in size, another storage process (liquid hydrogen) could provide a different form of transport (tanker vessel).

- The impacts of the worksite (very short term, from 1 to 2 years) should be clearly distinguished from those of the operating phase (long term, from 20 to 30 years).

- It appears that all these projects (e.g. tidal, wind, stream, wave, thermal power, etc.) will be achieved without releasing any products into the environment.

\section{Key indicators}

To appraise correctly the impacts of a marine RES project, it is important to specify clearly its real footprint, considering the various 'marine' sectors concerned by the project that are contiguous, but of varying importance and size. 
- The sector where the structure(s) are set up, which is the zone where energy is generated. With the exception of a tidal power project, this area covering several square kilometres will also hold a network of underwater cables.

- The sector concerned by the pathway (or the installation corridor) of the underwater cable exporting the energy generated towards the mainland. Its length will depend directly on the distance from the coast to the above-mentioned sector. Its true width is just a few metres, much less than the 'administrative' footprint set by the authority in charge of maritime safety. In the present tidal power sites located in bays and placed directly beside the shore, this marine corridor is non-existent.

- The sector where the cable arrives on land to be connected to the land grid. Its surface area will be larger in the Channel and Atlantic (due to tidal range) than in the Mediterranean. It will go from zero chart datum to the upper boundary of the maritime public domain (DPM).

The potential impacts of this type of marine renewables project will be due to the constant presence of the structures bearing the generators and underwater cables.

\section{Temporary impacts related to the worksite}

- Obstacle for shipping (see conflicts of use).

- Banning or limiting fisheries activities in the areas of development (see conflicts of use).

- Increased water turbidity. Creating foundations for the structures and burying the cables will inevitably put sediments and the elements they contain into suspension. This temporary or localized rise in water turbidity may affect fish and cause them to temporarily move away from the site. However, it should be borne in mind that this work is done in shallow water, that is, on seabeds that are disrupted by the swell each time there is a storm. In addition, the area is characterized by significant currents, which will enable the elements present in the water to be quickly diluted.

- Localized destruction of benthic fauna used as food by fished species. This impact will remain partial in nature, if food is not a limiting factor for the stocks found in the sector.

\section{- Permanent impacts at the end of the worksite}

- Reduction of areas accessible to fishermen (see conflicts of use).

- Noise, electrical and magnetic fields.

- Reserve effect through prohibiting access to all or part of these zones. Even if a zone is held as a reserve for a given species, the protection will benefit a variety of other species. The larger the reserve, the greater the protection.

- The reef effect from the base of the structures, if the submerged part has been favourably designed.

- A new sedimentary status for the seabed, since the environment will have found a new balance in terms of the currents. 


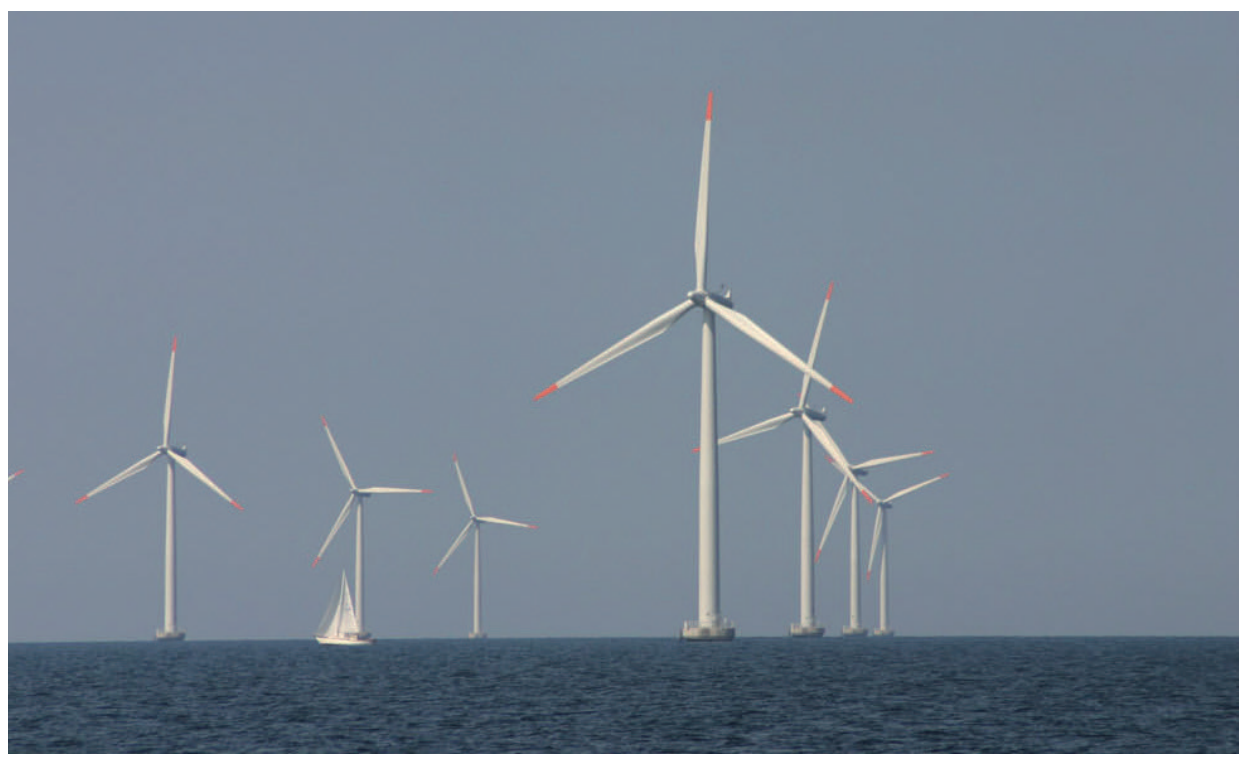

I Photo 29 : the Horns Rev offshore wind farm on the eastern coast of Jutland (80 wind turbines; $160 \mathrm{MW}$ ) where impact studies were conducted for 6 years (@ Dong Energy, DK).

- The case of tidal power projects that hold back a large mass of water and modify the natural cycle of the tides, etc., could lead to a modification of the earth's speed of rotation if these projects became more numerous. This means that the impact goes beyond the project's nearby geographical area.

\section{Impacts at the end of the project's operational life}

At the end of the project's useful life, when operations cease or if the 30-year lease granted expires (leases or concessions for use generally run for 30 years, but 25 years is currently provided for in cases of offshore power projects), there is the issue of its dismantlement, whether total or partial.

The order No 2004-308 on 29 March 2004, related to leases on public maritime property except for harbours, specifies in Article 2, the information to be provided in an application for a lease or concession. In Paragraph (h) it specifies that: 'if necessary, the nature of operations required to reverse the modifications made to the natural environment and the site, as well as its reclamation, restoration or rehabilitation of the premises at the end of the deed or the end of the utilization'. Article 8 of this order states that 'the agreement can provide, in order to ensure the effective reversibility of modifications made to the natural environment, for financial guarantees to be drawn up. Their amount is established taking into account the estimated cost of operations to reclaim, restore or rehabilitate the site'.

This means that the lawmakers provided for the reinstatement of the site to its initial condition where operations have stopped. Depending on the type of seafloor and the new 'natural' balance established, interpretations of this order 
could vary. An 'Eiffel Tower' effect (i.e. keeping what was planned to be a temporary structure in place because of its societal impact) could show some lasting advantages (e.g. gadoid fisheries on a sandy site) and mean that a wind farm would be part of this anthropogenic 'landscape' shaped by humans for more than a generation ('It's always been this way'). This situation could be an incentive for local populations to keep the structures for other advantages (e.g. richer, more productive ecosystem, recreational diving site, ecotourism, training, etc.).

\section{Looking back (over the past 20 years) \\ The case of the La Rance tidal power plant}

The Rance basin on the coast of Brittany is currently the only tidal power site whose long-term ecological impact can be assessed. It is, therefore, a reference for other projects beginning to be developed all over the world.

During its construction phase, which lasted from 1963 to 1966, the mouth of the Rance river was temporarily blocked by a $750 \mathrm{~m}$ long barrage, made up of a mobile barrage with six sluices, an inactive dyke and the station itself with its 24 turbines and a lock. During those 3 years, the barrage transformed an estuary with a wide tidal range (13.50 $\mathrm{m}$ during equinox tides) into a basin whose level is almost constant, subjected to sharp freshening from river inputs. This led to the almost total disappearance of marine flora and fauna, with the exception of a few invertebrates and fish that can adapt to a wide range of environments.

Since it was commissioned, the tidal power station has influenced the natural tidal system by prolonging the duration of low water and high water stands (periods when the water masses are immobilized) and by reducing the tidal range. This has entailed modifications over the entire estuary in terms of sedimentary dynamics and salinity distribution. The main benthic communities took nearly 5 years to become re-established (algae and lichens more quickly than the macrozoobenthos), and, depending on the species, the state of equilibrium within populations was observed to be reached in between 10 and 20 years.

\section{Other constructions at sea}

Previous impact studies on similar constructions, such as the isle of Ré bridge piers are hard to use because they are so site-specific and cannot be easily compared. Therefore, over the long term, except for tidal power systems which necessarily 'cut off' the ecosystem, most of the effects are diluted in the 'background noise' of natural variability, without taking into account the already noticeable disturbances from climate change, especially in temperature and $\mathrm{pH}$. This means that the usual parameters, such as impact measurement protocols, are not sufficiently tested to draw specific lessons from hindsight.

\section{Danish studies}

The largest environmental impact studies on offshore wind farms were conducted in Denmark from 1999 to 2006 on the HornsRev ( $80 \times 2$ MW units in the North Sea) and Nysted (72 × $2.3 \mathrm{MW}$ units in the Baltic Sea) farms. The scientific investigations covered: 
- subjective (visual) and socio-economic aspects;

- hydrography and coastal morphology;

- benthic flora and fauna on the farms and along the path of cables;

- electro-magnetic fields and potential impacts on fish;

- monitoring of marine mammal populations, such as porpoises and seals;

- monitoring of bird populations;

- creating new habitats.

The BACl (before, after, control impact) method was used. The studies were conducted by a study group made up of representatives of numerous partners: the enterprises involved, State agencies, World Wildlife Fund, Greenpeace and local groups of academics under the authority of five university professors, one of whom was Danish. Funding of 11 million euros was raised from a public tax on electricity consumption.

At the end of the 6-year study, results showed that the impact on the environment was very small overall. The increased diversity and biomass of fauna directly linked to the size of submerged surface areas ('reef' effects). Variations in the characteristics of fish populations were limited with respect to natural variations of species abundance. No effect from electro-magnetism was observed on their movements. Marine mammals (especially porpoises) fled the worksite zone because of the noise, but returned once the farms were in operation. Collisions involving birds were rare, and radar analyses showed that birds diverted their paths away from the structures. Only divers and Brent geese seem to have an aversion to wind turbines.

Finally, in terms of public acceptance, a project is positively viewed by a majority of the population once a distance of $8 \mathrm{~km}$ from shore is reached or exceeded, with a willingness to pay about 40 euros to take this distance to $12 \mathrm{~km}$.

Variations between the two sites suggest that it remains risky to extrapolate observations from one site to another, more so when there are significant differences between the ecosystems. This is why serious studies are required for each project and the development of standard methods to improve the comparability of studies.

\section{Outlook (for the next 20 years)}

Hypothesis 1

Accurate knowledge of impacts (not including tidal energy)

Hypothesis 2

Significant unanticipated and cumulative side-effects 


\section{Hypothesis 3}

In dedicated marine renewable energy locations (possible development)

\section{Bibliography}

Clavier J., Lechapt J.P., Retière C., Rivain V., 1983. Effets à long terme du fonctionnement de l'usine marémotrice sur l'évolution du peuplement des sables fins vaseux de la Rance. Oceanologica Acta, Proceedings of the 17th European Symposium on Marine Biology, Brest, pp. 75-79.

Copenhagen Strategy on Offshore Windpower Deployment, 2005. Available at http://ens. netbohandel.dk

Danish Energy Authority, Danish Forest and Nature Agency, DONG Energy and Vattenfal, 2006. Danish Offshore Wind. Key Environmental Issues. Available at http://ens.netbohandel.dk

Danish Energy Authority. Offshore Wind Power: Danish Experience and Solutions. Available at http://ens.netbohandel.dk

Desroy N., 1998. Les peuplements benthiques de substrats meubles du bassin maritime de la Rance. Evolution de la biodiversité et effets de l'activité prédatrice de Nephtys hombergii (Annélide Polychète) sur le recrutement. Graduate-studies Thesis, University of Rennes I, 240 p.

Retière C., 1989. Energie marémotrice et environnement aquatique. La Houille Blanche 2: 133-147.

\section{Websites}

http://www.hornsrev.dk

http://www.nystedhavmoellepark.dk/frames.asp

http://www.skovognatur.dk/Emne/Natura2000/English

http://www.offshorewindfarms.co.uk

http://www.cefas.co.uk 


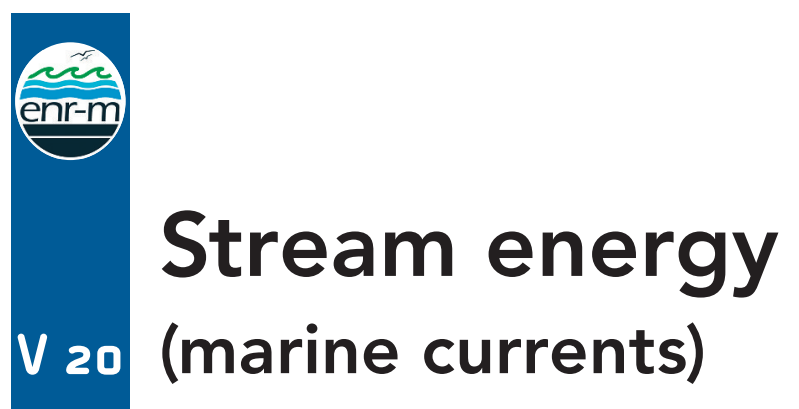

Component: 4. Marine renewable energies

Author: EDF Research \& Development (Cyrille Abonnel)

\section{Definition}

Kinetic energy from tidal currents, exploited by stream turbines (a sort of underwater wind turbine whose rotor is turned by the currents), producing electricity exported to shore via submarine cables.

A wide range of technological concepts is presently being developed 39 , but they can be ranked according to four major criteria (see Figure 20.1 below): (1) type of

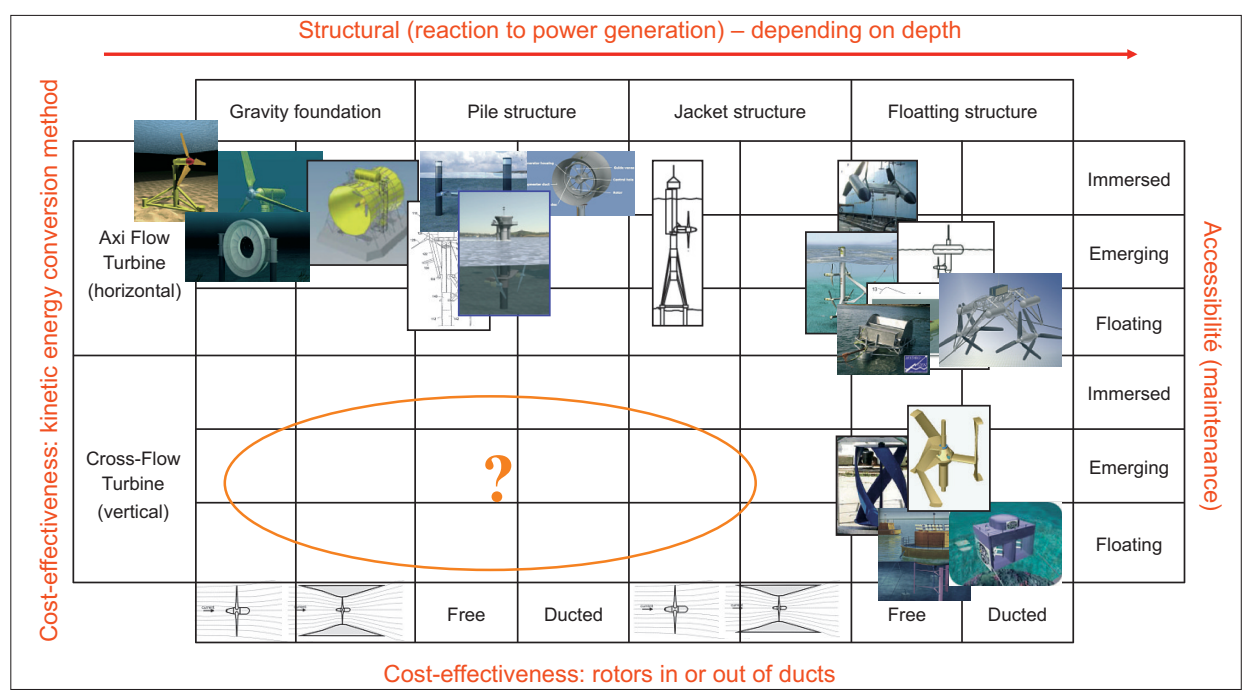

Table 20.1 : types of marine RES technologies depending on water depth, accessibility and cost (Source: EDF, adapted from Fraenkel, MCT, Le Havre 2006).

39. Twenty-five concepts developed in 2006 from the IEA's A Review and Analysis of Ocean Energy Systems - Development and Supporting Policies. 
turbine (axial-flow/cross-flow); (2) convergent-divergent (Venturi) or not; (3) type of foundation structure (gravity-base, pile, lattice or floating); (4) type of accessibility (emerging, immersed or floating). No machine is currently being industrially produced or used, but the first prototypes connected to grids are to be deployed at sea from 2008 onwards.

Favourable areas have water depths of at least $20 \mathrm{~m}$ for a sufficiently powerful machine (blade diameter $>15 \mathrm{~m}$ ) and current speeds greater than $2 \mathrm{~m} /$ second (straits, headlands, narrows, etc.). In Europe, stream energy resources are mainly found in the United Kingdom (75\%, half of which is in Scotland) and France (20\%, Brittany and Lower Normandy), with the remainder in Greece, Italy and Norway. The energy source is located between shallow $(<40 \mathrm{~m})$ and deeper water for the most part. Therefore, immersed designs will probably have the major share of the market in the long term, following an initial phase (between now and 2015?), during which above-water machines in shallow water and below-water machines will coexist.

The United Kingdom is the most active country and clearly the leader in Europe, with its significant R\&D means, an industry that can be mobilized (the same goal as for wind power, i.e. to diversify the offshore industry to prepare for declining fossil resources in the North Sea), and above all, a physical resource suitable for creating a national market. The other players are Ireland, Italy and Norway, and France to a lesser extent, in spite of its significant physical resources.

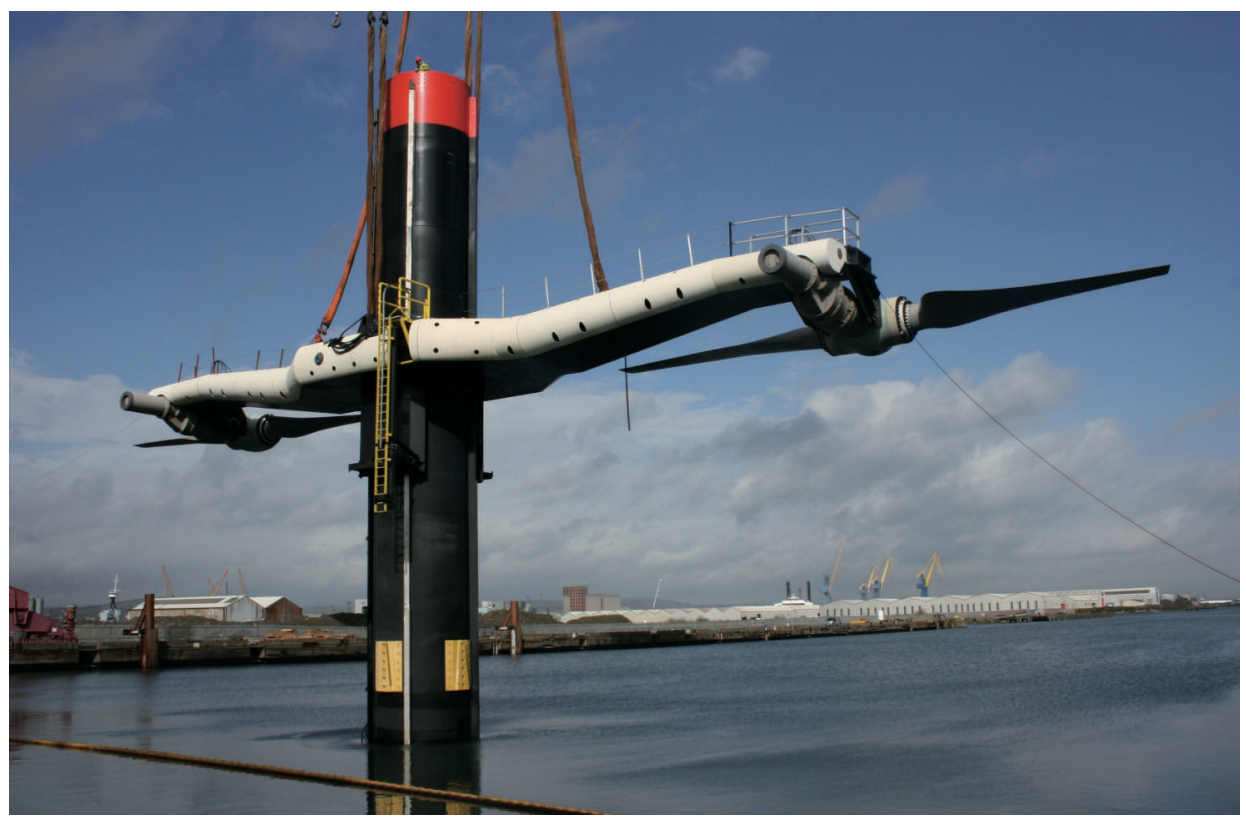

I Photo 30 : Seagen stream turbine installed at Strangford Narrows in Northern Ireland (๑) Marine Current Turbines Ltd, UK). 


\section{Key indicators}

\section{Known EU physical resources and their locations}

- CENEX study from1996: 48 TWh/year (36 United Kingdom, 10 France) making $12,500 \mathrm{MW}$ installed power.

- Black and Veatch 2005 study for United Kingdom resources: 13-23 TWh/year $\pm 30 \%$ around 18 TWh annually, around $4500 \mathrm{MW}$ installed power; hypothesis of a load factor of $45 \%$.

- EDF R\&D study 2006: 5-14 TWh/year (installed power between 2500 and $3500 \mathrm{MW}$, with the hypothesis of a range of load factors from $25 \%$ to $45 \%$ ).

The potential areas are mainly in the United Kingdom (i.e. Scotland, Wales, Cornwall, Channel Islands) and France (Cotentin peninsula, Brittany).

\section{Energy production with known technologies}

- Machines with maximum power from 0.3 MW to about 2 MW by 2009.

- Farms with 10-50 MW power are planned in the United Kingdom.

- Marine area exploitation density: $30 \mathrm{MW} / \mathrm{km}^{2}$.

- Equivalent operating time: 2000-4000 hours annually depending on technologies and the current velocity distribution

\section{Expected industrial costs}

About 2500-3500 euros/kW depending on water depth, type of ground, type of foundation, distance from coast and size of farm, etc.

\section{Technologies}

\section{Axial marine current turbines}

Typical power 0.5-1 MW in 2007 - 15-20 m diameter; 1.5-2 MW in 2010 - 15-20 m diameter; 2-3 MW in 2015-20-25 m diameter (this span could be further increased if technical problems are solved, such as size limited by cavitation effects, etc. Some developers are studying several stream turbine concepts for the same foundation structures). The sector has no industrial structure yet. To date, these technologies have been supported by small and medium enterprises with, at best, large industrial firms amongst their shareholders or investors. However, it is expected that the same players who are specialized in fields related to offshore wind will contribute to this market:

- metal structures for the foundations;

- underwater cables and electrical equipment (Nexans, Prysmiam);

- installations at sea using specialized vessels;

- ocean-meteorology study services;

- soil study services.

\section{Cross-flow marine current turbines}

First industrial builds will begin around 2012-15: state of the art helicoidal design promoted by GCK in the USA; university studies in the United Kingdom; the 'Kobold' technology developed by Ponte di Archimede in Italy (partnerships in Southeast Asia - Indonesia, the Philippines and China - supported by the UN). In France, there is the Harvest project (two patents and another being filed). 


\section{Life cycle}

Turbines are deployed for 20-25 years.

\section{Energy efficiency}

Intermittent but predictable generation: the number of hours in full power equivalent are similar to those for offshore wind (3000-4000 hours/year); sometimes less for sites with lowe energy sources. Large farms can be set up.

\section{There are comparable land-based and marine RES costs} for the same use (i.e. electricity, thermal energy, fuels, water)

The cost price for stream energy electricity: the Carbon Trust Marine Energy Challenge projection 40 is between 30 and 130 euros/MWh.

\section{Looking back (over the past 20 years)}

The first trials were made by IT Power (10 kW in 1994 with Scottish Nuclear) and studies with Aberdeen. The European CENEX project began in 1996 with an assessment of European resources but there was no noticeable activity except for work on wave power.

Growing mobilization in the United Kingdom started in 2001 (reporting to the House of Commons). Significant investments have been made since then, for example, the Carbon Trust, Supergen programmes (EPSRC), deployment funding ( $\mathrm{f50}$ million), etc. The resource was reassessed in 2004-05 (see the Black and Veatch study mentioned above).

In France, between 1999 and 2001, projects were launched by Hydrohélix Energies (now called Marénergie and which received the Brittany Marine Cluster label in 2005), EDF (marine current turbines) and INPG laboratories (the Harvest project, awarded the Tenerrdis cluster label in 2005). Support from the Agency for the Environment and Energy Management (Ademe) for these initiatives. The zoning process for marine renewable energy sources was launched by CIADT in 2004 (still underway). The first conference on marine RES was organized in 2004 in Brest (Sea Tech Week) by the French Research Institute for the Sea (Ifremer) and Ademe. A Franco-British seminar was held in Le Havre in January 2006. A Second International conference on Ocean Energy (ICOC) during Sea Tech Week was held in October 2008 in Brest. A 150 euros/MWh seed-in tariff was officially published in early 2007.

Dynamic development in the United Kingdom: the EMEC (European Marine Energy Centre) was created between 2001 and 2003 in the Orkney Islands with European and Scottish funding, where stream turbine (and wave power) prototypes can be set up and connected to the grid; 'marine energies' call for tenders by the Energy Technologies Institute in 2007.

There was growing interest in Canada (BC Hydro, OREG) and the USA (EPRI dynamics). Internationally, in 2001, an International Energy Agency (IEA) working 
group was created (IEA-OES); a European network called CA-OE was created in 2003 under FP6 (extending the 1998-2003 Wavenet network) and the European Ocean Energy Association (EU-OEA) was created in 2005.

Technological demonstrations were installed:

- for cross-flow concepts:

- Gorlov in 2001 in the USA;

- Kobold (EU Enermar project) in Italy;

- Harvest project launched in 2001 in France;

- for axial-flow designs:

- in 2003, EU Seaflow project (MCT) - 300 kW (not connected) in Cornwall;

- in 2003, Hammerfest Strøm prototype in Norway - 350 kW (connected to grid). $1 \mathrm{MW}$ prototype planned for 2010 with Scottish Power;

- Seagen project $(2 \times 600 \mathrm{~kW})$ from MCT (2004-2008), set up in Northern Ireland and connected to grid;

- in 2005, OpenHydro (Ireland) was created with a prototype (250 kW) set up at the EMEC in late 2006 and connected to the grid in 2008. Farm of 3 to 4 stream turbines planned at Aurigny and a $1 \mathrm{MW}$ prototype in the Bay of Fundy (Nova Scotia Power) in 2009;

- several other concepts are bein developed in Europe, the USA and Canada (Lunar Energy, Voith Siemens, Clean Current, Verdant, Morild, Tocardo, Neptune Power, etc.).

Interest for stream energy has emerged from several factors:

- the will on the part of the United Kingdom to revitalize the offshore industry in view of declining fossil resources in the North Sea;

- the hope of taking advantage of synergies with offshore wind (also under development) and the oil-related sector.

The field has not yet reached the industrial phase: the first industrial farms should be created around 2010, mainly in the United Kingdom and possibly in France. The same difficulties encountered by offshore wind technologies can be anticipated:

- the impossibility of access for maintenance and servicing operations under certain weather conditions (this is even worse for stream energy, since marine currents occur every 6 hours);

- limited capacity to accommodate grids in the coastal zone;

- acceptability of high voltage cables for other users of the sea, especially fishermen, which could lead to conflicts;

- impacts on birdlife (shoal areas are often hunting grounds);

- visual impact, since the large turbines are highly visible from several kilometres away. 


\section{Outlook (for the next 20 years)}

Hypothesis 1

Operations using stream turbines at great depths:

more powerful machines

Hypothesis 2

Underwater stream turbines (lower resource level than in Hypothesis 1, but corresponds to French sites; no conflicts over surface use)

Hypothesis 3

Technology hindered by maintenance issues: turbines kept only for use at the surface (part of the supporting structure emerging) 


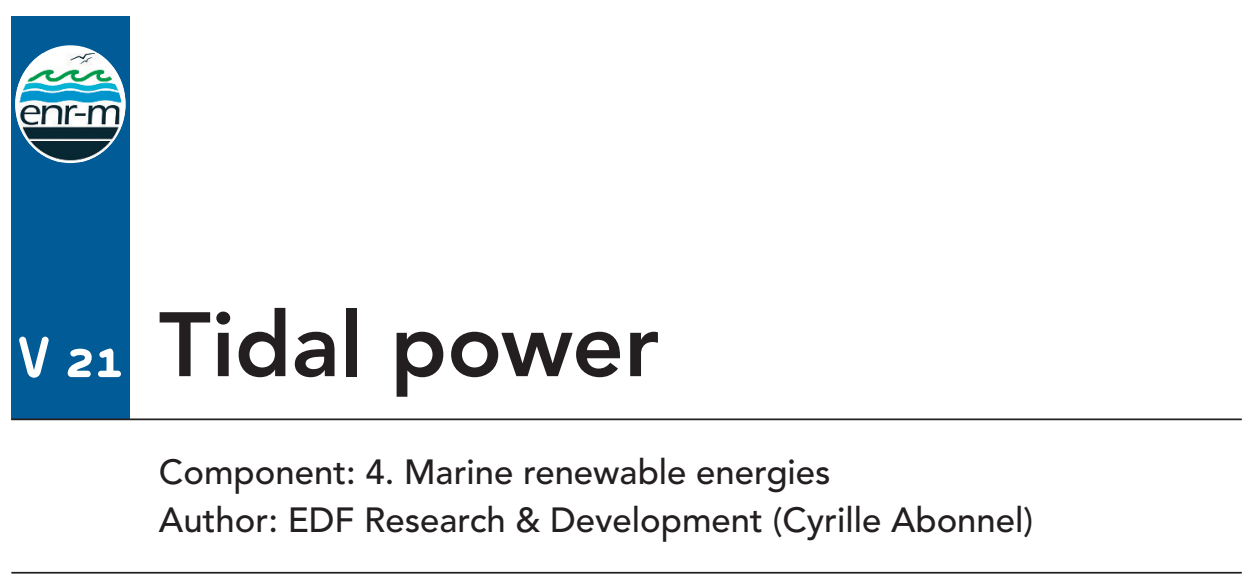

\section{Definition}

\section{The tides and harnessing their energy}

The tide is the variation in sea level due to the combined gravitational action of the moon and sun and these bodies' movements can be accurately calculated over thousands of years. Together with the regular movements, there are additional sea level variations due to weather, which are not entirely random. In practice, tidal forecasts only take what is predictable into account.

According to Bryden, who wrote the chapter on tidal energy in the World Energy Council's 2007 Survey of Energy Resources, there are two ways of exploiting tidal power. These are 'stream energy' or marine current power (see variables fact sheet 20) and 'tidal power' using tidal barrages.

The latter exploits the cyclic rise and fall of sea level by entrainment through a tidal barrage. There are many suitable places in the world where the local geography results in particularly large tidal ranges (the difference between high water and low water levels).

\section{Principle of operation for a tidal barrage}

An estuary or bay with a large natural tidal range is identified and then artificially enclosed with a barrier. The water is allowed to flow from one side of the barrage, through low-head turbines, to generate electricity. There are a variety of suggested modes of operation.

\section{Key indicators}

\section{Global resources and location}

According to EDF, the sites which could accommodate this type of development are scarce. They must indeed fulfil several specific conditions:

- a large tidal range;

- a site which can reasonably be enclosed with the construction of a barrier; 
- an inter-connected grid near the site to cope with the intermittent electricity generation, which is inherent to any tidal power station.

Globally, according to the World Energy Council (2007), an estimated 380 TWh/ year would be the potential generation capacity for developments of this type, with a world-installed power of $160 \mathrm{GW}$ and an availability of 2000 hours/year. Recovery of tidal energy goes back a long time, as shown by numerous tidal mills; these were barrage and retaining basin systems.

A few industrial developments have been implemented over the past 40 years (see below). The largest of them is the La Rance tidal power plant in France. There are a considerable number of sites technically suitable for development, as indicated by Boyle [3] and shown in Table 21.1. Table 21.2 lists the main projects under consideration.

\begin{tabular}{|l|c|c|c|}
\hline \multicolumn{1}{|c|}{ Site } & $\begin{array}{c}\text { Mean tidal range } \\
(\mathrm{m})\end{array}$ & $\begin{array}{c}\text { Barrage length } \\
(\mathrm{km})\end{array}$ & $\begin{array}{c}\text { Estimated annual } \\
\text { energy production } \\
(\mathrm{GWh})\end{array}$ \\
\hline $\begin{array}{l}\text { Severn estuary } \\
\text { (United Kingdom) }\end{array}$ & 7.0 & 17 & 12,900 \\
\hline $\begin{array}{l}\text { Solway Firth } \\
\text { (United Kingdom) }\end{array}$ & 5.5 & 30 & 10,050 \\
\hline $\begin{array}{l}\text { Bay of Fundy } \\
\text { (Canada) }\end{array}$ & 11.7 & 8 & 11,700 \\
\hline $\begin{array}{l}\text { Gulf of Khambhat } \\
\text { (India) }\end{array}$ & 6.1 & 25 & 16,400 \\
\hline
\end{tabular}

I Table 21.1 : possible sites for future tidal power farm (Source: Boyle, 1996).

\begin{tabular}{|l|c|}
\hline \multicolumn{1}{|c|}{ Site } & Installed power (MW) \\
\hline Severn estuary (United Kingdom) & 8600 \\
\hline Bay of Fundy (Canada) & 5300 \\
\hline San José (Argentina) & 5000 \\
\hline Kutch (India) & 900 \\
\hline Mersey (United Kingdom) & 700 \\
\hline Garolim (South Korea) & 480 \\
\hline
\end{tabular}

I Table 21.2 : potential sites being studied for future tidal power generation (Source: EDF).

\section{Energy production with known technologies}

The 240 MW barrage at the Rance tidal power plant uses bulb-type turbine units with both pump and generate around $540 \mathrm{GWh}$ (the equivalent of yearly residential consumption of a town of about 220000 inhabitants). The Sihwa tidal power station (planned to be commissioned in 2009, see below) is a $254 \mathrm{MW}$ plant with an expected annual power generation of $550 \mathrm{GWh}$. Since its bulbturbines only work with a simple filling effect, its energy generation will be close to that of La Rance in spite of its higher installed power. 


\section{Technologies}

Bryden's (World Energy Council, 2007) suggestion to distinguish between singlebasin and double-basin developments was taken.

\section{Single-basin scheme}

These schemes, as the name implies, require a single barrage across the estuary or bay that can hold back a large volume of water (Figure 21.2a). There are three different methods of generating electricity: ebb generation (after high tide), flood generation (after low tide) and the two-way mode. In every case, a combination of sluices and turbines connected to alternators is required.

\section{Ebb generation mode}

During the flood tide, incoming water is allowed to flow freely through sluices in the barrage. At high tide, the sluices are closed. Once the water outside the barrage has fallen sufficiently to establish a substantial head between the basin and the open water, it flows out through low-head turbines to generate electricity. The system can be considered as a series of phases, with periods of generation associated with stages in the tidal cycle (Figure 21.2a).

\section{Flood generation mode}

The sluices are kept closed during the flood tide to allow the water level to build up outside the barrage until the basin is practically empty. Then the turbine gates are opened at high tide making a sufficient difference between the sea level and barrage level to turn the turbines which generate electricity. According to Bryden (World Energy Council, 2007), although it is more interesting in energy terms this approach is generally viewed as less favourable than the ebb method, as keeping a tidal basin at low tide for extended periods could have detrimental effects on the environment and shipping.

\section{Two-way generation}

Two-way generation consists in extending the production time by allowing the turbines to work during ebb and flood generation. This is the case in the La Rance plant where the turbines and alternators are designed to work in both directions figure 21.2b).

\section{Production may be optimized by pumping}

The Rance plant's bulb-turbine generator can also pump water. At the end of the flood tide, the unit works 'backwards' and pumps the water from the seaward side to raise the basin level. The production will be greater, since the water will fall from a greater height and more water will flow through the turbine. In addition, pumping can limit the slack time in the basin. Pumping is an efficient way to both store and 'sublimate' the energy. In fact, pumping raises the water by $1.5 \mathrm{~m}$ at most, while turbining requires a drop of over $4.5 \mathrm{~m}$. The economic efficiency ratio is about 1 to 3 . 


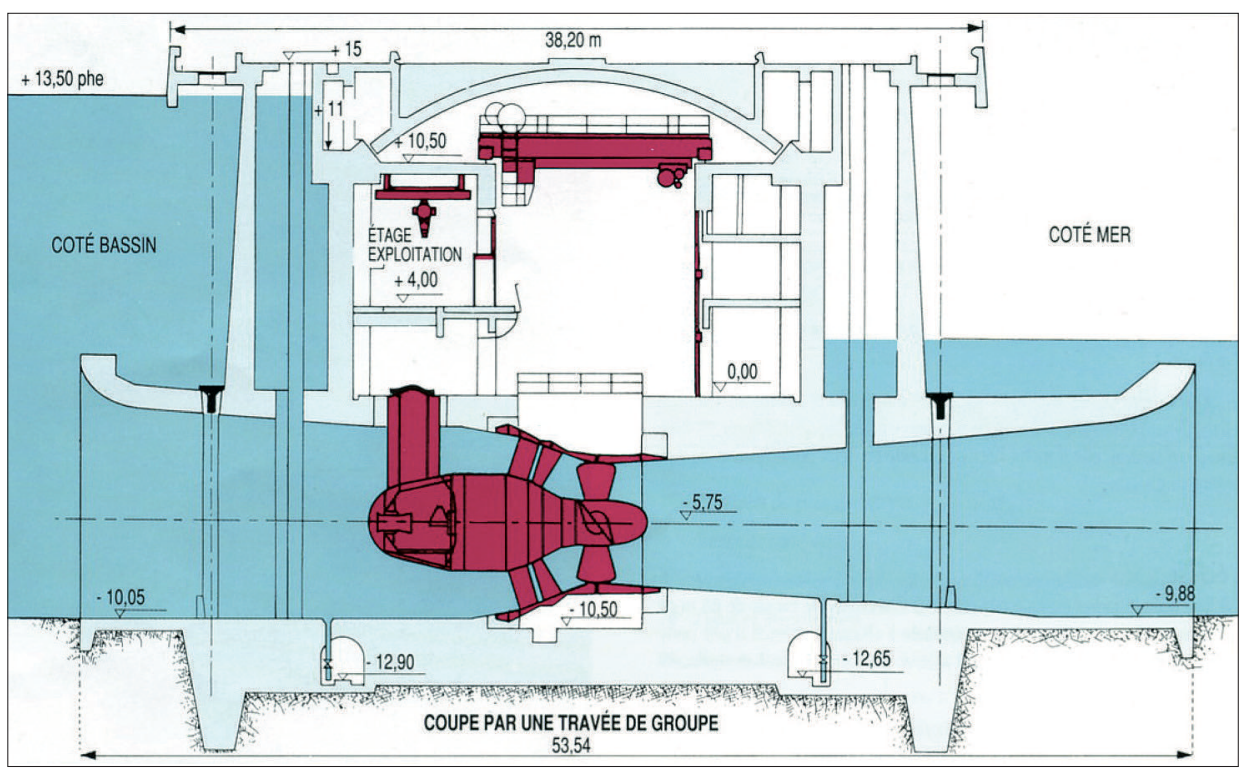

Figure 21.1 : cross-section of a bulb turbine generator unit of the Rance tidal power plant (Source: EDF).

\section{Double-basin scheme}

Single-basin systems suffer from the disadvantage that they only deliver energy during part of the tidal cycle and cannot adjust their delivery period to match the requirements of consumers. Double-basin systems (as shown in Figure 21.2b) have been proposed to allow an element of storage and to give time control over power output levels. The main basin would behave essentially like an ebb generation singlebasin system. A proportion of the electricity generated during the ebb phase would be used to pump water to and from the second basin to ensure that there would always be a generation capability. According to Bryden (World Energy Council, 2007), the overall efficiency of such low-head storage is unlikely to exceed $30 \%$, compared with the proven conventional pumped-storage systems that can exceed $70 \%$.

\section{Tidal lagoon}

Since tidal barrage systems can cause negative effects on both the environment and shipping, another design has been proposed but not produced to date, called the 'tidal lagoon'. Its operating principle is the same as bay barrage schemes, but the principal advantage is that the coastline and shipping routes would be unaffected, provided that the lagoon is correctly positioned. A much longer barrage would, however, be required for the same power output. Initial studies by the Tidal Electric (http://www.tidalelectric.com). Company suggest that with a judiciously chosen site, this could be a competitive solution.

\section{Energy efficiency}

As well as generating electricity, the barrage of the Rance plant also supports a road linking St-Malo to Dinard, which is an important element in development of 


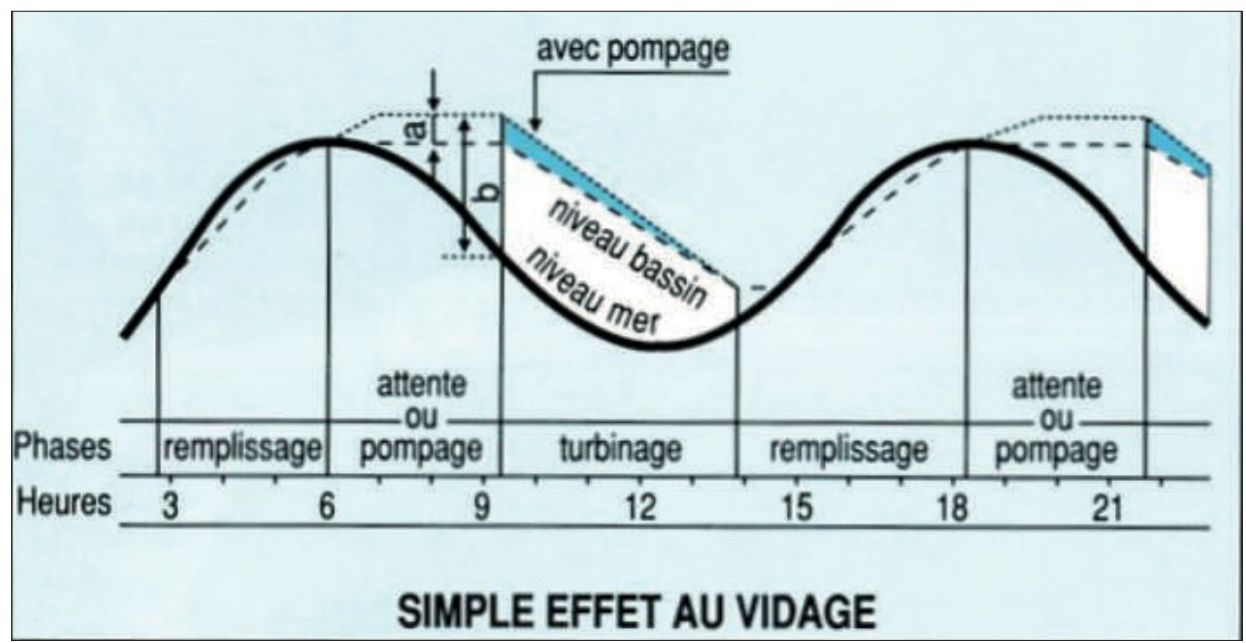

Figure 21.2a : ebb generation mode (Source : EDF).

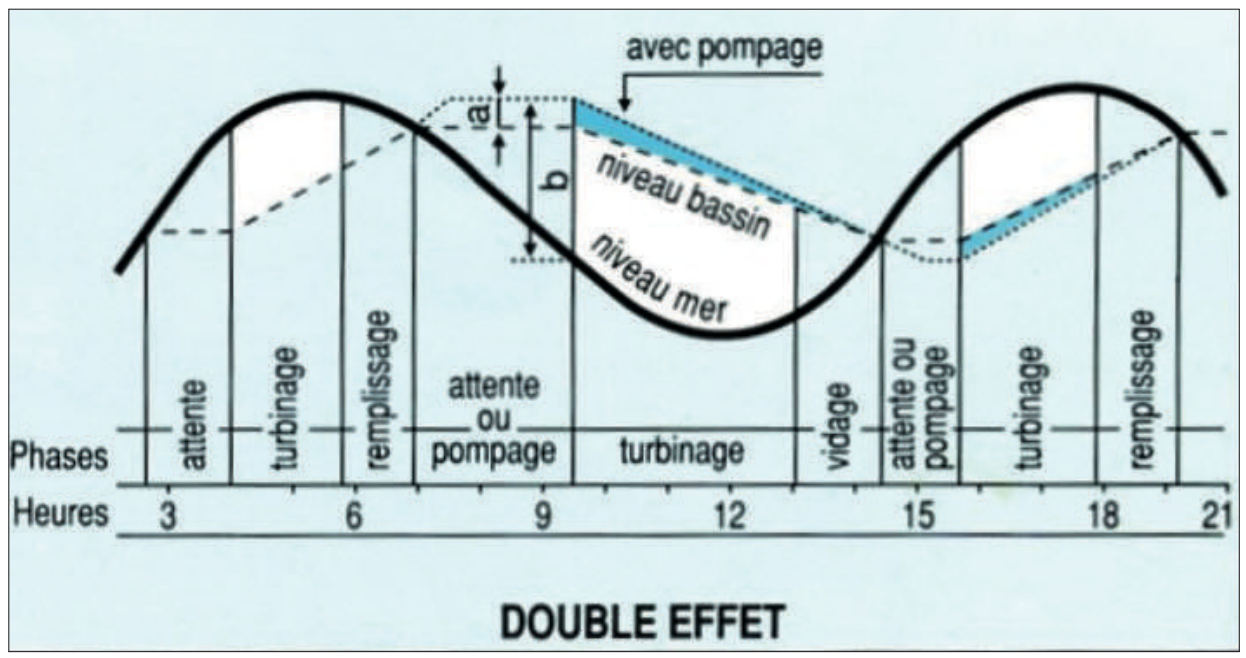

Figure 21.2b : flood generation mode (Source : EDF).

the area. Local residents often use this road, which avoids a nearly $30 \mathrm{~km}$ detour upstream of the Rance river. However, the carbon dioxide savings (shorter trips for all those vehicles) have not been evaluated precisely. The tourist impact is also significant (400,000 visitors yearly), although difficult to measure.

\section{Life expectancy}

The life expectancy of a tidal power infrastructure is particularly long compared with that envisaged for other ocean power sources, that is, several years. For example, in studies underway on the Severn estuary (see below), the proposed life expectancy is 120 years. 


\section{Looking back (over the first 40 years)}

As of today, the Rance tidal power station is the largest industrial development worldwide: with installed power of $240 \mathrm{MW}$ supplied as $10 \mathrm{MW}$ by a bulb-turbine generator.

Some smaller developments have been constructed in Russia (Kilaya Guba, 0.4 MW, 1968), China (Jingxia, 3 MW, 1980) and Canada (Annapolis, 20 MW, 1985). Other projects, although given considerable study, have never been completed, at least until now (the Chausey islands and Severn projects were abandoned in the 1970s and 1980s) owing to what was judged an excessive environmental impact, but also because they were not economically competitive with respect to other sources at the time.

After 35 years of production without any major accidents, the technology of these plants, similar to that of river hydropower. can be considered to be finalized.

In the late 1990s, South Korea decided to set up a power plant on an existing barrage at Sihwa Lake with $254 \mathrm{MW}$ installed power and annual power generation of about $550 \mathrm{GWh}$. Not only will it not produce greenhouse gas emissions, but it

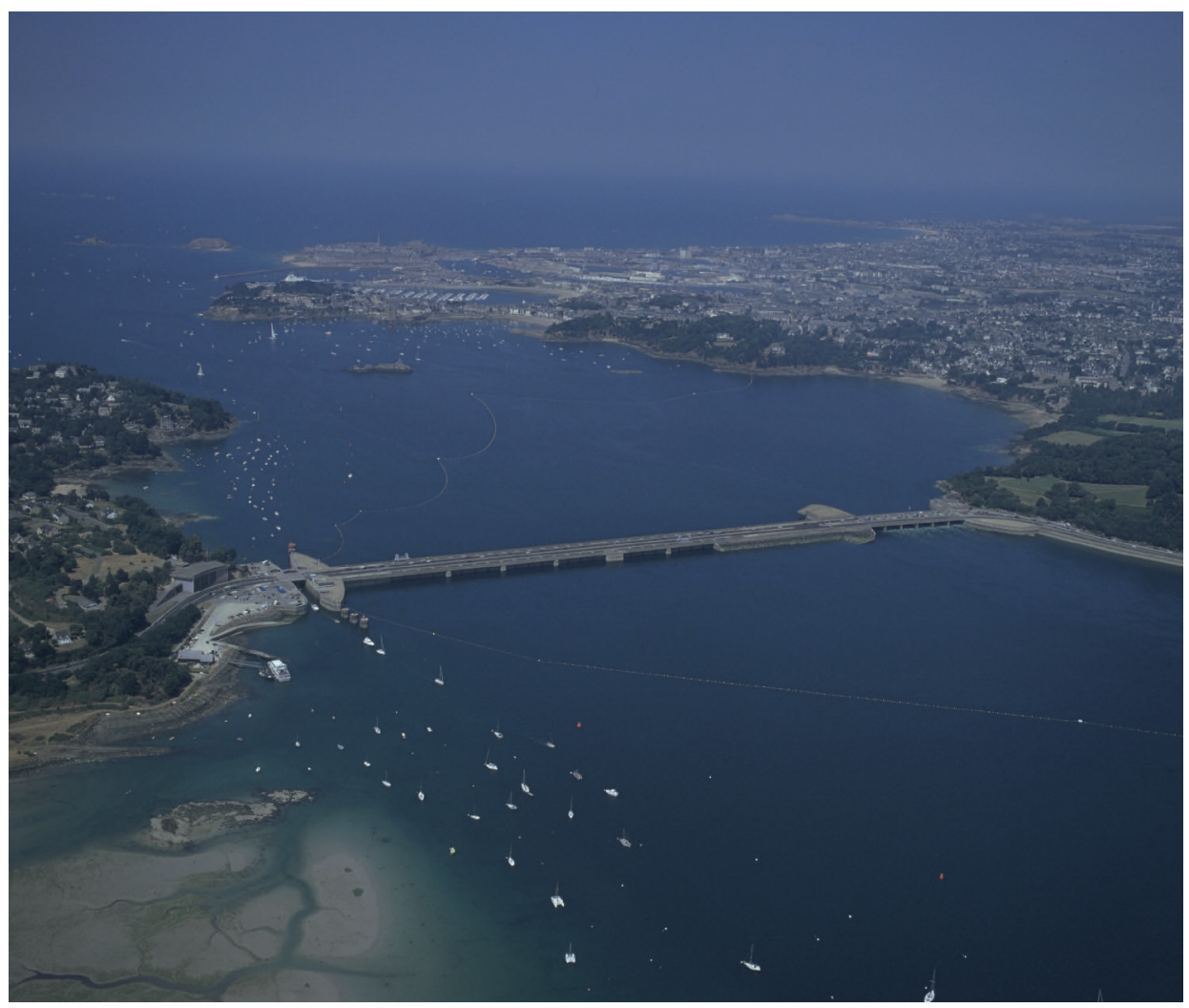

- Photo 31 : aerial view of the Rance tidal power plant near St-Malo in Brittany (France) (@) Médiathèque EDF). 
should help improve the management of sediments in the estuary. The project is currently being built and should be commissioned in 2009. This plant will use Andritz VA Tech Hydro one-way bulb-turbine units with no pumping.

\section{Outlook (for the next 20 years)}

Due to global changes in the field of energy, concepts like Tidal Electric's 'tidal lagoons' have come under new scrutiny over the past few years.

In this way, the United Kingdom is examining how to exploit its tidal power potential: a Sustainable Development Commission study has been available since 2007, and stakeholders like the World Wildlife Fund expressed their preference as early as 2002 (Ball, 2002) for a 'tidal lagoon' rather than the approaches put forward in the 1970-80s. The Department of Industry launched a feasibility study in early 2008 for the Severn estuary, with several types of designs:

- Weston-Cardiff barrage: 16 km of barrage, 8640 MW installed power generating 17 TWh; estimated budget of 19 billion euros (10-15\% uncertainty);

- Shoots barrage: 4 km of barrage, 1050 MW installed power generating 2.75 TWh; estimated budget of 2 billion euros (10-15\% uncertainty);

- Russell lagoon: type three land-bordered tidal lagoons, which could produce 6.48 TWh at a higher cost than that of the Weston-Cardiff barrage scheme.

The environmental and socio-economic stakes for users of these profoundly redeveloped regions are considerable. In addition, the lifetime of the project (120 years) means that several generations must be taken into account. The economic hypotheses taken to reflect the 'public-sector' or 'private sector' funding for such a project (the whole range of possibilities is being studied) are the determining factors for long-term economic viability.

Lessons learnt from the commissioning of the South Korean Sihwa Lake plant as well as studies in the United Kingdom and construction in coming years will help to determine how opportune a tidal power revival is on favourable sites worldwide. This will be either to generate electricity only or for a combined use to obtain other products (e.g. from aquaculture).

Given how open this context is, three hypotheses have been included here.

Hypothesis 1

Naturally favourable sites (shallowness and tidal amplitude), only for generating electricity

Hypothesis 2

Sites developed for tidal power plants and other uses (aquaculture)

Hypothesis 3

No development 


\section{Bibliography}

Ball I., 2002. Turning the Tide - Power from the Sea and Protection for Nature. Cardiff University for the Joint Marine Programme of the World Wildlife Fund and the Wildlife Trusts.

Boyle G. (ed.), 1996. Renewable Energy. Milton Keynes: The Open University.

Sustainable Development Commission [http://www.sd-commission.org.uk/pages/tidal. html]

Tidal Electric Company [www.tidalelectric.com]

World Energy Council, 2007. Survey of Resources. London: World Energy Council.

http://www.worldenergy.org/wec-geis/publications/reports/ser/tide/tide.asp 


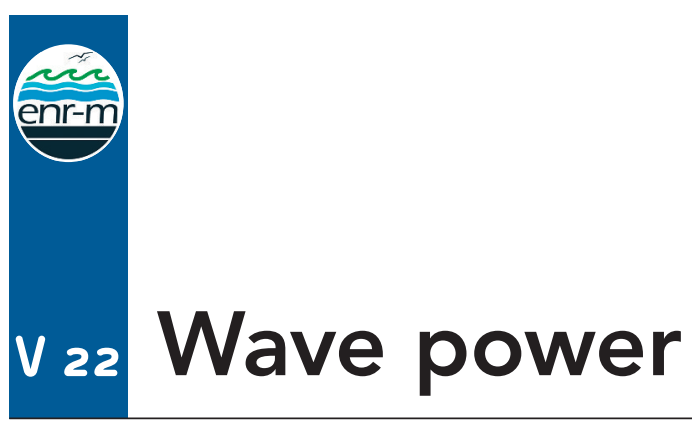

Component: 4. Marine renewable energies

Author: ECN and Ifremer

(Alain Clément, Michel Paillard, Marc Le Boulluec)

\section{Definition}

The energy of the wind blowing over water is dissipated by friction and transferred to the sea, giving rise to waves and swell. The waves interact to form longer and more regular waves, which can stretch in turn over thousands of kilometres while losing little energy through dissipation. The waves and swell transport mechanical energy made up of equal proportions of potential and kinetic energy. This energy can be harnessed either offshore, nearshore or onshore using devices that generate electricity, which is brought to shore via sub-sea cables.

At a given point, the wave power energy resource (the annual mean wave energy) is generally given in kilowatt per metre per unit wave crest length. The maximum worldwide is about $100 \mathrm{~kW} / \mathrm{m}$ and located at Cape Horn. Generally, the higher latitudes have better exposure to waves and the coasts of western Europe are particularly well endowed $(40-70 \mathrm{~kW} / \mathrm{m})$.

This resource is irregular over time and varies with the season. A site in our latitudes with an annual average of $65 \mathrm{~kW} / \mathrm{m}$, actually increases from $16 \mathrm{~kW} / \mathrm{m}$ in June to $160 \mathrm{~kW} / \mathrm{m}$ in January. It is interesting to note that this annual trend coincides with electricity demand in northern European countries.

A 'sea state' is characterized by the significant height of waves $(H \mathrm{~s})$ and the characteristic time period ( $T p$, for instance) estimated to be statistically stable over durations of about 1 hour. The energy level of the sea state is a simple function of $\mathrm{Hs}$ and $\mathrm{Tp}$. It, therefore, varies on time scales of about an hour.

This dual-variable representation is the simplest one used. More fine-tuned characterizations of sea states are being studied, notably by the French Research Institute for the Sea (Ifremer). Finding the maximal energy conditions is a major constraint with respect to the functionality, maintenance and structural resistance of converter devices. 


\section{Key indicators}

The mean power dissipated by the swell along the French Atlantic seafront is estimated to be $45 \mathrm{~kW} / \mathrm{m}$ in the Bay of Biscay. When integrated along the coastline of metropolitan France (from Bayonne to Dunkirk) over an entire year, this represents 417 TWh of raw power; that is, the equivalent of 420 TWh of electricity generated by French nuclear plants in 2001. This resource's potential on the west coast of the USA has been assessed at $440 \mathrm{TWh} /$ year, which is in the same order of magnitude as the country's hydropower production of 350 TWh/year in 1998.

According to a recent report (2006) from the International Energy Agency (IEA) [1], wave power potential should fall in the range of 8000 to 80,000 TWh/year. The World Energy Council indicates an average gross output of 1.3-2 TW, or 11,000-17,000 TWh/year.

Next, the technically exploitable resource must be determined, not just the natural reserves. According to a report from the European network Wavenet (2003), the technically exploitable resource is most likely found in the range 150-750 TWh/year.

\section{Installed electrical power with known technologies}

The IEA listed 53 projects in 2006 including:

- Limpet: 2 x 250 kW;

- Pelamis: 750 kW units;

- Searev: 500 kW;

- Wave Dragon on scale 1: between 4 and $7 \mathrm{MW}$ depending on the resource (24 and $36 \mathrm{~kW} / \mathrm{m}$ );

- AWS 2: $1 \mathrm{MW}$.

Limpet's output is low and the same can also be assumed for Pelamis. It should be noted that for a large number of wave power systems (e.g. point absorbers, oscillating water column (OWC), etc.), the size of the machines, the wattage that can be recovered and thus the installed power are linked to the wave length of the swell and cannot be modified for equal output as in wind or stream energy. In other words, a farm's power output can be adapted by the number of machines and not by their size.

A low capture factor is seen (typically 0.10) for systems with OWCs set up onshore, like Limpet. For second-generation nearshore systems (e.g. Pelamis, Searev, etc.) factors of 0.3 to 0.5 will be reached depending on the sites and technologies, making 2500-4500 hours of full power.

\section{Industrial costs}

Most systems have not reached or gone beyond the prototype stage. The information available today is quite unreliable.

Enersis announced 8.5 million euros in spending for the first Pelamis threemachine farm for $750 \mathrm{~kW}$, that is, 3.8 million euros/MW. Its installation cost is 1000-3000 euros/KW41 and production cost is 60 euros/MWh (projection for 2015). 


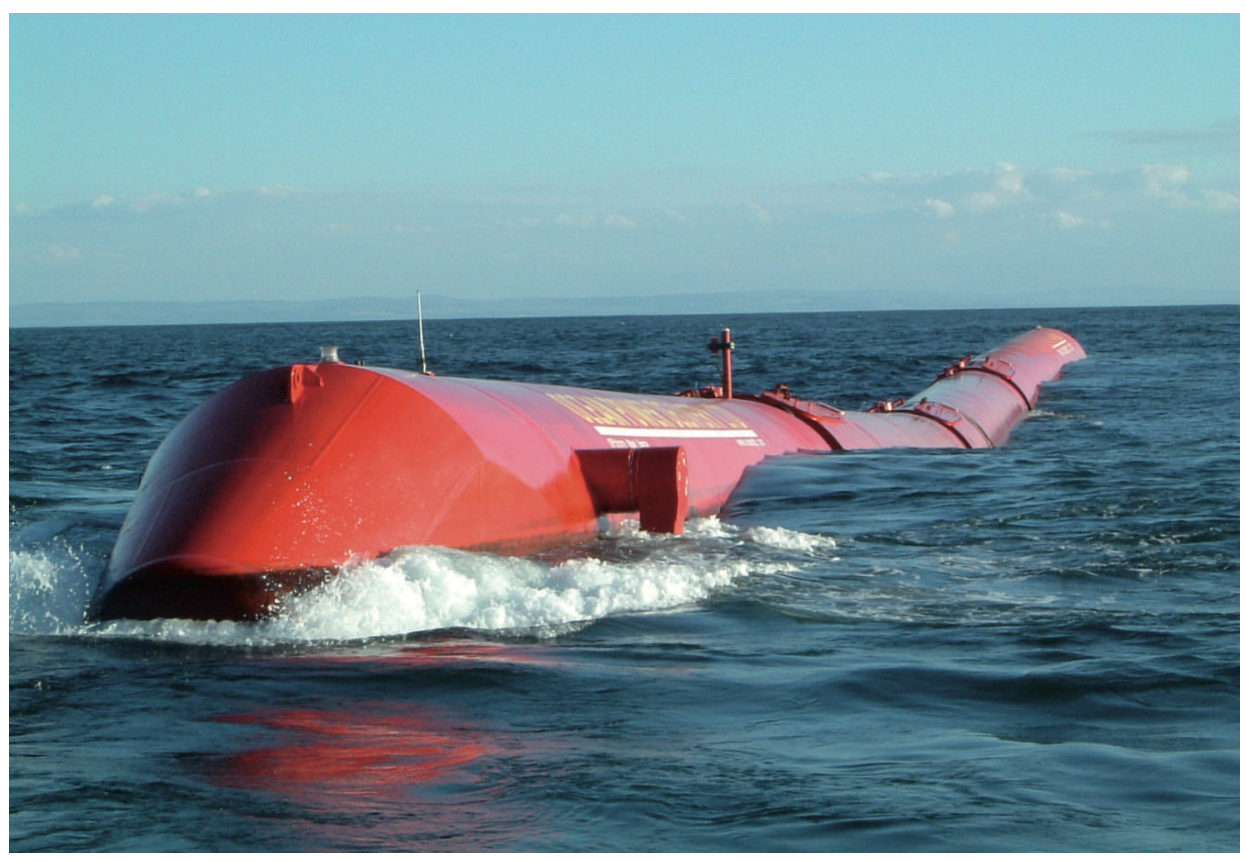

- Photo 32 : Pelamis system to recover wave energy being tested under smooth conditions at the European Marine Energy Centre in Scotland (@ Pelamis Wave Power Ltd, UK).

\section{Technologies}

'Wave power' covers a wide range of principles and concepts. Three guiding principles can be identified.

Making use of the internal movement of a water mass induced by an incident wave: these are OWCs whose alternative 'water piston'-type motion alternatively expels and takes in a volume of air through a turbine - the Wells turbine - which can use this alternating flow without changing its direction of rotation. OWCs can be deployed in coastal locations through civil engineering projects (e.g. Pico, Limpet, etc.) or, in more distant locations from shore, aboard dedicated special floaters (e.g. Mighty Whale, Wavebob etc.).

Using the motion of a (or several) floating body (or bodies) induced by waves: in every case, either an absolute motion with respect to a set point (a float moored to the seabed or on a fixed structure) through a hydraulic or electromagnetic induction system, or a relative motion (movements of two floats attached to each other by a joint like Pelamis (see photo 32), MaCabe Wave Pump, etc.), or in the motion of a mobile body compared with that of a Searev, PSFrog or other buoyant floating body, is needed.

Using the potential energy of a water mass because of the kinetic energy of incident waves: a man-made or natural ramp concentrates incident waves which, when they break, propel the water to a level above sea level, a large part of which 
is retained in a reservoir. A low pressure turbine then exploits this water column by emptying the reservoir into the sea (e.g. Wavedragon).

For resonance systems (e.g. OWC, SEAREV, etc.), active real-time control of the internal mechanics, like latching, means the response to waves and thus the energy recovered can be significantly increased.

Other systems, which are outside these three groups, such as the exploitation of the pressure effects induced by the orbital kinetics of the waves on appropriate bases: they include buoyancy efforts on turning blades which turn the turbines, external pressure fields compress the waterproof flexible masses or create internal flows using the Venturi effect. Some of these devices can also make use of current fields and thus also fall into the stream turbine category.

These four principles have given rise to operational achievements or intermediate scale prototypes. Numerous prototypes tested at sea met with accidents and were damaged or even sank. Others proved seaworthy, but so far, none has achieved qualification of theoretical production capacity through long-term trials.

\section{Lifespan of technologies}

There is a lack of feedback at present, but the machines must be designed to work for about 20 years, for standard cost-effectiveness thresholds to have a chance of being reached. Operation and maintenance costs are crucially significant in calculating the cost-effectiveness of developments. They must be reduced as much as possible right from the intial system design. Cost-effectiveness computations are typically done over 15 years.

\section{Energy efficiency: four uses, regularity or intermittence and technological competitiveness with other types of onshore or marine RES}

Wave energy generation is intermittent and variable, since it is related to the weather (as for wind power). However, its short-term (24-48 hours) predictability is excellent (especially because of satellite measurement and sea state forecasting software) and that should satisfy the electricity grid regulators.

Installed power density: it is estimated that about $20-30 \mathrm{MW} / \mathrm{km}^{2}$ of sea area occupied could be set up, that is, enough to supply on average 7000-8000 French households $/ \mathrm{km}^{2}$, taking a mean load factor into account.

Large farms producing several hundred megawatts could be planned. Portugal recently set aside a maritime area near Nazaré where up to $250 \mathrm{MW}$ of wave power generators are planned for installation. These technologies will be welcome on isolated islands; however, they require local storage or a supplementary source for weak networks (as with wind turbines on isolated sites).

The technology enjoys greater acceptability than offshore wind technology by coastal populations because it has little or no visual impact. Since it takes up part of the ocean area, conflicts could arise with some users of the sea (e.g. fishermen, yachtsmen, etc.) due to the total or partial (depending on the system) ban on working in the area. Negotiations must be carried out within the framework of coastal zone management rules, where they exist. 


\section{Comparable land-based and marine RES costs for the same use} (electricity, thermal, fuels, water)

There are few comparisons, except for onshore and offshore wind power:

- offshore wind: 100-130 euros/MWh (feed-in tariff is 130 euros /MWh);

- onshore wind: 40-80 euros/MWh (Wind power source - see variables fact sheet 24)

The planned cost is between 40 and 70 euros/MWh in $2015^{42}$.

Wave energy could be used to produce freshwater near isolated sites where fossil-fired power is expensive, either directly through the mechanical energy generated or by storing the energy produced.

An interesting point to note is that in a 2007 report, the European Commission estimated that the potential decrease in wave (and tidal current) power costs makes this technology one of the most promising for coming years, following photovoltaic.

Feed-in tariffs

- For the initial development phase of this sector, Portugal published a feed-in tariff of 23 cents/KWh or 230 euros/MWh.

- The United Kingdom offers a feed-in tariff of about 210 euros/kWh (when the price of the certificate delivered with each kilowatt hour produced is included).

- The tariff in France, which was published in March 2007, is 150 euros/MWh.

It should be noted that the cut off for cost-effectiveness as set by the developers is currently around 220 euros/MWh.

\section{Looking back (over the past 20 years)}

Interest arose in this form of renewable energy immediately following the first oil crisis in 1976. The interest of European, and to a lesser extent, Japanese scientists started from that time and quickly led to the development of hypotheses and experiments to test them. A scientific community rapidly grew, as shown by the (non-exhaustive) list below of international conferences held on the theme since 1978:

- Wave and Tidal Energy, British Hydromechanics Research Association (BHRA), Canterbury (United Kingdom);

- First International Symposium on Wave Energy Utilization, Gothenborg (Sweden), 1979;

- 2nd International Symposium on Wave and Tidal Energy, BHRA, Cambridge (United Kingdom), September 1981;

- 2nd International Symposium on Wave Energy Utilization, Trondheim (Norway), June 1982;

- Hydrodynamics of Ocean Wave-Energy Converters, IUTAM Symposium, Lisbon (Portugal) 1985;

- 3nd International Symposium on Wave, Tidal, OTEC and Small Scale Hydro Energy, BHRA, Brighton (United Kingdom), May 1986;

42. Ocean energy - Mårten Grabbe, Urban Lundin and Mats Leijon, Department of Electricity and Lightning Research, Uppsala University, Sweden. 
- $1^{\text {st }}$ European Wave Energy Symposium, sponsored by CEC, Edinburgh (United Kingdom), July 1993;

- $2^{\text {nd }}$ European Wave Power Conference, sponsored by CEC, Lisbon (Portugal), November 1995;

- 3rd European Wave Power Conference, sponsored by CEC, Patras (Greece), September 1998;

- $4^{\text {th }}$ European Wave Power Conference, sponsored by CEC, Aalborg (Denmark), December 2000;

- Numerical Methods in the Development, Design and Control of Wave Power Devices, Ecole centrale de Nantes (France), May 2001;

- 5th European Wave Power Conference, sponsored by CEC, Cork (Ireland), September 2003;

- $6^{\text {th }}$ European Wave and Tidal Energy Conference, Glasgow (United Kingdom). 2005;

- $1^{\text {st }}$ International Conference on Ocean Energy (OTTI), Bremerhaven (Germany), 2006;

- 7th European Wave and Tidal Energy Conference, Oporto (Portugal), 2007.

\section{Public-sector support for R\&D}

The British and Norwegians were the first to engage in this technology, since their resources are the greatest. Next were the Japanese, who had previous experience with the 'Masuda' buoys supplied by wave energy, the Swedes (although 'poor' in natural wind resources) and the Portuguese. In the mid-1980s, public funding was cut back, to the advantage of Norwegian and Japanese research at the time. Since then, the British have resumed their efforts and are today's leaders. Many countries outside Europe have prototype demonstration projects (e.g. China, India and Australia). In the USA, some companies have started projects without public subsidies and there has been a large increase in numbers in recent years, although it is difficult to distinguish between how many are simply publicized and how many are actual projects. In 2000, the Danes launched a nationwide programme to evaluate scientifically this renewable energy form.

From the early 1990s, the European Community included wave power in its R\&D and demonstration programmes and financed studies, such as the Resource Atlas, research of first-generation systems, etc. Two first-generation demonstration pilot power plants (Islay and Pico) received funding and reached the production phase in 2001. Since then other projects have been supported by the European Community.

In France, R\&D was carried out at Cnexo (later Ifremer) and at ENSM (which became the École centrale de Nantes) in the early 1980s. A mini-power plant project using breaking waves designed for Maré Island (Loyalty Islands in New Caledonia) was jointly developed by these organizations (thesis by M. Spiridakis in 1983). The laboratory at the École centrale de Nantes pursued work on this technology as a research theme ( 9 theses, 61 publications) from that time on and 
in 2002 launched a 500 kW wave power generator called Searev. Another project called Palms is being developed in the Brest area (A. Larivain).

\section{International stakeholders (developers)}

Of the 81 projects noted in 2006, the United Kingdom has the predominant position, followed by the USA and then Canada, Norway, Ireland, Australia and Portugal.

\section{R\&D stakeholders}

See the European 'Ocean Energy' coordinated action sites (appendix 2) and the IEA-OES [1].

\section{Outlook (for the next 20 years)}

\section{Hypothesis 1}

Strong development because of institutional support (see the Department of Trade and Industry in the United Kingdom) Several French concepts are accepted well due to consultation

\section{Hypothesis 2}

Little support so French actors are discouraged but foreign technologies are developed in France (see Pelamis)

\section{Hypothesis 3}

Difficulty in finding acceptability in coastal areas limits the supply chain's development

\section{Hypothesis 4}

Difficulties in becoming competitive with other renewable marine sources and development is exclusively in isolated sites (producing electricity and freshwater)

\section{Bibliography}

IEA, 2006. Review and Analysis of Ocean Energy Systems: Development and Supporting Policies. IEA-OES Report. Paris: International Energy Agency.

DGEMP/Dideme, 2004. Electricity Generation Benchmark Costs: Decentralized Generation Plants. Paris: General Directorate for Energy and Raw Materials. 


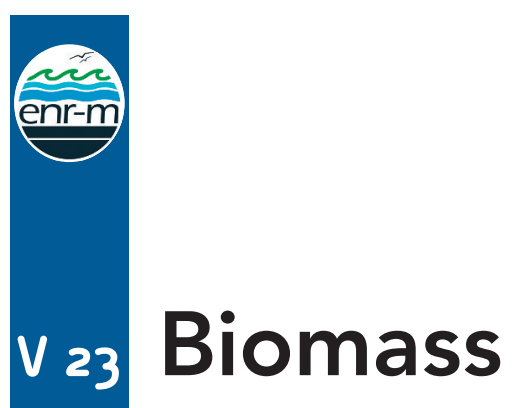

Component: 4. Marine renewable energies

Author: Ifremer (Jean-Paul Cadoret)

\section{Definition}

Seaweeds and algae form an assemblage of photosynthesizing organisms, but have different characteristics. There is no simple grouping which can define them and place in a consistent family, even when study is limited to single-celled microalgae. Hundreds of thousands of species (between 200,000 and 1 million) are found in aquatic environments all over the world; they provide $90 \%$ of aquatic primary production and $50 \%$ of global primary production. They have colonized every type of environment from polar ice to desert areas and hot springs. They have adapted to extreme conditions and can live in saltmarshes, acidic conditions or even under very low light conditions. As they are present at the surface of the oceans, they play a major role in the world's climate, acting like a factory transforming carbon dioxide into organic matter. This diversity has developed because of their outstanding adaptability and provides great potential for research and in industry. It can be expected that a similar wealth of new molecules, including lipids, will be found. Indeed, compared with terrestrial oilseed species, these micro-algae have many features that would be better for fatty acid production.

Micro-algae have the advantage over terrestrial crop plants in terms of:

- growth yields and resulting potential production per hectare that are greater than oilseed plants;

- no conflict with respect to food supplies;

- a much higher metabolic plasticity, making it easier to direct bio-production towards certain fatty acids;

- nitrogen and phosphorus cycles can be mastered by controlling the recycling of nutrients;

- possible combination with an industrial source of carbon dioxide;

- continuous harvesting is possible;

- no pesticides are needed;

- theoretically there are no conflicts in water management if they are farmed at sea;

- many by-products that can be utilized;

- the technology can be used in developing countries. 


\section{Key indicators}

\section{Micro-algae and biomass}

The distinction should be drawn between controlled photobioreactors with artificial or natural lighting, which produce high yields in return for major investment and operation costs, and production in natural settings, such as lagoons in extensive farms, where yields and costs are lower. (Data are given in amounts of algal 'dry matter' produced per square metre of surface area per day.)

When farmed outdoors, micro-algae can produce from $10 \mathrm{~g} / \mathrm{m}^{2} /$ day to $50 \mathrm{~g} / \mathrm{m}^{2} /$ day. The $10 \mathrm{~g} / \mathrm{m}^{2} /$ day yield corresponds to 36.5 tonne/ha/year, which should be put into perspective with data for terrestrial plant yields in Europe. Yields per hectare for oilseed rape are 3.34 tonne/ha and 2.24 tonne/ha for sunflower; algal biomass production is thus 10 -fold greater (http://www.industrie.gouv.fr/energie/ renou/biomasse/ecobilan-synthese.pdf).

\section{Micro-algae and lipids}

The main factors influencing lipid production are related to forms of stress: low temperature, intense light, nitrogen limitation, severe phosphate deficiency, silica limitation in diatoms and alkalinity. Not all of these parameters have the same influence, so it is essential to use factor-based analyses to estimate the interactions between them.

Relatively high figures have been reported for some micro-algae (Figure 23.1). Chlorella protothecoides could supply up to $52 \%$ of oil per cell in dry weight, or even $55 \%$ according to some authors. These figures should be put into perspective though, since they were cultured under heterophilic conditions. Other examples include Dunalliela tertiolecta producing up to $71.4 \%$ of total lipids, some strains of Nannochloropsis sp. 54\% and Nitzschia dissipata $66 \%$.

As an indication, a unit producing $13 \mathrm{~g} / \mathrm{m}^{2} /$ day (47.4 tonne/ha/year) using an algae that produces $50 \%$ oil, would supply the equivalent of 23.7 tonnes oil/ha/ year. The figure is far from the 100 tonnes of oil given on the 'Oilgae' website, but

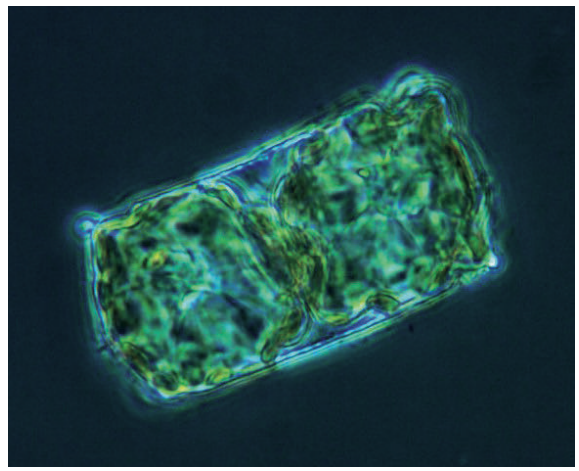

1 Photo 33 : the diatom Odontella aurita is the first micro-algae to be approved for human food consumption; it is rich in oils, especially EPA (๑) Ifremer, J.P. Cadoret). there is significant scope for improvement, both in terms of biomass productivity and selection of super-producing strains or even in metabolic orientation during the different cultivation phases. The amount of 23.7 tonnes of oil should be compared with that from palm oil production, considered to be one of the highest yielding terrestrial plants (6 tonnes/ha/year) or even 8 tonnes/ha/ year (Vaitiligom, Cirad, pers. com.).

\section{Indicated costs}

The price per barrel (159 litres) of algal biodiesel would range from $\$$ US61 to \$US127. The Biofuel System Esp Company 


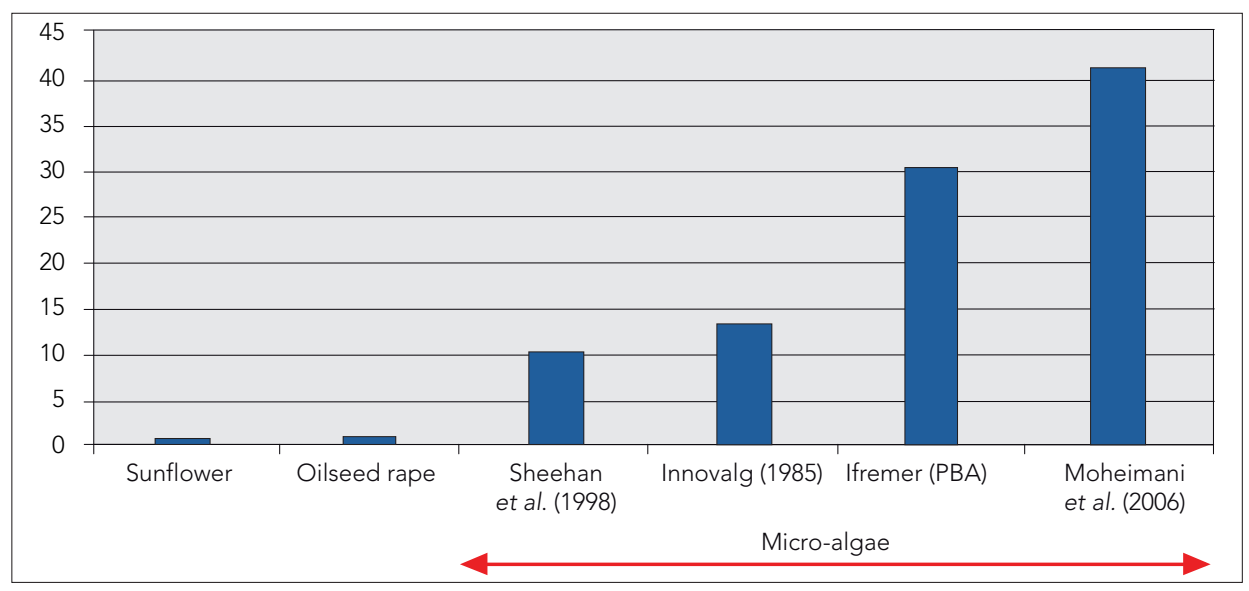

I Figure 23.1 : yields ( $\mathrm{g} / \mathrm{m}^{2} /$ day) of two land crops and algae from different experiments (Source : http://www.oilgae.com/algae/oil/yield/yield.html).

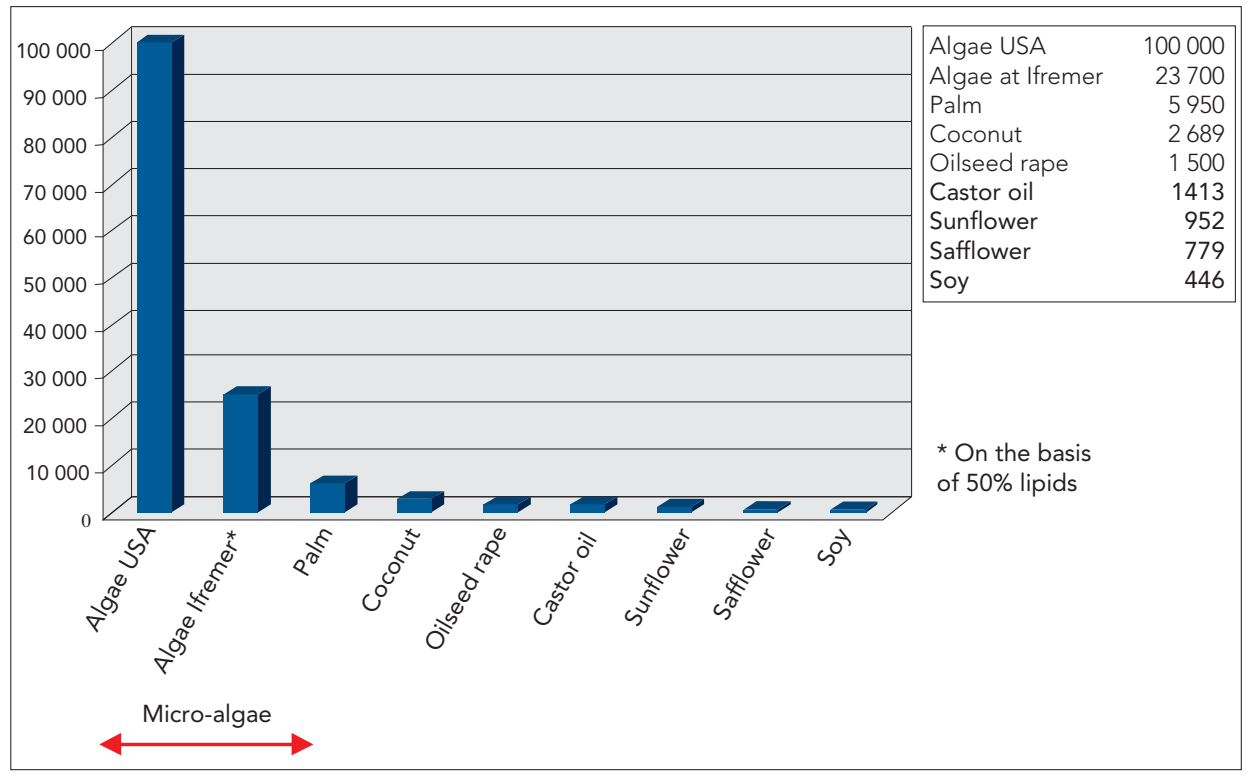

- Figure 23.2 : lipid productivity of various crop plants (yield in litres of oil per hectare) (Source : http://www.oilgae.com/algae/oil/yield/yield.html).

suggests that the price will range from 0.25 to 0.35 euros/litre, which would put the cost of a barrel of biodiesel at US $\$ 72$.

\section{Carbon}

This is controversial and requires further documentation and critical assessment. Announcements made by some companies defy the laws of physics.

A prospective analysis done for the ANR Shamash contract concluded that carbon fixation of between 130 and 280 tonnes of carbon dioxide/ha/year is possible (O. Bernard, pers. com.). 


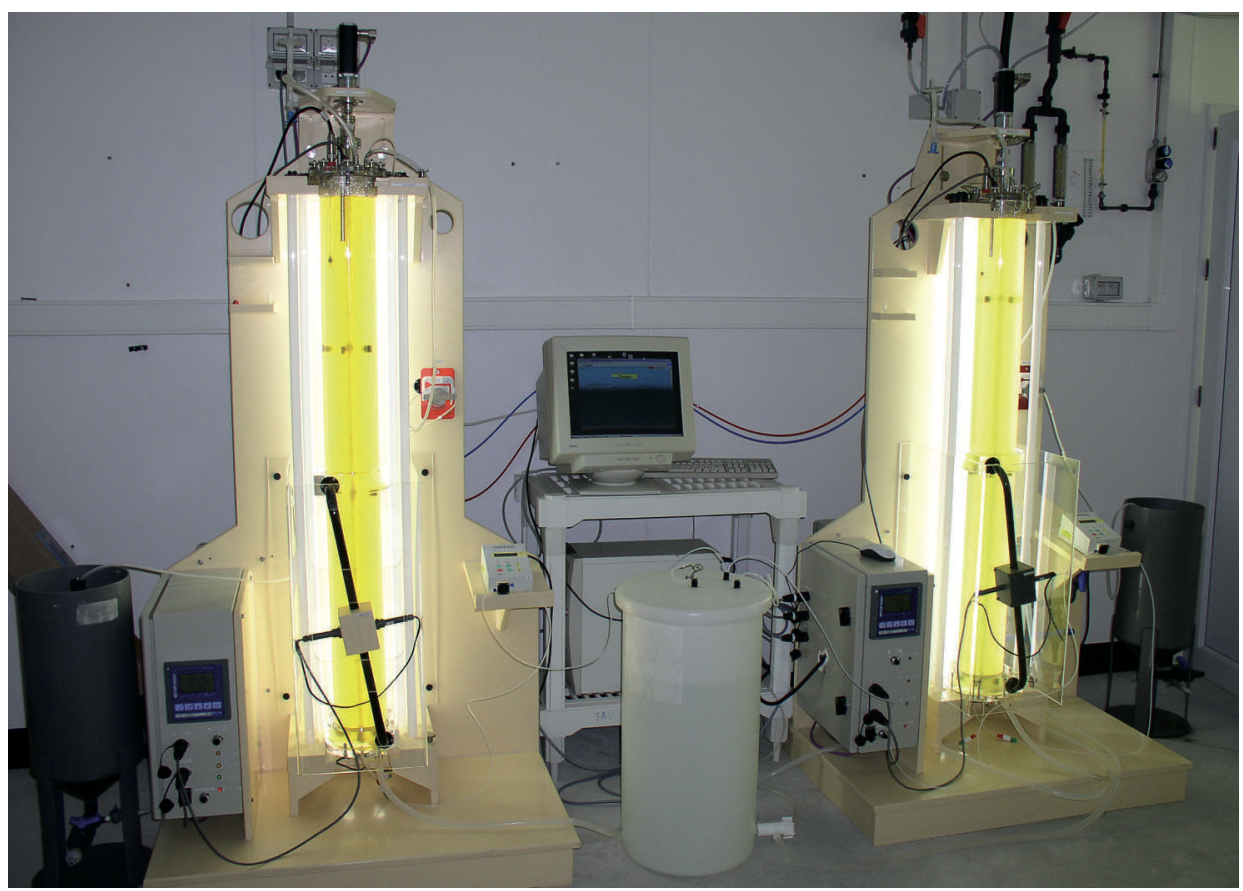

I Photo 34 : photobioreactors holding 17 litres used to feed the bivalve mollusc larvae and juveniles (@ Ifremer, J.P. Cadoret).

\section{Looking back (over the past 20 years)}

The report from the US National Renewable Energy Laboratory called A Look Back at the US Department of Energy's Aquatic Species Program: Biodiesel from Algae (ASP) is a reference in this field. It compiles the results from an exploratory programme which ran from 1978 to 1996.

\section{Research laboratories}

Available data on biofuels and micro-algae remain patchy. University laboratories present results obtained in laboratories, or at best, ponds. The results are then compared with those available for terrestrial plants grown in fields, where farmers already have the equipment and performances required.

The main stakeholders in this field of research are:

- USA: Universities of Hawaii, California, New Mexico and New Hampshire;

- Australia: South Australian Research and Development Institute, Universities of Flinderset and South Australia;

- Spain: Universities of Alicante and the Canary Islands;

- Holland: Universities of Amsterdam and Wageningen;

- Germany: Universities of Heidelberg, Kiel, Bremen and Tübingen;

- Malta: Molecular Biology Laboratory, Valetta, Malta; 
- United Kingdom: under the Supergen initiative, a range of actors like the Royal Agricultural College and the University of West of England (Department of Environmental Sciences) are working in this field.

\section{II Outlook (for the next 20 years)}

Using micro-algae to produce biofuel is only cost-effective if production makes maximal use of solar energy and requires minimal manpower. No contradictory analysis has been conducted with respect to the surface area necessary to farm micro-algae. What surface areas are available in France and Europe? How can the proximity of water treatment plants, power plants that emit carbon dioxide, and lagoons or ponds for seawater cultures be reconciled? If successful, how can the impact of growing algae on thousands of hectares of national wetlands be measured? Micro-algae are very sensitive to strong sunlight. Experiments carried out in New Mexico, USA also demonstrated the impact of cold nights and daytime evaporation in the desert. Winter cultures grown outdoors have low yields, for example, as low as $2 \mathrm{~g} / \mathrm{m}^{2} /$ day. These points temper statements made about countries with high levels of sunshine, which could become energy-independent. The micro-algae selected will have to show both high and stable lipid contents.

One solution would be to plan successive crops of species whose optimal cultivation features are adapted to different seasonal conditions, as well as presenting stable conditions for photosynthesis. This seems technically possible, but requires further research. Nutrient inputs have been omitted from most studies. They must be quantified, together with the addition and fate of silica in diatom metabolism. This factor will decisively impact on production costs. How to recover micro-algae remains a crucial point that requires study. It will depend on technical progress made in ultra-filtration and other solutions from process engineering. This issue will also have a strong impact on costs.

The alternative to centrifugation is to choose algae that flocculate or sediment easily. However, this type of alga will require processing to keep it in suspension and that will use energy. Future studies may enable a clear choice between freshwater and marine algae. Each has its advantages and drawbacks. When grown in freshwater, conflicts of use can arise. On the other hand, combining them with carbon dioxide sources will not always be possible on the seafront, or must at least be carefully planned. There is a high risk of contamination in open environments, whether from better adapted local micro-algae or from zooplankton predators. Finally, economic studies like those carried out on biofuels from terrestrial crops are still lacking. An American study gave figures that are possible, but highly optimistic. Although already presented as valid by some 'popular science' reports, they must still be checked or more firmly established.

Owing to the large amount of data already published on the subject, the role that micro-algae can play in the field of renewable energy and carbon dioxide storage seems obvious. Even if the optimistic figures of 100 to 150 tonnes of oil per hectare per year are divided by five or ten, the advantages of micro-algae are genuine. The issues for further exploration should now be listed and studied in 
depth. Among them, a full-scale study linked to analysis by economists should be prioritized. In this field, Ifremer has undeniable advantages with its know-how and long-term expertise in culturing micro-algae, access to biological resources not widely available in Europe and finally, its facilities, which enable it to produce literally any volume of cultures. If this pathway is not definitely closed when current industrial property and existing patents are analysed, oil-producing micro-algae will be a highly relevant choice to supplement the biofuel industry as a whole.

Hypothesis 1

Extensive production on developed maritime property

Hypothesis 2

Development abroad (imported to France)

Hypothesis 3

Application limited to high-tech products

Hypothesis 4

High-tech, intensive production on land,

genetically modified organisms, multi-applications 


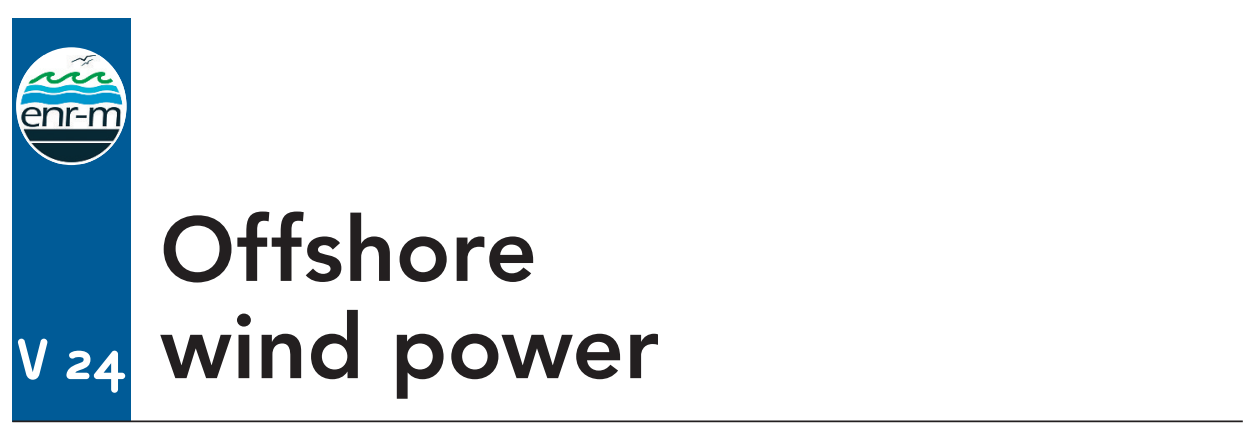

Component: 4. Marine renewable energies

Author: Saipem (Jacques Ruer)

\section{Definition}

Electricity is produced by turbines which harness energy from the wind blowing over stretches of sea and the electricity is carried to shore by sub-sea cables.

In current technology, wind turbines are moored on the seafloor, so the most favourable areas are in shallow water, typically less than $50 \mathrm{~m}$ and preferably less than $20 \mathrm{~m}$ deep. Broad areas of wind farms can be seen in the North Sea and Baltic Sea at distances from the coast exceeding $100 \mathrm{~km}$ at depths of less than $40 \mathrm{~m}$. These areas are mainly around the United Kingdom, the Netherlands, Denmark and especially, Germany. A lot of effort has been made to develop offshore wind power in Germany. The United Kingdom is also developing this industry, with the aim of diversifying sources of offshore energy to counter the decline of fossil resources in the North Sea.

German wind turbine manufacturers see offshore developments as a way of compensating for the decline in the market, since sites on land are beginning to reach saturation. In the future, floating wind turbines moored to the seafloor could be used, since they present fewer constraints in terms of depth limitations. They will provide access to a much larger resource, especially in Italy, Norway and France.

\section{I Key indicators}

Resources in Europe and their location

Garrad Hassan study (1995): 3028 TWh/year.

According to the International Energy Agency (IEA) 2000 study: 313 TWh/year (see below).

Potential zones are mainly located in the North Sea and Baltic Sea, as well as coastal fringes with shallow waters. 


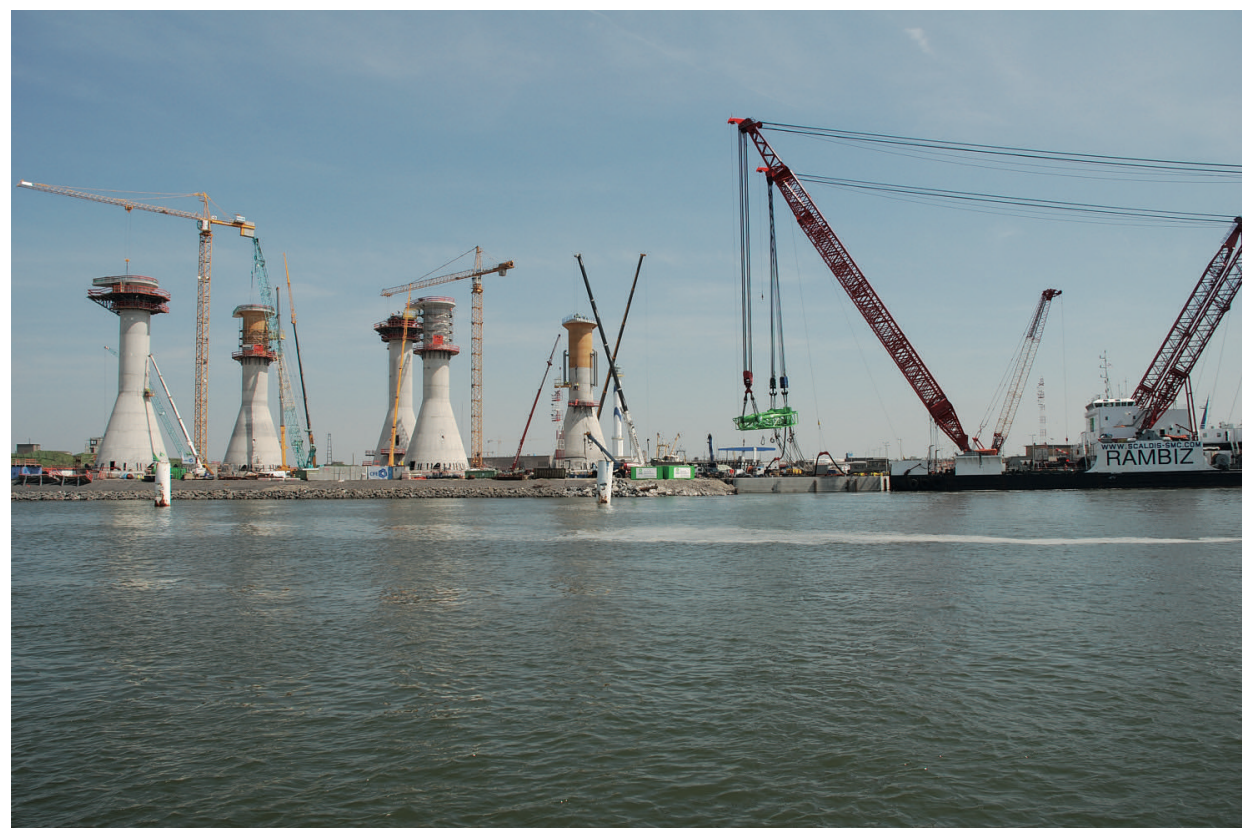

I Photo 35 : construction site for the foundations of the 300 MW Thornton Bank offshore wind farm in Belgium (@ Deme, BE).

\section{Energy yields with known technologies}

2-6 MW unit turbines today.

100-1200 MW farms planned in Germany.

Marine area exploitation density: $6 \mathrm{MW} / \mathrm{km}^{2}$.

Equivalent operating time greater than 3000-4000 hour/year.

\section{Industrial costs}

Around 1700-3000 euros/kW depending on water depth, type of ground, distance from the coast and size of farm.

\section{Technologies}

Moored wind turbines

Typical power: 2-3 MW in 2007; 5 MW - 120 m diameter in 2010; 10 MW - 160 m diameter in 2015.

This will probably not increase at a later date, since the residual market will no longer justify the manufacture of larger machines. 
Large wind turbines are developed and sold by northern European companies, particularly from Germany (e.g. Enercon, Siemens, GE, Repower, Nordex) and Denmark (e.g. Vestas). Other actors are working in associated fields, such as:

- metal structures for the foundations;

- underwater cables and electrical equipment (e.g. Nexans, Prysmiam);

- installations at sea using specialized vessels (e.g. A2sea, Mayflower, Mammoet van Oord, Eide);

- ocean-meteorology study services;

- ground investigation services (Fugro).

Floating wind turbines

First industrial-scale developments will be available around 2012-15, starting with $2 \mathrm{MW}$ power, followed by more powerful turbines (4-5 MW) after 2015.

The Hydro firm in Norway has developed a $120 \mathrm{~m}$ tall concrete spar-buoy for a $5 \mathrm{MW}$ turbine. In France, the Saipem firm is proposing an innovative concept while various studies are underway in the USA and Italy. These concepts are still too new to measure their potential impact here.

\section{Technology life cycle}

Turbines will be deployed for 20 years.

Steel structures: 100-200 kg of steel/kW (wind turbine and foundation).

\section{Energy efficiency}

Intermittent production. Large farms can be developed.

The number of equivalent full power hours is higher offshore than onshore (3000-4000 hour/year compared with 2200-3000 hour/year).

\section{Comparable land-based and marine RES costs}

Cost price for offshore wind electricity: 100-130 euros/MWh. Land-based wind electricity: 40-80 euros/MWh.

\section{Looking back (over the past 20 years) Background to recent developments}

The first offshore wind turbines were set up in 1993 in Denmark and the Netherlands (European Commission, 2001). They aroused strong political interest in northern Europe as a potential, large-scale source of renewable energy. The enthusiasm for offshore wind energy was the consequence of several factors:

- the will on the part of the United Kingdom to revitalize the offshore industry because of the declining fossil resources in the North Sea (BWEA, 2006);

- the political will on the part of Germany, Denmark, Sweden and the Netherlands to find a major source of renewable energy in order to move away from nuclear power and find new production areas once the areas of land-based wind farms became saturated; 
- the technical success of wind farms on land;

- the operators ambition to create and conquer an additional market to that of land-based wind power; they adapted the technology already proven on land for use at sea.

The total power is currently about $1000 \mathrm{MW}$, mainly produced in the United Kingdom, Holland and Sweden.

In France, a reference document was published by the Secretariat General for the Sea (2002). A call for tenders led to the first $105 \mathrm{MW}$ project off Veulettes sur Mer, which should become operational in 2009.

The official German position foresees huge development of offshore wind facilities, with a capacity of nearly $10 \mathrm{GW}$ in the North Sea and Baltic Sea (Bundesamt fuer Seeschiffahrt und Hydrographie). However, the financial prerequisites have not been fulfilled yet for the industry to take off (Bundesvesband Wind Energy).

Projects are being developed in the USA, Canada and China.

\section{Summary of the technology's development}

Offshore wind turbines were designed on the same basis as land turbines, which have shown their efficiency and effectiveness (i.e. three-bladed turbine whose rotor faces into the wind). Development efforts have mainly focused on designing the supporting structures. Depending on water depth and local wave conditions, moorings can range from gravity-base foundations, tripods or a single pile, which is the most cost-effective solution for sandy bottoms and depths of less than about $20 \mathrm{~m}$.

These structures seem to reach their limits at depths of approximately $40 \mathrm{~m}$. A European demonstration project called Beatrice uses jacket-type structures similar to those in the offshore oil industry at depths of $50 \mathrm{~m}$.

Construction at sea requires specialized installation vessels, which can hoist the turbines, as well as vessels to lay and bury the cables.

The difficulty in creating offshore wind farms was largely underestimated by project developers who mainly worked in the onshore wind industry. The experience highlighted some difficulties:

- high costs that constructors tried to lower by increasing the unit size of the machines; the costs proved to be higher than those expected at the outset;

- access for maintenance operations and servicing was impossible under certain weather conditions;

- it was difficult to carry out maintenance operations at sea;

- there was limited capacity to accommodate grids in the coastal zone;

- conflicts over use with other users of the sea, especially fishermen, due to the area used and high voltage cables;

- impacts on birdlife (shoal areas are often hunting grounds);

- the visual impact, since large turbines are highly visible from several kilometres away. 


\section{Outlook (for the next 20 years)}

Offshore wind projects call for massive capital investment and entail risks, which reduces the number of potential players.

In 1995, Garrad Hassan and Germanischer Lloyd (Matthies et al., 1995) conducted a European study on energy potential with the following hypotheses and theoretical resource levels:

- water depth $<40 \mathrm{~m}$;

- distance <10 km: 1852 TWh/year;

- distance $<20 \mathrm{~km}: 2615$ TWh/year;

- distance <30 km: 3028 TWh/year.

In 2000, a new study published by the IEA (2000) considered only water depths less than $20 \mathrm{~m}$, distances less than $20 \mathrm{~km}$, a surface-area occupation rate of $10 \%$ between 0 and $10 \mathrm{~km}$ and $20 \%$ between 10 and $20 \mathrm{~km}$. In that case, European potential falls to $313 \mathrm{TWh} /$ year, which corresponds to setting up 70,000-80,000 MW.

\section{Floating wind turbines}

Now going beyond wind turbine technology, which was adapted from onshore structures and involved turbines anchored to the seabed, floating wind turbines are beginning to be seen (Figures 24.1). They can be justified when water depths

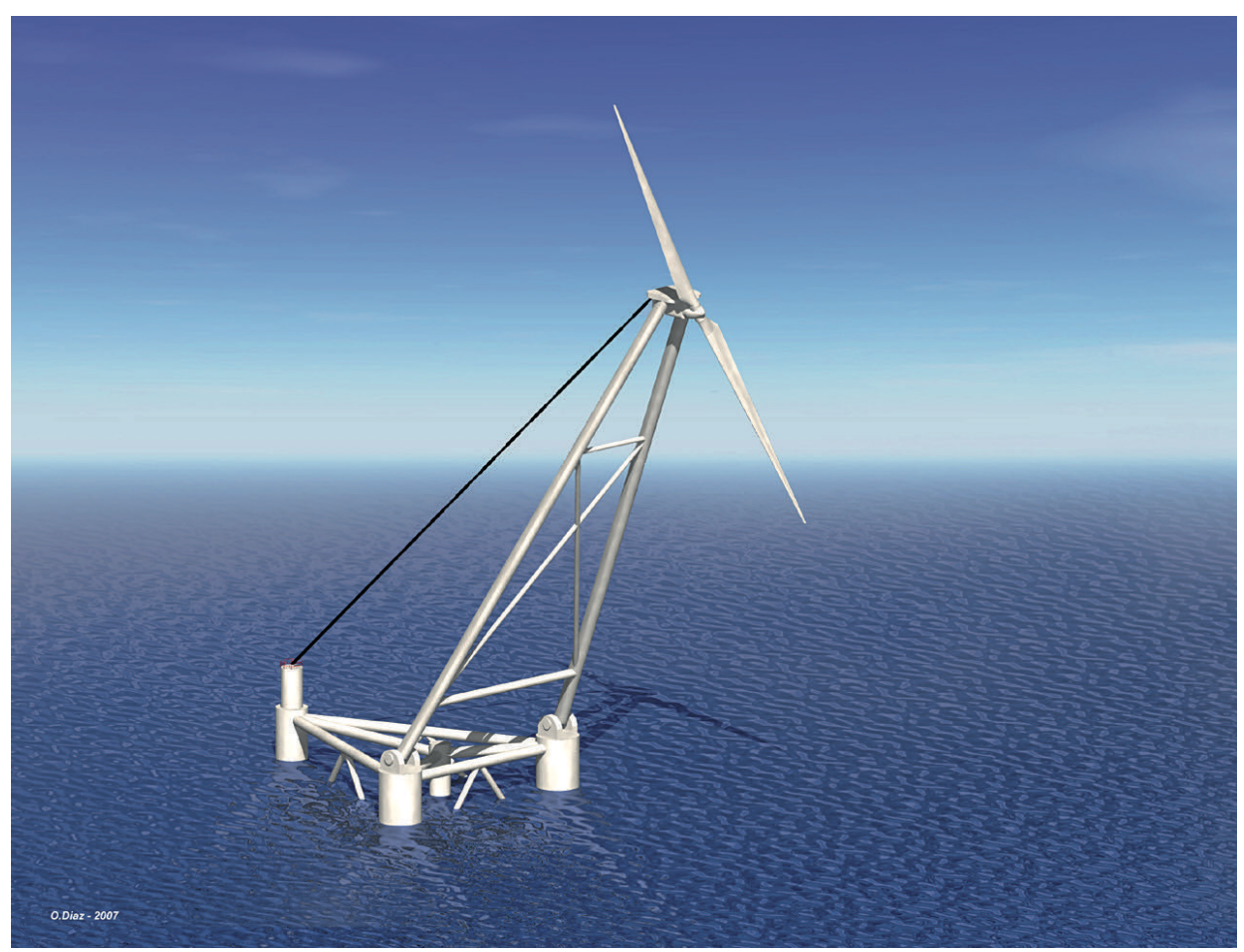

I Figure 24.1 : Saipem design: two-bladed downwind rotor (Source : Saipem). 
for moored wind turbines would require such a large amount of steel that floating structures become much cheaper. Covered housings have to be perfected for these wind turbines and the appropriate tethered moorings, together with dynamic electrical connections (publication Sea Tech Week).

Bringing this type of turbine on to the market would make it possible to set up farms in areas further from the coast. The potential resource would increase sea tech week 2008, as can be seen in the example of the British potential map (Figure 24.2). To the west of the Scottish coast, the average wind speed is approximately $10 \mathrm{~m} / \mathrm{second}$, which is much greater than on the nearshore, where current wind turbines are placed.

It can be conjectured that use of this distant wind power will be favoured if costeffective electricity power links are perfected, as well as by deploying another energy carrier, like hydrogen, for instance, rather than electricity.

\section{Hypotheses}

\section{Hypothesis 1}

Progressively reduced costs by adapting land-type wind turbines for offshore use - limited development

\section{Hypothesis 2}

Developing specifically offshore wind turbines with reduction in costs

Hypothesis 3

Developing floating wind turbines and access to a much greater resource

\section{Bibliography}

Atlas of UK Marine Renewable Energy Resources. London: Department for Trade and Industry. [www.dti.gov.uk/files/file27746.pdf]

Bundesamt fuer Seeschifffahrt und Hydrographie [website www.bsh.de]

Bundesverband Wind Energy [www.wind-energie.de]

BWEA, 2006. Offshore Wind at a Crossroads. London: British Wind Energy Association. [www.bwea.com]

European Commission, 2001. Concerted Action for Offshore Wind Energy in Europe. Report to the European Commission. 2001.

Danish Energy Agency, 2000. Offshore Wind Energy. Paris: International Energy Agency.

Danish Wind Industry Association [www.windpower.dk] 
Husum Wind Energy, 2004. Wind Energy Study. Assessment of the Wind Energy Market until 2012. Wind Energy International Trade Fair, Hamburg, 11 May, 2004. [www. windenergy-hamburg.de]

Matthies, H.G. et al., 1995. Study of Offshore Wind Energy in the EC. Final Report of Joule I contract JOUR-0072 commissioned by the Commission of the European Communities CEC, Verlag Natürliche Energien, Brekendorf, Germany.

Publication Sea Tech Week [www.ifremer.fr/dtmsi/colloques/seatech04/mp/proceedings_pdf] Secretariat General of the Sea, 2002. Offshore Wind Energy. Recommendations for a National Policy. New York: United Nations.

www.beatricewind.co.uk 


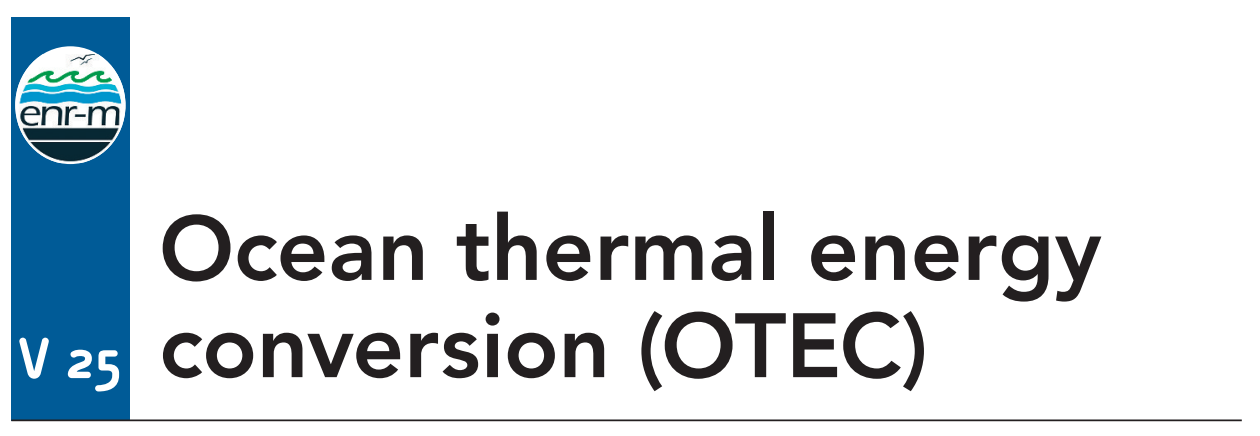

Component: 4. Marine renewable energies

Author: Ifremer (Jean Marvaldi)

\section{Definition}

Ocean thermal energy conversion technology harnesses the calorific potential of warm surface water and cold deep water used separately or together.

There are three possible uses for cold deep water:

- used separately to provide cooling for direct air-conditioning;

- used with warm surface water to produce mechanical/electrical energy;

- used jointly with warm surface water for desalinization of seawater (cascading evaporation-condensation processes).

The warm water from the surface can be utilized as a thermal source for air-conditioning systems or driving a heating pump.

\section{I Key indicators}

\section{EU resources}

A temperature difference of at least $20^{\circ} \mathrm{C}$ is the determining factor for combined warm/cold water utilizations. For direct cooling, the cold water temperature typically required is $6^{\circ} \mathrm{C}$. For all types of onshore facilities, another determining factor is the distance from shore of the required depth of water at $6^{\circ} \mathrm{C}$.

The temperature gradient or direct seawater air-conditioning from cold deep water can only be considered in EU territories located in the inter-tropical belt. The most favourable areas have a surface temperature which remains above $26^{\circ} \mathrm{C}$ all year round.

Using surface water as a heat source for cooling or heating systems with a heat pump can be employed at the various latitudes of mainland Europe's coastal areas. 


\section{Energy production with known technologies}

\section{Direct air-conditioning using cold water}

Cooling is ensured by cold deep water being distributed either directly to air-conditioners or through a freshwater pipe loop with a seawater/freshwater heat exchanger.

Cold water can be pumped either to a single user or to supply a distribution network. This application could enable approximately $80 \%$ of electricity consumption of cooling generation units to be saved.

The cold water/electricity substitution factor is about $0.6 \mathrm{~m}^{3} / \mathrm{kWh}$.

\section{Typical sizing parameters}

Hotel Intercontinental of Bora-Bora installation (2006).

- Cooling power: $1600 \mathrm{kWf}$.

- Cold water pipe: diameter 0.40 m, length 2200 m, depth 915 m.

- Pumping power: $15 \mathrm{~kW}$.

\section{Production of mechanical/electrical power}

Power is produced by low temperature thermodynamic cycles where the working fluid evolves trough three steps: vaporization by hot water; driving an AC generator-turbine; condensation by cold water. The small difference in temperature (about $20^{\circ} \mathrm{C}$ ) and the low heat-energy conversion yield (about $4 \%$ ) involve large specific flow rates of warm and cold water.

Two main cycles have been experimented in demonstration installation.

- Open cycle: the working fluid is steam obtained by low pressure flash vaporization of about one percent of the warm seawater flow.

- Closed cycle: the working fluid is ammonia running through a closed circuit (freon gas is no longer considered in current projects).

The net distributed electric power is about $75 \%$ of the raw power generated, mainly once the energy required for pumping warm and cold water and extracting dissolved gases, in open cycle, is subtracted.

The cycles are compared in Table 25.1.

\begin{tabular}{|l|l|}
\multicolumn{1}{|c|}{ Open cycle } & \multicolumn{1}{c|}{ Closed cycle } \\
\hline $\begin{array}{l}\text { No metal surface exchangers (unless } \\
\text { producing freshwater as a by-product) }\end{array}$ & $\begin{array}{l}\text { Large exchange surfaces of the evaporator } \\
\text { to be protected from biofouling }\end{array}$ \\
\hline $\begin{array}{l}\text { Exchangers and turbines are large (due to } \\
\text { the high specific volume of steam at very } \\
\text { low pressure) }\end{array}$ & \\
\hline $\begin{array}{l}\text { The equipment must be vacuum sealed; } \\
\text { dissolved gases discharged in the } \\
\text { exchangers must be extracted by } \\
\text { recompression }\end{array}$ & $\begin{array}{l}\text { Safety measures must be taken because of } \\
\text { the ammonia }\end{array}$ \\
\hline $\begin{array}{l}\text { Freshwater is a possible by-product (with a } \\
\text { direct-contact condenser) }\end{array}$ & \\
\hline
\end{tabular}

I Table 25.1 : comparison of the advantages and drawbacks of OTEC open and closed cycles. 


\section{Typical sizing parameters}

- Thermal power at exchangers: 30-40 MW of heat/MW (gross) electricity.

- Flow rates:

- cold water: 1-2 m³/second/MW (gross) electricity;

- warm water: 2-3 m³/second/MW (gross) electricity.

- Desalinated water by-production in open cycle: 1000 m³/day/MW (gross) electricity.

- Cold water pipe: diameter 3 m for 5 MW (net) electricity.

- Cold water requirements are from 5 to $10 \mathrm{~m}^{3}$ per net $\mathrm{kWh}$.

\section{Desalination}

Desalination can be carried out in various cycles based on cascading evaporationcondensation process with a low unit temperature difference.

A comparison with conventional processes is shown in Table 25.2.

\begin{tabular}{|l|l|}
\hline \multicolumn{1}{|c|}{ Advantages } & \multicolumn{1}{c|}{ Drawbacks } \\
\hline $\begin{array}{l}\text { No heat required to reheat water } \\
\text { to be distilled (compared with thermal } \\
\text { processes) }\end{array}$ & $\begin{array}{l}\text { The small temperature difference available } \\
\text { requires large flows of warm and cold water }\end{array}$ \\
\hline $\begin{array}{l}\text { Lower specific electricity consumption } \\
\text { (compared with mechanical } \\
\text { or membrane-based processes) }\end{array}$ & $\begin{array}{l}\text { Large exchange surface areas } \\
\text { Need for cold deep water supply } \\
\text { (pipeline and pumping station) }\end{array}$ \\
\hline
\end{tabular}

I Table 25.2 : advantages and drawbacks of desalination by OTEC.

\section{Typical sizing parameters}

- Flow rates:

- cold water: around $15 \mathrm{~m}^{3} / \mathrm{m}^{3}$ of freshwater;

- warm water: $80-100 \mathrm{~m}^{3} / \mathrm{m}^{3}$ of freshwater.

- Electricity consumption: 4-6 kWh/m³ of freshwater.

It takes 3-6 $\mathrm{m}^{3}$ of cold water to save $1 \mathrm{kWh}$ of electricity, compared with a mechanical process consuming $8.5 \mathrm{kWh} / \mathrm{m}^{3}$ of freshwater.

\section{Air-conditioning or heating using heat pump systems in temperate zones}

There are three ways of implementing this technology:

- seawater from the surface or shallow depths is under the $6^{\circ} \mathrm{C}$ limit: it cools a chilled water distribution loop through an exchanger;

- seawater is above the $6^{\circ} \mathrm{C}$ limit: it cools the condensers of the chilling generators of the distribution loop;

- seawater is distributed to cool the condensers of air-conditioners to replace the ambient air.

In the cold season, seawater is used as a heat source for the generators, which work as heat pumps in the distribution network. 


\section{Typical sizing parameters}

Stockholm cooling/heating installation (1995)

Baltic Sea water pumped at the surface or at depths less than $20 \mathrm{~m}$ supplies either:

- four $25 \mathrm{MW}$ heat pumps for heating in winter;

- six titanium plate exchangers on the cooling network (60 MW cooling) in summer.

In autumn, the water on site is not sufficiently cold and must be cooled by heat pumps before being circulated in the exchangers.

An urban distribution network of $4 \mathrm{~km}$ through a main pipe with a diameter of $0.8 \mathrm{~m}$.

\section{Industrial costs}

The cost figures are provided by studies made by French Research Institute for the Sea (Ifremer) with industrial partners around 1985. The values given correspond to 1985 costs in French francs converted into euros.

Electricity generation: 16,000 euros/ $/ \mathrm{kW}$ net for a net $5 \mathrm{MW}$ power station.

Freshwater production: 1.5 million euros for a module producing $500 \mathrm{~m} 3 /$ day not including investments for the cold water supply.

\section{Technologies}

\section{Already tested technologies}

Cold water pipes made of high density polyethylene (HDPE) with diameters up to $1.5 \mathrm{~m}$ and flows of $2 \mathrm{~m}^{3} / \mathrm{second}$.

Complete energy systems in open and closed cycles up to a few hundred kilowatts of electricity.

Desalination systems of a few hundred to $1000 \mathrm{~m}^{3} /$ day.

\section{Intermediate step}

Cold water pipes with diameters up to 3-4 $\mathrm{m}$ and flows of 8-14 $\mathrm{m}^{3} / \mathrm{second}$.

Complete energy systems in open and closed cycles up to 5-10 MW of electricity.

\section{Continuing developments}

Complete energy systems in open and closed cycles producing several megawatts of electricity either on land or on platforms.

\section{Life cycle}

Cooling distributions systems gradually retired over 30 years.

Power generation system gradually retired over 25 years.

Desalination modules gradually retired over 15 years.

\section{Energy efficiency}

Continuous production. Annual availability of $90 \%$. 


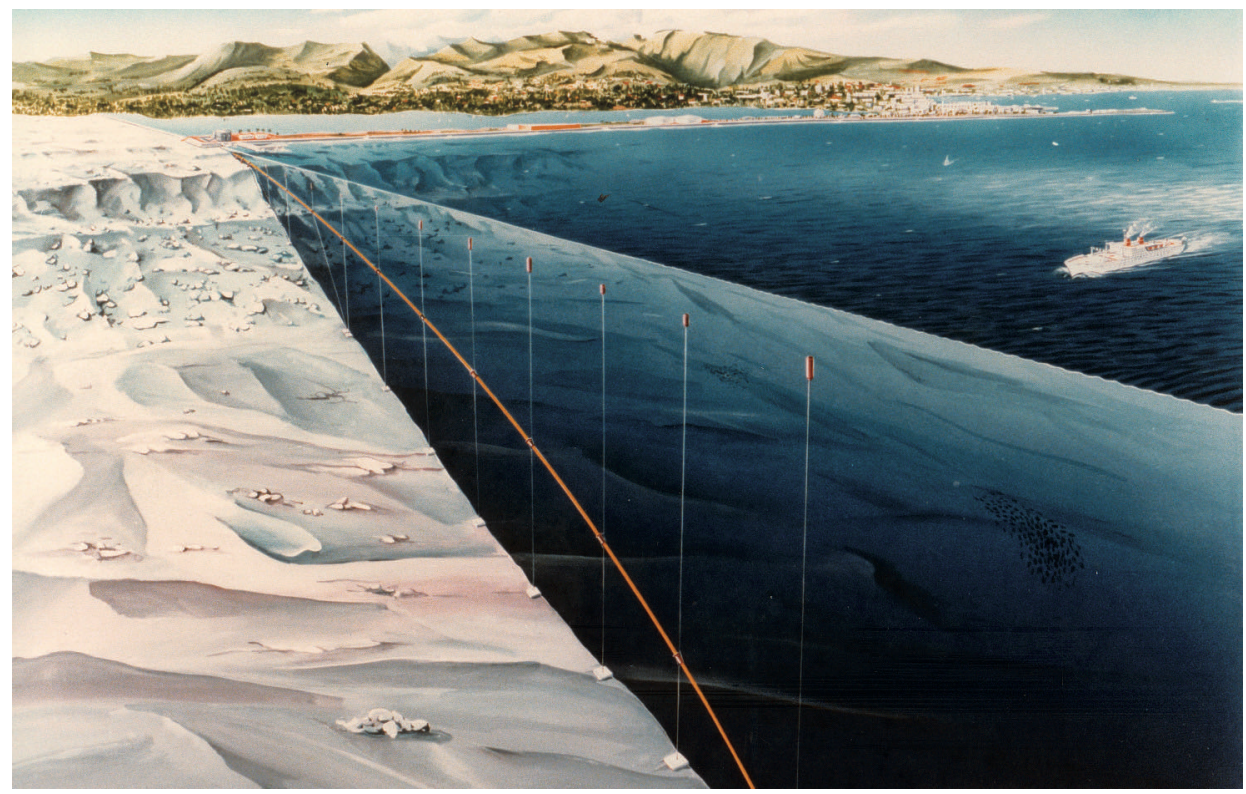

I Figure 25.1 : Artist's illustration of the ocean thermal energy conversion project at Tahiti (@ Ifremer)

Production (of electricity or freshwater) varies proportionally to the seasonal variation of temperature difference (TD) resulting from variations in surface temperature. For instance, for a maximum TD of $20^{\circ}$, a drop of $4^{\circ} \mathrm{C}$ in temperature will result in a $20 \%$ reduction in power.

\section{Costs of energy and freshwater produced by OTEC}

The cost figures are provided by studies made by Ifremer with industrial partners around 1985. The values given correspond to 1985 costs in French francs converted into euros.

Electricity generation: 270 euros/MWh distributed for a net $5 \mathrm{MW}$ power station. Freshwater production: 4-5 euros/m³ for modules producing from 500 to $1000 \mathrm{~m}^{3}$ / day.

\section{Looking back (over the past 20 years)}

France

\section{Electricity generation}

1982-86: Pre-project study for an OTEC pilot plant producing $5 \mathrm{MW}$ net of electricity at Papeete, Tahiti (Ifremer, contracting authority; EIG Ergocean, project manager).

\section{Desalination}

1986-88:

- Technical and economic studies for desalination modules producing 250-1000 m³/day (Ifremer with the Sidem company or CEA-Grenoble). 
- Technical and economic studies to make and install HDPE pipes with diameters ranging in size from 0.30 to $0.50 \mathrm{~m}$ (Ifremer and offshore engineering firms).

- Preliminary technical and economic studies on desalination facilities (about $500 \mathrm{~m}^{3}$ /day) at various sites (e.g. Cape Verde, Bora-Bora, Mataïva).

Direct air-conditioning using cold water

2006: Project to create a cooling distribution company in Papeete, Tahiti.

Air-conditioning or heating using heat pump systems in temperate zones 2007: Project for air-conditioning/heating of a residential and service industry area at La Seyne (Var) using a distribution loop for chilled/heated freshwater by heat pumps (Ingetec design office, Monaco).

Note: The Climespace company runs a land-based cold water distribution network for air-conditioning in Paris. The condensers in the cooling units (52 MWf) are cooled by water from the Seine.

\section{Europe}

\section{Electricity generation}

No significant actions apart from a few feasibility studies (e.g. United Kingdom, Italy, the Netherlands).

\section{Desalination}

No significant actions apart from a few feasibility studies.

Direct air-conditioning using cold water

2006: Contract to build a cooling network at Curaçao (five buildings for services and hotels due to be commissioned in March 2008 - an investment of 15 million euros) by SEACON International (a subsidiary of Evelop, Dutch Econcern group).

Air-conditioning or heating using heat pump systems in temperate zones Since the 1970s, several Ingetec systems have been in operation in Monaco.

Sweden 1995: A cooling network for Stockholm (60 MWf) was constructed by Market Street Energy Inc. (St. Paul, Minnesota, USA).

Greece 2002: Seawater distribution network for cooling air-conditioner condensers to replace ambient air on the island of Hydra (CEA-GrenobleGRETH).

\section{USA}

\section{Electricity generation}

Mid 1970s to mid 1980s: Numerous Department of Energy (DoE) contracted studies:

- pre-projects for onshore and floating plants up to a hundred megawatts by industrial firms; 
- experimental studies on closed and open cycles by national institutes (e.g. SERI, Denver, Argonne National Laboratory, etc.) and consultancy firms under contract;

- R\&D organizations, the Natural Energy Laboratory of Hawaii Authority (NELHA) and Pacific International Center for High Technology Research (PICHTR) created in Hawaii and successive warm water and cold water pumping systems of increasing capacity created.

Late 1970s to late 1990s: Series of experimental studies and pilot-plants built in Hawaii.

\section{Closed cycle}

1979: Mini-OTEC by Lockheed: ammonia with titanium plate exchangers, $50 \mathrm{~kW}$ gross electricity $/ 10 \mathrm{~kW}$ net electricity; on a barge at 1.5 nautical miles from shore; HDPE pipe - diameter $0.60 \mathrm{~m}$, length $670 \mathrm{~m}$.

1980: OTEC-1: ammonia, 1 MW gross output; only tube exchangers, no turbine tested; on former oil-tanker T2; array of three HDPE pipes - diameter $1.10 \mathrm{~m}$, length $670 \mathrm{~m}$.

1988-99: ALCAN (Canada)-GEC (UK)-NELHA; ammonia with aluminium plate exchangers; on land; warm water and cold water supplied by NELHA.

\section{Open cycle}

1983-89: Experiments on seawater exchangers: heat and mass transfer scoping test apparatus platform (HMTSA).

1990-98: Net Power Producing Experiment (NPPE): pilot plant fitted into a concrete tower; peak $255 \mathrm{~kW}$ gross electricity $/ 100 \mathrm{~kW}$ net electricity; in operation from 1992 to 1998; supplied by NELHA for warm water $\left(0.6 \mathrm{~m} 3 / \mathrm{second}, 26^{\circ} \mathrm{C}\right)$ and cold water $\left(0.4 \mathrm{~m}^{3} / \mathrm{second}, 6^{\circ} \mathrm{C}\right)$.

Since 2000: Plant study applications (energy and freshwater) upon request from various contracting authorities (e.g. State of Hawaii, US Navy), drawn up by a few consultancy firms (like OCEES International Inc., Ocean Engineering and Energy Systems) created by former researchers.

US Navy Diego Garcia base: closed cycle and desalination, on land, $10 \mathrm{MW}$ electricity/3800 m³/day; cold water pipeline - diameter $5.2 \mathrm{~m}$, length $3400 \mathrm{~m}$; depth $700 \mathrm{~m}$.

\section{Desalination}

From 1990: Preliminary studies for various sites (e.g. Cape Verde, 1998, Hawaii, 2004).

\section{Direct air-conditioning using cold water}

1986: Air-conditioning for buildings at NELHA.

From 2000: Studies and proposals to build by Makai Ocean Engineering on various sites, such as Hawaii.

2006: Installation for the Intercontinental Hotel on Bora-Bora by Makai Ocean Engineering. 
2007: Cooling network (87 MWf) project on Honolulu by Honolulu SWAC (Group Market Street Energy, St Paul, Minnesota).

\section{Japan}

\section{Electricity generation}

1982: Closed cycle plant on the Isle of Nauru by Toshiba and TEPC, $120 \mathrm{~kW}$ gross electricity/31 kW net electricity; cold water pipeline - diameter $0.70 \mathrm{~m}$, length $945 \mathrm{~m}$. Destroyed by a typhoon after a few months.

From 1970: University of Saga, IOES: R\&D and laboratory experiments on closed cycle loops and variants.

2002: Co-operation by IOES and National Institute of Ocean Technology (NIOT) (India) for 1 MW OTEC demonstration project (see India).

2007, May: Xenesys Inc. R\&D centre created (in Japan): industrial development of IOES research. Due to be commissioned in April 2008.

Desalination

From 1980: University of Saga, IOES: R\&D and laboratory experiments on loops.

\section{India}

\section{Electricity generation}

From 1980: R\&D activities at NIOT; pre-projects for plants with MECON Ltd (Andaman, Nicobar and Lakadive islands).

2002: Closed cycle pilot plant, 1 MW electricity on 'Sagar Shakthi' barge; cold water pipeline diameter $-0.90 \mathrm{~m}$, length $1100 \mathrm{~m}$. The pipeline broke during installation.

\section{Desalination}

From 1980: R\&D activities at NIOT.

2007: Pilot installation of 1000 m³/day on 'Sagar Shakthi' barge $30 \mathrm{~km}$ from shore (Ennore Port, Chennai). Water is carried to shore in towed water bags. Unit capacities up to 10,000 m³/day envisaged. Planned sites: Lakhadive islands and Puducherry. Other projects: process study on hot water discharge from electricity power stations $\left(40^{\circ} \mathrm{C}\right)$ and surface water $\left(28^{\circ} \mathrm{C}\right)$.

\section{Taiwan}

1980-90: Feasibility studies

\section{China}

Air-conditioning or heating using heat pump systems in temperate zones From 2006: A cooling/heating network was created in the city of Dalian, bay of Xinghai (in the northeast of the country).

\section{Canada}

Air-conditioning or heating using heat pump systems in temperate zones 1986: Cold seawater distribution network for air-conditioning in service industry complexes in Halifax. 
Note: on land, similar systems make use of cold lake water in Toronto (Lake Ontario) and at Cornell University (Lake Cayuga) in New York State.

\section{Outlook (for the next 20 years)}

\section{Hypothesis 1}

Continuity: applications for cooling air-conditioning (and heat pumps); used for electricity and freshwater at isolated sites

\section{Hypothesis 2}

Average development: applications for cooling air-conditioning electricity and water in tropical areas

Hypothesis 3

Faster development: hypothesis $2+$ use of nutrients from deep water for biological productions 


\section{Appendix}

\section{Glossary of acronyms (cf. appendix 3)}

\section{|| Websites}

\begin{tabular}{l}
\multicolumn{2}{c|}{ Organizations } \\
\begin{tabular}{|l|l|}
\hline OTEC News & Uttp://www.otecnews.org/ \\
\hline Makai & http://www.makai.com/ \\
\hline NREL & http://www.nrel.gov/ \\
\hline NELHA & http://www.nelha.org/ \\
\hline NIOT & http://www.niot.res.in/ \\
\hline OCEES & http://www.ocees.com/main2.htm/ \\
\hline Saga University & http://www.ioes.saga-u.ac.jp \\
\hline Xenesys (Venture business with Saga Univ) & http://www.xenesys.com \\
\hline GRETH & http://www.greth.fr/ \\
\hline Honolulu SWAC & http://honoluluswac.com/ \\
\hline Evelop (Pays-Bas)- EnR - SWAC & http://www.evelop.com/ \\
\hline Cornell University (Lake cooling) & http://www.utilities.cornell.edu \\
\hline Enwave Energy Corporation (Lake cooling) & http://www.enwave.com/enwave/ \\
\hline Natural Resources Canada (Lake cooling) & http://www.nrcan-rncan.gc.ca/com/ \\
\hline District Energy Library (Stockholm) & http://www.energy.rochester.edu/ \\
\hline IRC-Int. Water \& Sanitation Center & http://www.irc.nl/ \\
\hline Renewable Energy Access & http://www.renewableenergyaccess.com/ \\
rea/home
\end{tabular} \\
\hline
\end{tabular}




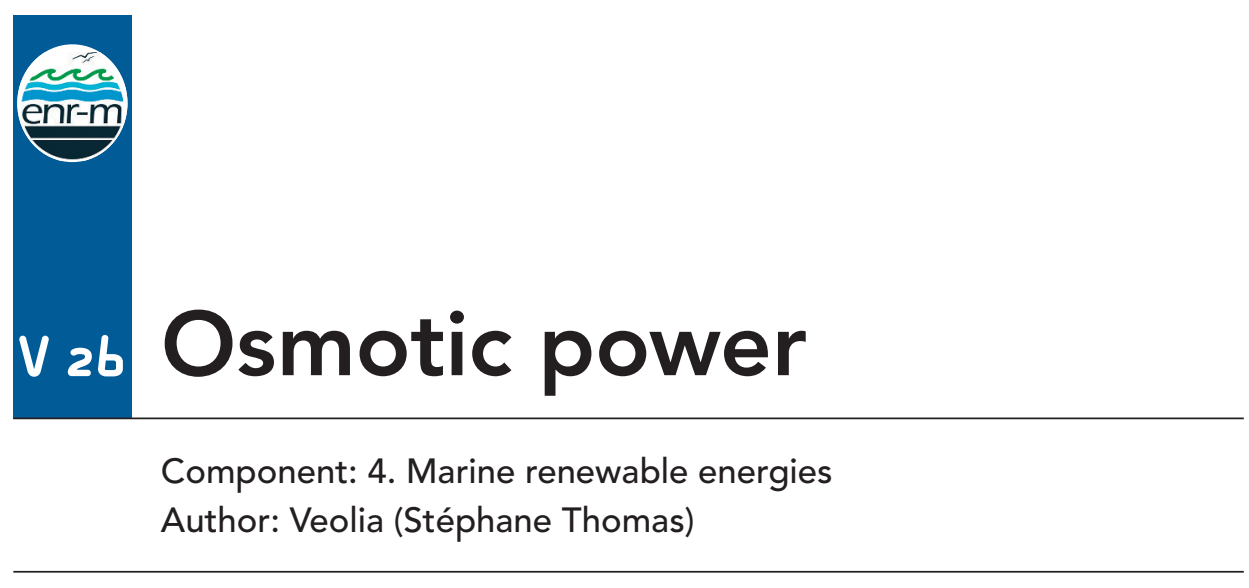

\section{Definition}

\section{Principles and technologies}

Principle: energy is extracted by using osmosis (see Figure 26.1).

Technology 1: pressure-retarded osmosis (PRO)

- freshwater and saline water are separated using a semi-permeable membrane;

- freshwater crosses the membrane;

- osmotic pressure/flow is generated;

- a turbine rotates and produces electricity;

- final product is a mix of freshwater/saltwater.

The technology requires a continuous supply of water tanks (freshwater and saltwater) to stabilize energy generation. Filtration or pre-treatment of freshwater may be required.

In the model, $80-90 \%$ of the water with a low salt gradient is transferred across the membrane into the pressurized saltwater. The diluted and now brackish water from the membrane compartment is split into two flows: one-third of the brackish water goes into the turbine, while two-thirds is returned to retain the pressure on the saltwater feed (Source: doc. Statkraft/osmotic power). The technology has developed beyond the laboratory testing phase. Maximum power is $2.8 \mathrm{MW}$ for a freshwater flow of $1 \mathrm{~m}^{3} / \mathrm{second}$.

Technology 2: reverse electrodialysis (RED)

- freshwater and saltwater are separated using a selective ion membrane;

- the saltwater ions cross the membrane;

- current is generated.

Technical operation has been confirmed in the laboratory, but the cost of the membranes prevents pre-commercial development. Maximum power is $1 \mathrm{MW}$ for a freshwater flow of $1 \mathrm{~m}^{3} /$ second. 


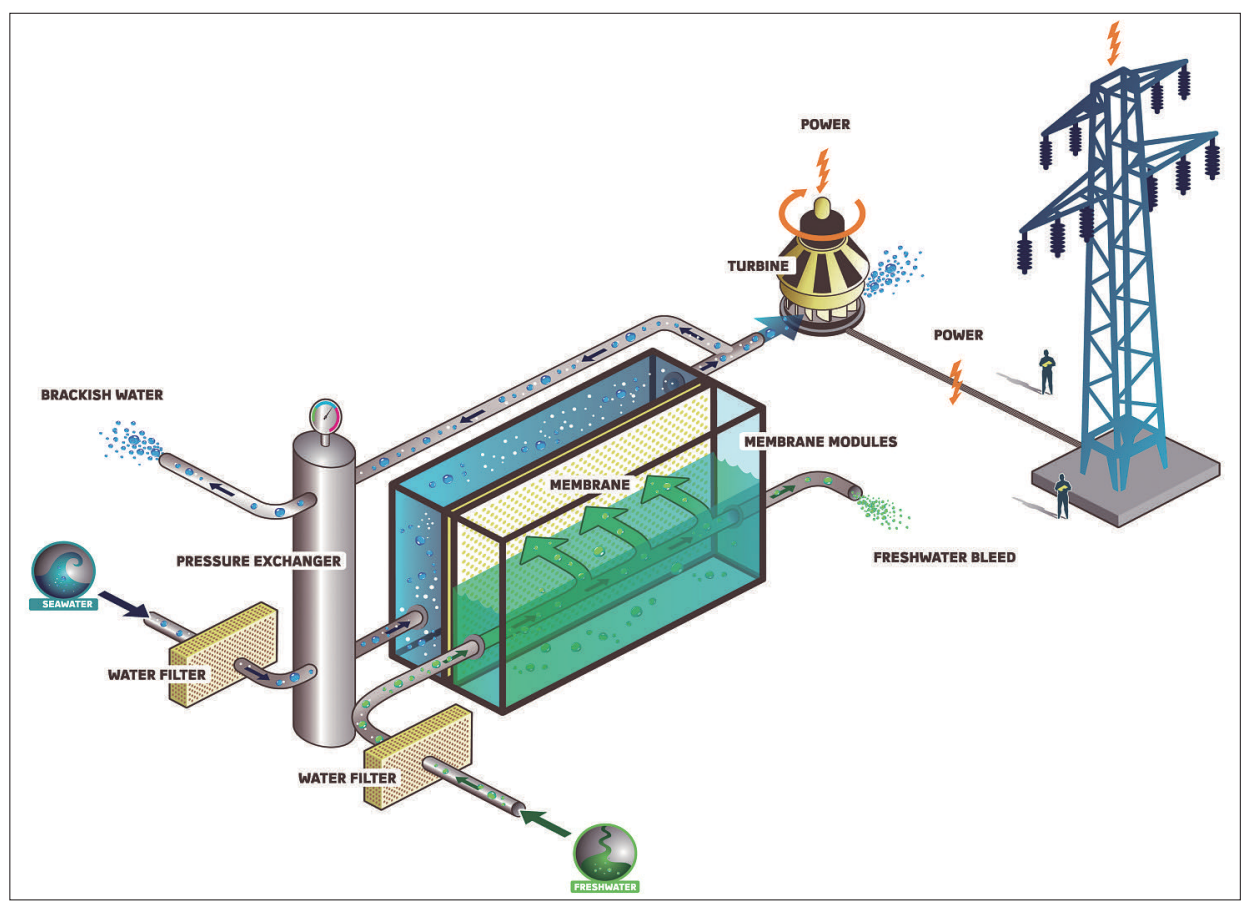

I Figure 26.1 : the production of electricity using osmotic pressure (Source: http://exergy.se/ goran/cng/alten/proj/98/osmotic/).

Technology 3: Vapour pressure difference utilization (VPDU)

The pressure from freshwater steam vapour differs from that of seawater and the difference is utilized to power an electricity turbine.

This technology encounters the same problems as ocean thermal energy conversion (OTEC) (e.g. pipeline costs, equipment, etc.), which has resulted in it being less developed than the previous two technologies.

\section{Key indicators}

Potential

Worldwide osmotic or 'salinity power' potential from studies conducted from 1975 to 1985 is 2000 TWh/year. However, no commercially viable technologies are expected until at least 5-15 years from now.

\begin{tabular}{|l|c|c|}
\multicolumn{1}{|c|}{ Streams or rivers } & $\begin{array}{c}\text { Average flow rate } \\
\text { (m3/second) }\end{array}$ & $\begin{array}{c}\text { Potential energy } \\
\text { (GWh) }\end{array}$ \\
\hline Local stream & 10 & 88 \\
\hline Namsen river (Norway) & 290 & 2,560 \\
\hline Rhine (Germany) & 2,200 & 19,520 \\
\hline Mississippi (USA) & 18,000 & 160,000 \\
\hline
\end{tabular}

- Table 26.1 : energy potential from osmotic power depending on freshwater flow (Source: http:// www.oceansatlas.com/unatlas/uses/EnergyResources/Background/Salinity/sp1.html). 


\section{Typical technical data for each application}

\section{General features}

A few ratios and data obtained for the 'PRO' technology:

- with a pressure of over 10 bars applied in the saltwater tank, a freshwater flow of 1 m/second generates $1 \mathrm{MW}$ (Source: http://fr.wikipedia.org/wiki/\%C3\%89nergie_ osmotique);

- typical operational pressure is 11-15 bars (Source: doc. Statkraft/osmotic pressure);

- a difference in salinity of 3\% corresponds to the potential energy of a $250 \mathrm{~m}$ waterfall (Source: http://exergy.se/goran/cng/alten/proj/98/osmotich;

- if the salt concentration at the start is 3.5\%, then the osmotic pressure will be about 28 bars (Source: http://exergy.se/goran/cng/alten/proj/97/o/\#_ Toc461960127, Tomas Harrysson, David Lönn and Jesper Svensson).

\section{Membranes}

The average useful life of materials is 3-5 years.

Two types of polymers are used: CAB (cellulose acetate) and CPA (composite polyamide). The required surface area of the membrane is $200,000-250,000 \mathrm{~m}^{2}$ per MW or 4-6 W/m² (Source: http://exergy.se/goran/cng/alten/proj/98/osmotic/ and doc. Statkraft/osmotic pressure).

Size

Takes up little space: a $250 \mathrm{~kW}$ unit has the volume of a 40-foot container (Source: http://www.yourgreendream.com/articles_blueenergy.php).

\section{Cost data}

The technology has very high costs (all sources agree) of about US $\$ 36,000 / \mathrm{kW}$ (combined estimates).

Cost of the membrane: Osmotic Inc. 1997 data - US $\$ 0.20 / \mathrm{m}^{2}$ in the case of production using $2 \mathrm{~km}^{2}$ membrane (energy generation about $3.2 \mathrm{MW}$ ), making US $\$ 125,000 / M W$ for the cost of membrane in 1977. According to several authors, the costs of these membranes will not have changed much as little work has been done in this field since 1977.

Other costs: pumping/installation - no figures, but costs should be significant (see http://www.oceansatlas.com/unatlas/uses/EnergyResources/Background/ Salinity/sp1.html).

Studies in 1975-85 gave figures between US\$0.02 and US\$1.3/kWh for PRO and RED technologies. The most recent preliminary study (1995) gave figures between US $\$ 0.035$ and US $\$ 0.07 / \mathrm{kWh}$ for the PRO technology. The forecast cost (from the Statkraft/osmotic pressure document) by 2015 is 40-50 euros/MWh.

\section{Life expectancy}

The membrane has a short life expectancy under operating conditions (a maximum 6 months if no precautions are taken) (Source: http://exergy.se/goran/ cng/alten/proj/97/o/\#_Toc461960127 by Tomas Harrysson, David Lönn and Jesper 
Svensson). When water quality is controlled (pre-treatment/filtration), the useful life can reach 7-10 years (Source: Statkraft/osmotic pressure document).

\section{Examples of PRO process unit deployment (design phase)}

(Source: http://exergy.se/goran/cng/alten/proj/97/o/\#_Toc461960127)

Installations can be underground or sub-sea.

Sub-sea unit: SHEOPP converter

A submarine hydro-electric power plant anchored to the sea floor with potential energy for freshwater and osmotic flow to supply turbines.

Specifications:

- anchored on the sea floor;

- freshwater is collected (e.g. from stream, aquaduct, etc.) and piped through a turbine, which generates electricity, then through an underwater tank and is disseminated towards the sea through semi-permeable membranes; osmotic flow is generated and moves the turbine;

- an extraction pump may be necessary depending on operating conditions (e.g. impurities in the freshwater);

- minimum depth for optimal operation of the process is $110 \mathrm{~m}$.

Underground unit

Specifications:

- anchored on land;

- circuit: freshwater is collected at sea level and carried $90 \mathrm{~m}$ underground through pipes (9 bars); the freshwater flow generated by passing through an osmosis unit (fed by seawater pumped at the surface) makes a turbine placed upstream of the osmosis unit turn and generate electricity, along with a diluted solution at 9 bars, which is pumped towards the surface.

Advantages/interests

- a renewable process with low environmental impact;

- non-intermittent;

- compartmentalized.

\section{Looking back (over the past 20 years)}

A European project is looking at this resource and a study prototype is running at Sunndalsøra, Norway. The goal is to develop the membranes, examine their performance over time and demonstrate that acceptable costs are feasible (Source: Ecrin-Opecst).

Statkraft (a large Norwegian electricity producer) was created in 1997 and is the coordinator of several European projects on salinity power. Partners are Sintef (Norway), Forshungzentrum GKSS (Germany), Helsinki University of Technology (Finland) and IICTPOL (Portugal). Research is focusing on membrane performance and up-scaling the processes under study. 


\section{Outlook (for the next 20 years)}

Hypothesis 1

Optimization of less costly membranes; micro-power plants

Hypothesis 2

No competitiveness

Hypothesis 3

Technological developments (e.g. nano- and biotechnology, salt pump, electro-osmosis)

\section{Bibliography}

Aaberg R.J., 2003. Osmotic power: a new and powerful renewable energy? Refocus 4 (6): 48-50.

Gerstandt K., Peinemann K.-V., Skilhagen S.E., Thorsen T., Holt T., 2008. Membrane processes in energy supply for an osmotic power plant. Desalination 224 (1-3): 64-70.

Jones A. T., Finley W., 2003. Recent Developments in Salinity Gradient Power. In Oceans 2003 Proceedings 4, pp 2284-2287.

Olson M., Wick G.L., Isaacs J.D., 1979. Salinity gradient power: utilizing vapour pressure differences. Science 206: 452-454.

Seymour R.J., Lowrey P., 1992. State of the art in other energy sources. In Ocean Energy Recovery. Seymour R.J. (ed.) New York: ASCE, Ocean Energy Recovery: The State of the Art. Texas A\&M University, pp. 258-275.

Skilhagen S.E, Dugstad J.E., Aaberg R.J. 2008. Osmotic power: power production based on the osmotic pressure difference between waters with varying salt gradients. Desalination 220 (1-3): 476-482. 


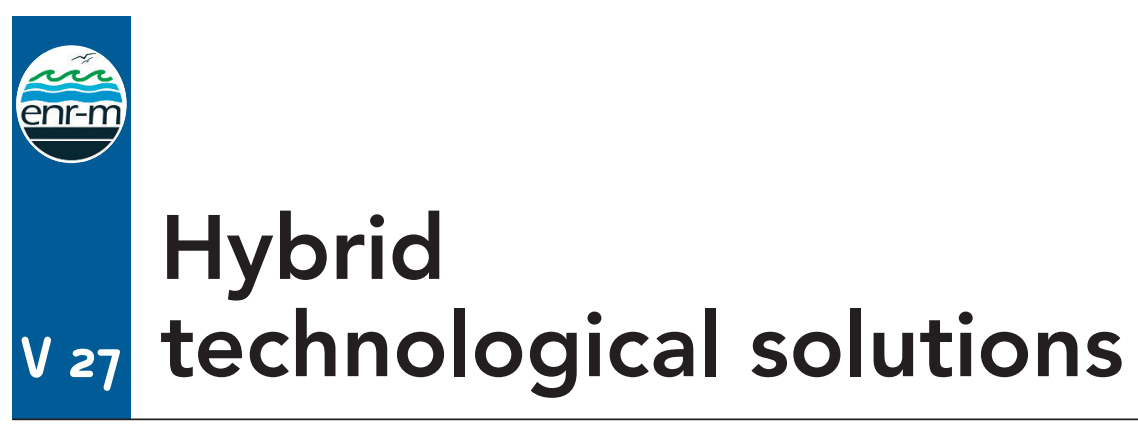

Component: 4. Marine renewable energies

Author: V Lamblin and collective contribution

\section{Definition}

Technologies can be used simultaneously for several purposes, both onshore and offshore. For instance, a thermal power plant can provide both heat and electricity or ocean thermal energy conversion (OTEC) can be a source for cooling while providing freshwater. This hybridization of uses is dealt with in the variables fact sheets for the related technology (e.g. V25 for OTEC or V22 for wave power). This variable aims to seek ways of combining technologies, which could not only optimize energy generation (like electrical power) for a given site and lower maintenance costs, but also examines how these technological combinations could fulfil different energy uses.

\section{Key indicators}

- Sites favourable for the use of several marine energy technologies.

- Technical compatibility in the association of specific technologies and synergies.

- Experiments using several ocean energy technologies in association.

\section{Looking back (over the past 20 years)}

- Sites favourable for several energy sources: windy areas with strong currents (several sites on Europe's Atlantic seaboard), areas where both warm surface water and cold deep water are found together with strong, regular wind: this is the case of many tropical islands.

- Compatibility in technical terms (see Table 27.1: X if compatible, add N if conditions of technical compatibility are particularly favourable).

\section{- Examples of specific synergies:}

- wind and wave; tide and currents: possibility of combining the effects on the same machine;

- wave and osmotic or 'salinity power': using mechanical energy from waves to produce freshwater via reverse osmosis;

- biomass and OTEC: recovering deep water rich in minerals to enhance the growth of marine algae. 


\begin{tabular}{|c|c|c|c|c|c|c|c|}
\hline & $\begin{array}{l}\text { Wind } \\
\text { power }\end{array}$ & $\begin{array}{l}\text { Wave } \\
\text { power }\end{array}$ & $\begin{array}{l}\text { Stream } \\
\text { energy }\end{array}$ & $\begin{array}{l}\text { Tidal } \\
\text { power }\end{array}$ & OTEC & $\begin{array}{l}\text { Osmotic } \\
\text { energy } \\
\text { 'Salinity } \\
\text { power' }\end{array}$ & $\begin{array}{c}\text { Biomass } \\
\text { energy }\end{array}$ \\
\hline Wind power & & $\mathrm{XN}$ & & $x$ & $x$ & & \\
\hline Wave power & & & $x$ & $x$ & $x$ & $\mathrm{XN}$ & \\
\hline Stream energy & & & & $\mathrm{XN}$ & & & \\
\hline Tidal power & & & & & & & \\
\hline OTEC & & & & & & & $\mathrm{XN}$ \\
\hline $\begin{array}{l}\text { Osmotic energy } \\
\text { ('salinity power') }\end{array}$ & & & & & & & \\
\hline Biomass energy & & & & & & & \\
\hline
\end{tabular}

- Table 27.1 : compatibility and synergies in combining marine renewable energies technologies.

In addition to synergies between ocean energy sources, photovoltaic solar panels could be added on to facilities at sea to increase electricity production. Moreover, some forms of energy can be beneficial for aquaculture, like OTEC, which can retrieve nutrients from deep water, and biomass, part of which can be used to manufacture compound feed for various types of farmed species (especially fish and crustaceans).

\section{Outlook (for the next 20 years)}

Hypothesis 1

Independent development

No synergy except in highly favourable niches

\section{Hypothesis 2}

Opportunistic development (multi-use sites)

The demand for electricity and freshwater or for cooling and electricity will lead, for example, to the association of marine technologies in a given location to limit the amount of marine area used

\section{Hypothesis 3}

\section{Development through determined efforts}

Supply is optimized by combining technologies (e.g. wind and wave, tidal power and currents, OTEC and biomass, etc.) in order to maximize the return on investments in setting up the site, including connection to the land grid and operational maintenance 


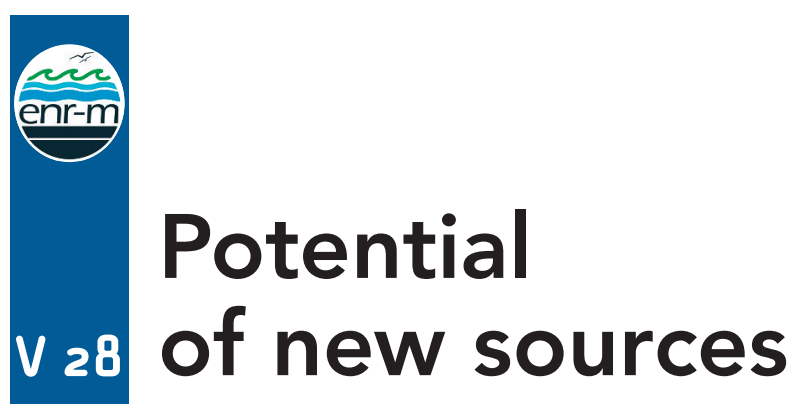

Component: 5. Marine renewable energy research and development Author: Ifremer (Bertrand Chapron)

\section{Definition}

It is impossible to quantitatively measure the energy potential and constraints of new resources. This variable remains subjective. It ties in with the hypotheses selected.

\section{Key indicators}

- Increased outreach to inform the general public, direct and indirect incentives, individual and collective awareness and societal acceptance of the causes and risks (economic and ecological) of global change.

- Growing number of projects and maintainance of existing projects based on old principles (i.e. hard-liner tenacity, will to succeed) that often present great constraints without the expectation of exceptional energy performance.

- Scientific and technical questioning extended to various theme-based communities.

- Amount of R\&D investment and critical mass of private-sector and academic stakeholders.

- Number of patents filed.

\section{Looking back (over the past 20 years)}

There is a relative continuity in the efforts made to find new resources. However, no significant breakthrough seems to have emerged over the past 20 years.

Although no initial objectives were devoted to marine renewables, major scientific and technical progress now provides some interesting perspectives. A few examples are found in research on nanotechnologies and genetics. Results in recent years open up some new aspects to explore, such as using nanotechnologies to store and trap molecules or genetics and genome tools to make selection and enhancement of micro-algae both easier and quicker, so that they can be utilized by industry to produce fuel and other molecules with high added-value.

Furthermore, scientists and industrial firms interested in the energy potential of hydrogen will be interested in the technological advances resulting from deep 
sea exploration. Over the past few years, phenomena of synthesis and serpentinization of large quantities of hydrogen (and methane) have been discovered on the edges of ocean ridges. Together with the challenge of possibly controlling these gases, the discoveries will certainly spur research into finding innovative solutions to store and transport this energy potential. This could also encourage efforts to exploit more traditional resources.

The past 20 years have also been marked by advances in knowledge about the environment and in means of global observation. Satellite observations enable more accurate analyses to be made of environmental conditions over the entire Earth (e.g. surface wind speeds, wave height and sea level, ice extension, sea surface temperature, surface currents, etc.). Computational modelling based on these observations also improve precision and resolution. Increasingly accurate environmental characterization and real-time monitoring of trends can now be made using these techniques.

\section{Outlook (for the next 20 years)}

From a monitoring status over the past few years, research, development projects and innovation, large-scale testing, operations and analyses will begin to advance towards a more active phase. The economic stakes, environmental requirements, social expectations and geopolitical trends are factors which will instigate research, stimulate innovative programmes and develop the creative potential needed to progress beyond today's limitations. Through necessity (e.g. fossil energy prices, climate change, etc.), technological developments and innovations can be envisaged. Within this general outlook, three main hypotheses can be given, realizing that the probability of a totally pessimistic hypothesis is too low for it to be selected.

\section{Hypothesis 1}

No aspect is neglected in the bid to discover new resources and efforts are reinforced. For instance, new fields could cover geothermal energy, exploiting sub-sea cascading, analysing biomimicry, biotechnologies, etc.

\section{Hypothesis 2}

Innovation and/or better control of existing technologies: electrolyte batteries, developing new sites (e.g. concentration of wave energy, currents, floating tanks for micro-algae, etc.), robotics and geomimicry, hybrid operations, genetic selection, etc.

\section{Hypothesis 3}

A technical breakthrough concerning energy storage and transport, or taking advantage of global climate change and modification of some environmental conditions 


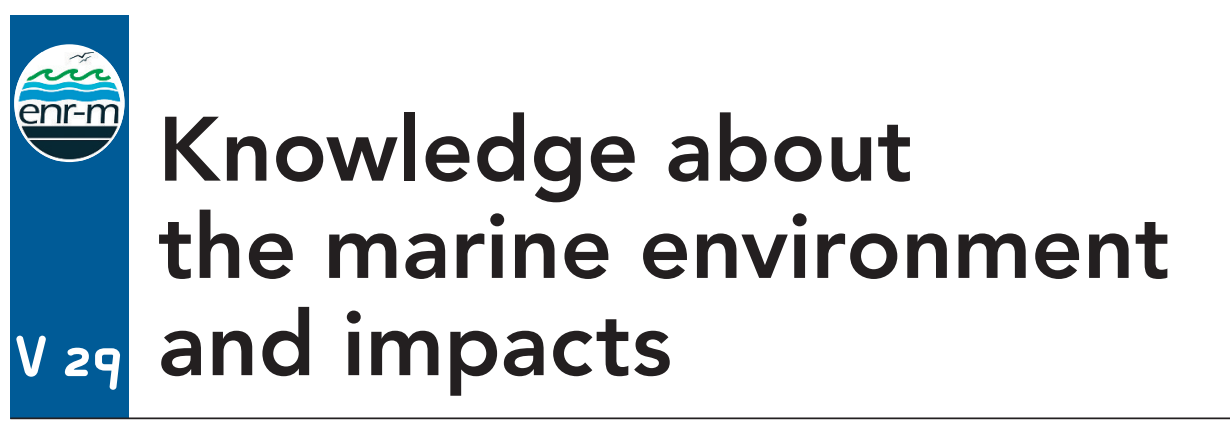

Component: 5. Marine renewable energy research and development Author: Ifremer

\section{1- Definition}

The term 'marine environment' is used generically here, in that it encompasses not only morpho-sedimentary, physical and chemical, biological and fisheries science parameters, but also the human uses that are present in the sector.

Any project for a marine renewable energy production facility requires that its impacts on both the natural surroundings and uses be assessed as precisely as possible.

This assessment will be all the more relevant if knowledge about the chosen location is not only both detailed and accurate, but above all adapted to the project and focused over the entire site. The site, in the broadest sense, includes:

- the area where energy is produced;

- the corridor or area where this energy is transported;

- the 'marine' zone where it arrives on land.

It also includes their respective surrounding areas, the size of which will be specific to the marine RES project and to the site's general configuration.

\section{Key indicators}

In any project, the initial phase involves the exchange of opinions between the project promoter and the State services, on the one hand, and the organizations representing the users (i.e. professional fisheries) on the other, in order to define and validate the various requirements.

- Analysing the baseline state of the site and its marine environment, dealing with natural resources and natural maritime areas or recreational areas affected by developments and constructions. Documents to be produced include various types of mapping (e.g. bathymetric, morpho-sedimentary, current measurement, meteorological maps, etc.), an inventory of biological natural 
resources, a census of the various human activities (e.g. fishing, aquaculture, marine aggregate extraction, shipping or boating, civil or naval navigation, protected nature or historical sites, etc.), and some of these activities can engender total or partial restrictions on the use of the site.

- Technical presentation of the project.

- Assessing the project's effects on the environment as described above that is, the resources on the one hand and uses on the other, distinguishing where possible between temporary effects related to the work site and permanent impacts ensuing from operations.

- Recommending measures to reduce or eliminate the project's impacts on health and the environment, as well as estimating the corresponding costs.

- Proposal for possible monitoring studies. The study contents and timescales will be adapted to each project. Results obtained will first enable foreseen impacts to be confirmed and second, specify a dismantlement strategy (whether total or partial) at the end of the facility's useful life.

\section{Looking back (over the past 20 years)}

During the past 20 years, marine energy projects were somewhat forgotten in France, both in metropolitan France and the overseas DOM-COM. Indeed, the tidal power plant at La Rance dates back to the 1960s and tidal energy projects for the Chausey islands and the Cotentin peninsula were the last to be studied in the early 1980s before being abandoned. The ocean thermal energy conversion (OTEC) project in the French DOM-COM overseas departments was developed in the 1970s before being set aside.

Only in the late 1990s did the concept of offshore wind farms along the coasts of metropolitan France start to be considered - often on the initiative of North European industrial corporations like the Germans or British who were already involved in the first offshore wind installations.

Internationally, various studies have been carried out on the environmental impacts of offshore wind farms, especially in Denmark, Germany and more recently in the Netherlands and United Kingdom. It is difficult to utilize their results due to the wide range of observations and analytical methods used, since each project has it own environmental specificities, and furthermore, specific methods to deal with the important issue of uses. The issue of public acceptance of the projects remains closely linked to the national (how important RES are in the country's energy policy) and local context, especially where they concern inshore fisheries, coastal tourism and the permanent jobs created there.

The governmental call for offshore wind farm tenders in 2004 was the determining factor in reviving these projects. Beyond the result obtained (only one project was awarded a label), the call for tenders showed the heterogeneity of the impact notices filed, which does not bode well for future impact studies.

To mitigate this heterogeneity, the French Research Institute for the Sea (Ifremer)'s website gives a generic set of specifications, which can be adapted to various 


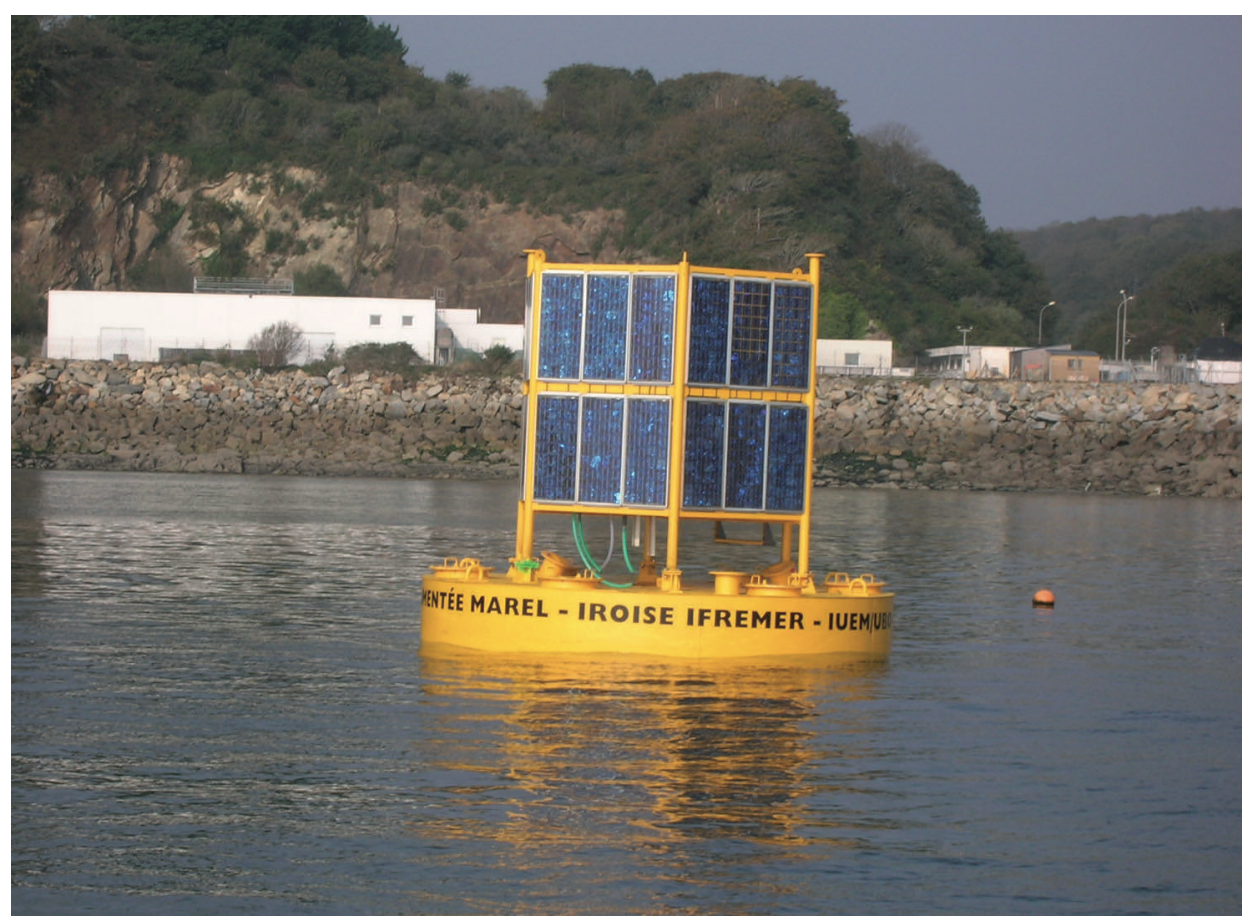

Photo 36 : Marel station for multi-parameter measurements; arrays of this type of buoy provide better information about the coastal environment and make it easier to monitor the impacts of any development (C) Ifremer/TSI).

marine RES projects. It aims to provide a guide for environmental studies in this type of project and the foreseeable impacts as well as aiding project management.

\section{Outlook (for the next 20 years)}

Given the multiplicity of new demands for marine RES, appropriate knowledge about the marine environment and uses has become a necessity in order to assess correctly the true impacts of various projects. This knowledge is also generated by exchanges of resources between petitioners and publication of results obtained in order to optimize the contents of future impact studies, the unit price of which is often very high. Beyond the regulatory and administrative obligation to produce an impact study and possibly monitoring studies at specific intervals, it is important to define properly what should be included, with neither excessive nor extreme requirements, so that contributions can be pooled and studies for later projects both facilitated and improved.

Therefore, the choice of hypotheses is mainly based on the capacity to share the lessons drawn from recent or future studies. This ability is directly linked to the 
State's vision of the maritime area in question and its will for integrated development or on the contrary, its concern to limit State intervention to arbitration between users.

The current situation will continue (Hypothesis 1) and each impact study will remain specific; in this case, the project promoter (the 'client') will pay for all the studies (before, during and after), and the State or responsible authority will simply verify that the specifications are complied with, without a general vision for the area's long-term development. Tools and methods will be improved, either by the consultancy firms who ensure the mapping and monitoring studies or by research organizations, which will publish the effects of these developments but at a much later time.

Alternatively, the State and responsible authority (up to the EU level) consider that better knowledge on the impacts of development related to marine RES provides an opportunity to harmonize tools and methods used for measurements and monitoring as well as being a means to facilitate the planning and management of coastal areas (Hypothesis 2); in which case, it is logical that the community or authority bear most of the costs. This arrangement makes it easier for research laboratories to be involved from the earliest stage of projects, through targeted European calls for tender, for instance, and ensures that the knowledge of a development's effects progress more quickly. This is especially true if synergies between several complementary uses can be demonstrated (e.g. OTEC and aquaculture or offshore wind and fisheries).

As a result of pooling of information obtained by both companies and public and private sector research, both methods and tools will progress (Hypothesis 3), however, the absence of a vision for the overall development of the coastal area will make it impossible to capitalize on this knowledge. Thus, it will be up to project promoters to finance the studies and monitoring, which is not a favourable situation for the emergence of an integrated approach to the area near the continental shelf.

Hypothesis 1

No effort is made to improve the tools and methods (opportunities for development projects are not seized). The client pays

\section{Hypothesis 2}

Progress is made with tools, methods and development of results on national or European levels. The State and/or the EU pays

\section{Hypothesis 3}

Tools and methods progress but are not shared. The client pays 


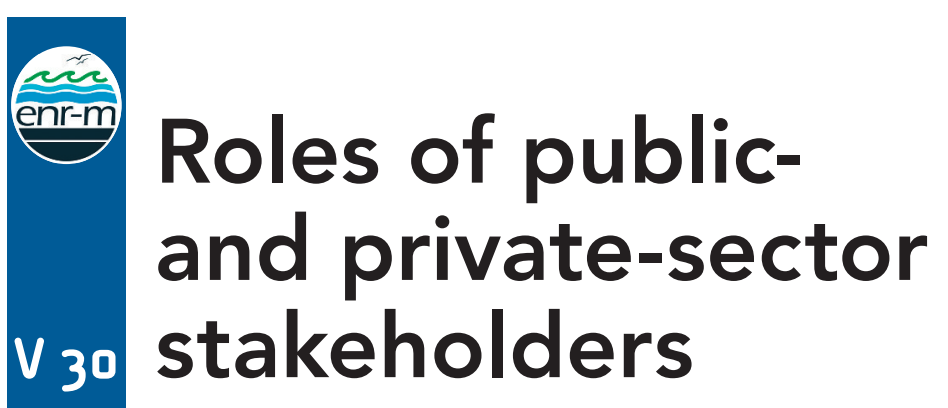

Component: 5. Marine renewable energy research and development Author: DCNS (Marc Boeuf) and Ifremer

\section{Definition}

Public- and private-sector stakeholders play an active role in R\&D for marine RES. This variable encompasses the role of each one, the individual or collective strategy in the short or long term, the main projects carried out and the partnerships, which are either established or sought.

\section{Key indicators}

The indicators can be grouped to show the three types of 'potential' considered in stakeholder strategies.

\section{Technical and geographic potential}

- Exploitable sites and their appraisal and location.

- Technical possibilities and constraints of coexistence for different types of energy generation on the same site.

- The number of prototypes tested, operational installations and patents filed (all sites).

\section{- Economic potential}

- Unit cost of production depending on the marine RES supply chain and exploitable sites.

- Amount of R\&D investment (public or private).

- The turnover of equipment manufacturers and electricity producers.

\section{Strategic potential (strategy of companies and the authorities)}

- Public incentives (local and national) for projects in which industries and universities collaborate.

- Pace of performance: the ability of the public authorities, through policy instruments and adequate incentives, to reach the projected level of generation from marine RES by the planned date.

- Co-operation and competition between enterprises.

- Competition between supply chains (to find funding and mobilize makers of equipment). 


\section{General observations}

The influences of these three types of 'potential' interact: thus, the technical and geographical constraints are correlated to production costs, which in turn are correlated to public and private investment strategies and relations of co-operation/competition.

The backcasting analysis below highlights:

- the current and future technical potential (list of projects);

- the actors in the field (e.g. manufacturers, investors, R\&D, joint ventures).

By considering these points, the outlook for the strategic potential and the role played by stakeholders can be examined.

Several indicators concern industry-sensitive and sometimes confidential information and, therefore, can only be hypothesized.

The indicators either omit the technical capacity (or assume it has been solved) for decentralized generation to be accepted by the electricity transport and distribution grid networks, as well as the problems of managing an electricity supply with an increasing share of decentralized units, which are sometimes difficult to regulate.

They also omit the question of the price of raw materials, particularly that of a barrel of oil; the implicit hypothesis being a continued rise in prices, as in the price of fossil energy sources.

\section{Looking back (over the past 20 years)}

\section{Census of stakeholders}

The businesses and pressure groups related to this sector can be broken down into five categories of stakeholders.

\section{Constructors and service providers}

- Designers of innovative processes using marine renewables (e.g. currents, tide, waves and swell).

- Turbine manufacturers (i.e. wind and stream turbines).

- Manufacturers of foundations and designers of offshore infrastructures.

- Underwater cable manufacturers, shippers and marine logistics.

- Installers and integrators.

- Marine RES/offshore design offices, consultancies, service and engineering firms.

\section{Electricity producers}

- Operators of marine RES production sites.

- Electricity suppliers.

\section{Oil companies}

- Major groups involved in the different steps from extraction to distribution.

- Equipment manufacturers working directly with the oil sector. 


\section{Public structures}

- Public organizations to help develop marine RES.

- Ministries concerned.

- Universities and public-sector research centres.

- Local and regional authorities.

Users (mainly those in the coastal zone)

- Residents of coastal municipalities.

- Those involved in activities using the shore and coastal areas (e.g. committees of fishermen, shellfish farmers, fish farmers, operators exploiting marine aggregates, harbours and shipping, tourist boards, etc.).

- NGOs and various associations for protection (Ligue pour la Protection des Oiseaux (LPO) the bird protection society, Greenpeace, etc.).

Most of the following descriptions of projects are taken from the report by Adam Westwood (2004) called Refocus Marine Renewable Energy Report; Prospects, Technologies and World Markets (RMRER) and Infocéans newsletters.

\section{Offshore wind power}

Many, mainly European, companies are specialized in offshore wind power.

\section{Background}

The first offshore wind turbine offshore was installed in 1991 at Vindeby in the Baltic Sea off the island of Lolland (Denmark) by the SEAS service firm. In 2002, Horns Rev (Denmark) became the largest offshore wind farm in the world, with a 160 MW capacity. In 2004, there were 19 operational offshore wind farms worldwide, with 327 turbines producing a total of 617.6 MW (RMRER).

\section{Projects}

Most of the projects commissioned since 2006 or to be commissioned by 2012 are located in the North Sea (United Kingdom, the Netherlands and Denmark). They are also found in the English Channel and Irish Sea. With a few exceptions (like Lake Ontario), the projects are European. Each one's installed power ranges from approximately 100 to $1000 \mathrm{MW}$, with 20-200 units. The unit power of the turbines is usually about 3-5 MW.

\section{Tidal and stream power}

\section{Background}

Most of the companies or consortia proposing electricity generation from tidal and current energy are British.

\section{Projects}

Several projects, since 2003 and up until 2010, are located in the United Kingdom. However there are others in the USA and Canada, Scandinavia and Italy. Projects for this very recently developed technique comprise a simple prototype of several (up to 100) turbines. 


\section{Wave power}

\section{Background}

The only entirely submerged wave energy converter was designed by TeamWork Technology. It is called the Archimede Wave Swing and has two cylinders acting as a piston. Trials were conducted in 2002-03 off the shores of the United Kingdom. A prototype was deployed in 2004 and is currently in the pre-marketing phase.

In 1990, Tom Dennis invented a parabolic wall to focus wave energy in a chamber where the oscillating water column activates a turbine. Energetech (Oceanlinx since 2007) finished the validation testing for the system in 1997. It is being experimentally tested in Australia and the USA.

Pelamis is a system with a series of semi-submerged cylindrical sections linked by hinged joints (150 m length, $3.5 \mathrm{~m}$ in diameter). Compression motion at the joints supplies hydraulic motors. The prototype was tested in 2002. An operational unit was set up in Scotland at the European Marine Energy Centre (EMEC) in 2004. Several installations are either planned or underway in Portugal and the United Kingdom.

PowerBuoys (Ocean Power Technologies): these buoys are submerged and bob up and down along a rigid pole anchored to the seabed. Trials were run in 1998 and the system has been operational in Hawaii since 2004. Several deployments are planned in the United Kingdom, Spain and Australia.

\section{Projects}

These techniques have led to projects in a wide range of locations, like southern Europe, the United Kingdom, Australia and the USA. The installed power varies greatly, from a few megawatts to $500 \mathrm{MW}$ in the largest projects.

\section{Biomass}

Several countries, such as Germany, Australia, Spain, France, United Kingdom, Japan, the Netherlands and the USA (Hawaii), are looking at this high potential technology for the medium term. The large degree of variability seen in the first experiments calls for caution, but the potential for this supply chain is gradually being confirmed, due both to the rise in cost of fossil energies and the questions raised by conventional terrestrial crop biofuels, which use large surface areas, fertilizers and other inputs and are criticized for this in a period of food crop tensions.

\section{Thermal and osmotic energy}

These two technologies are not sufficiently developed to solicit actual stakeholder strategies.

\section{Other stakeholders}

There are dozens of companies (i.e. service providers, advisers, engineering, production and other firms), universities and research centres, which support and promote renewable energies in general in all the large Organization for Economic Co-operation and Development (OECD) countries, which makes it impossible to 


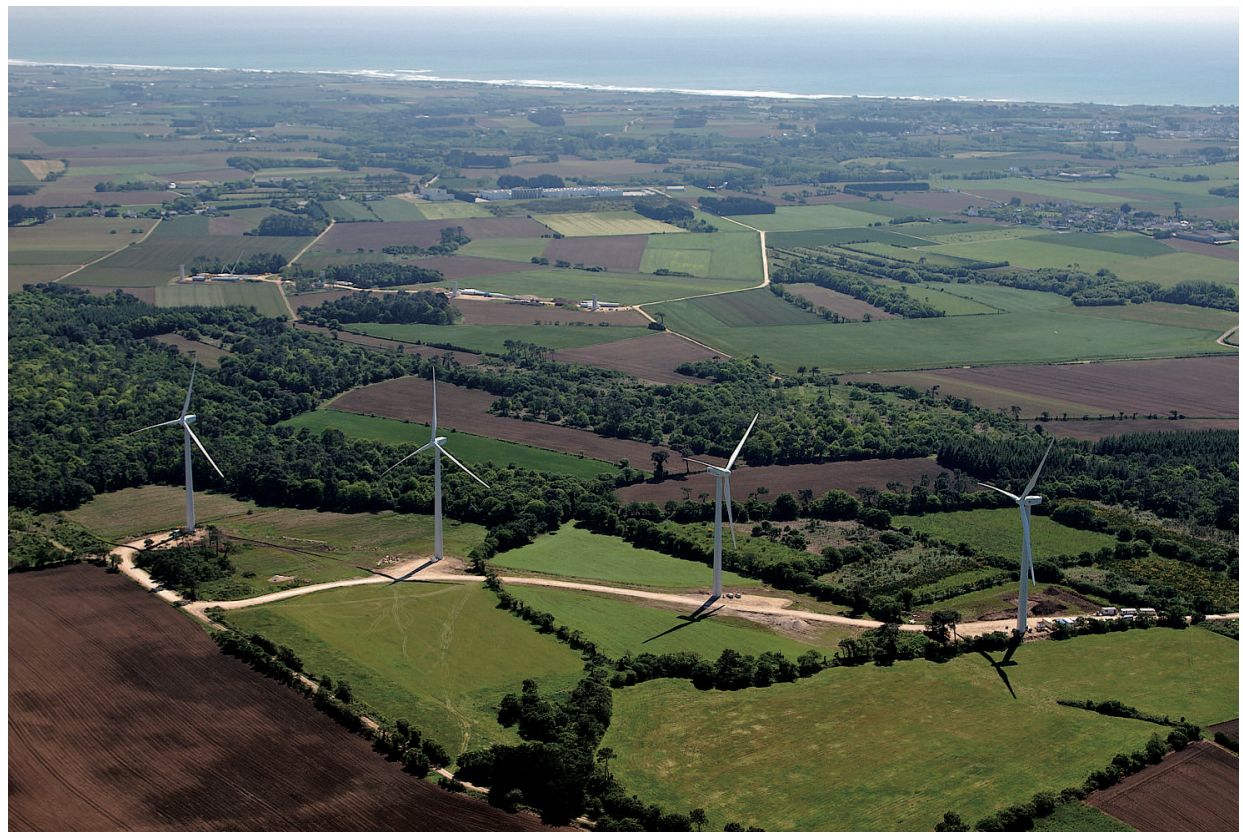

Photo 37 : onshore wind turbines must be fitted into an often dense fabric of activities and infrastructures, as seen here in the Finistère region of Brittany (C) D. Glévarec - Planète 360, Quimper, FR).

determine the strategies for each structure or even each country due to the growing internationalization of industrial energy groups.

\section{Backcasting analysis outcome}

The backcasting carried out led to the following general observations.

Technical constraints can be managed, given the number, size and reliability of the enterprises involved in the various marine RES supply chains and in the design and manufacture of equipment which can be used by all the chains. However, two parameters remain crucial: (1) the unit cost of production, which will mainly influence competition between supply chains; and (2) the footprint and surface unit yield given the space constraints, particularly in Europe.

The supply chains for marine renewables have developed unequally in geographical terms. Two zones are over-represented in most chains: the largest is the North Sea and all the United Kingdom seafronts and the other is North America. These regions are similar in that the gross domestic product/inhabitant is very high, they have a strong equipment manufacturing base, R\&D capacity, a high density of large small and medium size enterprises (SMEs) (contrary to southern Europe), academic excellence in their universities, strong environmental awareness on the part of the population, definite or temporary retreat from nuclear-powered electricity generation compared with the 1970s uncontrolled 
costs for nuclear energy in other countries, pollution and carbon dioxide problems related to conventional power plants in spite of their strongly competitive prices, unequal will and determination on the part of the authorities and unequal subscription to the Kyoto Protocol.

Unsurprisingly, the position acquired by these supply chains in energy generation led to: (1) a determined effort by national and local authorities (i.e. subsidies, regulated feed-in tariffs for grids, protectionism, local building permits); and (2) a concentration of innovative enterprises and R\&D clusters.

Generally speaking, the above hypotheses have not been exclusive, but more often complementary. In practice, they should be tested above all outside the North Sea and United Kingdom.

\section{Outlook (for the next 20 years)}

\section{Major trends}

Analysis of the global wind power sector is interesting. In fact, when the scenarios are assessed in terms of technologies, offshore wind power appears to be the main source for exploitation in the timeframe set because of its maturity. Several major trends can be identified:

- strong and lasting growth of the wind power market worldwide, especially in emerging countries like China and India (+26\% per year on average up to 2016, according to BTM Consult); a post-oil position is beginning to be taken into decision-makers' planning periods;

- the power generated in the projects is becoming comparable to a conventional or nuclear power plant (e.g. the $1000 \mathrm{MW}$ Beatrice project);

- with increased demand and fossil energy prices perceived as being irreversibly increasing, interest is growing with new industrial firms being set up, vertical integration with suppliers being bought out by the constructors and finally, a growing number of partnerships on a global scale;

- local resistance to some developments will grow with the size and number of projects.

\section{The roles of stakeholders}

Industrial firms (constructors/original equipment manufacturers) are moving towards a logical and foreseeable strategy for vertical integration to secure their capacity for development in view of the large markets and the need for reliability in both lead times and performance. The large number of operators and countries' will to develop the sector will help to encourage them to look for partnerships.

Electricity producers will increase their market share in marine RES as much to diversify as to secure their position with respect to consumers as well as the authorities, since 'green' energy sources are seen as naturally 'responsible', 'ethical' and 'the future' and thus more likely to receive funding or aid. However, the sharp increase in price of raw materials will make these companies' strategies highly dependent on national feed-in policies. 
Oil companies will try to diversify their energy mix as oil supplies dwindle. They will also want to display an image that their production is 'positive and accountable' by highlighting their investments in clean, renewable energy sources. It will take time, however, before they are able to influence the strategies of other stakeholders.

Public organizations and administrations will waver depending on the general geopolitical context, between the will to ensure energy security for countries through an active policy of support for supply chains or letting the market choose the best adapted, highest performance technologies.

Users of the coast, and above all its permanent residents, will be torn between the temptation of the 'nimby' ('not in my backyard') syndrome and acknowledging that marine RES are useful, such as an awareness of the need to reduce greenhouse gas emissions, a positive image and local jobs.

\section{Drivers of the three hypotheses}

When the different types of strategies for all stakeholders are examined, two bodies clearly play a key role. They are the public authorities (including local authorities who play an important role in authorizing developments and coastal zone management) and companies, with the main 'cursor' set by feed-in tariffs by the grid and more generally that of public support for R\&D in the sector.

If States or regional political bodies on various scales (i.e. from regions as the French know them to EU level) decide on a determined policy of support for a long-term strategy, the potential for developing marine RES will be high. This will be especially true through industrial partnerships, which can guarantee efficient transfer from research to development and maintain the dynamics of development by attractive feed-in tariffs and aid for the least mature technologies (Hypothesis 1).

If, on the contrary, the risk-taking is assumed by the companies alone, a context of seeking maximum independence will be required. Only the most mature technologies (including offshore wind) can develop within alliances formed to find economies of scale on a global level (Hypothesis 3). This development will also depend on the investors' ability to provide finance, which will favour large groups or corporations and make broader partnerships even more interesting.

Between these two extremes, recurrent crisis situations, with stop and go effects on world energy demand, will necessitate partnership, through obvious mutual interest, between the authorities and private-sector players, particularly in research to reduce costs and develop appropriate technologies on a regional scale (Hypothesis 2). In fact, a large number of joint ventures can already been seen in the sector worldwide.

\section{Hypothesis 1 \\ Strong incentives from national and EU authorities for public/private sector partnerships for R\&D (clusters) to promote RES, including marine RES}


Hypothesis 2

Following a crisis, industrial firms take the initiative for co-operation between companies and with R\&D organizations

Hypothesis 3

Little co-operation between research stakeholders; outside collaboration

\section{Consequences of hypothesis 1}

- Hypothesis 1 assumes that the pace of implementation will be satisfactory (see key indicators above).

- In countries where it already exists (northern Europe, North America), this policy will lead to local emphasis on the 'business as usual' approach.

- In countries where it is still lagging, the effect of this policy will depend on the existing base of SMEs and R\&D organizations. Potentially favourable effects, especially in Spain and to a lesser extent in Italy, countries where the SME and R\&D bases are emerging or still small and can be strengthened in this way. Possible effects in eastern Europe or the eastern Mediterranean, but on a basis which is imported from northern and western Europe and North America: potential setting up of SMEs and R\&D organizations in these countries, provided that the public incentive schemes are well adjusted (opening up to foreign projects).

\section{Consequences of hypothesis 2}

- Geographically, this hypothesis is less equitable than Hypothesis 1.

- The technological and commercial position of companies and R\&D organizations in northern Europe and North America gets stronger.

- Industrial protection is organized within production and R\&D networks.

- Case by case negotiations between enterprises and authorities in strategic regions like the eastern Mediterranean, but also, and above all, Latin America, Southeast Asia and possibly China.

- Setting up of joint ventures together with local production units (much less certain for R\&D).

\section{Consequences of hypothesis 3}

- Hypothesis 3 is taken in the absence of strong external pressure (e.g. global warming effects perceived as more moderate than predicted, fewer fears about the availability of raw materials, etc.).

- It assumes that there will be little co-operation between public-sector R\&D and that of the private sector, that is, business as usual in countries where this situation exists (southern Europe, etc.). 
- The development of marine RES is mainly commercial: sale and export of equipment via the investors.

- Compared with Hypothesis 2, the development of marine renewables supply chains is not necessarily slowed. However, Hypothesis 3 limits the networks for co-operation and strengthens the position of designers, manufacturers and existing R\&D organizations (northern Europe, North America and a few companies in other regions).

\section{A few examples (main source: RMRER)}

Talisman Energy is planning to convert North Sea oil infrastructures into wind farms, this is, the Beatrice wind farm offshore from Scotland. It is a challenge in terms of the technology, location and size.

A similar project is underway on oil rigs in the Gulf of Mexico.

Spending on transport, installation of foundations and offshore turbines has risen sharply in the period from 2005 to 2009.

Starting production from wave and stream power systems should total $47 \mathrm{MW}$ over the 2005-09 period.

Germany has targeted a 2000 MW offshore wind power capacity by 2020 . However, no project has yet materialized, in spite of the 32 building permits issued (24 in the North Sea, 8 in the Baltic Sea), owing to insufficiently favourable economic conditions.

The Eskom group is examining different experiences using ocean energy worldwide. At the end of the study, Eskom may run trials in South Africa. 
APPENDIXES 



\section{Appendix 1}

\section{List of Steering Committee members}

\begin{tabular}{|c|c|c|}
\hline Name & Capacity & Organizations \\
\hline Jean Yves PERROT & Chairman and CEO & Ifremer \\
\hline Maurice HÉRAL & Director of Foresight and scientific strategy & Ifremer \\
\hline Jean-Luc DEVENON & Scientific and technological advisor & Ifremer \\
\hline Michel PAILLARD & $\begin{array}{l}\text { Head of 'Marine renewable energies' } \\
\text { project }\end{array}$ & Ifremer \\
\hline Antoine PRESTAT & $\begin{array}{l}\text { Deputy Director for Enhancement } \\
\text { and utilization }\end{array}$ & Ifremer \\
\hline Denis LACROIX & Coordinator of Foresight unit & Ifremer/Agropolis \\
\hline \multicolumn{3}{|c|}{ Facilitation expertise and Foresight methodology } \\
\hline Hugues de JOUVENEL & General Director of Futuribles & Futuribles \\
\hline Véronique LAMBLIN & Director of Strategy and Foresight Studies & Futuribles \\
\hline \multicolumn{3}{|c|}{ Outside experts } \\
\hline Cyrille ABONNEL & $\begin{array}{l}\text { 'Marine energy sources' project leader } \\
\text { EDF R\&D }\end{array}$ & EDF \\
\hline Jean-Luc ACHARD & Research director, Harvest Project leader & $\begin{array}{l}\text { CNRS/LEGI - Geophysical } \\
\text { and industrial flows laboratory }\end{array}$ \\
\hline Jean-Louis BAL & Director of Renewable energy sources & $\begin{array}{l}\text { Ademe-Agency for the environment } \\
\text { and energy management }\end{array}$ \\
\hline Marc BEUF & $\begin{array}{l}\text { Head of R\&D and Marine Cluster naval } \\
\text { manager }\end{array}$ & DCNS \\
\hline Philippe BREANT & $\begin{array}{l}\text { Director of potable water and membranes } \\
\text { network }\end{array}$ & Veolia - Environment R\&D \\
\hline $\begin{array}{l}\text { Mathieu CHABANEL, } \\
\text { represented by } \\
\text { Katrin MOOSBRUGGER }\end{array}$ & $\begin{array}{l}\text { Deputy to Assistant manager } \\
\text { Head of coastal \& environment bureau } \\
\text { (PVL3) }\end{array}$ & $\begin{array}{l}\text { Meeddat* - Directorate of Maritime, } \\
\text { Road and River Transport }\end{array}$ \\
\hline Pierre CHAUCHOT & $\begin{array}{l}\text { Chairman of the Club for Research } \\
\text { on man-made structures at sea }\end{array}$ & Ifremer Brest - DCB/ERT \\
\hline Martine CHOQUERT & $\begin{array}{l}\text { Project officer for 5th Sub-Division } \\
\text { for Energy supply and management }\end{array}$ & $\begin{array}{l}\text { Meeddat* - General Directorate } \\
\text { for Energy and raw materials (DGEMP) }\end{array}$ \\
\hline Alain CLÉMENT & Director of Fluid mechanics laboratory & $\begin{array}{l}\text { École centrale de Nantes - Fluid mechanics } \\
\text { laboratory (LMF) }\end{array}$ \\
\hline Bernard COMMERE & $\begin{array}{l}\text { Project officer at the Ministry of Higher } \\
\text { education and research - DGRI }\end{array}$ & $\begin{array}{l}\text { Department A4 - MESR }{ }^{\star \star} \\
\text { Biotechnologies, Resources, Agronomy }\end{array}$ \\
\hline Pascale DELECLUSE & Deputy Director of Research & Météo-France-CNRM \\
\hline Anna GIGANTINO & Head of Science and Technology projects & $\begin{array}{l}\text { European Commission / DG Research Unit } 3 \\
\text { New and renewable energy sources }\end{array}$ \\
\hline Frédéric JOUVE & $\begin{array}{l}\text { Delegated Director for Renewable energies } \\
\text { and the Environment }\end{array}$ & $\begin{array}{l}\text { EDF / R\&D - Division of Research } \\
\text { and Development }\end{array}$ \\
\hline Éric LEMAITRE & $\begin{array}{l}\text { Project officer at the Ministry } \\
\text { of Higher education and research - DGRI }\end{array}$ & $\begin{array}{l}\text { Department A4 - Energy, Transport, } \\
\text { Environment and Natural Resources }\end{array}$ \\
\hline Gilbert LE LANN & Project officer & Secretariat-General for the Sea \\
\hline $\begin{array}{l}\text { Philippe MAZENC } \\
\text { represented by } \\
\text { Sophie Dorothée DURON }\end{array}$ & $\begin{array}{l}\text { Head of coastal and maritime activities } \\
\text { office } \\
\text { Head of Marine environment cluster }\end{array}$ & Meeddat $^{\star}$ - Maritime Affairs Directorate \\
\hline $\begin{array}{l}\text { Antoine-Tristan } \\
\text { MOCILNIKAR }\end{array}$ & $\begin{array}{l}\text { Adviser and Expert in energy supply chains, } \\
\text { Environment and Sustainable development } \\
\text { manager }\end{array}$ & DIDD - Mission for the Mediterranean \\
\hline $\begin{array}{l}\text { Sylvain de MULLENHEIM } \\
\text { represented by } \\
\text { Frédéric Le LIDEC }\end{array}$ & $\begin{array}{l}\text { Director of Public affairs } \\
\text { Director of Marine development }\end{array}$ & DCNS \\
\hline
\end{tabular}




\begin{tabular}{|c|c|c|}
\hline Name & Capacity & Organizations \\
\hline Christian NGO & $\begin{array}{l}\text { General delegate for the Écrin association } \\
\text { Scientific director Cabinet atomic energy } \\
\text { commission }\end{array}$ & Écrin/CEM \\
\hline Cyril POUVESLE & $\begin{array}{l}\text { Project officer at the Energy, Agriculture } \\
\text { and Industry bureau }\end{array}$ & $\begin{array}{l}\text { Meeddat* - Economic Studies and } \\
\text { Environmental Assessment Directorate } \\
\text { (D4E) }\end{array}$ \\
\hline Philippe SERGENT & Scientific director & $\begin{array}{l}\text { Cetmef - Marine and river technical studies } \\
\text { centre }\end{array}$ \\
\hline Hélène THIENARD & Project officer at the Energy observatory & $\begin{array}{l}\text { Meeddat* - General Directorate } \\
\text { for Energy and raw materials (DGEMP) }\end{array}$ \\
\hline Stéphane THOMAS & $\begin{array}{l}\text { Head of Decentralized } \\
\text { and renewable energies cluster }\end{array}$ & Veolia - Environment R\&D Energy \\
\hline \multirow{2}{*}{$\begin{array}{l}\text { Didier VERGEZ } \\
\text { represented by } \\
\text { Thomas RENAUT }\end{array}$} & Head of New Business and Participation & Total - Renewable energy sources division \\
\hline & Head of Marine energies at Total & Total - Gas and New energies division \\
\hline
\end{tabular}

* Meeddat: ministry of the Environment, Ecology, Sustainable development and Spatial planning

** MESR: ministry of Higher education and Research 


\section{Appendix 2}

\section{List of Working Group members}

\begin{tabular}{|c|c|c|}
\hline Name & Capacity & Organization \\
\hline Michel PAILLARD & $\begin{array}{l}\text { Head of 'Marine renewable energies' } \\
\text { project, working group co-facilitator }\end{array}$ & Ifremer \\
\hline Denis LACROIX & $\begin{array}{l}\text { Coordinator of Foresight unit, } \\
\text { working group co-facilitator }\end{array}$ & Ifremer Agropolis \\
\hline Véronique LAMBLIN & $\begin{array}{l}\text { Director of Strategy and Foresight Studies, } \\
\text { working group coordinator }\end{array}$ & Futuribles \\
\hline Cyrille ABONNEL & 'Marine energy sources' project leader & EDF - R\&D division \\
\hline Marc B氏UF & Head of R\&D & DCNS Brest \\
\hline Jean Paul CADORET & $\begin{array}{l}\text { Director of Algal physiology and } \\
\text { biotechnology laboratory }\end{array}$ & Ifremer \\
\hline Bertrand CHAPRON & Director of Space oceanography laboratory & Ifremer \\
\hline Jérôme CLAUZURE & Study manager & Meeddat*/DTMRF/PVL3 \\
\hline Jean-Luc DEVENON & Scientific and technological adviser & Ifremer \\
\hline Luc DREVES & $\begin{array}{l}\text { Director of Coastal environment } \\
\text { and aquaculture resources department }\end{array}$ & Ifremer \\
\hline Sophie-Dorothée DURON & Head of Maritime environment cluster & Meeddat* \\
\hline Marie-Cécile De GRYSE & $\begin{array}{l}\text { Project officer at the Energy, Agriculture } \\
\text { and Industry bureau }\end{array}$ & $\begin{array}{l}\text { Meeddat* Economic Studies } \\
\text { and Environmental Assessment Directorate } \\
\text { (D4E) }\end{array}$ \\
\hline Régis KALAYDJIAN & Maritime economics research scientist & Ifremer \\
\hline Jean MARVALDI & $\begin{array}{l}\text { Engineer in Instrumental systems } \\
\text { and technologies department }\end{array}$ & Ifremer \\
\hline $\begin{array}{l}\text { Antoine-Tristan } \\
\text { MOCILNIKAR }\end{array}$ & $\begin{array}{l}\text { Advisor and Expert in energy supply chains, } \\
\text { Environment and Sustainable development } \\
\text { manager }\end{array}$ & DIDD - Mission for the Mediterranean \\
\hline Cyril POUVESLE & $\begin{array}{l}\text { Project officer at the Energy, Agriculture } \\
\text { and Industry bureau }\end{array}$ & $\begin{array}{l}\text { Meeddat* - Economic Studies } \\
\text { and Environmental Assessment Directorate } \\
\text { (D4E) }\end{array}$ \\
\hline Jacques RUER & $\begin{array}{l}\text { Deputy director for Innovation } \\
\text { and emerging technologies }\end{array}$ & $\begin{array}{l}\text { Saipem SA - Technological Development } \\
\text { Division }\end{array}$ \\
\hline Nils SIEBERT & $\begin{array}{l}\text { Project officer in the Renewable energy } \\
\text { source department }\end{array}$ & $\begin{array}{l}\text { Ademe-Agency for the environment } \\
\text { and energy management }\end{array}$ \\
\hline Nicolas TCHERNIGUIN & $\begin{array}{l}\text { Deputy Director of Development } \\
\text { for new offshore technologies }\end{array}$ & Technip - New offshore technologies \\
\hline Stéphane THOMAS & $\begin{array}{l}\text { Head of Decentralized } \\
\text { and renewable energies cluster }\end{array}$ & Veolia - Environment R\&D Energy \\
\hline Patrick VINCENT & $\begin{array}{l}\text { Director of Programmes } \\
\text { and project coordination }\end{array}$ & Ifremer \\
\hline
\end{tabular}




\section{Appendix 3}

\section{Glossary of acronyms}

\begin{tabular}{|c|c|}
\hline ACP & Africa, Caribbean, Pacific \\
\hline ADB & Asian Development Bank \\
\hline Ademe & Agency for the environment and energy management \\
\hline ANR & French national research agency \\
\hline AOME & animal oil methyl ester \\
\hline APP & Asia-Pacific Partnership \\
\hline ASEAN & Association of Southeast Asian Nations \\
\hline ASPO & Association for the Study of Peak Oil \\
\hline BHRA & British Hydromechanics Research Association \\
\hline $\mathrm{BSH}$ & Bundesamt für Seeschiffart und Hydrographie \\
\hline BWEA & British Wind Energy Association \\
\hline CAS & Strategic Analysis Centre \\
\hline CCSR & Center for Climate Systems Research \\
\hline CDM & Clean development mechanism \\
\hline CEFAS & Centre for Environment, Fisheries and Aquaculture Science \\
\hline CEl & Central European Initiative \\
\hline CEP & Centre d'etudes prospectives et d'informations internationales \\
\hline $\mathrm{CIP}$ & Competitiveness and Innovation Framework Programme \\
\hline $\mathrm{CIS}$ & Commonwealth of Independent States \\
\hline COWRIE & Collaborative Offshore Wind Research Into the Environment \\
\hline DEFRA & Department for Environment, Food and Rural Affairs \\
\hline DGEMP & General Directorate for Energy and Raw Materials (Meeddat) \\
\hline DIDD & Inter-ministerial Delegation for Sustainable Development \\
\hline Dideme & La Direction de la demande et des marchés énergétiques \\
\hline & Department of Energy (USA) \\
\hline DOM-COM & French overseas departments and local authorities \\
\hline DPM & maritime public domain (state-owned) \\
\hline DTI & Department for Trade and Industry \\
\hline $\mathrm{EBI}$ & European Bank of Investment \\
\hline ECSC & European Coal and Steel Community \\
\hline EEC & European Economic Community \\
\hline EEZ & Exclusive Economic Zone \\
\hline EMEC & European Marine Energy Centre \\
\hline EPF & European pressurized reactor (4th generation nuclear reactor) \\
\hline EURATOM & European Atomic Energy Community \\
\hline VIS & Wind Integration Study \\
\hline & Food and Agriculture Organization (United Nations) \\
\hline FDI & foreign direct investment \\
\hline FP & Framework Programme \\
\hline IFP & French Petroleum Institute \\
\hline GCC & gasification combined cycle \\
\hline GDP & gross domestic product \\
\hline GIS & geographic information system \\
\hline GMO & genetically modified organism \\
\hline Gtoe & gigatoe = one billion tonnes oil equivalent \\
\hline & watts (1 billion watts) \\
\hline & I. \\
\hline
\end{tabular}




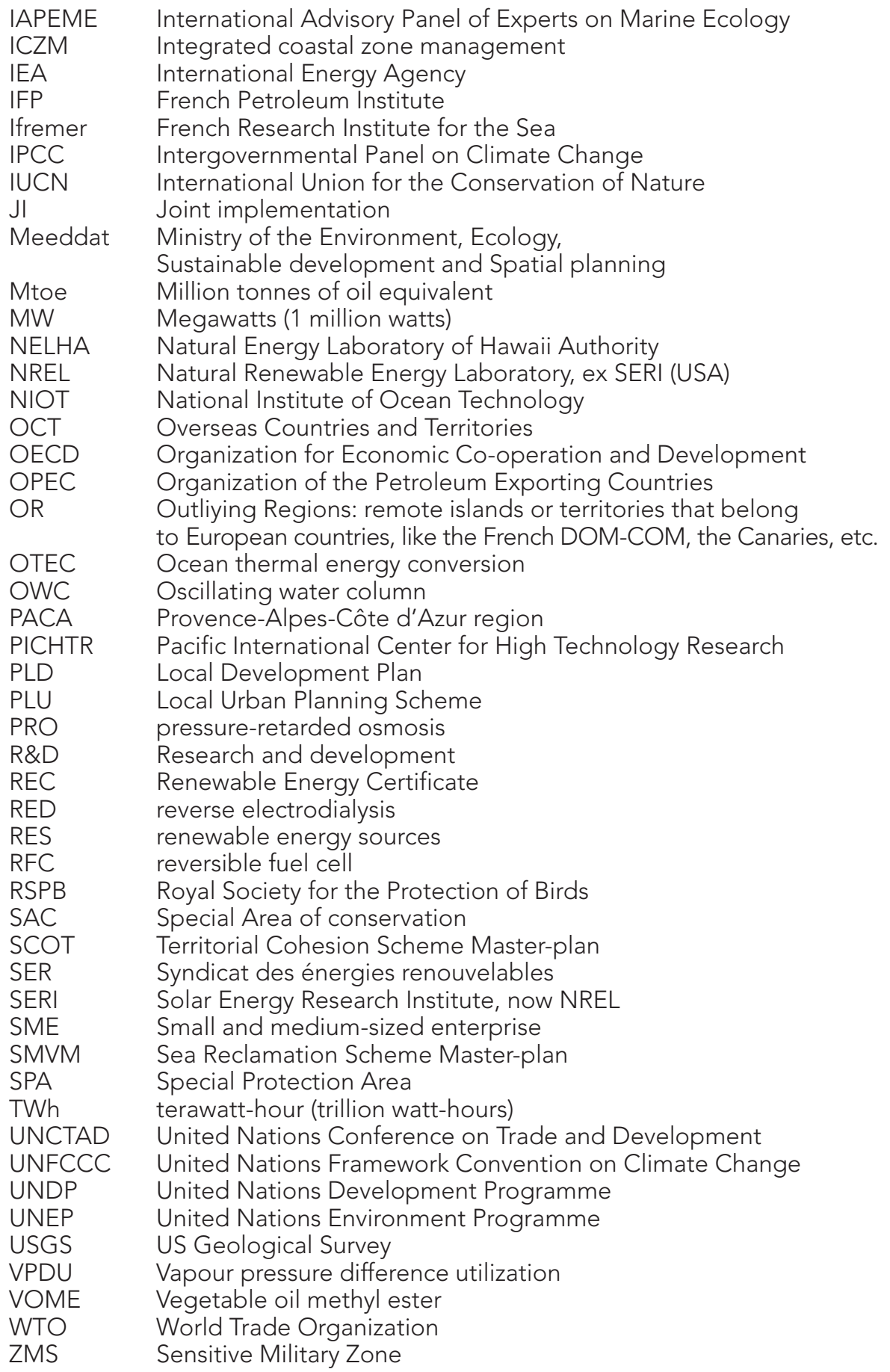




\section{Appendix 4}

\section{Glossary for the scenario method}

- Variable: a factor, parameter or driving element which influences the system. Knowledge of a variable can help in understanding its status, addressing it or even controlling its development. It is an element of the system which exercises or which may exercise an influence on the issue studied. In a foresight system, a variable is often a mix of factor and actor (a factor usually evolves under the influence of one or several actors or stakeholders).

- Key indicators: variables which have the most influence on the system in question (the most dependent are set aside).

- Hypothesis: possible development or trend for a variable by a given time horizon.

- Component: set of related variables based on the same theme or same group of stakeholders.

- Scenario: description of the system at a given time horizon and the pathway leading to its final state.

- Micro-scenarios: partial scenarios related to a component of the system.

- Macro-scenarios: global scenarios related to the entire system.

- Stakes: an identified issue which holds the potential for positive or negative change, that is, opportunities or threats, which must be taken into account in order to construct a prospective outlook and determine a strategy. Whether in groundwork or the battlefield, the stakes are what can be won or lost. One of foresight's roles is to identify the future stakes that can be imagined, especially over the long term. 


\section{Appendix 5}

\section{List of 30 variables grouped by component and corresponding author(s)}

\section{World context}

1. Global geo-economics ............................... Futuribles

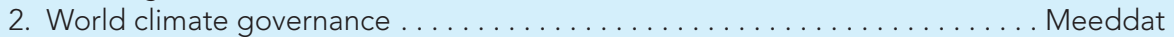

3. Energy demand, including Europe by region ................... Futuribles

4. Freshwater demand by region ......................... Futuribles

5. Security and price of fossil fuels .......................... Technip

\section{European and French context}

6. Political strategy \& energy independence: targets

DIDD

7. Specificities of islands (including OR and OCT)

Ifremer/Collective

8. Enforcement \& control, relevant tools in France. . . . . . . . . . . . . . . . . Meeddat

9. Regulatory instruments for biofuels ...........................

10. Energy research budget and allocation by energy source. . . . . . . . . Futuribles

11. Structuring and managing the electricity grid . . . . . . . . . . . . . . Ademe

12. Energy storage and transport technologies .................... Saipem

13. Changes in centralized electricity generation. ................ EDF/R\&D

\section{Areas of operation}

14. Global population distribution including European coasts........ Futuribles/lfremer

15. Regional marine spatial planning. .......................... Ademe

16. Public acceptance ................................... Ifremer

17. Changes in sea uses and conflicts . . . . . . . . . . . . . . . . . Meeddat

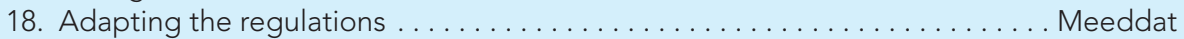

19. Environmental impacts ............................... Ifremer

Marine renewable energies

20. Stream energy (marine currents) . . . . . . . . . . . . . . . . EDF/R\&D

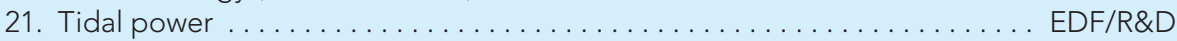

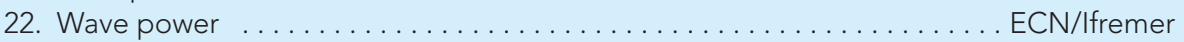

23. Biomass ..................................... Ifremer

24. Offshore wind power............................. Saipem

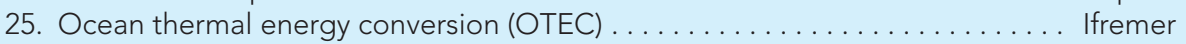

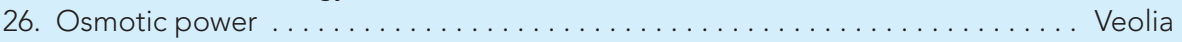

27. Hybrid technological solutions............................. Collective

\section{Marine renewable energy research and development}

28. Potential of new sources . . . . . . . . . . . . . . . . . . . . . . . . . . . . . . . . Ifremer

29. Knowledge about the marine environment and impacts. . . . . . . . . . . . . Ifremer

30. Roles of public- and private-sector stakeholders' .............. DCNS/Ifremer 


\section{Appendix 6}

\section{Cost assessment of possible and normative scenarios}

\begin{tabular}{|c|c|c|c|c|c|c|}
\hline \multirow[b]{2}{*}{ Technology } & \multicolumn{3}{|c|}{$\begin{array}{c}\text { Scenario } 1 \\
\text { Crisis and Emergency }\end{array}$} & \multicolumn{3}{|c|}{$\begin{array}{c}\text { Scenario } 2 \\
\text { Co-operation }\end{array}$} \\
\hline & $\begin{array}{l}\text { Installed } \\
\text { power (MW) }\end{array}$ & $\begin{array}{l}\text { Electricity } \\
\text { generation } \\
\text { (TWh) }\end{array}$ & $\begin{array}{l}\text { Energy } \\
\text { generation } \\
\text { (Mtoe) }\end{array}$ & $\begin{array}{l}\text { Installed } \\
\text { power (MW) }\end{array}$ & $\begin{array}{l}\text { Electricity } \\
\text { generation } \\
\text { (TWh) }\end{array}$ & $\begin{array}{l}\text { Energy } \\
\text { generation } \\
\text { (Mtoe) }\end{array}$ \\
\hline Wind power & 4000 & 12.0 & 1.03 & 10000 & 30.0 & 2.58 \\
\hline OTEC Air cond Met France MW & 400 & 0.7 & 0.06 & 800 & 1.5 & 0.12 \\
\hline OTEC Elect. tropics & 50 & 0.4 & 0.03 & 115 & 0.7 & 0.06 \\
\hline OTEC Air cond tropics MW & 400 & 0.7 & 0.06 & 2000 & 3.6 & 0.31 \\
\hline OTEC water tropics & \multicolumn{3}{|c|}{1.7 million $\mathrm{m}^{3} /$ year } & \multicolumn{3}{|c|}{3.3 million $\mathrm{m}^{3} /$ year } \\
\hline Stream energy (marine currents) & 100 & 0.3 & 0.03 & 1000 & 3.0 & 0.26 \\
\hline Tidal power & 400 & 1.0 & 0.09 & 600 & 1.5 & 0.13 \\
\hline Wave power & 100 & 0.3 & 0.03 & 2000 & 6.0 & 0.52 \\
\hline Biomass & \multicolumn{2}{|c|}{$\begin{array}{c}1 \text { site i.e. } 2000 \text { ha } \\
\text { (Guyana or New } \\
\text { Caledonia) }\end{array}$} & 0.05 & \multicolumn{2}{|c|}{10 sites. i.e. 20000 ha } & 2.5 \\
\hline Osmotic power & 0 & 0 & 0 & 0 & 0 & 0 \\
\hline Assessment & \multicolumn{3}{|c|}{ 1,38 Mtoe } & \multicolumn{3}{|c|}{ 6.48 Mtoe } \\
\hline Electricity & 4650 & 14.0 & 1.21 & 13715 & 41.2 & 3.55 \\
\hline Air Cond. & 800 & 1.4 & 0.12 & 2800 & 5.1 & 0.43 \\
\hline Fuel & & & 0.05 & & & 2.50 \\
\hline Eau & \multicolumn{3}{|c|}{1.7 million $\mathrm{m}^{3} /$ year } & \multicolumn{3}{|c|}{3.3 million $\mathrm{m}^{3} /$ year } \\
\hline
\end{tabular}




\begin{tabular}{|c|c|c|c|c|c|c|c|c|}
\hline \multicolumn{3}{|c|}{$\begin{array}{c}\text { Scenario } 3 \\
\text { Everyman for himself }\end{array}$} & \multicolumn{3}{|c|}{$\begin{array}{c}\text { Scenario } 4 \\
\text { Local independance }\end{array}$} & \multicolumn{3}{|c|}{ Normative scenario } \\
\hline $\begin{array}{l}\text { Installed } \\
\text { power } \\
\text { (MW) }\end{array}$ & $\begin{array}{c}\text { Electricity } \\
\text { generation } \\
\text { (TWh) }\end{array}$ & $\begin{array}{l}\text { Energy } \\
\text { generation } \\
\text { (Mtoe) }\end{array}$ & $\begin{array}{c}\text { Installed } \\
\text { power (MW) }\end{array}$ & $\begin{array}{c}\text { Electricity } \\
\text { generation } \\
\text { (TWh) }\end{array}$ & $\begin{array}{c}\text { Production } \\
\text { énergétique } \\
\text { (Mtep/an) }\end{array}$ & $\begin{array}{c}\text { Installed } \\
\text { power (MW) }\end{array}$ & $\begin{array}{c}\text { Electricity } \\
\text { generation } \\
\text { (TWh) }\end{array}$ & $\begin{array}{c}\text { Energy } \\
\text { generation } \\
\text { (Mtoe) }\end{array}$ \\
\hline 2000 & 6.0 & 0.52 & 4000 & 12.0 & 1.03 & 4000 & 12.0 & 1.03 \\
\hline 200 & 0.4 & 0.03 & 800 & 1.5 & 0.12 & 15 & 0.1 & 0.01 \\
\hline 25 & 0.2 & 0.02 & 115 & 0.7 & 0.06 & 200 & 1.4 & 0.12 \\
\hline 200 & 0.4 & 0.03 & 2000 & 3.6 & 0.31 & 40 & 0.3 & 0.02 \\
\hline \multicolumn{3}{|c|}{0.8 million $\mathrm{m}^{3} /$ year } & \multicolumn{3}{|c|}{3.3 million $\mathrm{m}^{3} /$ year } & \multicolumn{3}{|c|}{0.8 million $\mathrm{m}^{3} /$ year } \\
\hline 200 & 0.6 & 0.05 & 50 & 0.2 & 0.01 & 400 & 1.4 & 0.12 \\
\hline 240 & 0.6 & 0.05 & 240 & 0.6 & 0.05 & 500 & 1.3 & 0.11 \\
\hline 100 & 0.3 & 0.03 & 150 & 0,5 & 0.04 & 200 & 0.8 & 0.07 \\
\hline \multicolumn{2}{|c|}{ Other use } & negligible & \multicolumn{2}{|c|}{5 sites i.e. 10000 ha } & 1.25 & \multicolumn{2}{|c|}{2000 ha } & 0.05 \\
\hline 0 & 0 & 0 & 0 & 0 & 0 & 0 & 0 & 0 \\
\hline \multicolumn{3}{|c|}{0.73 Mtoe } & \multicolumn{3}{|c|}{ 2.87 Mtoe } & \multicolumn{3}{|c|}{1.53 Mtoe } \\
\hline 2565 & 7,7 & 0.67 & 4555 & 14.0 & 1.19 & 5300 & 16.9 & 1.45 \\
\hline \multirow[t]{2}{*}{400} & 0.8 & 0.06 & 2800 & 5.1 & 0.43 & 55 & 0.4 & 0.03 \\
\hline & & negligible & & & 1.25 & & & 0.05 \\
\hline \multicolumn{3}{|c|}{0.8 million $\mathrm{m}^{3}$ /year } & \multicolumn{3}{|c|}{3.3 million $\mathrm{m}^{3} /$ year } & \multicolumn{3}{|c|}{0.8 million $\mathrm{m}^{3} /$ year } \\
\hline
\end{tabular}





Conception graphique, mise en page et impression

bialec, nancy (France)

Dépôt légal n 69731 - février 2009 

The ocean is a huge reservoir of renewable energy sources, such as wind, currents, tides, waves, marine biomass, thermal energy, osmotic power, and so on. Like other maritime nations in Europe, France enjoys significant potential to develop these energy sources, especially overseas.

In March 2007, Ifremer's chairman and chief executive officer launched a prospective foresight study on these energies for the time horizon of 2030. With support from the Futuribles consulting group, twenty French partners representing the main stakeholders in the sector carried out this work. Their objectives were to identify the technologies, specify the socio-economic prerequisites for them to emerge and be competitive and assess their respective impacts on power sources and the environment.

What was learned from this study can be applied well beyond France, at a time when a European maritime strategy is taking shape.

Michel Paillard, an engineer at Ifremer, has conducted the activity described in this book since the early 2000s. Since January 2008, he has been the leader of the "Marine renewable energy sources" project.

Denis Lacroix, a research scientist at Ifremer, worked for 30 years in aquaculture, especially tropical aquaculture, then in International relations, especially in the Mediterranean; since 2007, he has led Ifremer's foresight unit.

Véronique Lamblin, a trained engineer, has worked over that past ten years in designing foresight scenarios. She first worked in an industrial group on long term strategy and has been with Futuribles since 2002.

On the cover: Maintenance operation done by helicopter on a Danish offshore wind turbine (C) Dong Energy, Denmark

Price: $50 €$

ISBN: 978-2-7592-0183-9

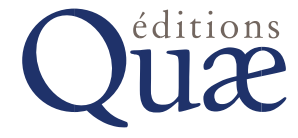

\section{Ifremer}

Éditions Cemagref, Cirad, Ifremer, Inra www.quae.com

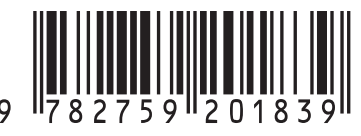

Ref.: 02106 